\title{
RELAÇÕES ECONÔMICAS DO CEARÁ E A IMPORTÂNCIA DA ÁGUA E DA ENERGIA ELÉTRICA NO DESENVOLVIMENTO DO ESTADO
}

\section{PATRICIA VERÔNICA PINHEIROS SALES LIMA}

Engenheiro Agrônomo

Orientador: Prof. Dr. Joaquim José Martins Guilhoto

Tese apresentada à Escola Superior de Agricultura "Luiz de Queiroz", Universidade de São Paulo, para obtenção do título de Doutor em Ciências, Área de Concentração: Economia Aplicada.

PIR A C I C A B A

Estado de São Paulo - Brasil

Maio - 2002 


\section{Dados Internacionais de Catalogação na Publicação (CIP)}

DIVISÄO DE BIBLIOTECA E DOCUMENTAÇÃO - ESALQ/USP

Lima, Patricia Verônica Pinheiro Sales

Relações econômicas do Ceará e a importância da água e da energia elétrica no desenvolvimento do Estado / Patricia Verônica Pinheiro Sales Lima. - Piracicaba, 2002. $250 \mathrm{p}$.

Tese (doutorado) - Escola Superior de Agricultura Luiz de Queiroz, 2002. Bibliografia.

1. Ceará 2. Desenvolvimento econômico 3. Energia elétrica 4. Recursos hídricos 5. Relações econômicas I. Título

CDD 333.7932

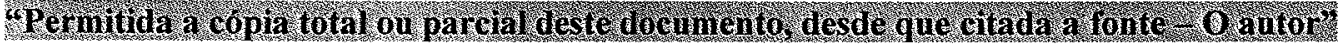


Dedico

a Francisco e Maria Beatriz aos meus pais Moacir e Lourdese aos meus irmãos Kátia, Jusverre e Karine com todo o meu amor. 


\section{AGRADECIMENTOS}

A Deus, a quem tudo é possível.

Aos professores Francisco Crocomo, Míriam Bacchi, Maria Cristina Ortiz e Ricardo Shirora, pelas contribuições dadas ao longo deste trabalho.

Aos professores do curso de Economia Aplicada da ESALQ-USP que, direta e indiretamente contribuíram para o enriquecimento de meus conhecimentos.

Aos colegas do Departamento de Economia Agrícola da Universidade Federal do Ceará e ao centro de ciências Agrárias pelo apoio necessário à realização desta Tese.

À CAPES, pelo auxílio financeiro.

À Companhia de Gestão dos Recursos Hídricos do Ceará - COGERH e à Companhia de Água e Esgoto do Ceará - CAGECE, pelo fornecimento de informações valiosas relativas ao consumo de água no Estado do Ceará.

Aos amigos Beatriz, Carla, Carlos e Izabel, Casimiro, Cleise e Emerson, Jaênes e Cândida, Márcia, Ricarda e Sílvia pela amizade firmada nestes últimos anos e a todos os outros com quem pude desfrutar momentos agradáveis.

À Cristina, Elaine, D. Lourdes e Sr. Osório pelo carinho com que sempre me receberam em minhas idas e vindas à Piracicaba.

A todos os funcionários da ESALQ, pela atenção e prazer com que atendem a todos os estudantes de pós-graduação. 
Quero aqui fazer um agradecimento especial ao professor Guilhoto, pelo respeito profissional e atenção demonstrados durante todo o período em que me orientou, pelo apoio constante, amizade e tranqüilidade diante das dificuldades surgidas nas diferentes etapas desta Tese, enfim, pela oportunidade de convívio que me proporcionou não só um enriquecimento intelectual mas, também, moral, os quais vou levar comigo para sempre. 


\section{SUMÁRIO}

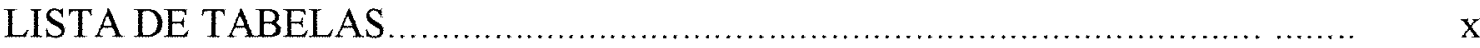

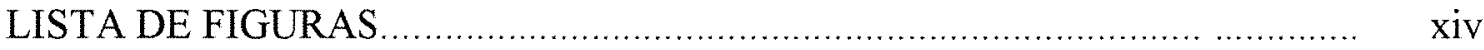

LISTA DE QUADROS .......................................................................... xvi

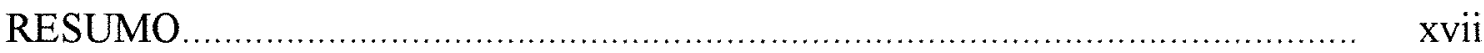

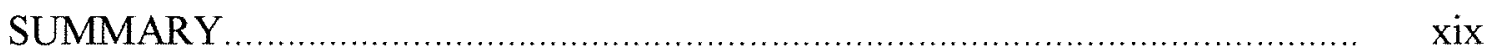

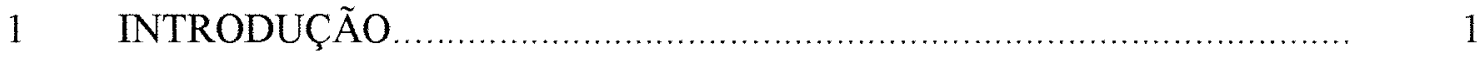

1.1 O problema e sua importância ........................................................... 1

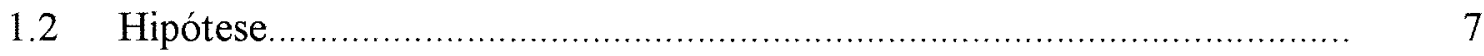

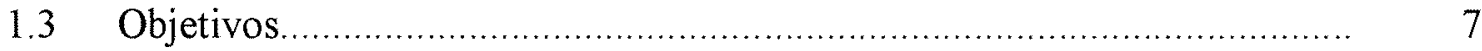

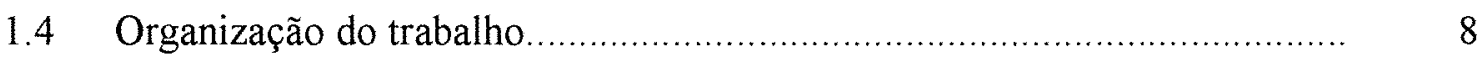

2 A ECONOMIA, O GERENCIAMENTO DOS RECURSOS HÍDRICOS E O SETOR DE ENERGIA ELÉTRICA NO CEARÁ

2.1 Panorama econômico e social do Ceará ….............................................. 11

2.2 Os recursos hídricos no Estado do Ceará …............................................. 18

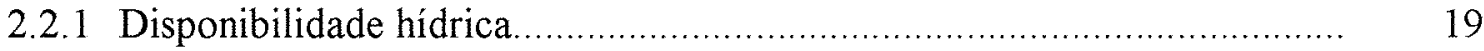

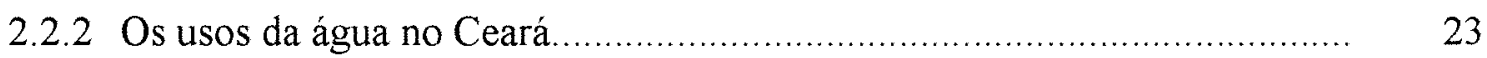

2.2.3 Conflitos gerados pelo uso da água...................................................... 28

2.2.4 Experiência do Ceará no gerenciamento dos recursos hídricos................. 31

$2.3 \quad$ O setor de energia elétrica no Ceará ...................................................... 38

2.3.1 Energia e economia....................................................................... 39

2.3.2 Geração, transmissão e distribuição de água no Ceará............................... 42 
2.3.3 Consumo de energia elétrica no Ceará.................................................... 54

3 ANÁLISE DE INSUMO-PRODUTO ................................................. 60

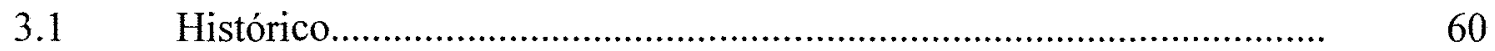

3.2 Teoria básica do modelo de insumo-produto........................................... 62

3.3 Quadro de insumo-produto................................................................ 68

3.4 Modelos de insumo-produto regionais............................................... $\quad 74$

3.5 Modelos de insumo-produto com mais de uma região.......................... 78

3.5.1 Modelos de insumo-produto inter-regionais......................................... 78

3.6 Modelos de insumo-produto e meio ambiente...................................... 81

3.6.1 Modelo de Cumberland................................................................... 82

3.6.2 Modelo de Daly............................................................................... 83

3.6.3 Modelo de Isard........................................................................... $\quad 86$

3.6.4 Modelo de Vitor................................................................................ 87

4 USO DE MODELOS DE INSUMO-PRODUTO NO GERENCIAMENTO DOS RECURSOS HIDRICOS.......................... $\quad 90$

4.1 Modelos de insumo-produto e a estimação da demanda por

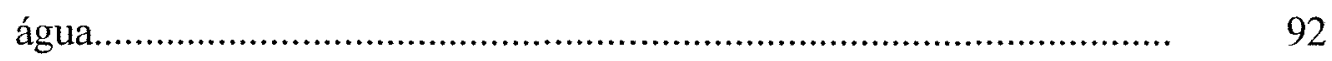

4.1.1 Modelo de insumo-produto (produto x setor)....................................... 94

4.1.2 Estrutura do modelo econômico-ecológico.............................................. 96

4.2 Modelo insumo-produto e poluição da água........................................ 98

4.2.1 Matriz regionalizada das relações interindustriais............................... 99

4.2.2 Matriz dos coeficientes de poluição...................................................... 102

4.2.3 Tabelas de impacto.......................................................................... 104

4.3 Modelo de insumo-produto e estimação do valor da água.................... 105

4.3.1 Aproximação do valor adicionado....................................................... 106

5 METODOLOGIA .................................................................. 110

5.1 Matriz de insumo-produto para o Ceará - 1992 …............................... 110

5.1.1 Técnica do quociente locacional simples............................................. 111

5.1.2 Construção da matriz de insumo-produto para o Ceará......................... 112 
5.2 Construção da matriz inter-regional .................................................. 115

5.2.1 Construção da matriz de consumo intermediário ............................... 117

5.2.2 Estimação da demanda final .......................................................... 119

5.2.3 Atualização das matrizes para o ano de 1999.................................... 119

5.3 Métodos de análise das relações intersetoriais no modelo inter.-

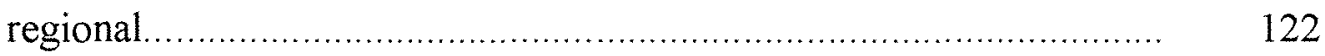

5.3.1 Índices de ligação Hirschman-Rasmussen......................................... 123

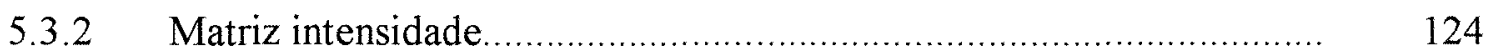

5.3.3 Campo de influência ................................................................. 125

5.3.4 Índices puros de ligações (enfoque GHS) …..................................... 126

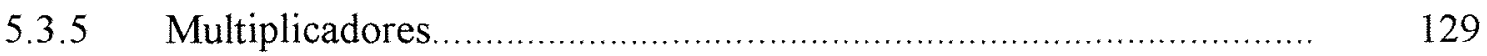

5.4 Incorporação da água e energia elétrica à matriz de insumo-produto do Ceará.

5.4.1 Modelo utilizado .................................................................. 131

5.4.2 Construção dos vetores de água e energia elétrica............................. 136

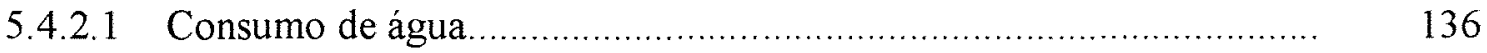

5.4.2.2 Consumo de energia elétrica.......................................................... 139

6 RESULTADOS E DISCUSSÃO …............................................ 140

6.1 Índices de ligação Hirschman-Rasmussen........................................... 141

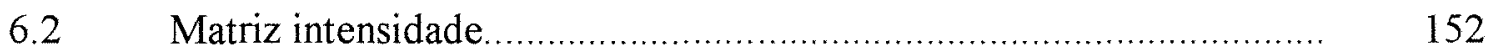

6.3 Campo de influência ................................................................ 156

6.4 Índices puros de ligações.............................................................. 158

6.5 Influência das demandas finais sobre a produção no sistema inter-

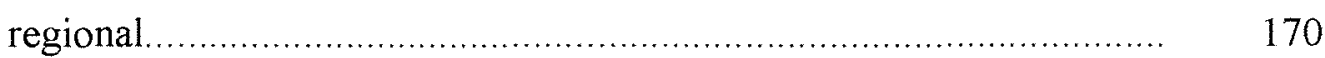

6.6 Impactos provocados na produção, renda, emprego e importações decorrentes de variações na demanda final........................................ 180

7 ALOCAÇÃO DA ÁGUA E DA ENERGIA ELĖTRICA ENTRE OS SETORES ECONÔMICOS DO ESTADO DO CEARÁ..................... 198

7.1 Coeficientes de consumo de água e energia elétrica nos diferentes setores da economia do Ceará. 
7.2 Impactos sobre o consumo de água decorrentes de uma variação na demanda final................................................................................... 201

7.3 Impactos sobre o consumo de energia elétrica decorrentes de uma variação na demanda final.................................................................. 206

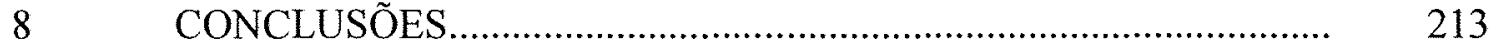

REFERÊNCIAS BIBLIOGRÁFICAS ......................................................... 218

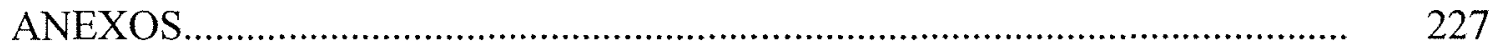




\section{LISTA DE TABELAS}

Página

1 Taxa geométrica de crescimento do PIB para o Estado Ceará......................

2 Participação dos setores econômicos no PIB do Ceará - 19952000

3 Taxa de crescimento do PIB real, segundo os setores econômicos, Brasil, Nordeste e Ceará - 1999 (1)

4 Exportações do Ceará em 1999 - Valores em milhões US\$ FOB

5 Importações cearenses em 1999 - Participação percentual.

6 Principais Indicadores Sociais - Brasil, Nordeste e Ceará 1999

7 Principais açudes do Ceará por capacidade de volume de água armazenada

8 Quantidade de obras hídricas no Ceará por tipo.

9 Taxa de Urbanização e situação de domicílios no Ceará - Anos, 1980, 1991, 1996 e 2000.

10 Municípios com maiores taxas de crescimento populacional no período 1996-2000.

11 Principais rebanhos cearenses em número de cabeças e seu respectivo consumo de água - $1999 .$.

12 Áreas irrigadas nos agropolos do Ceará - 2000 
13 Taxas de crescimento anuais do PIB real segundo os setores econômicos-1980/1999.

14 Taxa de crescimento do consumo de energia elétrica industrial, comercial e residencial no Ceará - 1992/2000 (\%)

15 Usinas de geração de energia elétrica no Estado e algumas de suas características -2001

16 Infra-estrutura energética - Ceará - 1998-1999

17 Consumo e consumidores de energia elétrica segundo as classes de consumo - Ceará - 2000 .

18 Taxa de crescimento no consumo de energia elétrica nos Estados do Nordeste no período 1992/2000.

19 Comportamento dos consumidores de energia elétrica no Ceará.

20 Perfil de consumo dos principais consumidores industriais de energia elétrica no Ceará - 1998-1999.

21 Índices de ligação Hirschman-Rasmussen para trás e para frente para as regiões Ceará, resto do Nordeste e resto do Brasil 1999 - índices independentes

22 Índices de ligação Hirschman-Rasmussen para o sistema interregional Ceará, resto do Nordeste e resto do Brasil 1999.

23 Índices puros totais nas regiões do sistema inter-regional - Índices independentes e normalizados.

24 Índices puros de ligação para trás e para frente no sistema interregional - Índices normalizados.

25 Índices puros totais no sistema inter-regional - Normalizados.......

26 Índices puros de ligação regionais ( $\$ 1000,00$ correntes de 1999) 
27 Setores-chaves consolidados no sistema inter-regional - Critério menos restrito dos índices de Hirschman-Rasmussen e critério do indice puro total de ligação

28 Produção total induzida pela demanda final no sistema interregional ( $\mathrm{R} \$ 1000,00$ correntes de 1999).

29 Participação da produção induzida das regiões Ceará, Resto do Nordeste e Resto do Brasil na produção induzida total do sistema, 1999 ( $\mathrm{R} \$ 1000,00$ correntes de 1999)

30 Importância de cada região na indução da produção no sistema inter-regional.

31 Produção setorial induzida pela demanda final do sistema interregional (R $\$ 1000,00$ correntes de 1999)

32 Multiplicadores de produção para o Ceará (R\$1000,00/ unidade monetária de demanda final).

33 Multiplicadores de produção para o resto do Nordeste (R $\$ 1000,00 /$ unidade monetária de demanda final) ......................................

34 Multiplicadores de produção para o Resto do Brasil (R\$1000,00/ unidade monetária de demanda final) ...................................

35 Geração de renda direta e indireta decorrente de um choque de R\$1 milhão na demanda final no sistema inter-regional - 1999....

36 Geração de emprego direto, indireto, induzido e total decorrente de um choque de R\$1 milhão na demanda final no sistema interregional - 1999 .

37 Geração de emprego total decorrente de um choque de $\mathrm{R} \$ 1$ milhão na demanda final e produção setorial no sistema inter-regional 1999 .

38 Participação das importações no volume total de produção no sistema inter-regional em 1999 - \% 
39 Geração de importações diretas, indiretas, induzidas e totais decorrentes de um choque de $\mathrm{R} \$ 1$ milhão na demanda final no sistema inter-regional - 1999

40 Coeficientes de consumo de água e energia elétrica dos setores econômicos do Estado do Ceará - 1999

41 Impactos de um aumento de R \$ 1 milhão na demanda final sobre o consumo de água dos setores econômicos do Estado do Ceará - 1999. $\left(\mathrm{hm}^{3}\right)$

42 Ordenação decrescentes dos setores conforme sua capacidade de geração de renda, emprego e consumo de água diante de um aumento de $\mathrm{R} \$ 1$ milhão na demanda final de todos os setores da economia

43 Repercussões econômicas decorrentes de uma restrição no consumo de energia elétrica no Ceará - Tendências.

44 Impactos de um aumento de R\$ 1 milhão na demanda final sobre o consumo de energia elétrica dos setores econômicos do Estado do Ceará 1999. (MWh).

45 Ordenação decrescente dos setores conforme sua capacidade de geração de renda, emprego e consumo de energia elétrica, diante de um impacto de $\mathrm{R} \$ 1$ milhão na demanda final de todos os setores da economia. 


\section{LISTA DE FIGURAS}

Página

1 Indústrias de transformação ativas, por gênero, no Ceará $-1999 \ldots . .$. 13

2 Empresas de serviços, por atividade econômica - Ceará 1999.........

3 Bacias hidrográficas do Estado do Ceará.

4 Evolução da participação das fontes energéticas no consumo total de energia no Brasil-1984 a 1999

5 Taxas de crescimento do PIB e consumo de energia no Ceará $1992 / 2000$.

6 Estrutura organizacional do setor elétrico brasileiro.

7 Participação das usinas na geração de energia elétrica no Brasil 2001

8 Capacidade de geração de energia elétrica no Brasil por Unidade da Federação em 2001 - (\%).....................................................

9 Participação das usinas na geração de energia elétrica no Ceará 2001

10 Integração eletroenergética brasileira.

11 Consumo de energia elétrica no Ceará por classes de consumo $1992-2000$

12 Comportamento de consumo de energia elétrica dos principais consumidores industriais do Ceará - 1985-2000.

13 Modelo econômico ecológico

14 Ligações para trás e para frente de Hirschman-Rasmussen para o Ceará no sistema inter-regional 
15 Ligações para trás e para frente de Hirschman-Rasmussen para o Resto do Nordeste no sistema inter-regional............................. 146

16 Ligações para trás e para frente de Hirschman-Rasmussen para o Resto do Brasil no sistema inter-regional.

17 Padrões médios de comportamento dos índices de ligação de Hirschman-Rasmussen para o sistema inter-regional.

18 Matriz de intensidade do resto do Brasil

19 Matriz de intensidade do resto do Nordeste usando a hierarquia do resto do Brasil

20 Matriz de intensidade do Ceará usando a hierarquia do resto do Brasil

21 Coeficientes setoriais com maior campo de influência no sistema inter-regional: Ceará, resto do Nordeste e resto do Brasil......

22 Índice puro total das regiões Ceará, resto do Nordeste e resto do Brasil no sistema inter-regional- Normalizado.

23 Participações das produções setoriais na produção total induzida pela própria demanda e das demandas finais das outras regiões Região Ceará

24 Participações das produções setoriais na produção total induzida pela própria demanda e das demandas finais das outras regiões Região Resto do Nordeste.

25 Participações das produções setoriais na produção total induzida pela própria demanda e das demandas finais das outras regiões Região Resto do Brasil 


\section{LISTA DE QUADROS}

Página

1 Quadro de insumo-produto simplificado conforme Leontief..

2 Tabela insumo-produto simplificada de Daly................................... 83

3 Tabela insumo-produto proposta por Daly...................................... $\quad 85$

$4 \quad$ Estrutura do modelo insumo-produto proposto por Isard...................

$5 \quad$ Estrutura do modelo de Vitor................................................................ 88

6 Trabalhos envolvendo modelos insumo-produto e o recurso natural

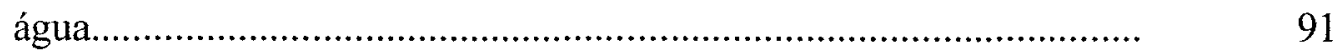

7 Consumo intermediário............................................................. 116

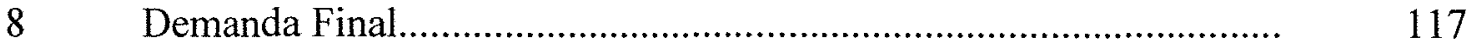

9 Modelo insumo-produto após a incorporação dos insumos água e

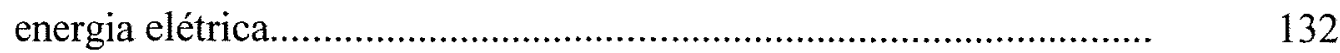

$10 \quad$ Consumo de água para diferentes culturas em um ano......................... 138 


\title{
RELAÇÕES ECONÔMICAS DO CEARÁ E A IMPORTÂNCIA DA ÁGUA E DA ENERGIA ELÉTRICA NO DESENVOLVIMENTO DO ESTADO
}

\author{
Autora: PATRICIA VERÔNICA PINHEIROS SALES LIMA \\ Orientador: Prof. JOAQUIM JOSÉ MARTINS GUILHOTO
}

\section{RESUMO}

Este estudo tem como objetivos principais a identificação das relações econômicas entre os setores localizados nas regiões Ceará, resto do Nordeste e resto do Brasil e a análise da estrutura de consumo de água e energia elétrica no estado do Ceará no ano de 1999. Para alcançar o primeiro objetivo foi construído um modelo interregional de insumo produto, o qual foi submetido às técnicas de insumo-produto, que permitem identificar a interação entre as regiões, os setores-chave de cada uma das regiões e o impacto de variações na demanda sobre o nível de renda, emprego e importação. A análise do padrão e consumo de água e energia elétrica no Ceará foi feita a partir da construção de um modelo ecológico de insumo-produto que identifica os setores mais propensos a aumentar o consumo destes recursos diante de variações na demanda final. As conclusões verificadas a partir dos resultados mostram as interações entre as regiões estudadas e as diferenças nas estruturas produtivas de cada uma delas, principalmente do resto do Brasil em relação às demais regiões, indicando a necessidade de políticas de desenvolvimento específicas para cada região. Quanto ao perfil de consumo de água e energia elétrica no Ceará, uma comparação entre os impactos provocados pelos investimentos feitos no Ceará sobre a renda, emprego, consumo de 
água e energia elétrica mostrou a necessidade da associação do gerenciamento destes recursos às políticas econômicas adotadas pelo governo para assegurar que todos os setores tenham acesso aos mesmos, garantindo desta forma a continuidade do desenvolvimento econômico do Estado. 


\title{
ECONOMIC RELATIONS OF THE STATE OF CEARA AND THE IMPORTANCE OF WATER AND ELETRIC ENERGY IN STATE'S DEVELOPMENT
}

\author{
Author: PATRICIA VERÔNICA PINHEIRO SALES LIMA \\ Adviser: Prof. JOAQUIM JOSÉ MARTINS GUILHOTO
}

\section{SUMMARY}

This study aimed to distinguish the economic relations among sectors located in regions of Ceará, the rest of Northeast and the rest of Brazil, and to analyze of the electrical energy and water consumption structure in the Ceara state in 1999. In order to reach the first aim, it was established an inter-regional model of input-output, which was submitted to input-output techniques, which enable us to distinguish the interaction among the regions, the key-sectors of each region and the impact of variations on demands of income standards, employment and importation. The analysis of the standard and consumption of water and electrical energy in the Ceará state was accomplished based on the establishment of an ecological model of input-output, which states the sectors most likely to increase the consumption of these resources in face of variations in the final demand. The conclusions obtained from the results show that the interactions among the regions studied and the differences in the productive structures 
of each of them, mainly from the rest of Brazil in relation to the other regions, point to the need of specific development policies for each region. As for the water and electrical energy consumption profile, a comparison among the impacts derived from investments made in the Ceará state in the income, employment water and electrical energy consumption revealed the need of adjustment of this resource management to the economic policy adopted by the government to make sure that all the sectors benefit from them, vouching, this way, the continuity of the economic development of the State. 


\section{INTRODUÇÃO}

\subsection{O problema e sua importância}

A água é a substância mais abundante da Terra, ocupando $70 \%$ da superfície do planeta. Porém, segundo Santos (2001) apenas $1 \%$ de toda a água está disponível para uso, armazenada nos lençóis subterrâneos, lagos, rios e atmosfera. Os outros $99 \%$ estão distribuídos nos oceanos, 97\%, e nas geleiras, $2 \%$, o que os tornam inaproveitáveis. Na última década a demanda por água apresentou um grande crescimento, motivada principalmente pela expansão industrial e urbana, pelo aumento na qualidade de vida da população e pelo desenvolvimento agrícola.

Dados do Worldwatch Institute (1993) apontam que em cada uma das principais áreas de uso da água, como a agricultura, a indústria e as famílias, as demandas têm aumentado rapidamente. Nos últimos cinqüenta anos o uso global da água mais que triplicou. Segundo Campos (2001), o acréscimo na demanda de água resulta em um declínio na sua qualidade. A cada ano a qualidade da água diminui devido ao lançamento contínuo de esgotos e resíduos industriais e agrícolas, o que a torna imprópria ao consumo.

A sociedade depara-se desta forma, com um cenário onde a disponibilidade de água torna-se limitada devido a três fatores principais: grande demanda, uso excessivo e desregrado (desperdício) e poluição. Este cenário preocupante tem despertado o interesse de diversos especialistas e organismos internacionais. Segundo eles, existe uma relação entre consumo de água e um bom desempenho econômico e 
social de uma região ${ }^{1}$ o que torna a utilização racional deste recurso natural uma questão estratégica para o desenvolvimento, uma vez que trata-se de um insumo presente em quase todas as atividades humanas sendo usado, entre outros objetivos, para irrigação na agricultura, na produção industrial, para uso doméstico, para pesca, geração de energia e como gerador de empregos na infraestrutura de sua distribuição.

A pressão existente sobre os recursos hídricos obrigou os governos a darem uma maior atenção à água numa perspectiva econômica e ambiental. A água passou a ser encarada como um bem econômico. A noção de disponibilidade e abundância de água aos poucos está sendo substituída por uma conscientização mundial da necessidade de se alcançar a eficiência técnica e econômica na sua utilização, onde todas as possibilidades de aproveitamento sejam tratadas conjuntamente. É inconcebível nos dias atuais que países, desenvolvidos ou não, ignorem a necessidade de uma gestão e planejamento dos recursos hídricos.

A gestão dos recursos hídricos consiste essencialmente em melhorar o desempenho do setor água através do aumento na qualidade e quantidade de água disponível, prevenindo e resolvendo os conflitos existentes entre usuários competidores. Segundo Silva (2001), a restauração do equilíbrio entre o consumo de água e o abastecimento dependerá principalmente de iniciativas do lado da demanda.

Uma gestão será eficiente se for orientada por princípios econômicos. A análise econômica da água ganhou maior destaque no Brasil a partir de 1993 quando teve início a formulação da "Lei das Águas", lei 9.433, promulgada em janeiro de 1997. Esta lei baseia-se em quatro princípios fundamentais e, conforme já subentendido, confere uma visão econômica à água. De acordo com Motta (1998), estes princípios são:

\footnotetext{
1 o consumo "per capita" de água é um dos indicadores de riqueza e de qualidade de vida de uma população, e aumenta no mesmo sentido que o desenvolvimento econômico e social. (www.Geocities.com/rainforeste/canopv/9399/ambiente global/water/waterintro.html).
} 
- gestão por bacia: reconhece que o uso da água é múltiplo, excludente e gera externalidades;

- unicidade da água: permite melhor definição e garantia de direitos de uso da água;

- exigência de um plano de gestão: introduz os elementos de disponibilidade e demanda do recurso no tempo;

- instrumento de cobrança: determina o preço para a água.

O Ceará apresenta-se como um Estado problema sob o aspecto da disponibilidade hídrica. Segundo dados fornecidos pela Secretaria de Recursos Hídricos do Ceará, mais de $90 \%$ do seu território encontra-se localizado no semi-árido, que se caracteriza pela má distribuição de chuvas no tempo e no espaço e alta taxa de evaporação. Sua precipitação média anual é de aproximadamente $750 \mathrm{~mm}$ (Figueroa, 1977). Como agravante, $70 \%$ deste território é formado por rochas cristalinas que dificultam a retenção de água e impedem a formação de reservas hídricas. Em conseqüência deste quadro, tem-se uma escassez na oferta de água que exige por parte dos governantes a adoção de estratégias, tais como: construção de açudes, perfuração de poços, construção de cacimbões e cisternas e utilização de fontes e lagoas naturais.

Os fatores descritos acima fizeram com que o Ceará adotasse uma postura séria em relação ao gerenciamento dos recursos hídricos. A poluição, uma outra causa da escassez de água, embora seja uma questão importante, não tem prioridade no Estado. Hoje o Estado tem uma política de recursos hídricos voltada principalmente para a alocação eficiente da água ${ }^{2}$. Esta política é avançada até mesmo para os padrões internacionais, sendo definida pela lei estadual de recursos hídricos $n^{\circ} 11.996$, de julho de 1992. Seus objetivos principais são:

\footnotetext{
${ }^{2}$ Segundo Kemper (1997), um recurso é usado eficientemente quando seu valor é maximizado. No caso dos recursos hídricos a eficiência significa a mudança de uso dentro de setores ou entre setores.
} 
- assegurar o desenvolvimento sustentado compatível com a oferta de água;

- assegurar a oferta de água em quantidade e qualidade para as gerações atuais e futuras;

- planejar e gerenciar, de forma integrada, descentralizada e participativa o uso múltiplo, controle, conservação, proteção e preservação dos Recursos Hídricos.

A partir desta lei foram estabelecidas políticas destinadas a tornar mais eficaz a gestão dos recursos hídricos cearenses. Estas políticas são essenciais para combater os problemas oriundos do mau uso destes recursos dentre os quais pode-se destacar o comprometimento da oferta de energia elétrica.

A energia elétrica é um insumo essencial à maioria das atividades e, dependendo da forma como é utilizada (com ou sem racionamento) pode ter diferentes impactos sobre o nível de produção de determinadas atividades. Conforme o grau de interligação da economia, a diminuição na oferta de energia pode provocar a sua desarticulação, pois altera a organização da cadeia produtiva, dos turnos de trabalho, o nível de emprego, etc.

Embora sujeito aos problemas decorrentes da escassez de água, o Estado do Ceará tem alcançado, desde 1986, um dos mais elevados índices de crescimento econômico, resultado das mudanças político-econômicas deflagradas a partir do primeiro governo Tasso Jereissati. Conforme pode ser observado na Tabela 1, o Ceará vem apresentando um considerável aumento na sua taxa geométrica de crescimento do PIB regional. Em termos de estrutura do PIB, Tabela 2, o setor indústria aumentou a sua participação relativa no PIB regional em detrimento dos setores agropecuária e serviços no período 85-95. Segundo Vasconcelos (1999), esse fato pode estar associado ao Programa de Promoção Industrial e Atração de Investimento do Estado, iniciado no período 1990-1995. 
Tabela 1. Taxa geométrica de crescimento do PIB para o Estado do Ceará - 1995/2000.

\begin{tabular}{lrrrrrr}
\hline Setor/Período & 1995 & 1996 & 1997 & 1998 & 1999 & 2000 \\
\hline Agropecuária & $-4,20$ & 5,50 & $-21,40$ & $-27,10$ & 27,90 & 7,90 \\
Indústria & 7,30 & 7,10 & 8,60 & 5,70 & 3,80 & 5,30 \\
Serviços & 5,70 & 6,80 & 0,80 & 2,20 & 4,20 & 3,60 \\
Total & 5,50 & 6,80 & 1,80 & 2,10 & 4,60 & 4,60 \\
\hline
\end{tabular}

Fonte: SUDENE/CPE/INE, Contas Regionais (2000)

Tabela 2. Participação dos setores econômicos no PIB do Ceará - 1995-2000.

\begin{tabular}{lrrrrrr}
\hline Setor / Período & 1995 & 1996 & 1997 & 1998 & 1999 & 2000 \\
\hline Agropecuária & 9,66 & 9,64 & 6,36 & 5,62 & 9,50 & 9,5 \\
Indústria & 34,49 & 33,89 & 38,07 & 40,08 & 47,80 & 47,8 \\
Serviços & 55,85 & 56,47 & 55,57 & 54,30 & 42,70 & 42,7 \\
Total & 100,00 & 100,00 & 100,00 & 100,00 & 100,00 & 100,0 \\
\hline
\end{tabular}

Fonte: Fundação Instituto de Pesquisa e Informação do Ceará - IPLANCE (2000)

Sabe-se no entanto, que a industrialização do Ceará tende a aumentar o consumo de água e energia elétrica. Entretanto, a oferta destes na região, conforme já mencionado, é limitada. Diante disto, torna-se necessário encontrar respostas para questões do tipo: como e até que ponto a escassez de água pode limitar o desenvolvimento do Estado? Qual o impacto que uma alteração no padrão industrial de uso da água provoca sobre os demais setores primário e terciário? A água disponível no Estado é suficiente para atender a aumentos na demanda industrial? Qual o impacto de uma diminuição no consumo de energia elétrica sobre a produção?

Não basta encontrar soluções para o aumento da oferta através de investimentos em infra-estrutura. Diante de um quadro de escassez de água e energia elétrica é preciso adotar uma gestão voltada para a demanda, cujo objetivo seja orientar o consumo de ambos os recursos. 
Nos países desenvolvidos a demanda de água tem sido estudada sob vários aspectos. Porém, no Brasil são poucos os estudos referentes a este tema o que dificulta a elaboração de previsões de demanda mais confiáveis por parte dos gerenciadores de recursos hídricos. Assim, é essencial que sejam realizados estudos voltados para a utilização da água quer analisando o impacto de variações na demanda final dos setores econômicos sobre a disponibilidade de água, quer analisando os efeitos na mudança na demanda de água sobre a economia como um todo.

Considerando a questão da energia elétrica, segundo Ministério da Fazenda (2001), sabe-se que os cortes no suprimento de energia são eficazes mas não são eficientes como forma de diminuir o consumo, pois podem provocar o aumento de horas extras, penalizam os setores de baixo consumo energético (como serviços) e aqueles que operam com plena capacidade. Como alternativa sugere-se a transferência de energia entre setores. Porém, para que isto seja possível é necessário o conhecimento do comportamento dos setores em relação às variações no padrão de uso de energia elétrica.

O modelo de Insumo-Produto proposto por Leontief apresenta-se como um instrumental metodológico adequado a este propósito uma vez que permite estudar as relações intersetoriais bem como os impactos provocados por alterações na demanda de um determinado setor sobre os demais setores produtivos da economia de uma região. $\mathrm{O}$ emprego e as vantagens de se utilizar este método podem ser vistos mais detalhadamente no capítulo três deste estudo.

A seguir descreve-se a hipótese desta pesquisa e seus objetivos. Pretende-se com este estudo fornecer subsídios para que os planejadores de políticas públicas no Ceará identifiquem as prioridades de uso da água e da energia elétrica no Estado, permitindo que todos tenham acesso a estes recursos para satisfazer suas necessidades. 


\subsection{Hipótese}

A continuidade do desenvolvimento experimentado pelo Ceará na última década está atrelada à disponibilidade de água e energia elétrica, insumos presentes em quase todos os processos produtivos da economia. Se esta hipótese for verdadeira, o estabelecimento de prioridades de uso e a racionalização das quantidades empregadas destes insumos entre os diferentes setores econômicos são essenciais para assegurar que as mudanças econômicas verificadas no Estado continuem ocorrendo e atingindo todos os segmentos da sociedade.

\subsection{Objetivos}

Diante do exposto na sub-seção 1.1, o objetivo geral desta pesquisa é avaliar o impacto de uma variação na demanda por água e energia elétrica no setor industrial sobre os demais setores da economia cearense. Assume-se como objetivos específicos:

- construção de um modelo de insumo-produto inter-regional envolvendo as regiões: Ceará, Resto do Nordeste, Resto do Brasil;

- identificação dos setores com maior capacidade de interação no sistema econômico e análise do grau de dinamismo da economia;

- estimação do impacto de variações na demanda final dos setores sobre a produção, renda, emprego e importação;

- identificação e análise da importância da água como insumo produtivo na economia do Estado;

- verificação da disponibilidade da água para atender às necessidades da indústria sem prejudicar os demais setores da economia;

- identificação dos setores mais susceptíveis às variações provocadas pela restrição ao consumo de energia; 


\subsection{Organização do trabalho}

Este trabalho é dividido em oito partes: esta introdução, onde é abordado o problema a ser estudado, ressaltando a sua importância; o capítulo dois onde é traçado um panorama da economia do Ceará, apresentando-se a situação hídrica do Estado, além do que está sendo feito para contornar os problemas causados pelos longos períodos de estiagem no Estado, e ainda o comportamento do setor de energia elétrica; o capítulo três que descreve o modelo de Leontief, suas características, aplicações e limitações; o capítulo quatro que traz a aplicação do modelo de insumo-produto na resolução de questões relacionadas ao gerenciamento dos recursos hídricos e energéticos; o capítulo cinco com a metodologia proposta para que os objetivos desta pesquisa sejam alcançados; em seguida o capítulo seis, onde são apresentados os resultados referentes à análise estrutural do modelo inter-regional, o capítulo sete relacionado à compreensão do comportamento do setores cearenses quanto ao consumo de água e energia elétrica e, finalmente, o capítulo oito com as conclusões obtidas. 


\section{A ECONOMIA, O GERENCIAMENTO DOS RECURSOS HÍDRICOS E O SETOR DE ENERGIA ELÉTRICA NO CEARÁ}

Desde de 1986, o Ceará vem experimentando uma série de mudanças substanciais em sua economia, atribuídas essencialmente à ação do governo estadual no que concerne aos programas de atração de investimentos industriais para o Estado. No entanto, existem ressalvas quanto a esse comportamento. Para alguns críticos do governo, certos setores da economia, a agropecuária por exemplo, foram relegados a um plano secundário em detrimento da indústria. Além disso, observa-se que questões sociais como educação, mortalidade infantil e saneamento básico não obtiveram resultados tão expressivos quanto os alcançados pela economia. O Estado ainda se encontra entre os mais pobres do país.

Este capítulo tem como objetivo mostrar a necessidade de se apoiar todos os setores econômicos conjuntamente com os programas sociais, para se alcançar um desenvolvimento econômico-social global com resultados mais efetivos para a população.

As políticas de desenvolvimento propostas pelo governo estadual devem considerar as vulnerabilidades existentes no Estado, principalmente àquelas referentes às condições climáticas, responsáveis pela escassez de água e crises no abastecimento de energia elétrica. Deste modo, acredita-se que uma política com dimensões econômicas e sociais deve enfatizar o gerenciamento dos recursos hídricos e estabelecer critérios para a utilização de energia por parte dos diferentes setores econômicos, pontos fundamentais para a melhoria da qualidade de vida, à medida que envolve questões como: 
- Promoção de atividades com excelentes potencialidades de crescimento, tais como agricultura irrigada e agroindústria, o que acarretaria o aumento no nível de emprego e salários, reduzindo as desigualdades e a pobreza;

- Aumento no número de pessoas com acesso à água de boa qualidade e energia elétrica, através da regularização da oferta de ambos os recursos, garantindo assim que os mesmos sejam usados racionalmente e de forma justa pelo conjunto da sociedade;

- Diminuição das perdas físicas de água e desperdício de energia e conseqüente aumento da produtividade dos setores econômicos que utilizam estes dois insumos no processo produtivo

- Aumento do Índice de Desenvolvimento Humano - IDH - uma vez que a gestão dos recursos hídricos atua sobre os três componentes deste índice: esperança de vida, nível educacional e renda "per capita";

- Utilização racional da água e energia elétrica, com redução do seu consumo, tornando-os mais acessíveis a todos os segmentos da cadeia de insumo-produto;

A primeira parte do capítulo descreve o panorama da economia do Ceará em $1999^{3}$, ano de interesse deste estudo, e apresenta alguns indicadores sociais do Estado. $\mathrm{Na}$ segunda parte, é feita uma síntese da situação hídrica do Estado e a descrição da postura do governo no combate à escassez de água através do gerenciamento dos recursos hídricos, na terceira e última parte é feita uma descrição do comportamento do mercado de energia elétrica cearense.

\footnotetext{
${ }^{3} \mathrm{O}$ ano escolhido para a análise foi o de 1999 por ser este ano o que apresenta as informações mais recentes necessárias à construção do modelo inter-regional utilizado neste estudo, segundo o Instituto Brasileiro de Geografia e Estatística (IBGE).
} 


\subsection{Panorama econômico e social do Ceará}

O Estado do Ceará está localizado na região Nordeste do Brasil e ocupa uma área de $146817 \mathrm{~km}^{2}$, o correspondente a $1,7 \%$ da área do Brasil e $9,4 \%$ da área do Nordeste. O Estado está dividido em 184 municípios e possui uma população de 7.417.402 habitantes, conforme o Censo de 2000 do IBGE. Com 93\% do seu território inserido em uma zona semi-árida, está sujeito a precipitações irregulares e secas periódicas. Como consequiência disto, os cursos dágua são temporários, permanecendo secos durante o verão. Os açudes existentes garantem o desenvolvimento agropecuário durante a escassez de água.

Apesar dos problemas climáticos enfrentados pelo Estado, nos últimos onze anos a economia cearense apresentou uma taxa de crescimento acima da economia brasileira em razão principalmente dos elevados investimentos na área industrial provocados pelos incentivos fiscais oferecidos pelo governo estadual. Existe uma tendência de aumento da participação relativa do PIB cearense em relação ao nacional.

Conforme Vasconcelos et al. (1999), o PIB cearense aumentou sua participação no PIB nacional de 1,65\% em 1990 para 1,72\% em 1995. Em 1999 esta participação, segundo dados do IBGE foi de $2,79 \%$.

Os indicadores econômicos apontam que o PIB estadual cresceu aproximadamente 4,6\% em 1999 (Tabela 3), posicionando-se acima das médias nacional e regional. Como pode ser observado, o PIB foi condicionado por comportamentos desiguais entre os grandes setores econômicos, uma vez que o setor agropecuário apresentou um crescimento de $27,9 \%$, a indústria $3,8 \%$ e os serviços $4,2 \%$. O resultado do setor primário foi conseqüência de uma comparação com uma produção bastante baixa no ano anterior devido a problemas de estiagem, o que mostra a vulnerabilidade do setor. 
Tabela 3. Taxa de crescimento do PIB real, segundo os setores econômicos, Brasil, Nordeste e Ceará - 1999 (1).

\begin{tabular}{lccc}
\hline DISCRIMINAÇÃO & BRASIL & NORDESTE & CEARÁ \\
\hline Total da Economia & 1,01 & 3,30 & 4,60 \\
Agropecuária & 9,49 & 10,60 & 27,90 \\
Indústria & $-1,69$ & 1,70 & 3,80 \\
Serviços & 1,33 & 3,10 & 4,20 \\
\hline
\end{tabular}

Fonte: SUDENE/CPE/INE,Contas regionais (2001)

(1) Dados preliminares

Segundo Iplance (2000), a agropecuária cearense está voltada essencialmente para as espécies nativas, com destaque para o caju, algodão, lagosta, camarão e mandioca. Na agricultura são importantes também as culturas do arroz, feijão, cana de açúcar, milho, laranja, banana, coco da baía e frutos tropicais como manga, acerola, melão. Na pecuária têm importância a avicultura e a criação de lagosta e camarão em cativeiro.

A estrutura do PIB por setor, Tabela 2, mostra claramente o bom desempenho do setor industrial do Estado. A cada ano observa-se um aumento da participação da indústria no PIB estadual. Isto é resultado dos incentivos criados a partir de projetos como o Programa de Incentivos ao Financiamento de Empresas (PROVIN) ${ }^{4}$, Fundo de Investimento do Nordeste $(\mathrm{FNE})^{5}$, entre outros. Atualmente estão sendo criadas na Federação das Indústrias do Estado do Ceará (FIEC), câmaras de Comércio e Indústrias com países europeus a fim de se obter o desenvolvimento de um parque industrial mais sólido. Além disso, a estruturação do Porto do Pecém é outro projeto que traz grandes expectativas para a indústria do Ceará.

\footnotetext{
4 Neste programa são concedidos incentivos fiscais às empresas que se localizam no interior do Estado com o objetivo de promover a interiorização da indústria e a geração de empregos na região rural.
} 
Segundo dados do Iplance (2000) em 1999 a indústria de transformação cresceu 4,03\%, destacando-se as indústrias metalúrgicas $(22,12 \%)$, têxteis $(11,88 \%)$ e vestuário (8,68\%). Estas indústrias, em conjunto com as indústrias de minerais não metálicos, de calçados e artefatos e produtos alimentares são as mais importantes do Estado. A Figura 1 mostra as indústrias de transformação, por gênero, no Ceará, em 1999.

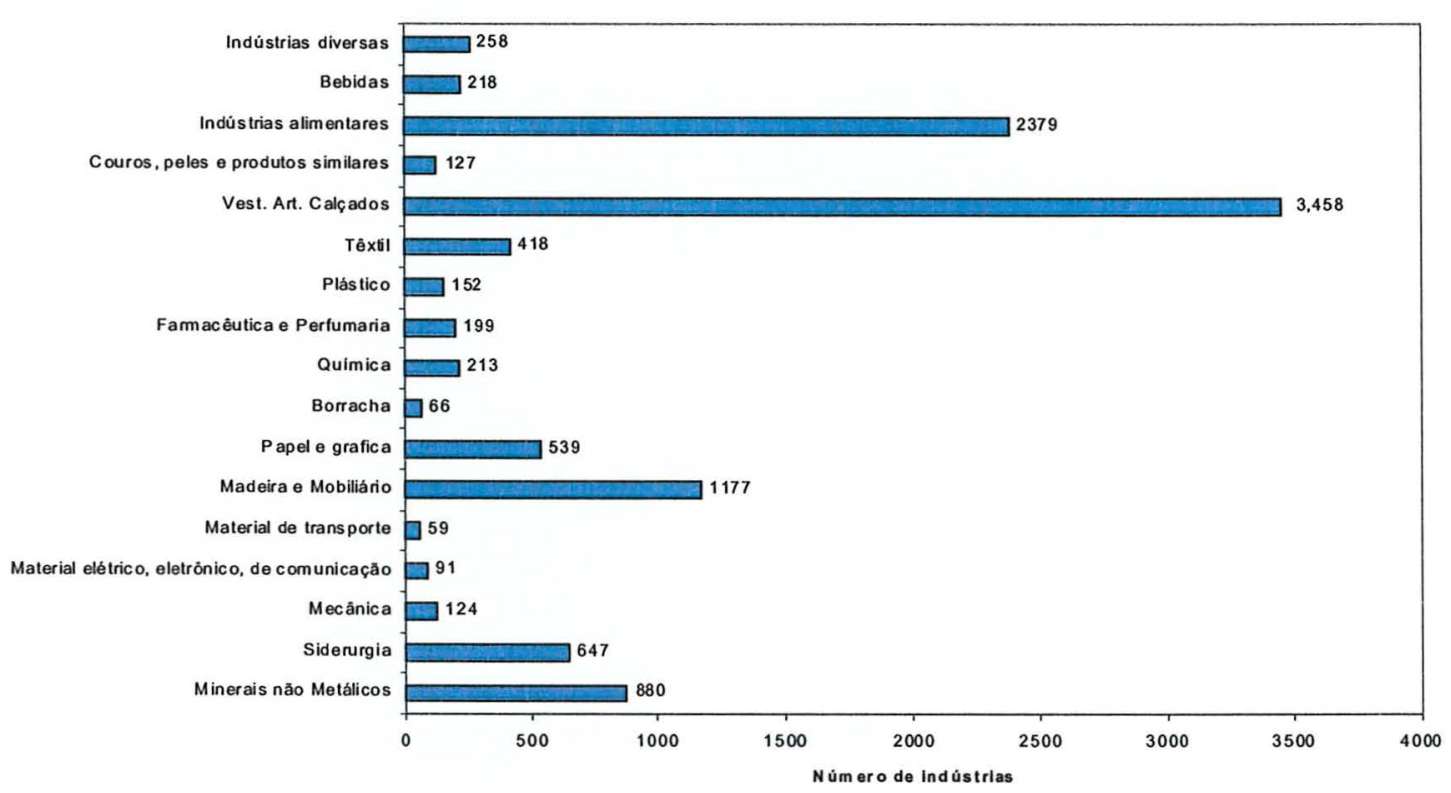

Figura 1 - Indústrias de transformação ativas, por gênero, no Ceará -1999.

Fonte: IPLANCE (2000)

As empresas prestadoras de serviços no Ceará, responsáveis pela maior parcela do PIB estadual, estão representadas na Figura 2.

5 Mecanismo de incentivos fiscais com apoio à indústria tradicional de médio porte para torna-la moderna e competitiva . Trata-se de um programa do Governo Federal. 


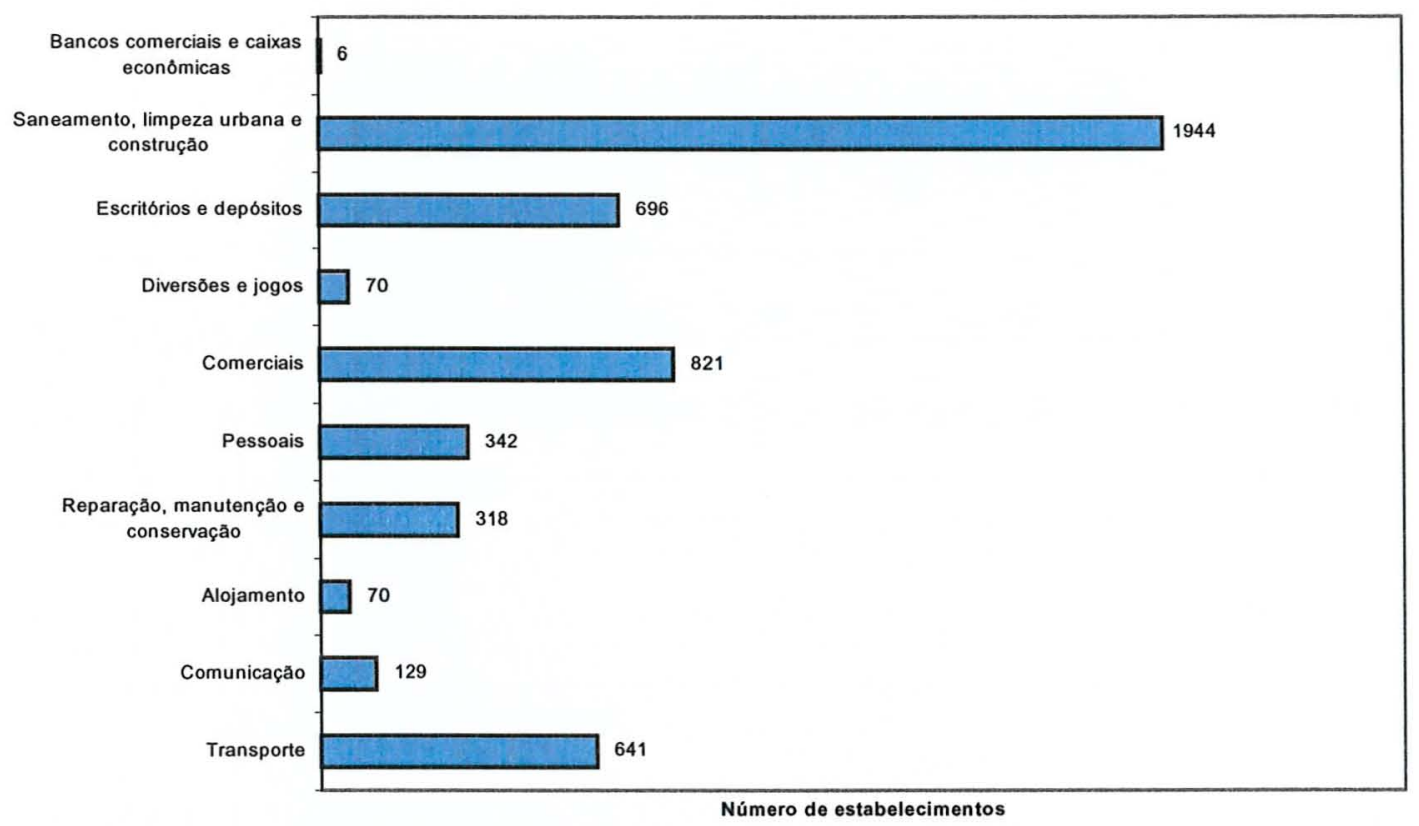

Figura 2 - Empresas de serviços, por atividade econômica - Ceará, 1999.

Fonte: IPLANCE (2000)

Segundo o Iplance (2000), as exportações cearenses em 1999, atingiram US\$ 371 milhões. O Estado do Ceará encontra-se na $3^{\mathrm{a}}$ posição, em termos de valor, em relação aos demais estados nordestinos, e na $14^{\mathrm{a}}$ em relação aos demais estados brasileiros. Do lado das importações o Estado alcançou, em 1999, o valor de US\$ 573 milhões. Em decorrência desse resultado, o Ceará ocupa a $11^{\text {a }}$ colocação entre os estados brasileiros e o $3^{\circ}$ lugar entre os nove estados nordestinos. A balança comercial estadual registrou um saldo negativo de US\$ 202 milhões. As Tabelas 4 e 5 mostram, respectivamente, os principais produtos da pauta de exportação e importação do Ceará no ano de 1999. 
Tabela 4. Exportações do Ceará em 1999 - Valores em milhões US\$ FOB.

\begin{tabular}{lcc}
\hline \multicolumn{1}{c}{ Produto } & Valor exportado & Participação (\%) \\
\hline Castanha de caju & 115786 & 31.19 \\
Calçados em couro em geral & 37141 & 10.01 \\
Lagosta & 29638 & 7.98 \\
Tecidos & 28737 & 7.74 \\
Calçados de borracha & 22118 & 5.96 \\
Ceras vegetais & 20155 & 5.43 \\
Couros & 18692 & 5.04 \\
Fios & 11025 & 2.97 \\
Consumo de bordo & 6236 & 1.68 \\
Camarões & 6229 & 1.63 \\
Demais produtos & 75443 & 20.30 \\
Total exportado pelo Estado & 371206 & 100.00 \\
\hline
\end{tabular}

Fonte: MICT/ SECEX, Sistema Alice (2000) 
Tabela 5. Importações cearenses em 1999 - Participação percentual.

Produto

Participação (\%)

Trigos e misturas 16,52

Gasóleo - óleo diesel 11,78

Algodão debulhado 8,63

Óleos brutos de petróleo 7,96

Querosene para aviação 5,67

Butanos liquefeitos 3,25

Outros tipos de algodão 2,04

Máquinas e aparelhos para indústria de panificação 1,91

Outras máquinas e aparelhos 1,70

Outras espécies de milho em grão 0,22

Fibras de poliéster 0,13

Outros produtos 40,79

Total 100,00

Fonte: MICT/ SECEX, Sistema Alice (2000)

Apesar da crise gerada na economia pelo racionamento de energia imposto à sociedade, o Ceará continua com um crescimento positivo. De agosto de 2000 a agosto de 2001 apresentou um crescimento de 1,5\%, conforme dados do IBGE. Em 2000 o Estado ocupou o segundo lugar em crescimento industrial do país, perdendo apenas para o Rio Grande do Sul (CNI,2001). Porém, setores como vestuário e calçados não conseguiram evitar o desaquecimento na sua produção. As perspectivas para o Estado, no médio prazo, é que os problemas decorrentes da escassez de energia não causem maiores prejuízos à economia. Segundo Jorge Parente, presidente da Fundação das Indústrias do Estado do Ceará, FIEC, o Ceará está buscando o aumento da sua oferta de 
energia através de diferentes fontes: termoelétrica, eólica, utilização de uma linha de Tucuruí além de uma hidrelétrica que está sendo construída no Pará. ${ }^{6}$

O crescimento econômico descrito acima não impede que a maior parte da população enfrente sérios problemas sociais. Conforme Tabela 6 , uma comparação com dados nacionais nos mostra que a taxa de analfabetismo do Estado ainda é bastante elevada, alcançando $44,00 \%$ da população em 1999. A taxa de mortalidade infantil, ainda encontra-se entre as mais elevadas do país. No que se refere à distribuição de renda, $19,95 \%$ da população economicamente ativa tem renda igual ou inferior a um salário mínimo. Finalmente, o número de domicílios beneficiados com água encanada $76,40 \%$, é ainda baixo em relação aos dados nacionais, $89,2 \%$.

Tabela 6. Principais Indicadores Sociais - Brasil, Nordeste e Ceará - 1999.

\begin{tabular}{lccc}
\hline \multicolumn{1}{c}{ INDICADORES } & Ceará & Nordeste & Brasil \\
\hline Taxa de analfabetismo (\% de pessoas com 15 anos ou mais) & 44,0 & 41,0 & 29,0 \\
$\begin{array}{l}\text { Taxa de mortalidade infantil ( } \mathrm{n}^{\circ} \text { de óbitos/1.000 nascidos } \\
\text { vivos) }\end{array}$ & 52,0 & 53,0 & 35,0 \\
Domicílios com água encanada (\%) & 76,4 & 80,9 & 89,2 \\
\hline
\end{tabular}

Fonte: IBGE (1999)

Os indicadores apresentados acima apontam melhoras nas condições de vida e padrão de bem-estar da população em relação à década passada. No entanto, segundo Vasconcelos (1999), é necessário um grande e continuado esforço no sentido de se alterar o quadro atual, de modo a não se criarem obstáculos ao processo de transformação econômica vivido pelo Estado nestes últimos anos. São necessários

\footnotetext{
${ }^{6}$ Está sendo implantada uma termelétrica com a geração de 220 megawatts. Além disso, existe na região uma grande quantidade de ventos para implementação de parques eólicos.
} 
recursos para a execução de projetos que promovam o desenvolvimento econômico e social do Estado, solucionando os problemas atuais.

Acredita-se, especificamente, que investimentos em recursos hídricos, trarão um grande impacto positivo, tanto do ponto de vista econômico, através da criação de pólos agrícolas em zonas secas e da exploração da fruticultura irrigada em quase todos os municípios, quanto do ponto de vista social, através da possibilidade de acesso à água de boa qualidade a todas as regiões e da geração de emprego e renda.

A próxima seção descreve como são distribuídos os recursos hídricos do Ceará e algumas ações praticadas no sentido de promover o desenvolvimento de um sistema eficaz de gerenciamento dos recursos hídricos.

\subsection{Os recursos hídricos no Estado do Ceará}

O Ceará possui uma área de $146.817 \mathrm{~km}^{2}$ sendo que $97,5 \%$ desta área encontra-se no chamado "polígono das secas"" (Sudene,2001a), uma das regiões mais pobres em recursos hídricos do Brasil, caracterizada pela irregularidade das chuvas no tempo e no espaço. As suas principais características em relação ao recurso água são:

- rios intermitentes;

- águas subterrâneas limitadas;

- baixa precipitação e escoamento superficial pequeno se comparado com o restante do Brasil;

- altas temperatura e taxa de evaporação, o que torna a eficiência hidrológica dos reservatórios extremamente baixa;

\footnotetext{
${ }^{7}$ Conforme Sudene (2001), o Polígono das Secas compreende a área do Nordeste brasileiro reconhecida pela legislação como sujeita à repetidas crises de prolongamento das estiagens e, consequentemente, objeto de especiais providências do setor público.
} 
- grande parte da região apresenta sub-solo com baixa capacidade de armazenamento dágua ${ }^{8}$;

- pouca educação da população rural;

- estrutura fundiária concentradora de renda;

- existência de ampla infra-estrutura hídrica, embora pouco eficiente, construída ao longo dos anos. A água armazenada nem sempre é usada para os fins previstos oficialmente sendo muitas vezes apropriada pelos latifundiários da região.

Este conjunto de fatores faz com que a água seja considerada um bem público no Estado e obriga as autoridades a tomarem providências quanto à adoção de estratégias que garantam a sua oferta com qualidade e em quantidade suficientes para atender à população.

A seguir será feita uma abordagem sobre a disponibilidade hídrica do Ceará, os principais usuários da água, os conflitos existentes entre os mesmos e a forma como está sendo conduzido o gerenciamento dos recursos hídricos no Estado. É oportuno ressaltar que não existe aqui a pretensão de explorar exaustivamente estes assuntos mas apenas ressaltar alguns pontos esclarecedores.

\subsubsection{Disponibilidade hídrica}

Conforme Cogerh (2001), os recursos hídricos do Ceará estão divididos em 11 bacias hidrográficas: Coreaú, Acaraú, Aracatiaçu, Curu, Metropolitana, Poti, Banabuiú, Baixo Jaguaribe, Médio Jaguaribe, Alto Jaguaribe e Salgado (Figura 3). O maior rio é o Jaguaribe, o qual banha as regiões sul, centro e leste do Estado. O norte é banhado por pequenos rios com destaque para o Coreaú, Acaraú e Aracatiaçu.

\footnotetext{
${ }^{8}$ Quando existe água muitas vezes é salina e imprópria para o consumo.
} 


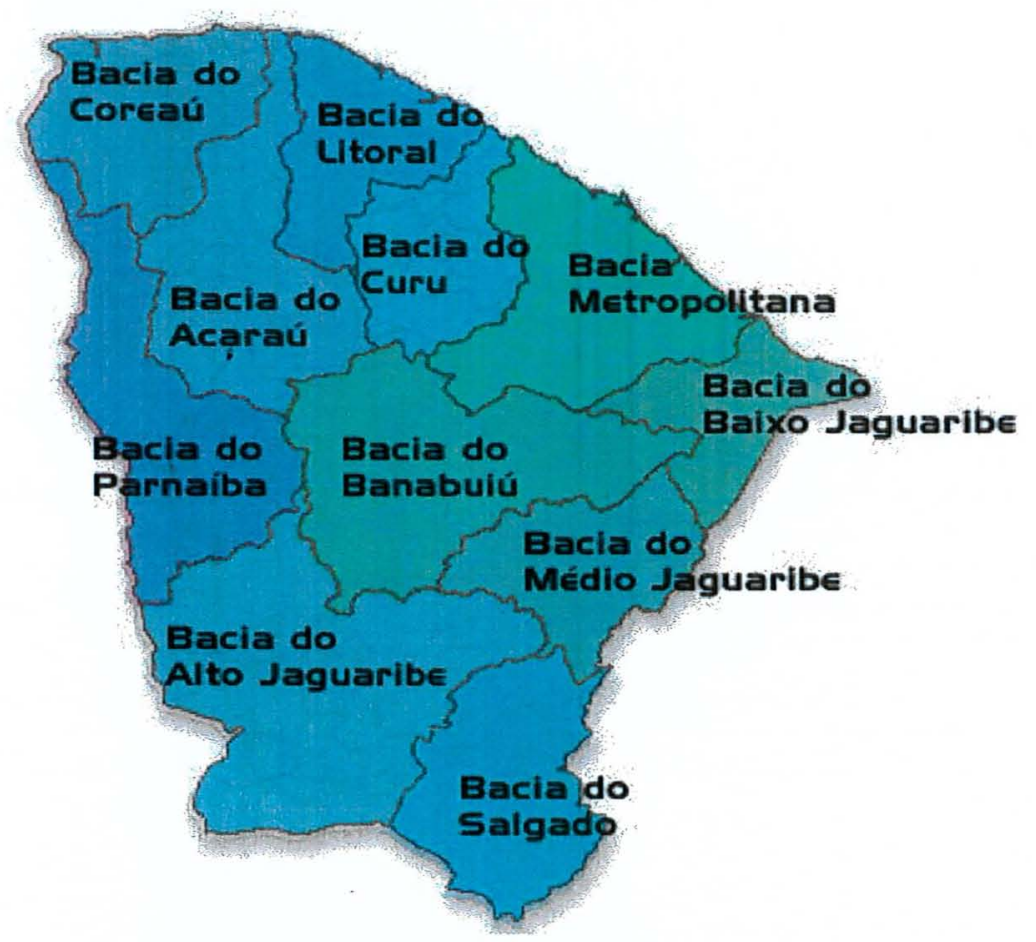

Figura 3 - Bacias hidrográficas do Estado do Ceará.

Fonte: COGERH (2001)

Uma característica importante do regime fluvial cearense é a sua intermitência. Por serem alimentados exclusivamente pelas águas das chuvas, sem nenhuma fonte perene, os rios estaduais costumam secar nos períodos de estiagem. Aliados a isto, solos rasos e cristalinos e uma alta taxa de evaporação contribuem para que a água escoe para o mar ou seja evaporada provocando, segundo o Ministério da Integração Nacional (2001), um desperdício estimado de $75 \%$ do excedente das águas das chuvas.

O Ceará vem desenvolvendo ao longo de décadas uma política de açudagem cujo objetivo principal é aumentar a capacidade de acumulação de água e suprir as suas necessidades hídricas. Segundo informações da Cogerh (2001), atualmente existem no Estado 7.227 açudes de pequeno, médio e grande porte com capacidade de armazenamento de 11,52 bilhões de metros cúbicos. Segundo Cavalcante (1997), esta quantidade de açudes faz do Estado a região com maior número de reservatórios do 
mundo. A oferta de água dos açudes será ampliada em 6,5 bilhões de metros cúbicos com a construção do açude Castanhão ${ }^{9}$, ainda em andamento. Dentre os açudes construídos destacam-se o Orós, no Jaguaribe e o Banabuiú, no rio do mesmo nome (Tabela 7).

Tabela 7. Principais açudes do Ceará por capacidade de volume de água armazenada.

\begin{tabular}{lcc}
\hline \multicolumn{1}{c}{ Açude } & Município & Capacidade $\left(\mathrm{m}^{3}\right)$ \\
\hline Castanhão & Alto Santo & 6,5 bilhões \\
Orós & Orós & 2 bilhões \\
Arrojado Lisboa (Banabuiú) & Banabuiú & 1,7 bilhões \\
Paulo Sarasate (Araras) & Varjota & 891 milhões \\
Pedra Branca & Banabuiú & 434 milhões \\
Pereira de Miranda (Pentecoste) & Pentecoste & 395 milhões \\
General Sampaio & General Sampaio & 322 milhões \\
\hline
\end{tabular}

Fonte: COGERH (2001)

Segundo Kemper (1997), existem duas categorias de açudes: os açudes de pequeno e médio porte cujo propósito é fornecer água aos diferentes usuários e os açudes de grande porte, que funcionam essencialmente como reserva de água para perenização dos rios.

Apesar de numerosos, os açudes não são suficientes para solucionar os problemas de abastecimento de água no Ceará. Embora haja disponibilidade deste recurso no inverno, a sua oferta é reduzida significativamente durante os periodos de seca gerando um fator de insegurança para a população e prováveis investidores. Para

\footnotetext{
${ }^{9} \mathrm{O}$ açude do Castanhão está situado na interligação das bacias do Ceará. Será três vezes maior que o açude de Orós, o maior do Nordeste. Possui dupla função estratégica: assegurar água durante os períodos críticos de estiagem e conter as enchentes nos anos especialmente chuvosos.
} 
garantir à população e aos empresários, a água necessária a suas atividades, os gerenciadores dos recursos hídricos têm como alternativa a construção de outras obras hídricas. A Tabela 8 apresenta o resumo destas obras no Estado.

Tabela 8. Quantidade de obras hídricas no Ceará por tipo.

\begin{tabular}{ccc}
\hline Obras hídricas & Construídas & Em construção \\
\hline Açudes & 7222 & 9 \\
Canais & 1 & 1 \\
Adutoras & 89 & 7 \\
Poços & 13970 & - \\
\hline
\end{tabular}

Fonte: SRH, SOHIDRA, CAGECE, CPRM (2001)

Segundo a Cagece, o Canal do Trabalhador possui $115 \mathrm{~km}$ de extensão e constitui-se numa alternativa de fornecimento de água para a região metropolitana de Fortaleza em casos de déficit hídrico no sistema formado pelos açudes Pacajus-PacotiRiachão-Gavião, responsável pelo abastecimento desta região. Atualmente está sendo construído o canal do Pecém com $26 \mathrm{~km}$ de extensão, com o objetivo de interligar os açudes Pereira de Miranda e Sítios Novos garantindo assim o abastecimento de água do complexo industrial e portuário do Pecém.

O Estado conta ainda com 13.970 poços, embora não apresente grandes mananciais hídricos subterrâneos. Segundo o Governo do Estado (2001), a reserva de água subterrânea possível de exploração é de 1,2 bilhões de metros cúbicos.

A política de gerenciamento dos recursos hídricos do Ceará está obtendo sucesso no preenchimento dos vazios hídricos ${ }^{10}$ existentes no Estado. A construção de reservatórios, adutoras, canais, além da perenização dos rios tem proporcionado a

\footnotetext{
${ }^{10}$ Segundo Kemper (1997), vazios hídricos são locais onde não existem obras de armazenamento de água.
} 
melhoria na qualidade de vida dos usuários da água. Porém, é importante ressaltar que os altos custos e a crescente dificuldade de encontrar locais adequados para construção dessas obras exige que a questão dos recursos hídricos seja tratada não apenas através do aumento na oferta de água.

\subsubsection{Os usos da água no Ceará}

O desenvolvimento da humanidade está associado ao uso da água. Sem a água, a vida como a conhecemos seria impossível. No Ceará, o crescimento populacional e econômico verificado nas últimas décadas tem provocado mudanças no quadro de uso da água. A demanda por este recurso aumenta a cada ano com a expansão industrial e urbana, a melhoria no nível de vida da população e o crescimento agrícola. Esta demanda segundo Vieira (2000), pode ser entendida, para efeito de planejamento dos recursos hídricos, como as quantidades de água expressas em unidades de volume, que devem satisfazer aos seus usos consultivos e não consuntivos ${ }^{1}$.

Os principais usos consuntivos da água ocorrem no abastecimento humano, pecuária (dessedentação), agricultura, indústria e comércio. A seguir são apresentados alguns aspectos destes usos no Ceará.

\section{Abastecimento humano}

$\mathrm{O}$ abastecimento humano consiste no uso mais nobre da água. Esta forma de utilização da água pode ser dividida em uso doméstico (como bebida, no preparo de alimentos, higiene pessoal, limpeza habitacional, entre outros) e uso público (escolas, hospitais, limpeza de ruas, combate a incêndios etc).

Segundo dados do Fundo das Nações Unidas para a Infância - Unicef (2001), o consumo humano representa apenas $6 \%$ do consumo total de água. Porém, isto não impede que uma região carente de recursos hídricos apresente problemas de

\footnotetext{
${ }^{11}$ Conforme Sores \& Gurjilli (2000) usos consultivos da água são aqueles em que há perdas entre o que é retirado de água e o que retorna ao curso natural. Usos não consultivos da água são aqueles em que estas perdas não ocorrem.
} 
abastecimento. O Ceará é um exemplo. O fornecimento contínuo de água no Estado esporadicamente é ameaçado pela diminuição da capacidade hídrica dos reservatórios devido a invernos com baixas precipitações, à concentração de pessoas em grandes áreas urbanas e ao rápido crescimento populacional.

Nos últimos anos tem-se observado o crescimento dos centros urbanos, principalmente aqueles que representam pólos de desenvolvimento industrial. Os projetos governamentais para fixar o homem no campo não estão alcançando o sucesso esperado.

A concentração de pessoas nas cidades cearenses pode ser analisada através das taxas de urbanização do Ceará nos últimos anos. A Tabela 9 mostra que em 2000, $71,5 \%$ da população encontra-se na zona urbana onde, segundo Tucci et al. (2001), o consumo de água é maior que na zona rural.

Tabela 9. Taxa de urbanização e situação de domicílios no Ceará - Anos, 1980, 1991, 1996 e 2000.

\begin{tabular}{cccc}
\hline Ano & \multicolumn{2}{c}{ População Residente } & Taxa de Urbanização \\
\cline { 2 - 3 } & \multicolumn{2}{c}{ Zona Urbana } & Zona Rural \\
& 2810351 & 2477902 & 53.14 \\
1980 & 4162007 & 2204640 & 65.37 \\
1996 & 4713311 & 2096483 & 69.21 \\
2000 & 5303741 & 2113661 & 71.50 \\
\hline
\end{tabular}

Fonte: IBGE (2001)

A Tabela 10 aponta os indicadores de crescimento populacional de alguns municípios cearenses. Pode-se observar que todos os municípios apresentaram altas taxas de crescimento e o Ceará como um todo cresceu $8,9 \%$, o que acarreta um 
considerável aumento na demanda de água. As maiores taxas de crescimento populacional estão associadas ao desenvolvimento da indústria (municípios de Caucaia, Horizonte, Pacajus e Pacatuba) e do turismo (Jijoca de Jericoacoara e Paracuru).

Segundo dados do Banco Mundial, o consumo médio diário de água no semi-árido do Nordeste é de 200 litros por pessoa. Considerando este mesmo consumo para o Ceará, estima-se que a demanda por água para o consumo humano no Estado aumentou de 1,36 bilhões de litros em 1996, para 1,48 bilhões de litros em 2000.

Tabela 10. Municípios com maiores taxas de crescimento populacional no período 19962000.

\begin{tabular}{lrrr}
\hline Município & \multicolumn{2}{c}{ Número de habitantes } & Taxa de crescimento \\
\cline { 2 - 3 } & \multicolumn{1}{c}{1996} & \multicolumn{1}{c}{2000} & \\
\hline Caucaia & 209.150 & 250.246 & 19.65 \\
Horizonte & 25.382 & 33.784 & 33.10 \\
Itapipoca & 80.249 & 94.340 & 17.55 \\
Jijoca de Jericoacoara & 9.571 & 12.084 & 23.92 \\
Pacajus & 37.076 & 43.830 & 18.22 \\
Pacatuba & 43.594 & 51.812 & 18.86 \\
Paracuru & 23.018 & 27.508 & 19.50 \\
Tianguá & 49.243 & 58.023 & 17.83 \\
Ceará & 6.809 .794 & 7.417 .402 & 8.9 \\
\hline
\end{tabular}

Fonte: IPLANCE (2000)

A água para abastecimento humano no Ceará é fornecida basicamente pela Companhia de Água e Esgoto do Ceará - Cagece, responsável pelo tratamento e distribuição de água para 152 dos 184 municípios cearenses. O restante dos municípios são atendidos pelo Fundo Nacional de Saúde (FNS) e por prefeituras municipais. 
Segundo a Cagece (2002) o consumo humano de água aumentou de 114,16 milhões de $\mathrm{m}^{3}$ em 1999 para 119,25 milhões de $\mathrm{m}^{3}$ em 2000

\section{Pecuária}

O Ceará não é um Estado de cultura pecuarista, principalmente devido as suas condições climáticas, condições estas que determinam o comportamento da população animal. As secas recorrentes têm provocado uma diminuição gradativa nos efetivos de alguns rebanhos.

A tabela 11 permite observar o número de animais do rebanho cearense e o seu respectivo consumo de água. Trata-se de uma demanda pequena relativamente aos demais usuários de água, a qual é suprida essencialmente através de açudes.

Tabela 11. Principais rebanhos cearenses em número de cabeças e seu respectivo consumo de água - 1999.

\begin{tabular}{lcc}
\hline Rebanho & Número de cabeças & Consumo de água (milhões de 1/dia) \\
\hline Bovinos & 2.167 .525 & 108.4 \\
Ovinos & 1.554 .973 & 15.5 \\
Suínos & 1.006 .062 & 12.6 \\
Caprinos & 773.102 & 7.7 \\
Asininos & 195.594 & 9.8 \\
Eqüinos & 134.568 & 6.7 \\
Total & 5.831 .824 & 160.7 \\
\hline
\end{tabular}

Fonte: Adaptado de Vieira (2000)

\section{Agricultura}

Em 2000 o Ceará apresentou um crescimento do setor agrícola da ordem de 7,94\% (IPLANCE, 2001), graças a investimentos voltados para o desenvolvimento 
regional que estimularam a substituição de culturas tradicionais de subsistência (milho, mandioca, feijão), as quais demandam pouca água mas não apresentam bons resultados econômicos, por culturas mais competitivas, como é o caso das frutíferas.

O desenvolvimento e a modernização agrícola que o Ceará vem experimentando implicam no aumento da demanda de água por recursos hídricos uma vez que a maioria das culturas em evidência no Estado necessitam de métodos de irrigação $^{12}$. $\mathrm{O}$ aumento no número de pólos irrigados comprova isso. Atualmente, segundo dados da Secretaria de Agricultura Irrigada (2001) existem 6 pólos irrigados, abrangendo um total de 55910 ha (Tabela 12). Considerando-se os projetos existentes, estima-se que a área irrigada do Estado alcance 92.390 ha nos próximos anos.

Tabela 12. Áreas irrigadas nos agropolos ${ }^{13}$ do Ceará - 2000.

\begin{tabular}{lccc}
\hline Agropolo & \multicolumn{2}{c}{ Área de Irrigação (ha) } & Total \\
\cline { 2 - 3 } & Pública & Privada & \\
\hline Baixo Acaraú & 2.439 & 1.326 & 3.765 \\
Metropolitano & 4.425 & 8.382 & 12.807 \\
Ibiapaba & 100 & 1.837 & 1.937 \\
Baixo Jaguaribe & 18.495 & 5.132 & 23.627 \\
Cariri & 293 & 4.399 & 4.692 \\
Centro Sul & 2.712 & 6.370 & 9.082 \\
Total & 28.464 & 25.746 & 55.910 \\
\hline
\end{tabular}

Fonte: SEAGRI-SIGA (2000)

\footnotetext{
${ }^{12}$ Segundo Kelman (2001) 1ha de terra irrigada utiliza a quantidade de água consumida por 200 pessoas ou até 400 pessoas dependendo do método de irrigação utilizado.

13 Segundo Secretaria de Agricultura Irrigada do Ceará - Seagri (2001), agropolo é uma área geograficamente delimitada envolvendo um número variável de municípios com potencial para a agricultura irrigada, onde existe clima e situação de parceria entre governo e sociedade, objetivando o desenvolvimento.
} 
A água destinada à agricultura é proveniente principalmente de açudes e rios, geridos pela Cogerh.

\section{Indústria}

Segundo o Iplance (2000) no Ceará, existem cerca de 11.000 indústrias, concentradas principalmente na região metropolitana de Fortaleza. A água é utilizada neste setor como matéria-prima, na produção de alimentos, produtos farmacêuticos, na refrigeração, metalurgia, lavagem de máquinas e fabricação de vapor, entre outros.

Como a indústria é o segmento que apresenta o maior crescimento econômico do Estado, a água destinada ao seu consumo apresentou um aumento na sua demanda. Conforme dados da Cagece, o consumo de água tratada do setor industrial aumentou $13,4 \%$ entre os anos de 1999 e 2000 . É importante ressaltar que estes valores referem-se apenas ao consumo industrial de água tratada, isto é, distribuída pela Cagece. As indústrias cearenses utilizam, ainda, água bruta, fornecida pela Cogerh e água proveniente de estações de tratamento particulares, sendo que esta última em escala bastante reduzida.

\section{Comércio}

O uso comercial da água no Ceará é feito pelos escritórios, oficinas, centros comerciais e lojas, bares, restaurantes, sorveterias, entre outros. A água é fornecida para estes estabelecimentos através da Cagece.

Além dos usos consuntivos da água, os usos não consuntivos também merecem ser destacados embora não tenham grande expressão como demanda de água no Ceará. São eles: geração de energia, navegação, pesca, recreação e turismo.

\subsubsection{Conflitos gerados pelo uso da água}

A possibilidade de uma crise mundial no abastecimento de água é uma preocupação dos governos de todos os países, desenvolvidos ou não. O reconhecimento 
de que a água é um recurso natural finito e de que a sua disponibilidade decresce anualmente gera uma crise entre seus usuários.Segundo Kemper (1997), entre as categorias de uso da água podem ser distinguidas: a) água para satisfazer as necessidades básicas humanas, b) água para satisfazer as necessidades do meio ambiente e c) para outros usos na indústria, agricultura e residências que excedam as necessidades básicas. A gestão dos recursos hídricos concentra-se basicamente na terceira categoria de .

Segundo dados da Unicef (2001) cerca de $73 \%$ da água consumida são utilizadas na agricultura, $21 \%$ na indústria e $6 \%$ nas residências. A competição torna-se cada vez mais intensa entre estes setores. A decisão a respeito da distribuição de água entre estes setores deve enfatizar os aspectos econômicos.

O desenvolvimento urbano e rural e a conseqüente alteração na distribuição da água exigem a racionalização do consumo, a contenção de desperdícios e cuidados com os efluentes que possam poluir os corpos dágua tornando-os impróprios ao uso. $\mathrm{O}$ cumprimento destas metas pode minimizar uma série de conflitos dentre os quais podese destacar os conflitos causados pelo desenvolvimento industrial e urbano e os conflitos causados pelo desenvolvimento rural.

Segundo Tucci et al. (2001), os principais conflitos provocados pelo desenvolvimento industrial e urbano são conseqüência dos seguintes fatores:

- degradação ambiental dos mananciais;

- aumento no risco de contaminação nas áreas de abastecimento provocado pela poluição orgânica e química;

- contaminação dos rios por esgotos domésticos e industriais;

- enchentes urbanas geradas pela inadequada ocupação do espaço e pelo gerenciamento impróprio da drenagem urbana;

- falta de coleta e disposição do lixo urbano. 
Ainda segundo os autores, a existência de problemas desta ordem provocam prejuízos econômicos, doenças veiculadas pela água (esquistossomose, cólera, febre tifóide, amebíase, disenteria bacilar etc.), perda de moradia e bens, enfim, queda na qualidade de vida da população.

Os conflitos decorrentes do desenvolvimento rural são mais perceptíveis. O crescimento da demanda por água pelas cidades e indústrias aumentou a competição entre estas e a agricultura. $\mathrm{Na}$ verdade, trata-se de conflito natural entre a agricultura e o abastecimento humano que está se agravando ainda com a pressão pelo aumento na produção de alimentos e pelo uso de métodos de irrigação.

$\mathrm{Na}$ competição cada vez mais intensa pelo uso da água, o grande volume deste recurso demandado pela agricultura e a degradação ambiental provocada pelo uso de agrotóxicos e pesticidas agravam os conflitos entre os agricultores irrigantes, agricultores de vazante $^{14}$, pescadores, usuários residenciais e indústria. Um dos grandes desafios dos gerenciadores é assegurar o aporte de água necessário para a agricultura irrigada. Porém, para que o setor não tenha o seu desenvolvimento limitado é necessário aumentar a eficiência dos sistemas de irrigação, diminuir os desperdícios e adotar um gerenciamento adequado dos efluentes agrícolas quanto aos riscos de contaminação. Conforme Postel (1992), o emprego de técnicas agrícolas mais sofisticadas possibilita a liberação de quantidades significantes de água para o uso industrial sem, contudo, causar qualquer prejuízo à agricultura.

Existem vários instrumentos adotados com o objetivo de alcançar a eficiência no uso dos recursos hídricos. Dentre os quais podem ser destacados a cobrança pelo uso da água, campanhas educativas e de conscientização ${ }^{15}$. O Estado do Ceará tem apresentado boas soluções para os conflitos de uso da água nas regiões mais

\footnotetext{
${ }^{14}$ Pequenos agricultores que praticam agricultura de subsistência nas áreas úmidas ao redor dos açudes ou ao longo dos rios, áreas estas também chamadas de vazantes.

${ }^{15}$ A experiência tem mostrado que este instrumento não é tão eficaz quando comparado à introdução de incentivos econômicos. Winpenny (1994).
} 
secas, estabelecendo mecanismos que permitem a utilização deste bem de forma ordenada, através de um gerenciamento integrado dos recursos hídricos.

\subsubsection{Experiência do Ceará no gerenciamento dos recursos hídricos}

No Ceará a seca é um fenômeno cíclico. Pode não acontecer em um ano, ou no seguinte, mas certamente virá, provocando graves problemas decorrentes da escassez de água. Diante deste fato é fundamental que haja um interesse por parte dos tomadores de decisão em aprimorar o gerenciamento dos recursos hídricos no Estado.

Segundo Soares et al. (2000) o gerenciamento dos recursos hídricos consiste em um conjunto de ações governamentais destinado a regular o uso, controle e preservação da água. Neste contexto foi criado o Plano Estadual de Recursos Hídricos no ano de 1992. Este plano avaliou a estrutura hídrica do Estado nos planos técnico, jurídico e institucional e serviu de base para a implantação da Política Estadual de Recursos Hídricos.

De acordo com Garjulli et al. (1998) a Política dos Recursos Hídricos no Ceará foi determinada por características naturais, sociais, econômicas e culturais do Estado, dentre as quais destacam-se:

- a água apesar de ser utilizada de múltiplas formas, é um bem limitado e escasso no Estado;

- o Estado não apresenta rios perenes e a garantia de água durante todo o ano só é possível através da intervenção humana por meio da construção de obras hídricas;

- a má administração da água gera graves conflitos entre os usuários e uma utilização inadequada deste recurso;

- a construção de obras hídricas no Estado são desvinculadas de um desenvolvimento integrado; 
- falta de controle público sobre as fontes de água localizadas em área privada;

- dependência da população em relação ao Estado.

A Política Estadual de Recursos Hídricos, prevista no artigo 326 da Constituição Estadual e definida pela Lei Estadual de Recursos Hídricos Lei № 11.996, de 24 de julho de 1992 tem como objetivo proporcionar os meios para que a água seja usada de forma racional e justa pelo conjunto da sociedade, em todo território do Ceará, assegurando desta forma o controle da água no que se refere a quantidade e qualidade, fatores preponderantes no desenvolvimento econômico-social da população. Seus elementos básicos são:

Plano Estadual dos Recursos Hídricos - elaborado em 1992, contém todo um estudo detalhado da capacidade e das potencialidades dos recursos hídricos em nível do Estado do Ceará e tem como objetivo viabilizar a utilização mais racional da água, sua proteção atual e futura, a defesa contra secas e inundações e um sistema de monitoramento climático e hídrico permanente.

Sistema Integrado dos Recursos Hídricos: é a estrutura institucional que garante a integração e a participação, onde os Comitês de Bacia, as Câmaras Técnicas e o CONERH - Conselho de Recursos Hídricos do Estado do Ceará, (órgãos colegiados) definem e executam a Política Estadual de Recursos Hídricos.

Fundo Estadual de Recursos Hídricos: é um fundo especial de recursos criado em 1992, para dar suporte financeiro à Política Estadual de Recursos Hídricos, que conta com recursos de programas e projetos governamentais e com os recursos que forem oriundos da cobrança pelo uso da água bruta.

A instituição formal da Política Estadual de Recursos Hídricos ocorreu em 1993 com a criação da Companhia de Gestão dos Recursos Hídricos - COGERH. Com a 
Cogerh o Ceará passou a adotar um modelo de gerenciamento dos recursos hídricos cujos princípios ou características essenciais são:

- Integração: considera todas as fases do ciclo hidrológico observando seus aspectos quantitativo e qualitativo;

- Descentralização: todas as decisões devem ser tomadas em nível de bacias hidrográficas ${ }^{16}$;

- Participação: todo o processo de gerenciamento em nível de bacia conta com a participação de representantes dos usuários, das instituições governamentais e não governamentais e da sociedade civil organizada.

Partindo destes princípios e considerando a bacia hidrográfica a sua unidade de planejamento e atuação, a Cogerh estimula a participação de todos os usuários de água na decisão de assuntos voltados aos recursos hídricos. Segundo Soares at al (2000), a participação dos usuários é garantida através da sua organização a qual é pautada:

- no conhecimento da situação hídrica da bacia hidrográfica;

- no respeito às formas de organização já existentes (associação, cooperativas etc.);

- na negociação de conflitos através de diálogos, subsídios técnicos e aparato legal;

- na definição conjunta de regras e normas de operação e preservação dos recursos hídricos.

Segundo a Cogerh, para a implementação do processo de organização dos usuários é necessário que sejam definidos três níveis de atuação:

\footnotetext{
${ }^{16}$ Bacia hidrográfica é uma área onde toda chuva que cai drena por riachos e rios secundários para um mesmo rio principal localizado em um ponto mais baixo, sendo separada das outras bacias por uma linha divisória denominada divisor de águas. (Soares et al., 2000).
} 
- açude: é o núcleo básico de organização dos usuários onde pescadores, vazanteiros, irrigantes e até mesmo o abastecimento das cidades dependem de um mesmo reservatório de água e devem portanto, decidir conjuntamente sobre sua utilização;

- vale perenizado: este é um nível um pouco mais complexo de atuação que envolve um ou mais açudes e trechos de rios onde encontram-se normalmente os grandes perímetros públicos irrigados, irrigantes privados, agro-indústrias, industrias e o abastecimento de várias cidades, os quais devem deliberar conjuntamente sobre a operação de um sistema perenizado.

- bacia hidrográfica: é o nível de atuação mais complexo que abrange toda a área de uma bacia hidrográfica, a qual deve ser entendida como uma unidade de planejamento e gestão, com todos os seus conflitos e potencialidades, onde a partir da consolidação do processo de organização dos dois níveis anteriores (açude e vale perenizado) serão constituídos os Comitês de Bacia $^{17}$ visando a concretização do processo de gestão participativa dos recursos hídricos.

Além da participação da sociedade, o gerenciamento dos recursos hídricos cearenses adota alguns instrumentos que auxiliam no controle sobre a quantidade, qualidade e distribuição da água no Ceará. Segundo Soares et al. (2000) são eles:

- planejamento: cujo objetivo é a adoção de práticas coerentes com a realidade existente na bacia hidrográfica;

\footnotetext{
${ }^{17}$ Segundo Lopes (2001), os comitês de bacias hidrográficas são colegiados compostos por representantes da sociedade civil, usuários da água e dos poderes públicos municipal, estadual e federal, que atuam como co-gestores nas políticas de gestão da água.
} 
- operação: objetiva principalmente a distribuição racional da água de acordo com a disponibilidade desta;

- cobrança pelo uso da água: prevista na Lei Estadual de Recursos Hídricos, objetiva diminuir o desperdício, aumentar a eficiência no uso da água, além de ser uma fonte arrecadadora de fundos para cobrir as despesas com a gestão, a operação e a manutenção das obras hídricas;

- monitoramento: objetiva acompanhar os aspectos qualitativos e quantitativos da água, servindo de informação para auxiliar a tomada de decisão da operação;

- manutenção: é realizada com o objetivo de recuperar e conservar as estruturas hidráulicas existentes na bacia hidrográfica;

- apoio à organização dos usuários: objetiva orientar os usuários para que estes possam gerenciar os recursos hídricos de forma correta;

- outorga: autorização, com validade anual, concedida pela Secretaria dos Recursos Hídricos que assegura ao usuário o direito de usar a água num determinado local, retirando-a de uma determinada fonte, com uma vazão definida e para uma finalidade também definida.

- licença para obras hídricas: autorização concedida pela Secretaria dos Recursos Hídricos para execução de qualquer obra ou serviço de oferta de água que altere o regime, a quantidade ou a qualidade dos recursos hídricos, tais como açudes, canais, barragens e poços. 
A preocupação com a preservação da água está presente na Política Estadual de Recursos Hídricos através de uma legislação específica sobre o assunto. Dentre as disposições legais relacionadas a este tema constam:

- Lei Estadual 11996/92, artigo $4^{0}$ que trata da criação do sistema de outorga para uso da água, regulamentado pelo Decreto 23067/94;

- Lei Estadual 10147/77 que dispõe do disciplinamento do solo para a proteção dos recursos hídricos;

- Lei Estadual 10148/77 que dispõe sobre a preservação e controle dos recursos hídricos no Ceará;

- Lei Estadual $12217 / 93$ que cria a Cogerh com a missão de gerenciar os recursos hídricos superficiais e subterrâneos constantes dos corpos dágua de domínio do Estado do Ceará, promovendo o seu uso racional, social, sustentado e justo.

Ainda como parte integrante do gerenciamento dos recursos hídricos, o governo estadual vem realizando uma série de obras que visam permitir uma justa distribuição das águas. Segundo a Secretaria de Recursos Hídricos do governo do Estado do Ceará - SRH, entre os principais projetos relacionados com a gestão dos recursos hídricos, destacam-se:

- construção do açude Castanhão. Com capacidade de armazenar um volume de 4,2 bilhões de metros cúbicos de água, este açude é o centro de um sistema integrado de bacias dos rios do Estado e terá como prioridades a irrigação de 43 mil hectares de terra e a garantia de abastecimento a 2.750 .000 pessoas mesmo em anos de seca.

- PROGERIRH - Programa de Gerenciamento e Integração dos Recursos Hídricos. Os objetivos centrais deste programa são: a) ampliação da 
oferta e garantia de água para usos múltiplos; b) aumento da eficiência da gestão do sistema integrado; c) promoção do uso múltiplo e eficiente da água; d) promoção do melhor uso do solo através do manejo adequado das micro-bacias críticas. Sua atuação abrange todo o setor de recursos hídricos do Estado.

- PROURB - Projeto de Desenvolvimento e Gestão dos Recursos Hídricos. Tem como objetivo desenvolver ações para regularizar a oferta de água em centros urbanos de médio porte criando possibilidades para o abastecimento humano e o desenvolvimento dos setores econômicos.

- PRODHAM - Programa de Desenvolvimento Hidroambiental das Bacias Hidrográficas. Tem como objetivo organizar o meio físico das microbacias hidrográficas contidas no semi-árido nordestino, com o intuito de recuperar as áreas degradadas.

- Programa de Integração de bacias - Este programa tem como objetivos aumentar a oferta de água através da construção de açudes de médio porte, expandir o sistema de transferência de águas baseado em adutoras, canais e perenização de rios.

O Ceará está amadurecendo a sua gestão de recursos hídricos servindo de referência a todo o Brasil. Em pouco tempo de atividade a Cogerh já é responsável pela manutenção da infra-estrutura hídrica do Ceará e pela operação coordenada dos açudes, através de consultas aos usuários. Porém, o modelo de gestão apresentado de forma sucinta nesta seção, ainda não é capaz de solucionar todos os problemas hídricos existentes. Observa-se uma carência quanto ao gerenciamento da demanda de água. É necessária a implantação de regras para a alocação da água durante as estiagens, o que traria uma maior confiabilidade para os consumidores residenciais e para alguns usos 
econômicos, como a indústria e a fruticultura irrigada, que atualmente relutam em se implantar na região devido à falta de garantia de suprimento de água.

\subsection{O setor de energia elétrica no Ceará}

O consumo de energia elétrica no mundo aumenta a cada ano em decorrência do crescimento demográfico, da elevação no padrão de vida da população e urbanização das cidades. No Brasil, a eletricidade vem ganhando espaço no balanço energético nacional, com o seu consumo crescendo a taxas mais elevadas que os demais energéticos.

Como pode ser observado através da Figura 4, a participação da eletricidade no consumo total de energéticos vem aumentando a cada ano. Segundo dados do Ministério das Minas e Energia (2000), a taxa de expansão do consumo de eletricidade nos últimos 15 anos ultrapassa a marca de $24 \%$, inferior apenas ao crescimento do consumo de gás natural (98\%). No Ceará observa-se o mesmo comportamento.

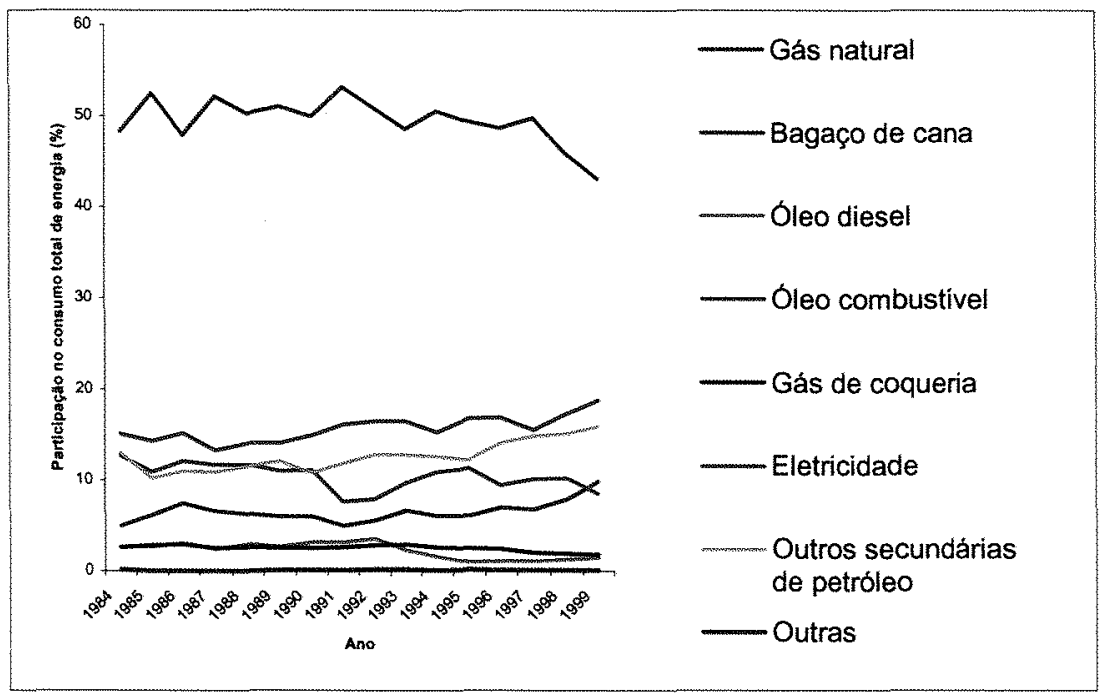

Figura 4 - Evolução da participação das fontes energéticas no consumo total de energia no Brasil - 1984 a 1999.

Fonte: Agênca Nacional de Energia Elétrica (2001) 
Diante deste cenário o planejamento do setor assume importância estratégica, à medida que antecipa as ações necessárias para a continuidade do fornecimento de energia elétrica. Para que ocorra um planejamento eficaz do setor de energia elétrica torna-se importante o conhecimento do comportamento do mesmo.

As usinas hidrelétricas de Paulo Afonso e Boa Esperança são as principais fornecedoras de energia elétrica do Ceará. $\mathrm{O}$ aumento no consumo de energia elétrica decorrente da crescente industrialização do Estado tem forçado a adoção de medidas que garantam a manutenção do suprimento de luz e força. Dentre estas medidas pode-se destacar três grandes investimentos: a linha de transmissão de Banabuiú-Fortaleza, com $180 \mathrm{~km}$ de extensão, ampliando em $20 \%$ a oferta em 38 municípios próximos à capital; a construção do Gasoduto Guamaré-Fortaleza, com $320 \mathrm{~km}$ de extensão, para oferta de 1,7 milhão de $\mathrm{m}^{3}$ por dia de gás natural, exclusivamente para abastecimento das indústrias e garantindo energia até o ano 2020; e a implantação de um parque piloto de energia eólica no Mucuripe, com quatro aerogeradores e potencial de 1,2 MW.

Esta seção pretende fazer uma descrição do setor de energia elétrica no Ceará. Para tanto são enfocados os seguintes assuntos: a importância do setor do ponto de vista econômico; a geração, transmissão, distribuição e consumo de energia elétrica no Estado.

\subsubsection{Energia e economia}

O acompanhamento da economia é essencial para a análise do comportamento da energia elétrica de uma região, uma vez que o setor de energia elétrica relaciona-se com todos os outros setores econômicos. Deste modo, pretende-se nesta sub-seção traçar um paralelo entre o crescimento econômico do Estado e o consumo de energia elétrica.

Conforme pode ser observado na Tabela 13, o PIB cearense vem apresentando taxas de crescimento positivas desde 1993. Quando se analisa a composição setorial a indústria destaca-se com as mais altas taxas no período 
compreendido entre 1995 e 1998. Isto pode ser explicado principalmente, conforme já comentado, pela política de incentivo à indústria por parte do governo estadual. Em 1999 a agropecuária apresentou um crescimento atípico com uma taxa correspondente à $27,9 \%$ devido a condições climáticas favoráveis às culturas e ao baixo desempenho do setor no ano anterior $(-27,1 \%)$.

Tabela 13. Taxas de crescimento anuais do PIB real segundo os setores econômicos 1980-1999.

\begin{tabular}{lcccr}
\hline Ano & Agropecuária & Indústria & Serviços & Total \\
\hline 1980 & $-13,5$ & 15,9 & 9,6 & 5,7 \\
1981 & $-13,1$ & $-1,8$ & 2,1 & $-0,7$ \\
1982 & 46,5 & 9,8 & 12,2 & 15,3 \\
1983 & $-68,1$ & 22,6 & $-0,3$ & $-0,7$ \\
1984 & 288,7 & 66,9 & 22,3 & 42,9 \\
1985 & $-7,2$ & $-17,9$ & 3,5 & $-5,2$ \\
1986 & $-9,8$ & $-10,3$ & 14,2 & 4,4 \\
1987 & $-18,8$ & 0,1 & $-2,2$ & $-3,0$ \\
1988 & 51,1 & 2,0 & 2,6 & 6,0 \\
1989 & $-18,6$ & 5,2 & 13,0 & 7,3 \\
1990 & $-13,0$ & $-2,6$ & $-15,1$ & $-10,7$ \\
1991 & 37,4 & 6,2 & 11,9 & 11,4 \\
1992 & $-21,4$ & 2,8 & 0,6 & $-1,1$ \\
1993 & $-54,0$ & 3,9 & 7,9 & 1,4 \\
1994 & 82,6 & 4,2 & 8,6 & 10,1 \\
1995 & $-4,2$ & 7,3 & 5,7 & 5,5 \\
1996 & 5,5 & 7,1 & 6,8 & 6,8 \\
1997 & $-21,4$ & 8,6 & 0,8 & 1,8 \\
1998 & $-27,1$ & 5,7 & 2,2 & 2,1 \\
1999 & 27,9 & 3,8 & 4,2 & 4,6 \\
2000 & 7,9 & 5,3 & 3,6 & 4,6 \\
\hline
\end{tabular}

Fonte: SUDENE/CPE/INE, Contas Regionais (2000)

Comparando-se a evolução da economia com o consumo de energia no Estado, Figura 5, pode-se observar que o consumo de energia cresceu em ritmo superior ao PIB no período compreendido entre 1993 e 1999. No ano 2000, no entanto, o crescimento da economia cearense foi 2,2 vezes maior que o consumo de energia. Isto pode ser atribuído à queda de consumo de energia elétrica na indústrias e nas 
residências, o que pode Ter sido provocada por adoção de medidas racionais de uso energia e pelas condições climáticas ocorridas neste ano, respectivamente.

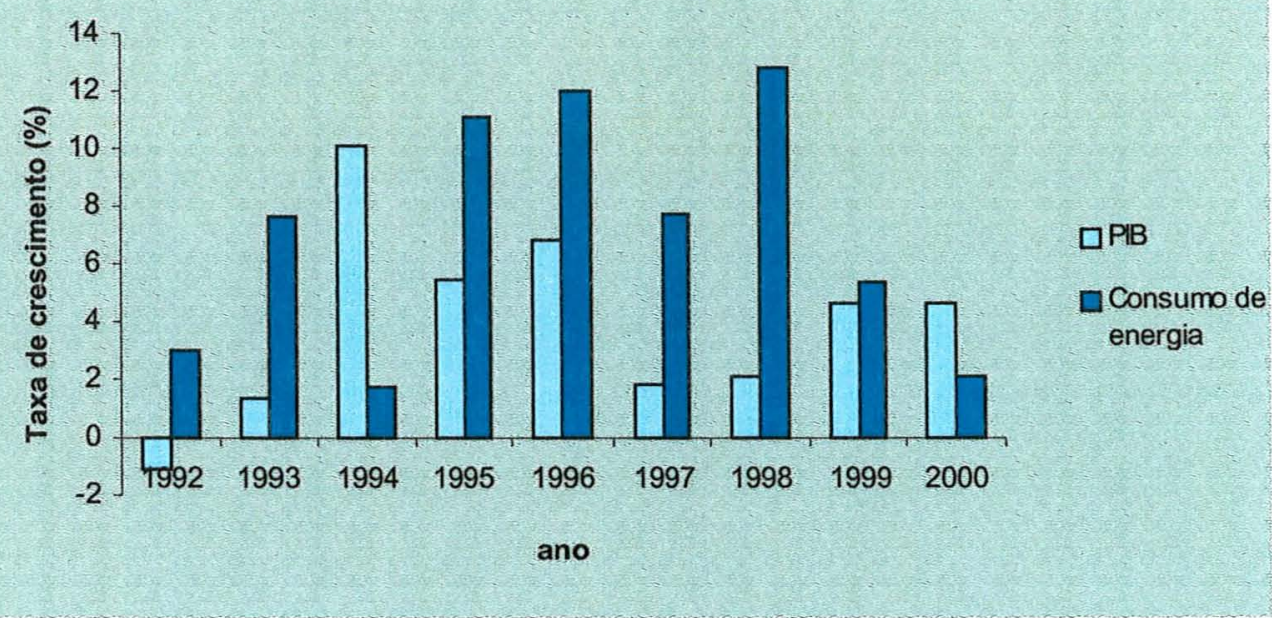

Figura 5 - Taxas de crescimento do PIB e do consumo de energia no Ceará - 1992/2000. Fonte: ELETROBRÁS/CHESF/ELETRONORTE/CEMAR/SUDENE-DPO-EPR,ContasRegionais (2000)

Considerando o comportamento dos consumidores industriais, comerciais e residenciais (Tabela 14) vê-se que o setor comércio, apresentou a maior taxa de crescimento no consumo de energia no ano 2000. Isto pode ser explicado pelo aumento no número de instalações e ampliação de estabelecimentos com elevados padrões de consumo e intensificação das atividades ligadas ao turismo e lazer, fatores que influenciam o consumo de energia elétrica deste setor. $\mathrm{O}$ consumo residencial apresentou as maiores taxas após o lançamento do plano real até o ano de 1998. Porém, a partir de 1999, as taxas começaram a declinar talvez como conseqüência da perda do poder aquisitivo da população que ocorreu nos dois últimos anos desta análise. A indústria, que reflete muito rapidamente o comportamento da economia, cresceu em ritmo inferior aos demais setores, mas aumentou significativamente o consumo de energia a partir de 1995, simultaneamente ao crescimento de sua produção e da economia cearense como um todo. 
Tabela 14. Taxa de crescimento do consumo de energia elétrica industrial, comercial e residencial no Brasil - 1992/2000 (\%).

\begin{tabular}{|c|c|c|c|c|}
\hline Ano & Indústria & Comércio & Residências & Total \\
\hline 1992 & 2,1 & 3,6 & 1,9 & 3,0 \\
\hline 1993 & 7,8 & 8,0 & 6,0 & 7,6 \\
\hline 1994 & 0,6 & 3,5 & 4,1 & 1,7 \\
\hline 1995 & 9,2 & 13,0 & 15,7 & 11,1 \\
\hline 1996 & 9,9 & 13,7 & 14,2 & 12,0 \\
\hline 1997 & 3,7 & 8,3 & 9,8 & 7,7 \\
\hline 1998 & 8,9 & 13,3 & 14,3 & 12,8 \\
\hline 1999 & 6,7 & 6,0 & 4,2 & 5,7 \\
\hline 2000 & 4,5 & 6,2 & $-1,0$ & 2,1 \\
\hline
\end{tabular}

Fonte: Ministério das Minas e Energia (2001)

Os dados apresentados nesta sub-seção mostram o bom desempenho do mercado de energia elétrica no Ceará, conseqüência essencialmente do Plano Real que proporcionou o controle do processo inflacionário e nos primeiros anos de vigência aumentou o nível de renda da população. O sucesso deste mercado exige eficiência nas atividades de geração, transmissão e distribuição de energia elétrica para assegurar o bem-estar de seus clientes. O funcionamento destas atividades no Ceará são comentadas na próxima sub-seção.

\subsubsection{Geração, transmissão e distribuição de energia elétrica no Ceará}

Esta sub-seção será iniciada com um rápido retrospecto da implantação do setor de energia elétrica em nível nacional e da sua estrutura organizacional, com o objetivo de propiciar uma melhor compreensão do funcionamento do setor de energia elétrica no Ceará. 
O desenvolvimento do setor de energia elétrica no Brasil teve início em 1883, com a construção da primeira hidrelétrica brasileira, em Ribeirão do Inferno, afluente do rio Jequitinhonha. Até a década de trinta a presença do Estado no setor foi bastante limitada. Porém, à medida que o Governo passou a incorporar os recursos hídricos ao patrimônio da União o sistema elétrico brasileiro começou a se reorganizar em bases estatais. Ao longo da década de cinqüenta quase todos os Estados tinham empresas estatais de energia elétrica. Em 1961 foram constituídas as Centrais Elétricas Brasileiras S/A (Eletrobrás); a partir de 1979 a estrutura do setor era quase integralmente estatal com alguns autoprodutores ${ }^{18}$ independentes. Esta estrutura vigorou até meados dos anos noventa, quando se deu a reestruturação do setor.

Atualmente o setor elétrico brasileiro apresenta a seguinte estrutura organizacional. Figura 6.

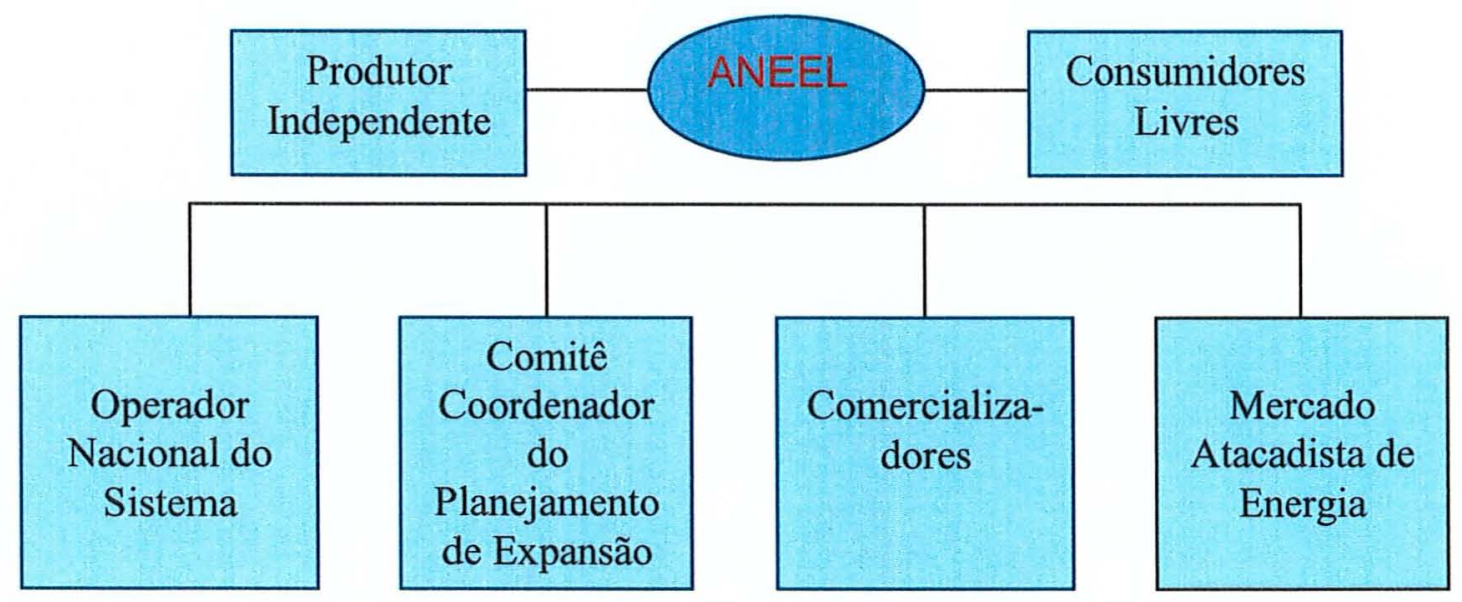

Figura 6 - Estrutura organizacional do setor elétrico brasileiro.

Fonte: Ministério do Planejamento, Orçamento e Gestão (2001)

\footnotetext{
${ }^{18}$ Autoprodutor de energia elétrica - É a pessoa física ou jurídica ou empresas reunidas em consórcio que recebem concessão ou autorização para produzir energia elétrica destinada ao seu uso exclusivo
} 
Cada um dos agentes do setor desempenha diferentes papéis, conforme descrição a seguir:

- ANEEL - Agência Nacional de Energia Elétrica: é uma entidade governamental independente criada em 1996, responsável pela regulamentação, fiscalização e equilíbrio nas relações entre os agentes do setor elétrico: Operador Nacional do Sistema, Mercado Atacadista de Energia, Comitê Coordenador do Planejamento da Expansão dos Sistemas Elétricos (CCPE), Consumidores livres, Produtor Independente de Energia e Comercializadores.

- Operador Nacional do Sistema - NOS: criado em agosto de 1998, sua função é coordenar e controlar a operação da geração e transmissão de energia elétrica nos sistemas interligados, zelando pela sua otimização. Trata-se de uma associação civil, reconhecida em lei, integrada pelas empresas de geração, transmissão e de distribuição, consumidores livres, produtores independentes de energia, representantes do governo e corretores.

- Mercado Atacadista de Energia - MAE: foi instituído, em 1998, por meio do Acordo de Mercado - um contrato de adesão e compromisso dos agentes elétricos com o novo modelo do setor. É o organismo responsável pela implantação e operação dos contratos de suprimento de longo prazo do setor. A entidade também supervisiona o consumo e monitora os preços.

- Participam do MAE: geradores de energia elétrica; concessionários ou autorizados com capacidade instalada acima de $50 \mathrm{MW}$; comercializadores de volumes anuais iguais ou acima de $300 \mathrm{GWh}$; importadores e exportadores de energia elétrica com carga igual ou superior a $50 \mathrm{MW}$. Podem também participar do MAE os geradores, autoprodutores acima de $50 \mathrm{MW}$ conectados a instalações de consumo, comercializadores e importadores com capacidade instalada ou carga elétrica abaixo dos valores mencionados acima. 
- Consumidores Livres: caracterizados pelas unidades consumidoras atendidas em tensão igual ou superior a $69 \mathrm{kV}$ e carga instalada igual ou superior a $3 \mathrm{MW}$. Também são consideradas livres, as unidades consumidoras que foram ligadas após 08/07/95 ou novos consumidores, qualquer que seja a tensão do fornecimento, que tenham uma demanda contratada mínima de $3 \mathrm{MW}$ em qualquer segmento horo-sazonal. Esses consumidores, desde de julho de 2000, podem optar pela compra da energia elétrica junto a qualquer fornecedor, negociando preços e demais condições contratuais, uma vez respeitados os atuais contratos de fornecimento, apesar de estarem automaticamente vinculados a área de concessão de uma concessionária de distribuição. Estima-se que existam cerca de 1.100 unidades consumidoras nestas condições, que respondem por $20 \%$ da demanda de energia do País.

- Produtor Independente de Energia: são as empresas que recebem a concessão ou autorização para produzir energia elétrica destinada a comercialização.

- Comercializadores: agentes autorizados pela Aneel para comercializar energia.

A seguir será feita uma descrição da dinâmica do setor de energia elétrica no Ceará desde a sua produção até o consumidor final. Um processo que envolve a geração, transmissão e distribuição de energia.

\section{Geração de energia elétrica no Ceará}

Segundo Piqueira (2000), entende-se por geração de energia elétrica a transformação de outra modalidade qualquer de energia em energia elétrica. Conforme o Ministério do Planejamento, Orçamento e Gestão (2001), a atividade de geração de energia elétrica é exercida mediante concessão ou autorização. Toda energia produzida deve ser destinada:

I - ao atendimento do serviço público de distribuição;

II - à comercialização livre; 
III - ao consumo exclusivo em instalações industriais ou comerciais do gerador, admitida a comercialização, eventual e temporária, dos excedentes, mediante autorização da Aneel.

No Brasil as fontes de energia empregadas para a produção de energia elétrica são :

- Energia hidráulica, proveniente da água. A geração neste caso ocorre nas usinas hidrelétricas (UHE) e pequenas centrais hidrelétricas $(\mathrm{PCH})$;

- Energia proveniente do petróleo e seus derivados, do carvão e do gás natural. A geração neste caso ocorre nas usinas termelétricas (UTE);

- Energia proveniente dos ventos. A geração neste caso ocorre nas usinas eolioelétricas (EOL);

- Energia proveniente dos combustíveis nucleares. A geração neste caso ocorre nas usinas termonucleares (UTN);

A Figura 7 mostra a distribuição das usinas geradoras em operação no Brasil.

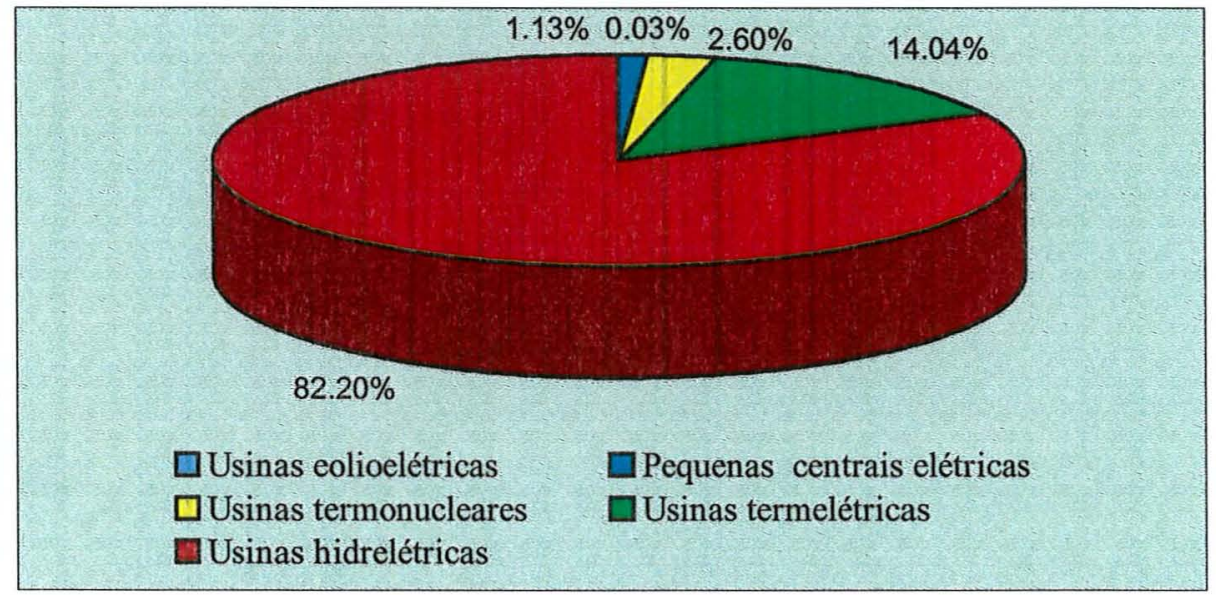

Figura 7 - Participação das usinas na geração de energia elétrica no Ceará - 2001. Fonte: Agência Nacional de Energia Elétrica (2002) 
A exploração dos serviços de geração de energia elétrica está aberta à participação da iniciativa privada através de processos de licitação ou autorização realizados pela Aneel. A geração termelétrica requer somente autorização, enquanto a exploração de aproveitamentos hidrológicos depende de concessão.

O Ceará é um Estado pouco expressivo na geração de energia elétrica. Segundo a Aneel a sua participação na capacidade de geração do país é de apenas 0,0421\%, Figura 8. Esta participação provém de 8 usinas, sendo que 6 estão em operação, gerando $31.746,20 \mathrm{~kW}$ de potência e 2 estão em construção (Tabela 15).

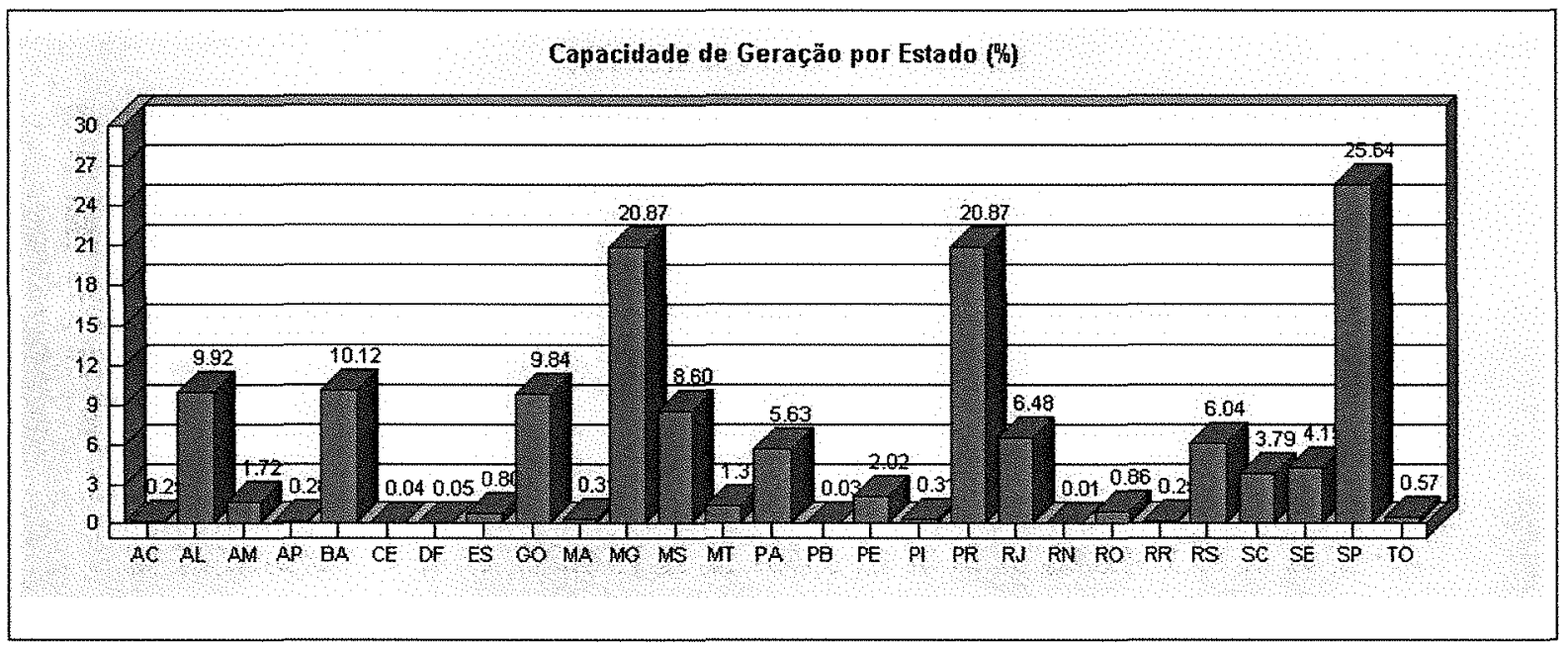

Figura 8 - Capacidade de geração de energia elétrica no Brasil por Unidade da Federação em 2001.

Fonte: Agência Nacional de Energia Elétrica (2002)

A escassez de recursos hídricos no Ceará faz com que prevaleçam as usinas térmicas e eólicas na produção de energia. Conforme a Figura 9 o parque gerador de energia elétrica no Estado se distribui da seguinte forma: 12,6\% correspondem às 
pequenas centrais hidrelétricas $(\mathrm{PCH})^{19}, 32,6 \%$ às termoelétricas (UTE) e $54,8 \%$ às eólicas (EOL).

${ }^{19}$ Central hidrelétrica com potência instalada entre 1 e $30 \mathrm{MW}$. (http://www.energiabrasil.gov.br/). 


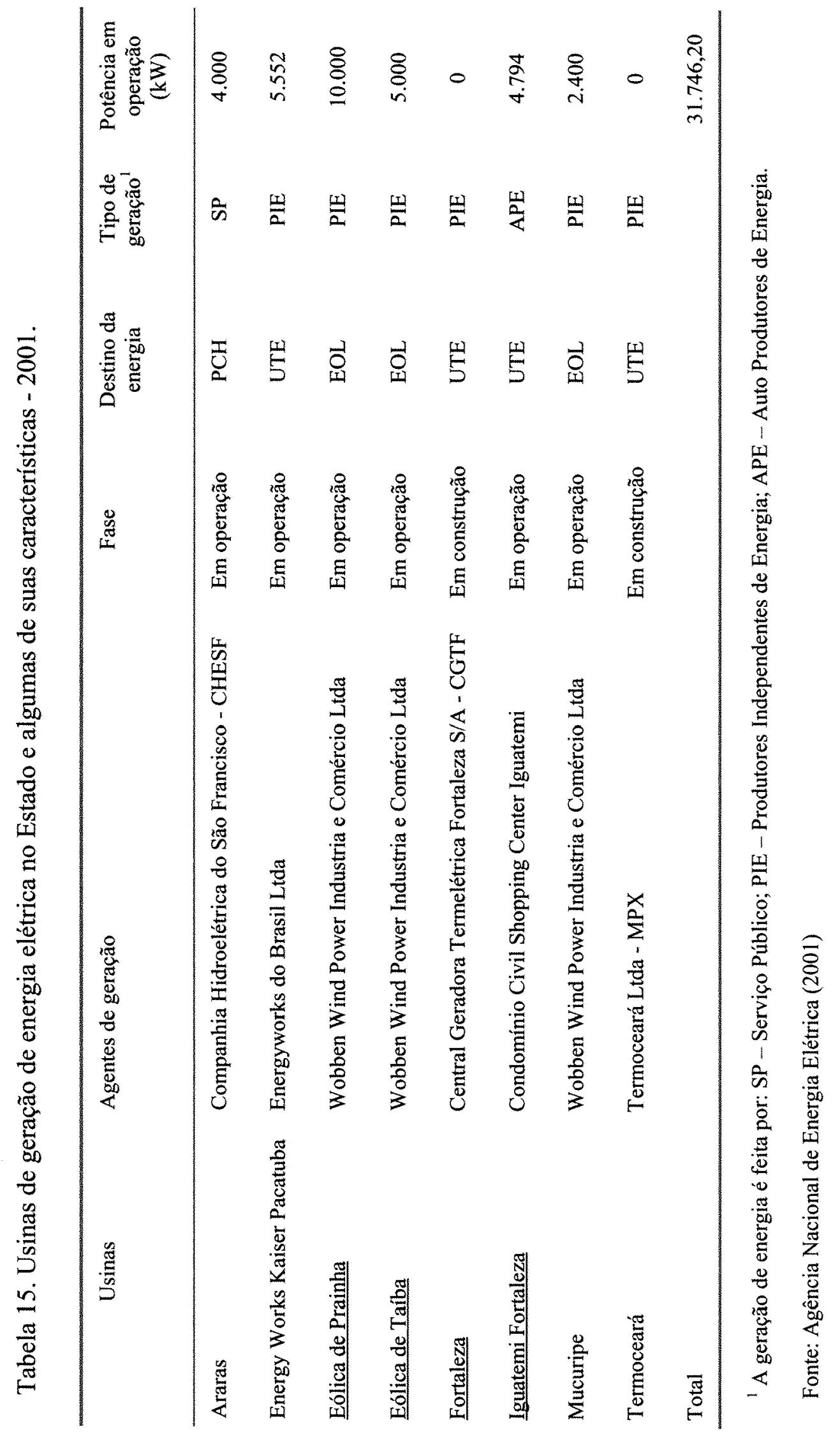




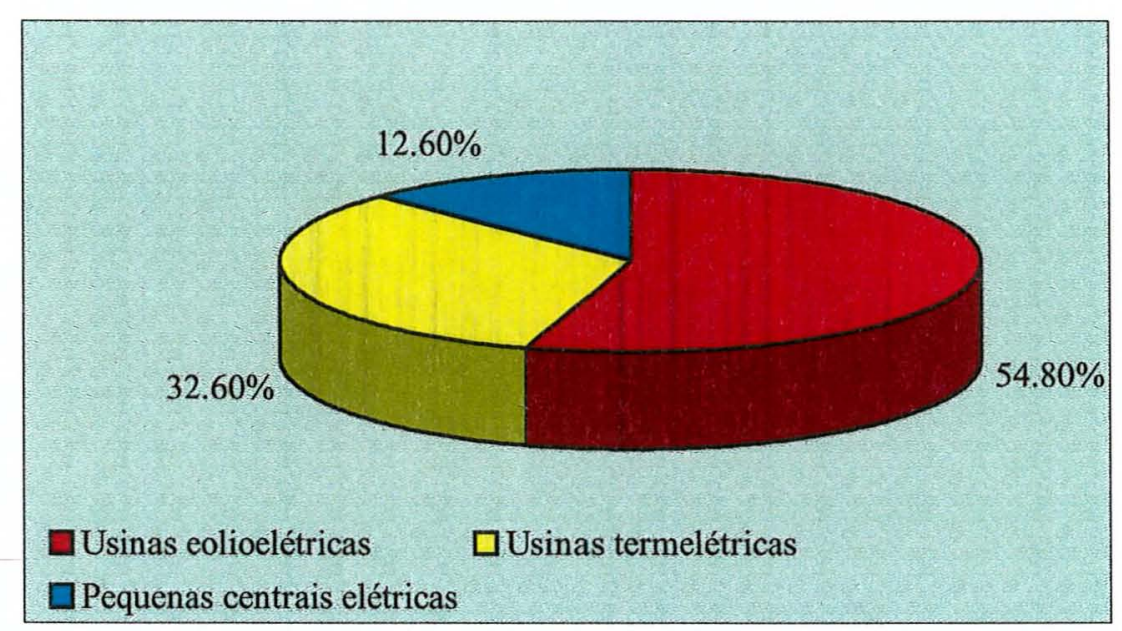

Figura 9 - Participação das usinas na geração de energia elétrica no Ceará - 2001. Fonte: Agência Nacional de Energia Elétrica (2001)

\section{Transmissão de energia elétrica no Ceará}

Segundo Piqueira (2001), a atividade de transmissão de energia consiste na transferência de energia elétrica do ponto de geração até a região consumidora.

As linhas de transmissão ${ }^{20}$ no Brasil apresentam grandes extensões devido à considerável distância entre os centros consumidores de energia elétrica e a localização das usinas hidrelétricas.

Atualmente o Brasil está quase que totalmente interligado de Norte a Sul através de um sistema interligado de eletrificação que permite a transferência de energia entre as suas regiões ${ }^{21}$. A Figura 10 mostra a integração eletroenergética brasileira. Como pode ser observado, além do que é produzido no Estado, o Ceará recebe energia elétrica proveniente das regiões Norte e Sudeste através do sistema interligado e de alguns Estados do Nordeste.

\footnotetext{
${ }^{20}$ Conjunto de condutores, isoladores e acessórios, usada para o transporte ou distribuição de eletricidade responsáveis pelo intercâmbio entre as empresas de energia elétrica.

${ }^{21}$ Segundo Pinazza e Alimandro (2001), apenas Amazonas, Roraima, Acre, Rondônia e Amapá e parte dos Estados do Pará e Mato Grosso ainda não fazem parte do sistema integrado de eletrificação.
} 


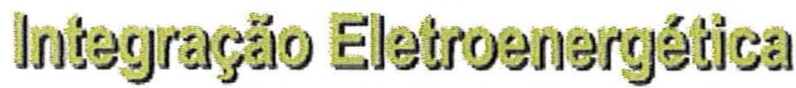

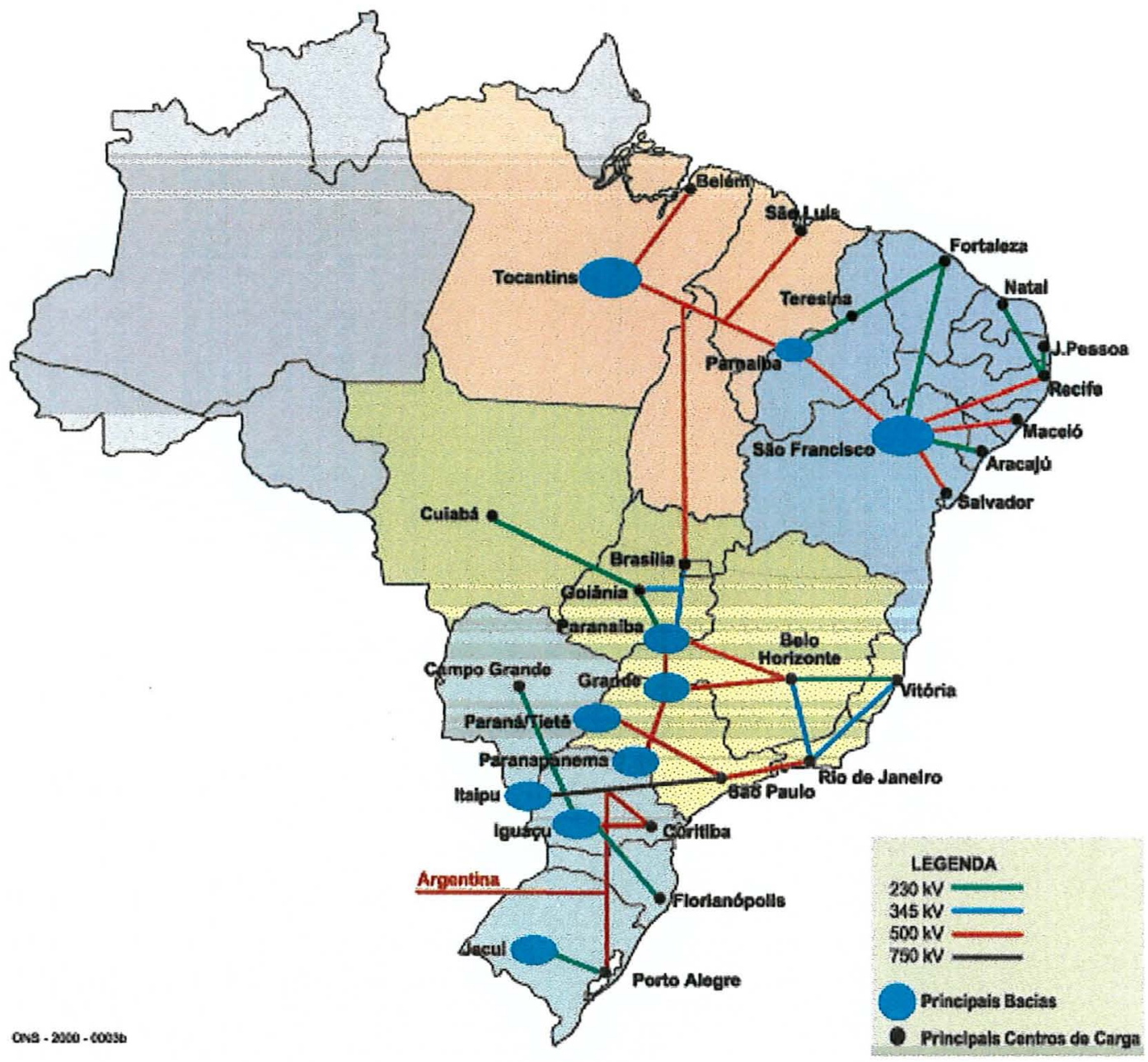

Figura 10 - Integração eletroenergética brasileira.

Fonte: Ministério do Planejamento, Orçamento e Gestão (2001)

A energia elétrica chega ao Ceará através de aproximadamente $2.600 \mathrm{~km}$ de linhas de transmissão, na grande maioria de propriedade de empresas estatais. O sistema 
de transmissão estadual conta ainda com 75 subestações $^{22}$, conforme dados da Companhia de Eletricidade do Ceará.

\section{Distribuição de energia elétrica no Ceará}

A distribuição de energia consiste na transferência de energia elétrica ao usuário final. É o estágio final do processamento de energia elétrica para atender às necessidades dos usuários residenciais, industriais e comerciais.

No Ceará a distribuição de energia é feita pela Companhia Energética do Ceará, privatizada em 1998 através de leilão no qual venceu o Consórcio Distriluz Energia Elétrica S.A., formado pelas empresas Enersis S.A., Chilectra S.A., Endesa da Espana S.A. e Companhia de Eletricidade do Rio de Janeiro - CERJ.

O serviço de distribuição de energia exige a padronização de equipamentos elétricos além da construção, operação e manutenção das redes nas áreas urbanas. Para assegurar a distribuição necessita-se ainda a construção de sub-estações com capacidade para captar a energia proveniente da transmissão e diminuir as tensões para níveis padronizados. Todas essas exigências criam a infra-estrutura necessária para assegurar a distribuição de energia elétrica a todos os usuários. A Tabela 16 apresenta a infraestrutura energética do Ceará em 1999.

\footnotetext{
22 Subestações - são equipamentos que fazem a transformação na tensão elétrica de uma tensão menor para uma maior (transformador elevador de tensão) e de uma tensão maior para uma menor (transformador abaixador de tensão).
} 
Tabela 16. Infra-estrutura energética - Ceará - 1998-1999.

\begin{tabular}{lcccc}
\hline Discriminação & \multicolumn{2}{c}{1988} & 1999 \\
\cline { 2 - 4 } & Realizado & $\begin{array}{c}\text { Acumulado } \\
\text { até } 1998\end{array}$ & Realizado & $\begin{array}{c}\text { Acumulado até } \\
1999\end{array}$ \\
\hline & 96 & 2.587 & 101 & 2.688 \\
$\begin{array}{l}\text { Construção de linhas de } \\
\text { transmissão (km) }\end{array}$ & 3.765 & 48.257 & 7.585 & 55.842 \\
$\begin{array}{l}\text { Construção/reforma de redes de } \\
\text { distribuição (km) }\end{array}$ & 2 & 74 & 1 & 75 \\
$\begin{array}{l}\text { Construção de subestações } \\
\text { Ampliação da capacidade instalada }\end{array}$ & 89 & 1.384 & 47 & 1.431 \\
das subestações (mva) & & & & \\
\hline
\end{tabular}

Fonte: Companhia Energética do Ceará (2000)

Esta infra-estrutura permitiu a comercialização de $5.690 .802 \mathrm{MWh}$ de energia elétrica em 1999, favorecendo 1.651 .777 habitantes no Estado. A Tabela 17 apresenta a composição do fornecimento de energia elétrica por classe de consumidores no ano 2000. O perfil do consumo de energia elétrica no Ceará será apresentado na próxima sub-seção. 
Tabela 17. Consumo e consumidores de energia elétrica segundo as classes de consumo - Ceará - 2000.

\begin{tabular}{lcc}
\hline Classe de consumo & Número de consumidores & Consumo de energia (MWh) \\
\hline Residencial & 1.543 .980 & 2.014 .583 \\
Industrial & 7.837 & 1.711 .143 \\
Comércio, serviços e outros & 132.751 & 1.072 .174 \\
Rural & 89.191 & 302.779 \\
Poder público & 20.828 & 298.575 \\
Iluminação pública & 185 & 290.624 \\
Serviços públicos & 781 & 174.491 \\
Total & 1.795 .553 & 5.864 .402 \\
\hline
\end{tabular}

Fonte: Companhia Energética do Ceará (2000)

\subsubsection{Consumo de energia elétrica no Ceará}

O objetivo desta sub-seção é fazer uma síntese do perfil do consumo de energia elétrica do Ceará com base em informações fornecidas pelo Instituto de Planejamento do Ceará - IPLANCE e pelo Balanço Energético Nacional. Alguns dados apresentados aqui já foram comentados em sub-seções anteriores deste capítulo, mas é pertinente a sua reapresentação.

Como reflexo das transformações ocorridas na estrutura produtiva e no grau de urbanização do Ceará o consumo de energia elétrica evoluiu $81,24 \%$ no período entre 1994 e 2000, segundo dados do Balanço Energético Nacional (2000). Conforme pode ser observado na Tabela 18 o Ceará é um dos Estados nordestinos com maiores taxas de crescimento no consumo de energia elétrica com valores superiores à media nordestina entre 1995 e 1999, período pós- real que coincidiu com a expansão industrial verificada no Estado e com o aumento no poder aquisitivo da população. Em 2000, no entanto, 
apesar de uma taxa positiva de crescimento o consumo estadual de energia elétrica $(2,1 \%)$ cresceu menos que o regional $(4,5 \%)$ em conseqüência, principalmente, da queda no consumo de eletricidade da indústria e das famílias.

Tabela 18. Taxa de crescimento no consumo de energia elétrica nos Estados do Nordeste no período 1992/2000.

\begin{tabular}{lccccccccc}
\hline ESTADOS & \multicolumn{7}{c}{ VARIACCAO (\%) ANUAL } \\
\hline & $1993 / 92$ & $1994 / 93$ & $1995 / 94$ & $1996 / 95$ & $1997 / 96$ & $1998 / 97$ & $1999 / 98$ & $2000 / 99$ & $2000 / 92$ \\
MA & 0,4 & 1,6 & 2,4 & 1,7 & 2,0 & 3,6 & 0,5 & 2,8 & 14,1 \\
PI & 4,8 & 3,7 & 10,0 & 8,9 & 10,2 & 11,5 & 1,3 & 5,7 & 41,7 \\
CE & 7,6 & 1,7 & 11,1 & 12,0 & 7,7 & 12,8 & 5,7 & 2,1 & 44,0 \\
RN & 7,7 & 3,8 & 13,3 & 10,4 & 8,3 & 11,4 & 5,6 & 2,8 & 45,9 \\
PB & 5,1 & 4,7 & 14,9 & 6,3 & 10,7 & 11,9 & 4,7 & 3,2 & 44,2 \\
PE & 4,7 & 2,2 & 7,9 & 5,6 & 7,4 & 6,2 & 1,5 & 6,1 & 32,5 \\
AL & $-1,0$ & 1,9 & $-0,6$ & 3,3 & 6,2 & 1,8 & $-1,5$ & 1,3 & 19,2 \\
SE & 6,7 & 2,6 & 5,6 & 6,3 & 9,7 & 8,0 & 7,0 & 3,6 & 38,0 \\
BA & 3,4 & 4,7 & 1,6 & 9,0 & 4,6 & 3,6 & $-2,4$ & 6,9 & 32,2 \\
NE & 3,4 & 3,0 & 4,9 & 6,8 & 5,8 & 6,1 & 1,0 & 4,5 & 32,1 \\
\hline
\end{tabular}

Fonte: ELETROBRÁS/ CHESF/ ELETRONORTE/ CEMAR/ SUDENE/DPO, EPR, Contas Regionais (2001)

Analisando-se o comportamento do consumo das classes demandantes de energia elétrica no Estado, Tabela 19 e Figura 11, observa-se que os consumo residencial e industrial de energia são bastante próximos sendo que o consumo residencial é o maior entre as classes analisadas. Quanto às taxas de crescimento o aumento no consumo das residências foi o mais expressivo após as mudanças ocorridas com o plano real porém, nota-se uma queda nos últimos dois anos. A tendência geral das classes analisadas é de aumento no consumo de energia elétrica. 
Tabela 19. Comportamento dos consumidores de energia elétrica no Ceará.

\begin{tabular}{|c|c|c|c|c|c|c|}
\hline Ano & $\begin{array}{l}\text { Residências } \\
\text { (MWh) }\end{array}$ & $\begin{array}{c}\text { Taxa de } \\
\text { crescimento } \\
(\%)\end{array}$ & $\begin{array}{l}\text { Indústrias } \\
\text { (MWh) }\end{array}$ & $\begin{array}{c}\text { Taxa de } \\
\text { crescimento } \\
(\%)\end{array}$ & $\begin{array}{c}\text { Comércio } \\
(\mathrm{MWh})\end{array}$ & $\begin{array}{c}\text { Taxa de } \\
\text { crescimento } \\
(\%)\end{array}$ \\
\hline 1991 & 1.015 .463 & - & 1.071 .763 & - & 517.711 & - \\
\hline 1992 & 1.034 .866 & 1,9 & 1.094 .294 & 2,1 & 536.357 & 3,6 \\
\hline 1993 & 1.097 .433 & 6,0 & 1.179 .569 & 7,8 & 579.445 & 8,0 \\
\hline 1994 & 1.142 .206 & 4,1 & 1.186 .170 & 0,6 & 599.97 & 3,5 \\
\hline 1995 & 1.321 .709 & 15,7 & 1.295 .013 & 9,2 & 677.983 & 13,0 \\
\hline 1996 & 1.508 .842 & 14,2 & 1.423 .130 & 9,9 & 770.576 & 13,7 \\
\hline 1997 & 1.656 .992 & 9,8 & 1.476 .118 & 3,7 & 834.677 & 8,3 \\
\hline 1998 & 1.883 .000 & 13,6 & 1.607 .000 & 8,9 & 946 & 13,3 \\
\hline 1999 & 1.963 .000 & 4,2 & 1.718 .000 & 6,7 & 1.003 .000 & 6,0 \\
\hline 2000 & 1.983 .000 & 1,0 & 1.796 .000 & 4,5 & 1.065 .000 & 6,2 \\
\hline
\end{tabular}

Fonte: ELETROBRÁS/ CHESF/ ELETRONORTE/ CEMAR/ SUDENE, DPO, EPR, Contas Regionais (2001) 


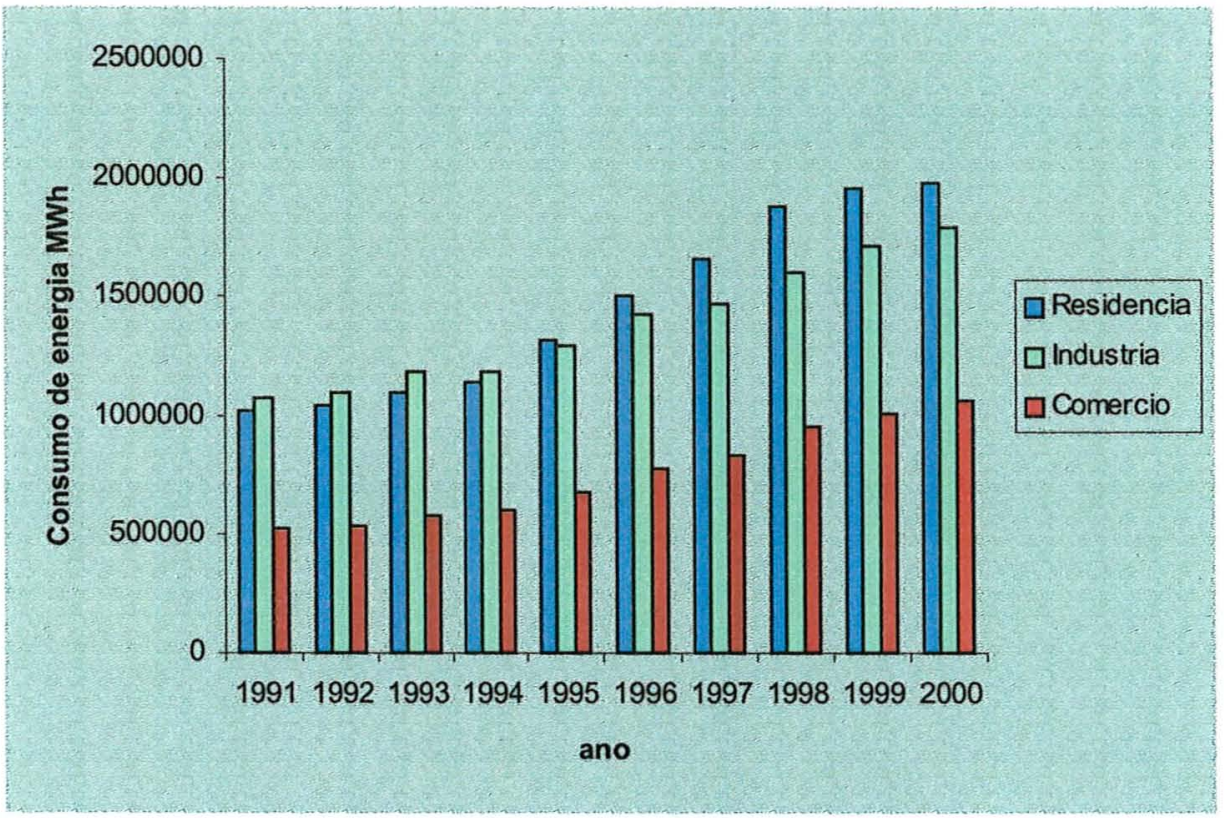

Figura 11 - Consumo de energia elétrica no Ceará por classes de consumo - 1992-2000. Fonte: Companhia Energética do Ceará (2000)

A Tabela 20 apresenta os principais consumidores industriais de energia elétrica no Ceará. Merecem destaque as indústrias têxteis, produtos alimentares, minerais não metálicos e metalurgia, responsáveis por $65,5 \%$ do consumo total da indústria. A Figura 12 mostra a evolução do consumo destes setores no período 19852000 tendo como base o ano de 1985. 
Tabela 20. Perfil de consumo dos principais consumidores industriais de energia elétrica no Ceará - 1998-1999.

\begin{tabular}{|c|c|c|c|c|c|}
\hline \multirow[t]{2}{*}{ Setor } & \multicolumn{2}{|c|}{ Consumo (MWh) } & \multicolumn{2}{|c|}{$\begin{array}{c}\text { Participação no } \\
\text { consumo total (\%) }\end{array}$} & \multirow[t]{2}{*}{$\begin{array}{l}\text { Variação } \\
\text { 99/98 (\%) }\end{array}$} \\
\hline & 1998 & 1999 & 1998 & 1999 & \\
\hline Têxtil & 633.425 & 688.486 & 42,95 & 43,52 & 8,69 \\
\hline Minerais não metálicos & 192.616 & 196.321 & 13,06 & 12,41 & 1,92 \\
\hline Metalurgia & 145.491 & 151.594 & 9,58 & 9,20 & 4,19 \\
\hline Produtos alimentares & 201.318 & 202.714 & 13,65 & 12,81 & 0,69 \\
\hline Outras indústrias & 301.852 & 348.952 & 20,76 & 22,06 & 15,60 \\
\hline Total & 1.474 .702 & 1.581 .964 & 100,00 & 100,00 & 7,27 \\
\hline
\end{tabular}

Fonte: IPLANCE (2000)

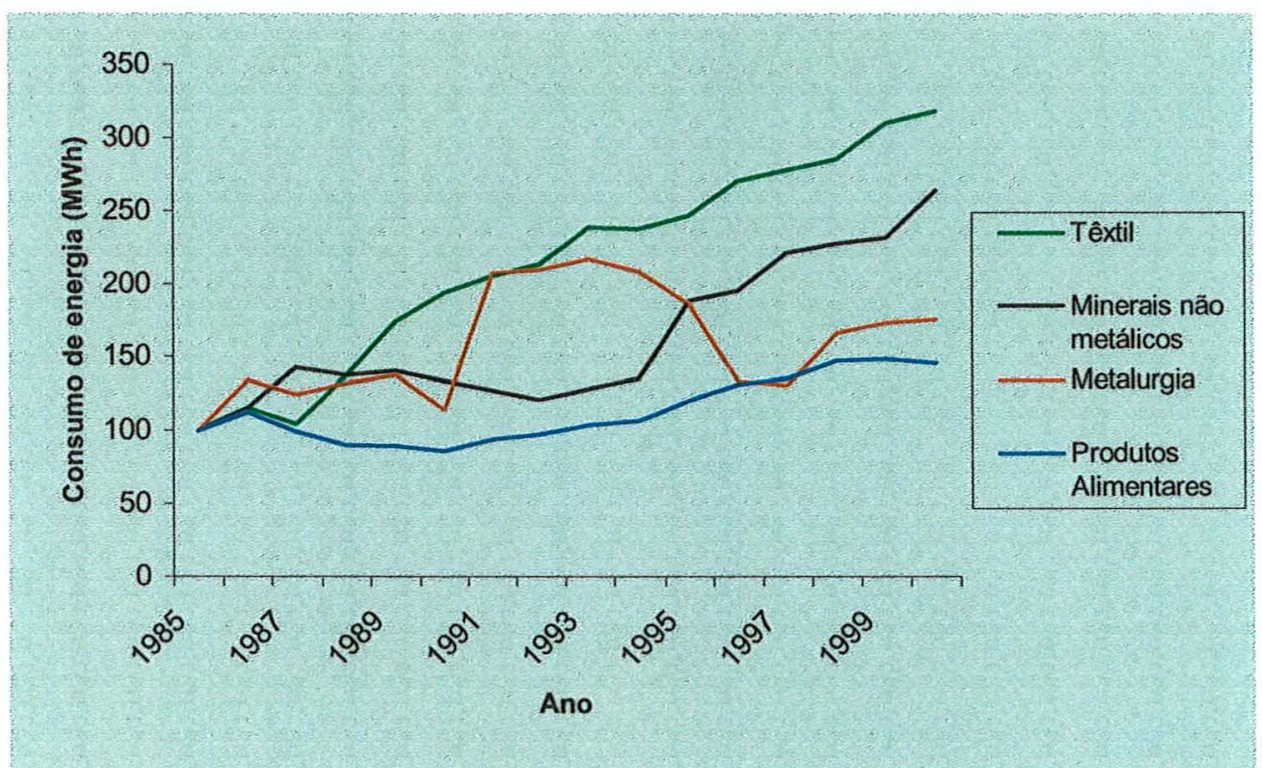

Figura 12 - Comportamento de consumo de energia elétrica dos principais consumidores industriais do Ceará - 1985-2000.

Fonte: IPLANE (2000) 
No cenário apresentado acima, onde existe um notório crescimento do mercado de energia elétrica, o planejamento deste setor assume importância estratégica, pois aponta para o fornecimento de energia elétrica em níveis compatíveis com o crescimento econômico esperado. Somente através de um planejamento voltado para a expansão do setor e para a conscientização da população quanto ao uso de energia elétrica poderão ser evitadas crises de abastecimento de energia.

Este capítulo mostrou a evolução econômica do Ceará nos últimos anos, apesar das adversidades climáticas (longos períodos de estiagem), até então consideradas fator determinante da pobreza do Estado. Ressaltou ainda a importância de uma gestão eficaz dos recursos hídricos e da energia elétrica, principalmente através de uma alocação ótima destes insumos, para manter esta evolução simultaneamente ao aumento na qualidade de vida da sociedade. Reconhecendo ser fundamental a realização de estudos sobre a demanda de água e energia elétrica, este trabalho pretende oferecer algumas contribuições aos planejadores de políticas públicas sobre o comportamento dos usuários destes recursos em relação ao seu uso. Para tanto, será utilizado o modelo de insumo-produto cuja estrutura teórica será apresentada no próximo capítulo. 


\section{ANÁLISE DE INSUMO-PRODUTO}

Este capítulo pretende abordar, de forma sucinta, a estrutura teórica do modelo de insumo-produto, o qual será utilizado como instrumental metodológico na concretização dos objetivos propostos no capítulo 1. Para tanto, apresenta-se os antecedentes históricos dos modelos de insumo-produto e a sua teoria básica. Em seguida, discorre-se sobre três de suas adaptações: os modelos regionais, os modelos inter-regionais e os modelos de insumo-produto e meio-ambiente.

\subsection{Histórico}

A análise insumo-produto é uma formalização dos conceitos lançados pelo economista francês François Quesnay em Tableau Économique (1758) e por Léon Walras em Élements dÉconomie Politique Pure (1874). Quesnay mostrou a interligação dos fatos econômicos a partir do setor agrícola, para ele único gerador de excedente e Walras formulou um modelo de equilíbrio econômico geral que, segundo Miernyk (1974), abandonava a idéia de equilíbrio parcial da economia, difundida até então, e apresentava uma economia onde os setores de produção eram dependentes das demandas de cada setor para os fatores de produção.

A aplicação empírica dos trabalhos de Walras surgiu a partir da publicação da primeira tabela de insumo-produto, por Wassily Leontief em 1936. Nesta tabela podese observar as relações entre cada setor da economia.

Em seu artigo de 1951, Leontief aponta que: 
"tem-se atualmente uma economia com alta concentração de teoria sem fatos, de um lado, e uma acumulação de fatos sem teoria, do outro". (Leontief, 1986).

Com o objetivo de resolver esta questão ele criou um método analítico o qual denominou de análise insumo-produto ou análise das relações interindustriais. Segundo Baumol (2000), Leontief nos proporcionou uma nova e poderosa ferramenta adaptável à investigação empírica e à análise de uma variedade de questões, dando-nos a possibilidade de ir além do que nossos predecessores (Williiam Prtty, Richard Cantillon, François Quesnay, Adam Smith, David Ricardo, etc.) sequer imaginaram chegar.

Atualmente o modelo de insumo-produto é um poderoso instrumento de análise econômica. De acordo com Considera (1997):

"é um modelo desenvolvido a partir da organização de informações estatísticas existentes sobre produção, consumo intermediário, distribuição primária da renda gerada, comércio exterior, impostos, salários etc."

Os Modelos de Insumo-Produto são aplicados principalmente no planejamento econômico e decisões de mercado, pois auxiliam na análise das estruturas econômicas e de impactos de políticas econômicas. Segundo Miller e Blair (1985), nos últimos anos têm sido aplicados ainda, em estudos inter-regionais, quantificação de consumo de energia, poluição ambiental e emprego associado com produção industrial, na busca de respostas para questões como:

- qual o impacto de um periodo de estiagem sobre a economia de um país ou região?

- qual a conseqüência de um aumento nas exportações de um setor sobre os demais setores da economia? 
- como a estrutura econômica de uma região favorece ou prejudica certos tipos de desenvolvimento econômico?

- como políticas de controle de qualidade e quantidade de água afetam setores específicos da economia de uma região?

A seguir será apresentada a estrutura teórica do modelo de insumo-produto.

\subsection{Teoria básica do modelo de Insumo-Produto}

Wassily Leontief desenvolveu nos anos trinta um modelo capaz de analisar e mensurar as relações entre as atividades econômicas de um país ou região durante um certo período. Este modelo foi denominado Modelo de Insumo-Produto ou Modelo de Leontief. O modelo de Insumo-Produto, como é mais conhecido, consiste, segundo Dervis at al. (1982):

"em um conjunto de $n$ equações lineares com $m$ incógnitas que pode ser resolvido através de inversão de matrizes. A solução do sistema fornece os requerimentos necessários de cada produto para satisfazer a demanda final de um determinado setor, o que consiste numa solução de equilibrio geral na esfera produtiva da economia. ${ }^{23 "}$

Segundo Considera (1997), essas informações são organizadas de tal forma que forneçam respostas às questões levantadas pela Teoria Econômica. Emerson (1989) afirma que existem quatro componentes básicos em um modelo de insumo-produto:

- uma matriz de transações interindustriais;

\footnotetext{
${ }^{23}$ Apesar de as variáveis utilizadas no modelo serem originalmente expressas em unidades fisicas, a tabela insumo-produto é apresentada em termos monetários (Leontief, 1983). Isto acontece devido a dificuldades de mensuração dos fluxos intersetoriais que surgem quando um setor produz mais de um produto e quando os produtos são expressos em unidades físicas diferentes.
} 
- uma matriz de requerimentos diretos ou matriz de coeficientes técnicos de insumos diretos;

- uma matriz de requerimentos diretos e indiretos ou matriz de coeficientes técnicos de insumos diretos e indiretos;

- uma matriz de requerimentos diretos e indiretos induzidos ou matriz de coeficientes técnicos de insumos diretos e indiretos induzidos.

Estes componentes podem ser representados a partir de um conjunto de informações organizados da seguinte forma:

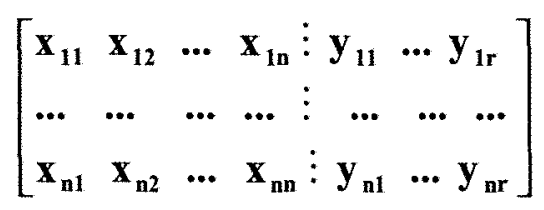

onde:

$\mathrm{x}_{i j}$ representa as vendas do setor $i$ para o setor $j$;

$\mathrm{y}_{i h}$ representa as quantidades ofertadas pelo setor $i$ para atender à demanda final do tipo $h$.

As informações acima correspondem à matriz de transações interindustriais a qual descreve o fluxo de bens e serviços entre todos os setores individuais de uma economia em um determinado período (ano). As colunas desta matriz mostram a composição dos insumos que uma indústria particular necessita para produzir seu produto. Suas linhas apresentam a distribuição da produção de uma indústria em particular através da economia. Em outras palavras, as colunas indicam as compras realizadas por uma indústria particular nas demais indústrias e as linhas indicam as vendas de uma indústria em particular para as demais indústrias. 
A matriz acima permite obter um sistema de equações lineares com relações de produção onde $\mathrm{x}_{i}$ é a quantidade produzida do produto $i$ e $\mathrm{y}_{i}$ a demanda final pelo bem $i$ :

$$
\left\{\begin{array}{l}
a_{11} x_{1}+a_{12} x_{2}+\ldots+a_{1 n} x_{n}+y_{1}=x_{1} \\
\ldots \quad \ldots \quad \ldots \quad \ldots \quad \ldots \quad \ldots \\
a_{n 1} x_{1}+a_{n 2} x_{2}+\ldots+a_{n n} x_{n}+y_{n}=x_{n}
\end{array}\right.
$$

Deste sistema de equações tem-se o que se chama a equação básica do Modelo ${ }^{25}$ de insumo-produto,que, na sua forma matricial, é expressa por:

$$
\mathbf{x}=(\mathbf{I}-\mathbf{A})^{-1} \cdot \mathbf{y}
$$

onde:

$\mathbf{x}$ é o vetor do valor da produção por atividade econômica, de ordem $(n \times 1)$

y é o vetor de demanda final total, de ordem $(n \times 1)$

A é a matriz de requerimentos diretos ou matriz de coeficientes técnicos de insumos diretos $(n \times n)$.

$(\mathbf{I}-\mathbf{A})^{-1}$ é a matriz de requerimentos diretos e indiretos ou matriz de coeficientes técnicos de insumos diretos e indiretos ou ainda a matriz inversa de Leontief, de ordem $(n \times n)$.

\footnotetext{
${ }^{25}$ Esta equação corresponde ao modelo aberto de Leontief, onde as importações correspondem a insumos primários cuja produção não é determinada endogenamente pelo modelo.
} 
Cada coluna da matriz A tem uma clara interpretação tecnológica, uma vez que é composta por um conjunto de oeficientes $a_{\mathrm{ij}}$, que representam a quantidade de insumo $i$ para se obter uma unidade do produto do setor $j$, sendo $a_{i j}<1$ e $\left(1-a_{i j}\right)>0$. Portanto, a matriz A descreve a estrutura tecnológica do processo produtivo. As mudanças nessa estrutura, no curto prazo, deverão ser pequenas e lentas. Admite-se que os coeficientes $\mathrm{a}_{\mathrm{ij}}$ sejam medidas fixas ${ }^{25}$, uma vez que o modelo de Insumo-Produto pressupõe retornos constantes de escala .

A matriz (I-A) $)^{-1}$ mostra os efeitos diretos e indiretos das modificações exógenas em qualquer dos componentes da demanda final sobre a produção de cada setor. Suas colunas indicam as quantidades de insumos diretos e indiretos que uma indústria utiliza das demais indústrias para atender a uma demanda final correspondente a uma unidade monetária de seu produto. Os requerimentos indiretos referem-se aos aumentos na produção de uma indústria devido à solicitação de outras indústrias que foram obrigadas a aumentar o consumo de insumos para atender a um crescimento na sua produção decorrente de um aumento em sua demanda. Portanto, este efeito em cadeia provoca um impacto sobre a produção total da economia significativamente maior que o impacto do aumento da produção inicial da indústria.

A matriz de requerimentos diretos e indiretos induzidos é similar à matriz de requerimentos diretos e indiretos sendo que inclui no sistema os efeitos da renda das famílias e de seus gastos.

Uma outra maneira de se chegar à equação do modelo de insumo-produto é considerar que a economia é dividida em n setores. Assim, a equação (1) é obtida a partir da seguinte identidade:

\footnotetext{
${ }^{25}$ Este pressuposto é alvo de uma das críticas centrais ao modelo de insumo-produto. Porém, segundo Sanchéz- Chóliz e Duarte (2000), apresenta a vantagem de simplificar a obtenção de resultados, dado que a matriz de coeficientes não sofre alterações.
} 


$$
X_{i}=\sum_{j=1}^{n} x_{i j}+C_{i}+G_{i}+I_{i}+E_{i}
$$

onde:

$X_{i}$ produção doméstica total do setor $i$ (demanda final e consumo intermediário).

$x_{i j}$ produção do setor $i$ utilizada como insumo intermediário pelo setor $j$ (consumo intermediário);

$C_{i}$ produção do setor $i$ que é comprada pelas famílias;

$G_{i}$ produção do setor $i$ que é comprada pelo governo;

$I_{i} \quad$ produção do setor $i$ que é destinada ao investimento;

$E_{i}$ produção do setor $i$ que é destinada à exportação;

Admitindo a hipótese de que o consumo intermediário $\left(\mathrm{x}_{i j}\right)$ é proporcional à produção doméstica total do setor $j\left(\mathrm{X}_{j}\right)$, pode-se estabelecer uma constante de proporcionalidade para as duas variáveis, o que permite escrever:

$$
\mathbf{x}_{\mathrm{ij}}=\mathbf{a}_{\mathrm{ij}} \cdot \mathbf{X}_{\mathrm{j}} \quad \text { ou } \quad \mathbf{a}_{\mathrm{ij}}=\frac{\mathbf{x}_{\mathrm{ij}}}{\mathbf{X}_{\mathrm{j}}}
$$

Portanto, substituindo-se (3) em (2) e fazendo-se $C_{i}+G_{i}+I_{i}+E_{i}=$ y tem-se a expressão que representa o sistema aberto de Leontief:

$$
X_{i}=\sum_{j=1}^{n} a_{i j} X_{j}+y
$$

onde:

$\mathrm{a}_{i j}$ coeficiente técnico direto 
Retornando à forma matricial:

$$
\mathbf{X}=\mathbf{A X}+\mathbf{y} \quad \Leftrightarrow \quad \mathbf{X}=(\mathbf{I}-\mathbf{A})^{-1} \mathbf{y}
$$

Fazendo-se $\mathbf{B}=(\mathbf{I}-\mathbf{A})^{-1}$, cada elemento $b_{i j}$ corresponde aos requisitos diretos e indiretos da produção total do setor $i$ necessários para produzir uma unidade de demanda final do setor $j$.

Segundo Haddad et al. (1989), os elementos $b_{\mathrm{ij}}$ apresentam as seguintes características:

- $b_{i j} \geq a_{i j}$, ou seja, cada elemento da matriz inversa de Leontief é maior ou igual ao respectivo elemento na matriz tecnológica, uma vez que o elemento $b_{\mathrm{ij}}$ indica os efeitos diretos e indiretos sobre a produção do setor $i$ para atender a uma unidade monetária de demanda final no setor $j$, enquanto o elemento $\mathrm{a}_{\mathrm{ij}}$ indica apenas os efeitos diretos; a igualdade entre os dois coeficientes ocorre no caso particular em que os efeitos indiretos são nulos;

- $b_{i j} \geq 0$, como os coeficientes técnicos de produção são fixos, não há possibilidade de substituição de insumos, de tal forma que uma expansão na demanda final do setor $j$ irá provocar um efeito positivo ou nulo sobre a produção do setor $i$, nunca um efeito negativo; o efeito nulo surgirá se não houver interdependência direta entre os setores $i \mathrm{e} j$

- $\quad b_{\mathrm{ij}} \geq 1$, se $i=j$, isto é, os elementos da diagonal principal da matriz inversa de Leontief serão sempre iguais a 1 ou maiores que 1, uma vez que o acréscimo de uma unidade na demanda final de um setor deverá provocar uma expansão na produção deste setor de pelo menos uma unidade monetária. 


\subsection{Quadro do Insumo-Produto}

O quadro de Insumo-Produto permite uma melhor compreensão do modelo proposto por Leontief pois descreve as atividades dos diferentes setores da economia em um determinado período. Segundo Haddad (1976), no quadro Insumo-Produto a estrutura do sistema econômico divide-se em oito seções:

- produtos intermediários.

- produtos dos setores industriais destinados ao consumo final, formação de capital, consumo do governo, exportações e variação de estoques.

- valor da produção em cada setor;

- custos primários em cada setor;

- bens e serviços finais não produzidos nos setores (importações);

- valor de cada categoria de custo primário;

- consumo dos setores;

- valor de cada componente da demanda final;

O Quadro 1 refere-se a um quadro de Insumo-Produto simplificado e permite uma melhor visualização das relações intersetoriais. 


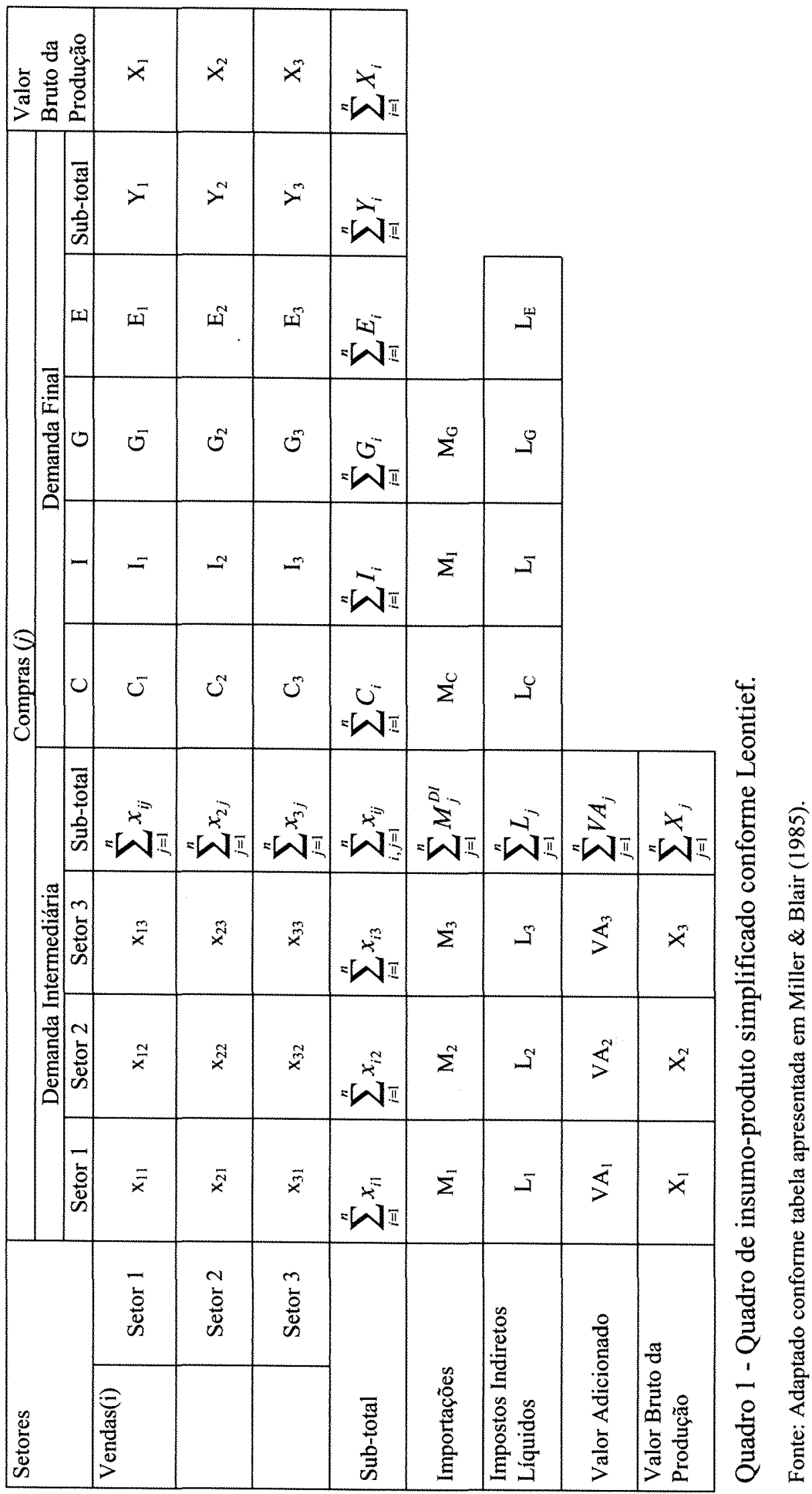


As transações representadas no Quadro 1 são as seguintes:

Vetores - linhas: representam a distribuição do produto através do próprio setor produtor, dos demais setores da economia e dos componentes da demanda final. São eles:

$\mathrm{x}_{\mathrm{ij}} \quad$ fornecimento de insumos do setor $i$ para o setor $j$;

$\mathrm{C}_{\mathrm{i}}$ fornecimento de insumos do setor $\mathrm{i}$ destinado ao consumo final privado;

$\mathrm{I}_{\mathrm{i}} \quad$ fornecimento do setor $i$ destinado ao investimento privado;

$\mathrm{G}_{\mathrm{i}} \quad$ fornecimento do setor $i$ destinado ao governo;

$E_{i}$ fornecimento do setor $i$ destinado às exportações para o resto do mundo;

$\mathrm{Y}_{\mathrm{i}}$ total da demanda final atendida pelo setor $i$;

$\mathrm{X}_{\mathrm{i}} \quad$ valor bruto da produção do setor $i$;

A partir dos vetores - linha pode-se estabelecer a seguinte igualdade:

$$
\mathbf{X}_{\mathrm{i}}=\sum_{\mathrm{j}=1}^{\mathrm{n}} \mathbf{x}_{\mathrm{ij}}+\mathbf{Y}_{\mathrm{i}}
$$

a qual mostra que para cada produto $i$, o total da oferta é igual ao total da demanda.

Vetores - coluna: representam a distribuição dos insumos através de todos os setores da economia, a despesa com os produtos importados e com os componentes do valor adicionado bruto do setor. São eles:

$\mathrm{X}_{\mathrm{j}} \quad$ custo de produção total do setor $j$;

$\mathrm{M}_{\mathrm{j}} \quad$ importações feitas pelo setor $j$; 
$\mathrm{L}_{\mathrm{j}} \quad$ total dos impostos indiretos líquidos recolhidos pelo setor $j$ (aluguéis, juros, lucros, impostos indiretos líquidos, e depreciações);

$\mathrm{VA}_{\mathrm{j}} \quad$ total do valor adicionado do setor $j$

A partir dos vetores - coluna pode-se estabelecer a seguinte igualdade:

$$
\mathbf{X}_{\mathrm{j}}=\sum_{\mathrm{j}=1}^{\mathrm{n}} \mathbf{x}_{\mathrm{ij}}+\mathbf{M}_{\mathrm{j}}+\mathbf{V A _ { j }}
$$

A qual mostra que a produção total em cada setor corresponde ao valor de insumos comprados dos outros setores, inclusive os importados, mais o valor adicionado nesse setor.

Como se trata de um sistema de equilíbrio geral, a soma dos elementos de todas as colunas é igual a soma dos elementos de todas as linhas. Esta expressão é:

$$
\sum_{\mathbf{i}} \mathbf{X}_{\mathbf{i}}=\sum_{\mathbf{j}} \mathbf{X}_{\mathbf{j}}
$$

$\ddot{\mathrm{E}}$ importante ressaltar que a teoria insumo-produto original apresenta algumas limitações:

- a análise insumo- produto assume retornos constantes de escala;

- $\quad$ assume-se que cada setor produz somente um tipo de produto;

- todas as indústrias de um mesmo setor empregam a mesma tecnologia de produção e produzem produtos idênticos;

- não existe substituição entre insumos;

- os coeficientes técnicos são fixos (quantidade de insumo para produzir uma unidade de produto é constante); 
- não há restrições de recursos (a oferta é infinita e perfeitamente elástica);

- assume-se eficiência na alocação de recursos;

- assume-se um equilíbrio geral na economia a um dado nível de preços;

- inexistência de ilusão monetária por parte dos agentes econômicos;

- preços constantes.

Porém, apesar destas dificuldades, a análise insumo-produto pode ser considerada uma das melhores ferramentas no estudo das relações entre setores em níveis regional, inter-regional e internacional (Guilhoto, 1995). Segundo Miernyk (1974), as limitações do modelo não impediram a sua difusão por todo o mundo, uma vez que mais de 40 nações adotam modelos baseados nesta teoria para o planejamento de suas economias.

Como argumentos que justificam a ampla utilização de modelos de insumoproduto e reforçam a sua validade, podem ser citados:

- os resultados coerentes obtidos em trabalhos passados;

- a lógica do modelo;

- o seu uso em níveis macro e microeconômico;

- a utilização de dados compreensíveis e consistentes;

- o grande número de equações envolvidas.

Pode-se afirmar ainda, segundo Fatemi (1998), que a natureza da tabela de insumo-produto torna possíveis: 
- a análise da economia como um sistema interconectado de indústrias o que permite o estudo das ligações interindustriais desde o estágio da matéria-prima até o produto final;

- a decomposição da mudança estrutural e conseqüentemente a identificação da origem destas mudanças, sua direção e magnitude;

- uma estimação consistente da importância relativa de variáveis como demanda doméstica, importações, exportações e tecnologia na produção e crescimento do emprego;

- a compreensão de como um fenômeno macroeconômico, como mudanças na demanda final, provoca mudanças microeconômicas;

- a comparação de impactos estimados com os níveis observados na atividade econômica de cada setor.

Os tomadores de decisão podem usar as informações derivadas dos modelos para identificar um crescimento industrial específico ou o desemprego em determinado setor, por exemplo. Finalmente, uma outra contribuição é proporcionar a fundamentação para outros modelos que incorporem diferentes aspectos da operação de economias nacional e regional.

Esta seção apresentou o modelo de insumo-produto tradicional, aplicado em nível nacional. Porém, com o crescente interesse pela análise econômica regional, o mesmo vem sendo modificado de modo a captar as diferenças existentes entre as regiões. A próxima seção apresenta os modelos de insumo-produto regionais e suas principais características. 


\subsection{Modelos de insumo-produto regionais}

Os modelos de insumo-produto regionais surgiram com a necessidade de estudos mais localizados ou que mostrem as relações diretas e indiretas entre regiões. A sua importância na análise econômica começou a crescer a partir dos anos 50 com Isard (1951), e Leontief (1951) e hoje são empregados na comparação das estruturas econômicas de produção e de produtividade entre as regiões e o resto do país, na mensuração do impacto regional de políticas econômicas, na análise das substituições de importações regionais e seu impacto sobre determinadas regiões, entre outras aplicações.

A metodologia empregada para a construção de matrizes nacionais não pode ser a mesma para a construção de matrizes regionais. A elaboração de matrizes de insumo-produto regionais depende da disponibilidade de informações básicas regionalizadas. Isto consiste em uma dificuldade pois algumas empresas exercem atividades em mais de uma região e os elementos da demanda final regionalizada nem sempre são encontrados, bem como as informações sobre o comércio de mercadorias, importação e exportação, com as demais regiões.

Nos anos em que são realizados censos econômicos, tem-se informações para a maioria das atividades em cada Unidade da Federação. Porém, essas informações além de não serem anuais, envolvem custos altíssimos. Com o objetivo de superar estes problemas, os pesquisadores vêm desenvolvendo métodos de construção de matrizes regionalizadas que não dependem das informações censitárias. São os chamados métodos sem informação censitária. Segundo Roundt (1978), estes métodos consistem em calcular a proporção de mercadorias produzidas na região e importadas a partir da matriz de coeficientes técnicos de produção ou da matriz de insumo-produto nacional.

Conforme a origem dos dados utilizados, os métodos de construção de matrizes regionalizadas podem ser classificados em: 
- métodos com informação censitária: aqueles que utilizam dados primários ou informações diretas. É a metodologia mais apropriada;

- métodos com informações censitárias limitadas: usados quando não há disponibilidade de dados diretos ou quando estes são inconsistentes. Estes métodos podem ser classificados como: a) puramente não censitários: aqueles que estimam os coeficientes de fluxos regionais através do ajustamento dos coeficientes técnicos nacionais inteiramente com base em informações publicadas sobre emprego, renda e produto regional por indústria; b) métodos parcialmente censitários: aqueles que estimam os coeficientes de fluxos regionais parcialmente com base em informações sobre emprego, renda ou produto regional por indústria.

É importante ressaltar que, na realidade, as matrizes de insumo-produto são híbridas, isto é, são construídas a partir de técnicas semi-censitárias que utilizam informações primárias e secundárias. Conforme a literatura, os termos não censitários e semi-censitários são usados indistintamente.

Segundo Roundt (1983), as técnicas de estimação utilizadas na construção de matrizes de insumo-produto regionais são divididas em:

- Método do quociente locacional;

- Método do balanço de mercadorias;

- Método do balanço iterativo ou RAS.

De acordo com Montoya (1998), os modelos regionais obtidos a partir de informações censitárias e informações censitárias limitadas podem ser agrupados, ainda, segundo a forma de cálculo dos seus coeficientes técnicos, em: 
- Modelos que constróem suas matrizes de insumo-produto regionais usando obrigatoriamente dados diretos e uma matriz de fluxos interregionais. ${ }^{26}$

- Modelos regionais que derivam de modelos nacionais, também denominados intranacionais. ${ }^{27}$

- Modelos que pressupõem estabilidade nos padrões de comércio interregional. Estes modelos podem ser classificados de acordo com as proporções de compra e venda em: a) modelos gravitacionais: aqueles onde os fluxos de comércio associam-se a custos de transferências e não são feitas referências à origem ou destino dos insumos quando estes são os mesmos; ${ }^{28}$ b) modelos de coeficientes linha: consideram que a proporção de produto vendida pelas diferentes regiões independe do nível de demanda das regiões compradoras ${ }^{29}$; c) modelos de coeficientes coluna: trabalham com número de setores e regiões conhecidos e cada região importa uma proporção fixa para suprir suas necessidades específicas. $^{30}$

$\mathrm{O}$ modelo de insumo-produto regional consiste em uma adaptação do modelo tradicional de Leontief que estuda as relações econômicas dentro de um país que pode ser empregado na análise das relações em uma única região (modelo regional, propriamente dito) ou várias regiões (modelo multirregional).

A construção de uma matriz regional geralmente envolve o cálculo de coeficientes técnicos regionais obtidos a partir da matriz nacional, uma vez que na maioria das vezes não existem coeficientes regionais disponíveis. Esses coeficientes,

\footnotetext{
${ }^{26}$ Ver Metzler (1950) e Isard (1951).

27 Ver Leontief (1953) e Leontief-Hoffernberg (1961).

${ }^{28}$ Ver Leontief - Strout (1963).

${ }^{29}$ Ver Hansen-Tiebout(1963) e Polenske (1970).

${ }^{30}$ Ver Chenery (1953) e Moses (1955).
} 
após um processo de ajustamento, permitem calcular a relação entre a produção local consumida internamente e a produção total disponível (consumida internamente e importada) e são obtidos da seguinte forma:

$$
\rho_{j}^{r}=\frac{\left(X_{j}^{r}-E_{j}^{r}\right)}{\left(X_{j}^{r}-E_{j}^{r}+M_{j}^{r}\right)}
$$

onde:

$\rho_{j}^{\mathrm{r}}$ participação da produção da atividade $j$ das região $r$ no total consumido da atividade $j$ na região $r$;

$\mathrm{X}_{\mathrm{j}}^{\mathrm{r}}$ é a produção da atividade $j$ na região $r$;

$\mathrm{E}_{\mathrm{j}}^{\mathrm{r}}$ exportações da atividade $j$ na região $r$ (para outras regiões e países);

$\mathrm{M}_{\mathrm{j}}^{\mathrm{r}}$ importações da região $r$ de bens e serviços produzidos pela atividade $j$;

A partir dos coeficientes de cada atividade desenvolvida na região $r$, aplicados proporcionalmente sobre a matriz de coeficientes nacionais de produção obtem-se o modelo de insumo-produto regional:

$$
\mathbf{A}^{\mathbf{r}}=\hat{\boldsymbol{\rho} \mathbf{A}}
$$

onde:

$\mathbf{A}^{\mathbf{r}}$ é a matriz dos coeficientes técnicos regionais;

$\hat{\rho}$ é a matriz diagonalizada das proporções calculadas para cada atividade;

A é a matriz dos coeficientes técnicos nacionais.

A produção regional pode ser escrita, conforme a equação básica de Leontief, como: 


$$
\mathbf{X}^{\mathbf{r}}=(\mathbf{I}-\hat{\mathbf{\rho A}})^{-1} \mathbf{Y}^{\mathbf{r}}
$$

Procedimentos como o adotado acima assumem os pressupostos de que a estrutura produtiva regional é proporcional à nacional e independente da atividade e que existe uma proporção fixa de importação para todas elas. É importante mencionar que a regionalização só levará a funções de produção compatíveis com a realidade econômica se aplicada a regiões bastante homogêneas. Estas fortes pressuposições, aliadas à necessidade de um grande volume de informações para a construção das tabelas, não devem ser consideradas como fator restritivo a aplicação dos modelos regionais.

\subsection{Modelos de insumo-produto com mais de uma região}

Os modelos de insumo-produto regionais são incapazes de captar relações importantes entre os setores da região em estudo com outras regiões, relações estas que influenciam a demanda de insumos regionais e conseqüentemente, a sua produção. Diante disto, Leontief ampliou o modelo regional de insumo-produto permitindo o estudo das relações de uma região com outras regiões. Esta adaptação deu origem aos modelos para mais de uma região, onde se destaca o modelo inter-regional de insumoproduto, o qual será apresentado, sucintamente, a seguir ${ }^{31}$.

\subsubsection{Modelos de insumo-produto inter-regionais}

Considere duas regiões, $L$ e $M$, com dois setores e um fluxo comercial interregional. A representação matemática das relações entre $L$ e $M$ pode ser feita a partir da matriz:

$$
\mathbf{Z}=\left[\begin{array}{ll}
\mathbf{Z}^{\mathrm{LL}} & \mathbf{Z}^{\mathrm{LM}} \\
\mathbf{Z}^{\mathrm{ML}} & \mathbf{Z}^{\mathrm{MM}}
\end{array}\right]
$$

\footnotetext{
${ }^{31}$ Maiores detalhes sobre os modelos de insumo-produto inter-regionais podem ser vistos em Miller e Blair (1985).
} 
Onde:

$\mathbf{Z}^{\mathbf{L L}}$ representa o fluxo monetário do setor $i$ para o setor $j$ dentro da região $L$;

$\mathbf{Z}^{\mathbf{L M}}$ representa o fluxo monetário do setor $i$ da região $L$ para o setor $j$ da região $M$;

$\mathbf{Z}^{\mathrm{MM}}$ representa o fluxo monetário do setor $i$ para o setor $j$ dentro da região $M$;

$\mathbf{Z}^{\mathrm{ML}}$ representa o fluxo monetário do setor $i$ da região $M$ para o setor $j$ da região $L$.

Conforme abordado anteriormente, no modelo insumo-produto para uma região, a produção total de um setor é expressa por:

$$
X_{1}=a_{i 1} X_{1}+a_{i 2} X_{2}+\ldots+a_{i n} X_{n}+Y_{i}
$$

No caso de duas regiões com dois setores tem-se:

$$
\begin{aligned}
& X_{1}{ }^{\mathrm{L}}=a_{11}{ }^{\mathrm{LL}} \mathrm{X}_{1}{ }^{\mathrm{L}}+\mathrm{a}_{12}{ }^{\mathrm{LL}} \mathrm{X}_{2}{ }^{\mathrm{L}}+\mathrm{a}_{11}{ }^{\mathrm{LM}} \mathrm{X}_{1}{ }^{\mathrm{M}}+\mathrm{a}_{12}{ }^{\mathrm{LM}} \mathrm{X}_{2}{ }^{\mathrm{M}}+\mathrm{Y}_{1}{ }^{\mathrm{L}} \\
& \mathrm{X}_{2}{ }^{\mathrm{L}}=\mathrm{a}_{21}{ }^{\mathrm{LL}} \mathrm{X}_{1}{ }^{\mathrm{L}}+\mathrm{a}_{22}{ }^{\mathrm{LL}} \mathrm{X}_{2}{ }^{\mathrm{L}}+\mathrm{a}_{21}{ }^{\mathrm{LM}} \mathrm{X}_{1}{ }^{\mathrm{M}}+\mathrm{a}_{22}{ }^{\mathrm{LM}} \mathrm{X}_{2}{ }^{\mathrm{M}}+\mathrm{Y}_{2}{ }^{\mathrm{L}} \\
& \mathrm{X}_{1}{ }^{\mathrm{M}}=\mathrm{a}_{11}{ }^{\mathrm{ML}} \mathrm{X}_{1}{ }^{\mathrm{L}}+\mathrm{a}_{12}{ }^{\mathrm{ML}} \mathrm{X}_{2}{ }^{\mathrm{L}}+\mathrm{a}_{11}{ }^{\mathrm{MM}} \mathrm{X}_{1}{ }^{\mathrm{M}}+\mathrm{a}_{12}{ }^{\mathrm{MM}} \mathrm{X}_{2}{ }^{\mathrm{M}}+\mathrm{Y}_{1}{ }^{\mathrm{M}} \\
& \mathrm{X}_{2}{ }^{\mathrm{M}}=\mathrm{a}_{21}{ }^{\mathrm{ML}} \mathrm{X}_{1}{ }^{\mathrm{L}}+\mathrm{a}_{22}{ }^{\mathrm{ML}} \mathrm{X}_{2}{ }^{\mathrm{L}}+\mathrm{a}_{21}{ }^{\mathrm{MM}} \mathrm{X}_{1}{ }^{\mathrm{M}}+\mathrm{a}_{22}{ }^{\mathrm{MM}} \mathrm{X}_{2}{ }^{\mathrm{M}}+\mathrm{Y}_{2}{ }^{\mathrm{M}}
\end{aligned}
$$

Fazendo-se:

$$
\begin{aligned}
& a_{i j}{ }^{L L} X_{j}^{L}=z_{i j}{ }^{L L} \\
& a_{i j}{ }^{M M} X_{j}^{M}=z_{i j}{ }^{M M} \\
& a_{i j}{ }^{L M} X_{j}^{M}=z_{i j}{ }^{L M} \\
& a_{i j}{ }^{M L} X_{j}{ }^{L}=z_{i j}{ }^{M L}
\end{aligned}
$$

Tem-se os coeficientes técnicos de produção: 
$a_{i j}^{L L}=z_{i j}^{L L} / X_{j}^{L}$

$a_{i j}{ }^{M M}=z_{i j}{ }^{M M} / X_{j}^{M}$

$a_{i j}{ }^{L M}=z_{i j}^{L M} / X_{j}^{M}$

$a_{i j}^{M L}=z_{i j}^{M L} / X_{j}^{L}$

onde:

$a_{i j}^{L L}$ representa o quanto o setor $j$ da região $L$ compra do setor $i$ da região $L$ para produzir uma unidade do produto.

$a_{i j}{ }^{M M}$ representa o quanto o setor $j$ da região $M$ compra do setor $i$ da região $M$ para produzir uma unidade do produto.

$\mathrm{a}_{\mathrm{ij}}{ }^{\mathrm{LM}}$ representa o quanto o setor $j$ da região $L$ compra do setor $i$ da região $M$ para produzir uma unidade do produto.

$\mathrm{a}_{\mathrm{ij}}{ }^{\mathrm{ML}}$ representa o quanto o setor $j$ da região $M$ compra do setor $i$ da região $L$ para produzir uma unidade do produto.

Isolando-se as demandas no grupo de equações (12), tem-se o sistema inter.regional completo :

$$
\begin{array}{lc}
Y_{1}{ }^{\mathrm{L}}=\left(1-\mathrm{a}_{11}{ }^{\mathrm{LL}}\right) \mathrm{X}_{1}{ }^{\mathrm{L}}-\mathrm{a}_{12}{ }^{\mathrm{LL}} \mathrm{X}_{2}{ }^{\mathrm{L}}-\mathrm{a}_{11}{ }^{\mathrm{LM}} \mathrm{X}_{1}{ }^{\mathrm{M}}-\mathrm{a}_{12}{ }^{\mathrm{LM}} \mathrm{X}_{2}{ }^{\mathrm{M}} \\
\vdots & \vdots \\
\vdots & \vdots \\
\mathrm{Y}_{2}{ }^{\mathrm{M}}=\left(1-\mathrm{a}_{21}{ }^{\mathrm{ML}}\right) \mathrm{X}_{1}{ }^{\mathrm{L}}-\mathrm{a}_{22}{ }^{\mathrm{ML}} \mathrm{X}_{2}{ }^{\mathrm{L}}-\mathrm{a}_{21}{ }^{\mathrm{MM}} \mathrm{X}_{1}{ }^{\mathrm{M}}-\mathrm{a}_{22}{ }^{\mathrm{MM}} \mathrm{X}_{2}{ }^{\mathrm{M}}
\end{array}
$$

Que, expresso na forma matricial corresponde a:

$$
Y=(I-A)^{-1} X
$$


Onde:

$$
\mathbf{X}=\left[\begin{array}{l}
\mathbf{X}^{\mathbf{L}} \\
\mathbf{X}^{\mathrm{M}}
\end{array}\right] \quad ; \quad \mathbf{A}=\left[\begin{array}{ll}
\mathbf{A}^{\mathrm{LL}} & \mathbf{A}^{\mathrm{LM}} \\
\mathbf{A}^{\mathrm{ML}} & \mathbf{A}^{\mathrm{MM}}
\end{array}\right] \quad \text { e } \quad \mathbf{Y}=\left[\begin{array}{c}
\mathbf{Y}^{\mathbf{L}} \\
\mathbf{Y}^{\mathbf{M}}
\end{array}\right]
$$

A resolução de (13) fornece as equações necessárias à análise interregional:

$$
\begin{aligned}
& \left(I-A^{L L}\right) X^{L}-A^{L M} X^{M}=Y^{L} \\
& -\quad A^{M L} X^{L}+\left(I-A^{M M}\right) X^{M}=Y^{M}
\end{aligned}
$$

O procedimento descrito acima é o mesmo para o caso de modelos com $\mathrm{n}$ regiões. Porém, é importante ressaltar que, quanto maior o número de regiões, maior o volume de dados exigidos.

\subsection{Modelos de insumo-produto e o meio ambiente}

Uma outra adaptação do modelo de insumo-produto proposto por Leontief são os modelos de insumo-produto e meio ambiente. Estes modelos consistem numa expansão do modelo tradicional de insumo-produto com o objetivo de quantificar e analisar as alterações no meio ambiente, associadas à atividade das indústrias em uma determinada região, principalmente aquelas provocadas pela poluição.

Conforme Leontief (1970) ressalta, este tipo de análise é perfeitamente coerente uma vez que poluição é um produto das atividades econômicas regulares, e em cada uma de suas múltiplas formas, é resultado do consumo particular de um insumo no processo produtivo.

Segundo classificação de Miller \& Blair (1985), existem três categorias de modelos de insumo-produto e meio-ambiente: 
- Modelos insumo-produto generalizados: formados a partir da adição de linhas e colunas à matriz de coeficientes técnicos, que reflitam a geração de poluição ou o seu decréscimo.

- Modelos econômico-ecológicos: consistem numa extensão do lado interindustrial do modelo tradicional, para incluir os setores do ecossistema com os fluxos entre economia e meio-ambiente .

- Modelos produto x setor: aqueles que expressam os fatores ambientais como mercadorias em uma tabela insumo-produto do tipo produto $\mathrm{x}$ setor.

Estes modelos utilizam uma matriz de coeficientes de poluição em conjunção com a matriz inversa de Leontief, de modo que se pode observar, juntos, um modelo de Leontief com os fluxos econômicos e um modelo ambiental com os fluxos de produtos ecológicos.

A seguir são apresentados, de forma sucinta, alguns trabalhos pioneiros na análise das interações entre economia e meio-ambiente através do instrumental insumoproduto. Espera-se com isto ressaltar a importância e a viabilidade destes modelos no fornecimento de subsídios ao planejamento de políticas preocupadas com as questões ecológicas.

\subsubsection{Modelo de Cumberland ${ }^{32}$}

Cumberland (1966), foi um dos primeiros pesquisadores a estudar as relações entre economia e ecologia. Para tanto, incorporou variáveis ambientais ao modelo tradicional de Leontief. O seu objetivo foi captar as interações entre os setores da economia e o meio-ambiente a partir dos custos e benefícios ambientais provocados em decorrência da demanda dos setores e da demanda final.

\footnotetext{
${ }^{32}$ A descrição deste modelo foi feita a partir de Abdallah \& Montoya (1998).
} 
A principal limitação deste modelo é a dificuldade em delimitar os custos e benefícios provocados ao meio-ambiente por atividade produtiva, individualmente. Isto impede o estabelecimento de uma relação fixa entre as atividades produtivas e os benefícios/custos ambientais. Porém, deve-se reconhecer seu mérito como uma das primeiras tentativas de integração economia-ecologia sob o ponto de vista de insumoproduto.

\subsubsection{Modelo de Daly}

Daly (1968), propôs um modelo de insumo-produto e meio-ambiente onde dividiu a economia total em setores humanos (relações econômicas) e não-humanos (relações ecológicas), Quadro 2.

\begin{tabular}{|c|c|c|}
\hline \multirow{2}{*}{ Setores vendedores } & \multicolumn{2}{|c|}{ Setores compradores } \\
\cline { 2 - 3 } & Humanos & Não - humanos \\
\hline Humanos & Quadrante 2 & Quadrante 1 \\
\hline Não - humanos & Quadrante 3 & Quadrante 4 \\
\hline
\end{tabular}

Quadro 2 - Tabela insumo-produto simplificada de Daly.

Fonte: Daly (1968)

O segundo quadrante expressa as relações entre os setores humanos; corresponde no modelo tradicional ao fluxo entre os setores, origem e destino, envolvendo apenas os bens econômicos. ${ }^{33} \mathrm{O}$ quarto quadrante representa a área referente à ecologia, onde ocorre interação somente entre setores não - humanos, envolvendo apenas os bens ecológicos. Finalmente, o primeiro e terceiro quadrantes contêm, respectivamente os fluxos de insumos dos setores humanos para os setores não-humanos

\footnotetext{
${ }^{33}$ Para Daly, os bens econômicos são aqueles que possuem preço positivo e bens ecológicos ou livres aqueles com preço zero ou negativo.
} 
(externalidades) e o fluxo dos setores não-humanos para os setores humanos. Estes quadrantes fornecem as ligações entre o segundo e quarto quadrante.

O Quadro 3 permite analisar mais claramente as relações propostas por Daly. As relações contidas neste quadro podem ser expressas matematicamente através da matriz de coeficientes técnicos. Considerando que cada linha do quadro é representada pela equação:

$$
\sum_{\mathrm{j}=1}^{\mathrm{n}} \mathbf{q}_{\mathrm{ij}}=\mathbf{Q}_{\mathrm{i}} \quad \mathrm{i}=1, \ldots, \mathrm{n}
$$

Os coeficientes técnicos de produção podem ser definidos como:

$$
a_{i j}=\frac{q_{i j}}{Q_{i}}
$$

No quadrante 2 , estes coeficientes são os próprios coeficientes técnicos de produção propostos por Leontief. Nos demais quadrantes tem-se o que Daly denominou coeficientes técnicos naturais. 


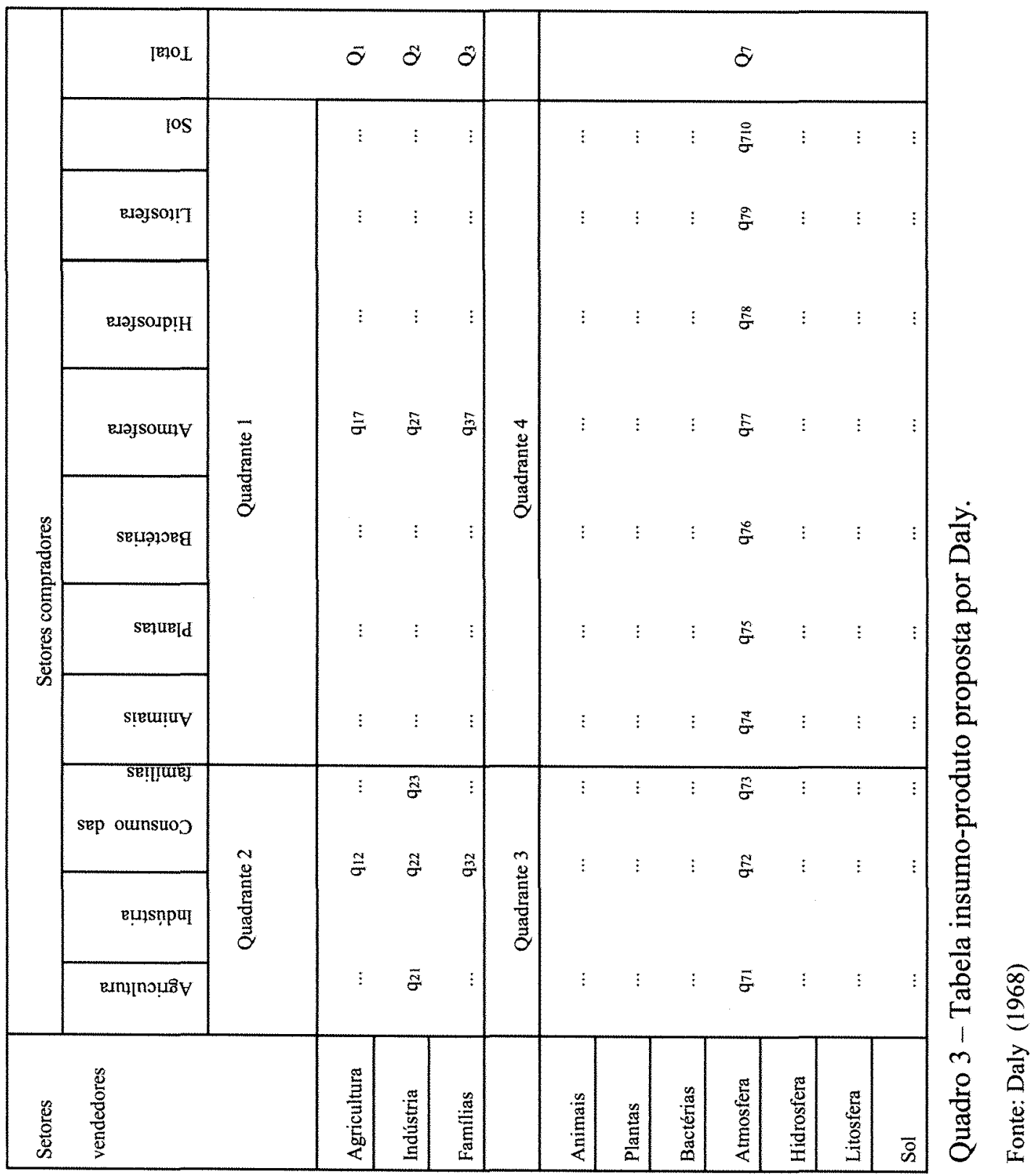


O modelo proposto por Daly, apesar de superar o modelo de Cumberland, ao considerar as relações entre setores econômicos e ecológicos contém ainda sérias limitações. Segundo Vitor (1972), nos setores econômicos os fluxos são medidos em unidades monetárias porém, nos setores ecológicos existe a impossibilidade de mensuração dos fluxos uma vez que os produtos ecológicos não possuem preço de mercado. Isto impede que as produções econômicas e ecológicas de um determinado setor sejam agregadas, limitando o poder de análise do modelo.

\subsubsection{Modelo de Isard ${ }^{34}$}

O modelo de Isard (1972) apresenta a vantagem, em relação aos modelos de Cumberland e Daly, de ser do tipo produto $\mathrm{x}$ setor, o que permite a classificação de vários produtos dentro de um mesmo setor e a valoração em termos monetários dos insumos e produtos ecológicos.

O Quadro 4 apresenta a estrutura do modelo de insumo-produto econômicoecológico proposto por Isard. Os setores econômicos e ecológicos são divididos conforme sua origem terrestre ou marinha. Assim, no primeiro quadrante tem-se as relações entre as atividades econômicas e ecológicas terrestres. Nos quadrantes II e III tem-se as interações entre as atividades econômicas e ecológicas terrestres e marinhas e no quadrante IV as interações entre as atividades de origem marinha.

Os coeficientes relativos aos fluxos entre as atividades econômicas e ecológicas são subdivididos em coeficientes econômicos, derivados endogenamente, e os coeficientes ecológicos, exógenos, obtidos a partir de dados técnicos. Os coeficientes que envolvem interações entre insumos ecológicos absorvidos na produção de bens econômicos e as interações entre os produtos ecológicos (despejos) provenientes do processo produtivo, são obtidos a partir da derivação das relações entre as quantidades físicas de insumo ou produto do meio ambiente e os valores da produção econômica.

\footnotetext{
${ }^{34}$ Os modelos de Isard e Vitor, são apresentados conforme descrito em Miranda(1980).
} 


\begin{tabular}{|c|c|c|c|c|c|c|}
\hline & \multirow{2}{*}{\multicolumn{4}{|c|}{ Setores }} \\
\hline & & & & & & \\
\hline & & & \multicolumn{2}{|c|}{ Terrestre } & \multicolumn{2}{|c|}{ Marinha } \\
\hline & & & Economia & Ecologia & Economia & Ecologia \\
\hline \multirow[t]{4}{*}{ Produtos } & Terrestre & Economia & \multirow{2}{*}{\multicolumn{2}{|c|}{ I }} & \multirow{2}{*}{\multicolumn{2}{|c|}{ II }} \\
\hline & & Ecologia & & & & \\
\hline & Marinha & Economia & \multirow{2}{*}{\multicolumn{2}{|c|}{ III }} & \multirow{2}{*}{\multicolumn{2}{|c|}{ IV }} \\
\hline & & Ecologia & & & & \\
\hline
\end{tabular}

Quadro 4 - Estrutura do modelo insumo-produto proposto por Isard. Fonte: Miranda (1980)

A maior crítica a este modelo consiste na obtenção dos coeficientes referentes ao meio ambiente, o que requer além de um forte rigor técnico, uma grande quantidade de dados. Uma outra questão refere-se à hipótese geral de funções lineares dos modelos de insumo-produto, muito frágil, quando se trabalha com variáveis ambientais.

\subsubsection{Modelo de Vitor}

O modelo proposto por Vitor (1972), também classificado como do tipo produto $\mathrm{x}$ setor, ampliou o modelo tradicional de Leontief através da adição de linhas referentes aos insumos ecológicos utilizados no processo produtivo dos setores econômicos e às descargas provenientes das transformações ocorridas neste processo.

No Quadro 5 tem-se uma simplificação deste modelo. Nele estão presentes as seguintes matrizes:

$\mathrm{V}$ é uma matriz $\mathrm{m} \times \mathrm{n}$ onde o elemento $\mathrm{v}_{\mathrm{ij}}$ corresponde ao insumo do $j$ ésimo setor, ofertado ao i-ésimo produto; 
$\mathrm{U}$ é uma matriz $\mathrm{n} \times \mathrm{m}$ onde o elemento $\mathrm{u}_{\mathrm{ij}}$ corresponde ao insumo do i-ésimo setor, ofertado ao j-ésimo produto;

$\mathrm{s}$ é uma matriz onde o elemento $\mathrm{s}_{\mathrm{ij}}$ corresponde ao i-ésimo insumo ecológico (terra, ar ou água) usado pelo j-ésimo produto econômico;

$\mathrm{r}$ é uma matriz onde o elemento $\mathrm{r}_{\mathrm{ij}}$ corresponde ao i-ésimo insumo ecológico (terra, ar ou água) usado pelo j-ésimo setor;

$\mathrm{v}$ é uma matriz onde o elemento $\mathrm{v}_{\mathrm{ij}}$ corresponde à descarga do i-ésimo produto ecológico pelo $j$-ésimo setor econômico;

$\mathrm{u}$ é uma matriz onde o elemento $\mathrm{u}_{\mathrm{ij}}$ corresponde à descarga $i$-ésimo produto ecológico pelo $j$-ésimo produto econômico;

Assim como nos demais modelos, neste, existe a dificuldade de obtenção de dados precisos. Porém, a tabela do tipo produto $\mathrm{x}$ setor, conforme já mencionado, permite a valoração dos produtos e insumos ecológicos além de obedecer ao princípio de equilíbrio dos materiais: $s=r=u=v^{35}$

\begin{tabular}{|c|c|c|c|c|c|}
\hline \multicolumn{2}{|c|}{} & \multicolumn{2}{c|}{ Economia } & \multicolumn{2}{c|}{ Ecologia } \\
\cline { 2 - 6 } & Produto & Setor & \multicolumn{2}{c|}{ Produção dos setores ecológicos } \\
\hline \multirow{2}{*}{\begin{tabular}{c} 
Economia \\
\cline { 2 - 5 }
\end{tabular}} & Produto & & $\mathrm{U}$ & & $\mathrm{u}$ \\
\cline { 2 - 6 } & Setor & $\mathrm{V}$ & & $\mathrm{v}$ & $\mathrm{v}$ \\
\hline \multirow{2}{*}{$\begin{array}{c}\text { Insumos } \\
\text { ecológicos }\end{array}$} & Terra, água e ar & & $\mathrm{r}$ & $\mathrm{s}^{\mathrm{s}} \mathrm{r}^{\mathrm{s}} \mathrm{v}^{\mathrm{s}} \mathrm{u}$ \\
\cline { 2 - 6 } & & $\mathrm{s}$ & $\mathrm{s}^{\mathrm{s}} \mathrm{r}$ & \\
\hline
\end{tabular}

Quadro 5 - Estrutura do modelo de Vitor.

Fonte: Miranda (1980)

35 O princípio de equilibrio de materiais nos diz que numa economia fechada, não havendo variações na massa do equipamento de capital, nos estoques dos produtos finais e semifinais e dos bens de consumo duráveis, a massa de insumos ecológicos deve ser igual à massa de seus produtos ecológicos. Richardson (1978). 
Com o crescente interesse mundial por questões ambientais, muitos trabalhos adotando modelos de insumo-produto e meio ambiente estão sendo realizados, o que tem levado ao aprimoramento desta técnica. Nesta seção procurou-se dar uma noção genérica sobre esses modelos. Maiores detalhes sobre a sua estrutura teórica podem ser encontrados em Miller \& Blair (1985). No próximo capítulo serão descritas algumas aplicações dos modelos de insumo-produto no planejamento e gerenciamento do meio ambiente, voltados especificamente para os recursos hídricos e energia elétrica. 


\section{USO DE MODELOS DE INSUMO-PRODUTO NO GERENCIAMENTO DOS RECURSOS HÍDRICOS}

Este capitulo tem por objetivo apresentar possibilidades de uso de metodologias baseadas no modelo insumo-produto, úteis no gerenciamento dos recursos hídricos. Apesar deste estudo tratar também da alocação da energia elétrica entre os diferentes setores do Ceará, optou-se pela ênfase nos estudos relacionados aos recursos hídricos por já existir uma bibliografia bem definida sobre modelos insumo-produto e energia elétrica, a qual pode ser consultada em Miller e Blair (1995).

Nos últimos anos vem crescendo o interesse da humanidade pela preservação do meio ambiente. A água, pela sua diversidade de uso é o recurso que mais tem recebido atenção dos pesquisadores. São inúmeros os estudos voltados para a sua utilização, conservação e distribuição. O modelo insumo-produto após sua expansão para captar os efeitos do meio ambiente sobre a economia, e vice-versa, vem fornecendo contribuições importantes neste sentido.

Cumberland (1966), Leontief (1970), Richardson (1972), Isard (1972), e Victor (1972) ao realizarem seus estudos incorporando fatores ecológicos à estrutura quantitativa tradicional do modelo insumo-produto tornaram possível a descrição das relações econômicas entre setores de uma região e o ambiente que os cerca e forneceram um instrumental metodológico cada vez mais difundido entre os pesquisadores preocupados com os impactos econômicos sobre o meio ambiente. O Quadro 6 apresenta alguns trabalhos envolvendo os modelos insumo-produto e a água, com diferentes objetivos. 


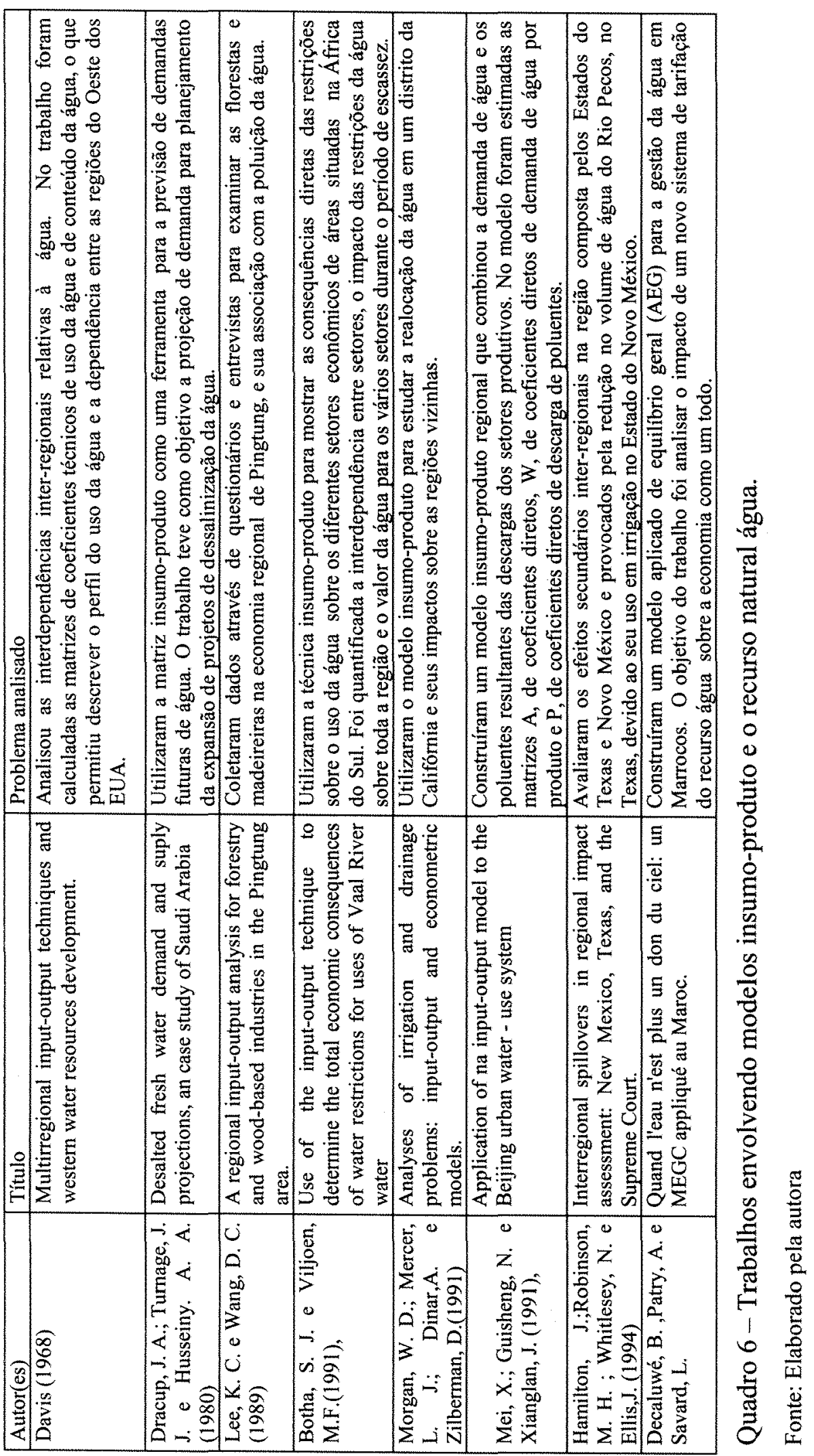


A seguir será apresentada a aplicação da análise insumo-produto em três questões fundamentais na gestão da água: a distribuição da água entre os diferentes setores da economia, o nível de poluição das águas e o estabelecimento do preço deste recurso.

\subsection{Modelo insumo-produto e a estimação da demanda por água}

A demanda por água provém quase que totalmente de três segmentos: agrícola, industrial e doméstico. Nos últimos anos, o aumento da concentração populacional, o crescimento urbano desordenado, o desenvolvimento dos setores industrial e agrícola têm gerado disputas pelo uso da água que podem limitar seus consumo a determinados grupos.

Segundo Lima (1999), o desenvolvimento brasileiro será comprometido caso não seja adotada uma política de recursos hídricos que estabeleça formas racionais de uso da água através do aproveitamento do potencial hídrico do país, do aumento da área irrigada e do acesso à população ao abastecimento de água potável.

Deduz-se assim, que estudos voltados para a utilização da água pelos diferentes setores da economia, quer analisando o impacto de variações na demanda final destes setores sobre a disponibilidade de água, quer analisando os efeitos na mudança de uso da água sobre a economia e o meio ambiente de uma região, podem ser um instrumento importante no gerenciamento dos recursos hídricos, auxiliando na identificação das prioridades de uso deste recurso.

Dabi e Anderson (1998), apresentaram um estudo neste sentido, onde utilizaram um modelo econômico-ecológico (produto x setor) para estudar a demanda de água em uma região rural. $\mathrm{O}$ objetivo dos autores foi examinar a aplicabilidade de um modelo capaz de determinar a demanda direta dos setores da economia por produtos econômicos e produtos ecológicos, no caso a água, consumidos no processo produtivo. 
$\mathrm{O}$ modelo econômico-ecológico (produto $\mathrm{x}$ setor) é uma expansão do modelo insumo-produto tradicional onde são adicionadas linhas dos insumos ecológicos e colunas dos produtos ecológicos resultando em duas sub-matrizes: uma correspondendo ao subsistema econômico e outra ao subsistema ecológico (ver Figura 13). Os sub-sistemas econômicos incluem atividades onde são empregados recursos naturais e humanos no processo produtivo. O subsistema ecológico inclui todos os aspectos ambientais que servem de suporte para a vida.

O modelo econômico-ecológico (produto $\mathrm{x}$ setor) exposto por Dabi e Anderson será melhor compreendido após a descrição da estrutura de um modelo insumo-produto (produto x setor).

\begin{tabular}{|c|c|c|c|c|c|}
\hline & & Indústrias & & & Produtos ecológicos \\
\hline & $\begin{array}{l}\text { A } \\
\text { B }\end{array}$ & A $B$ & final & total & C \\
\hline Produtos & & & & & \\
\hline A $B$ & & $\mathbf{U}$ & $\mathbf{E}$ & $\mathbf{Q}$ & $\mathbf{R}$ \\
\hline Indústrias & & & & & \\
\hline B & $\mathbf{V}$ & & & $\mathbf{X}$ & $\mathbf{S}$ \\
\hline $\begin{array}{c}\text { Valor } \\
\text { adicionado }\end{array}$ & & $\mathbf{W}$ & GNP & & \\
\hline $\begin{array}{c}\text { Produção } \\
\text { total }\end{array}$ & $\mathbf{Q}^{\prime}$ & $\mathbf{X}^{\prime}$ & & & $\mathbf{S}^{-}$ \\
\hline $\begin{array}{l}\text { Produtos } \\
\text { Ecológicos }\end{array}$ & $\mathbf{P}$ & $\mathbf{T}$ & & $\mathbf{T}^{-}$ & \\
\hline C $\quad \mathrm{D}$ & & & & & \\
\hline
\end{tabular}

Figura 13 - Modelo econômico-ecológico.

Fonte: Miller e Blair ( 1985) 


\subsubsection{Modelo insumo-produto ( produto $x$ setor )}

O modelo insumo-produto é um método de análise que quantifica sistematicamente as inter-relações entre os vários setores de um sistema econômico complexo. Segundo Leontief (1986), sua descrição matemática, pode ser feita a partir de um sistema de equações representado por:

$$
\mathbf{X}=\mathbf{A X}+\mathbf{Y}
$$

onde :

$\mathbf{X}=$ vetor $(n x l)$ com o valor da produção total por setor;

$\mathbf{A}=$ matriz $(n \times n)$ com os coeficientes técnicos diretos de produção, setor $\mathrm{x}$ setor;

$\mathbf{Y}=$ vetor $(n \times 1)$ com os valores da demanda final por setor.

Sob o enfoque produto x setor, a equação (1) é escrita como:

$$
\mathbf{Q}=\mathbf{B X}+\mathbf{Y}
$$

onde:

$\mathbf{Q}=$ vetor $(m \times 1)$ com o valor da produção total por produto;

$\mathbf{B}=$ matriz $(m \times n)$ com os coeficientes técnicos diretos de produção, produto $\mathrm{x}$ setor;

$\mathbf{E}=\operatorname{vetor}(\mathrm{m} \times 1)$ com os valores da demanda final por produto.

A matriz B dos coeficientes técnicos é obtida a partir de:

$$
\mathbf{B}=\mathbf{U}(\hat{\mathbf{X}})^{-1}
$$

onde: 
$b_{i j}=$ elementos da matriz B. Quantidade que o setor $\mathrm{j}$ requer do setor i para produzir uma unidade de produto;

$\mathbf{U}=$ matriz de uso $(m \times n)$, com todos os insumos envolvidos no processo produtivo;

$\hat{\mathbf{X}}=$ matriz diagonalizada de $\mathbf{X}(n \times n)$

A hipótese da tecnologia baseada na indústria admite que cada setor tem participação fixa no mercado, ou seja, a produção total do produto é dividida entre os setores em proporções fixas. Neste caso, o quanto cada setor produz de cada produto é estabelecido por:

$$
\mathbf{D}=\mathbf{V}\left(\hat{\mathbf{Q}}_{\mathrm{j}}\right)^{-1}
$$

onde:

$D=$ matriz $(n \times m)$ das frações de cada produto produzidas pelos diferentes setores;

$\hat{\mathbf{Q}}=$ matriz diagonalizada de $\mathbf{Q}(m \times m)$

Multiplicando ambos os lados da equação por $\hat{Q}$ :

$$
\mathbf{V}=\mathbf{D} \hat{\mathbf{Q}}
$$

onde:

$\mathbf{V}=$ valor da produção total por setor.

Como a produção total por setor é a soma de todos os produtos produzidos pelo setor: $\mathbf{X}=\mathbf{V}_{\mathbf{i}}$. e 


$$
\mathbf{X}=\mathbf{D} \cdot \mathbf{Q}
$$

Substituindo a equação $5 \mathrm{em} 2$ :

$$
\begin{aligned}
& \mathbf{Q}=\mathbf{B D} \mathbf{Q}+\mathbf{E} \\
& o \mathcal{U} \\
& \mathbf{Q}=(\mathbf{I}-\mathbf{B D})^{-\mathbf{1}} \mathbf{E}
\end{aligned}
$$

onde:

$(\mathbf{I}-\mathbf{B D})^{-1}=$ matriz $\left(\begin{array}{lll}m & x & m\end{array}\right)$ dos coeficientes técnicos de insumos diretos e indiretos, produto $\mathrm{x}$ produto.

Uma expressão equivalente a esta é:

$$
\mathbf{X}=\left[\mathbf{D}\left(\mathbf{I}-\mathbf{B D}^{-\mathbf{1}}\right)\right] \mathbf{E}
$$

onde:

$\left[\mathbf{D}\left(\mathbf{I}-\mathbf{B D}^{-1}\right]=\right.$ matriz dos coeficientes técnicos de insumos diretos e indiretos, setor $\mathrm{x}$ produto $(n \times m)$.

Alternativamente, tem-se ainda que:

$$
\mathbf{X}=\left[(\mathbf{I}-\mathbf{D B})^{-\mathbf{1}}\right] \mathbf{Y}
$$

onde:

$(\mathbf{I}-\mathbf{D B})^{-1}=$ é a matriz dos coeficientes técnicos de insumos diretos e indiretos, setor $\mathrm{x}$ setor $(n \times n)$

\subsubsection{Estrutura do modelo econômico - ecológico}

Os coeficientes dos produtos ecológicos são definidos da mesma forma que os coeficientes do modelo descrito acima. Costuma-se obter a matriz de uso da água e 
dos produtos ecológicos a partir da matriz X, produção por setor, em vez de $\mathrm{Q}$, produção por produto, porque não é comum a obtenção das quantidades empregadas dos produtos ecológicos no processo produtivo, principalmente quando são produzidos vários produtos. Assim, quando o modelo insumo-produto é expandido, para incluir os produtos ecológicos, os coeficientes técnicos são derivados a partir das seguintes relações:

$$
\text { I: } \quad \mathbf{G}=\mathbf{T}(\hat{\mathbf{X}})^{-1}
$$

onde:

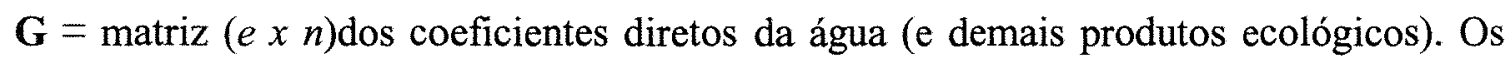
elementos de $\mathrm{G}, \mathrm{g}_{\mathrm{kj}}$, apresentam a quantidade água (e demais produtos ecológicos) usados na produção de uma unidade do setor $\mathrm{j}$;

$\mathbf{T}=$ matriz (e $\times n)$ de uso da água (e demais produtos ecológicos). Os elementos de $\mathrm{T}, \mathrm{t}_{\mathrm{kj}}$, correspondem à quantidade de água (e demais produtos ecológicos) usada na produção total do setor $\mathrm{j}$

$$
\text { II } \quad \mathbf{F}=\mathbf{S}^{\prime}(\hat{\mathbf{X}})^{-1}
$$

onde:

$\mathbf{F}=$ matriz (e $x n)$ dos coeficientes diretos da água (e demais produtos ecológicos). Os elementos de $\mathrm{F}$ correspondem à quantidade de água (e demais produtos ecológicos) produzida, por unidade de produto do setor $\mathrm{j}$.

$\mathbf{S}=$ matriz correspondente à parte ecológica do sistema.

A quantidade total de água (e demais produtos ecológicos) requerida no processo produtivo, por setor, é expressa por: 


$$
\mathbf{G}^{*}=\left\lfloor\mathbf{G}(\mathbf{I}-\mathbf{D B})^{-1}\right\rfloor \mathbf{Y}
$$

onde:

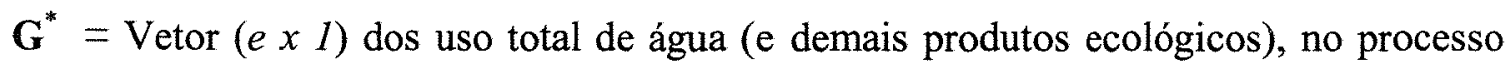
produtivo.

A produção total de água (e demais produtos ecológicos) produzida no processo produtivo é dada por:

$$
\mathbf{F}^{*}=\left[\mathbf{F}(\mathbf{I}-\mathbf{D B})^{-1}\right] \mathbf{Y}
$$

onde:

$\mathbf{F}^{*}=$ vetor ( $\left.e x 1\right)$ com a quantidade produzida de água (e demais produtos ecológicos) por total de produção dos demais setores produtivos.

Este modelo considera que o consumo de água das famílias é exógeno ao sistema.

\subsection{Modelo insumo-produto e poluição da água}

A degradação do meio ambiente tem aumentado proporcionalmente ao crescimento econômico, e a água, por seus múltiplos usos, é um dos recursos mais afetados. O manejo inadequado do solo, o uso de defensivos agrícolas, os dejetos lançados em águas fluviais, além dos efluentes lançados pelas indústrias, poderão comprometer a disponibilidade de água potável para a sociedade. Isto torna inaceitável a ausência de uma gestão de recursos hídricos capaz de evitar a depredação de mananciais pelos agentes econômicos. Lima (1999) ressalta que:

"como a água é utilizada em diversos processos industriais de produção, uma política de gestão de recursos hídricos deve levar em consideração a natureza destas atividades, de modo a 
não reprimi-las, mas torná-las mais adequadas às exigências ambientais."

Estudos utilizando as tabelas insumo-produto econômico-ecológicas vêm fornecendo subsídios para os administradores dos problemas ambientais gerados pelo crescimento econômico. Dentre estes estudos, encontra-se o de Miranda (1980) cujo objetivo foi auxiliar o gerenciamento dos recursos hídricos no que se refere à qualidade da água do rio Paraíba do Sul, destino dos despejos de grandes indústrias e de resíduos de fertilizantes, herbicidas e pesticidas das fazendas localizadas na região do Médio Paraíba .

Após uma revisão dos trabalhos de Isard (1968) e Vitor (1972), o autor apresenta a estimação da matriz das relações interindustriais na região e a matriz dos coeficientes de poluição das principais indústrias e, com base nestas duas matrizes elabora as tabelas de impacto, as quais mostram como os despejos industriais, que provocam a poluição das águas da região, se relacionam com as unidades monetárias da demanda final. A metodologia utilizada no trabalho, bem como seus resultados e limitações são descritos a seguir.

\subsubsection{Matriz regionalizada das relações interindustriais}

A matriz regionalizada das relações interindustriais foi estimada a partir da matriz das relações interindustriais do Brasil que por sua vez é derivada das matrizes de produção e insumos nacionais. A opção pela regionalização da matriz foi feita devido a dificuldades na elaboração de uma matriz específica e ao desejo de fornecer informações relevantes aos gerenciadores da bacia, importante fonte de abastecimento público de água da região.

A operacionalização das matrizes de produção e de insumos para a regionalização da matriz das relações interindustriais foi feita da seguinte forma: 
* Matriz de produção regionalizada e agregada para a região em estudo

A matriz de produção regionalizada e agregada foi obtida pela atribuição de pesos às linhas da matriz de produção, agregada em 25 setores. Assim, dados

$\left[\mathbf{V}^{*}\right]$ matriz de produção nacional agregada em 25 setores

[VI] matriz dos pesos referentes aos coeficientes extraídos entre os valores de produção setoriais relativas ao ano de 1970

$$
[\mathrm{VI}]=\left|\begin{array}{cc}
\frac{\mathrm{VP}_{1}^{\mathrm{R}}}{\mathrm{VP}_{1}^{\mathrm{BR}}} & \mathbf{O} \\
0 & \frac{\mathrm{VP}_{25}^{\mathrm{R}}}{\mathrm{VP}_{25}^{\mathrm{BR}}}
\end{array}\right|
$$

onde:

$\mathrm{VP}_{\mathrm{j}}{ }^{\mathrm{R}}=$ valor da produção do setor $\mathrm{j}$ na região;

$\mathrm{VP}_{\mathrm{j}}{ }^{\mathrm{BR}}=$ valor da produção no setor $\mathrm{j}$ no Brasil.

Obteve-se:

$$
\left[V^{* 2}\right]=[V I]\left[V^{*}\right]
$$

onde:

$\left[\mathrm{V}^{\star 2}\right]=$ matriz de produção agregada e regionalizada (setor $\mathrm{x}$ produto)

A matriz $\left[V^{* 2}\right]$ quando expressa em termos de coeficientes fornece a participação setorial no mercado de produtos e contém as importações efetuadas pela região e aquelas realizadas pelo resto do país sendo representada através da matriz de market-share $\left[\mathbf{V}^{3 *}\right]$. Cada elemento de $\left[\mathbf{V}^{3^{*}}\right]$ é expresso por: 


$$
\mathbf{V}_{\mathrm{ij}}^{3^{*}}=\frac{\mathbf{V}_{\mathrm{ij}}^{2^{*}}}{\sum_{k=1}^{\mathrm{n}} \mathbf{V}_{\mathrm{ik}}^{2^{*}}}
$$

Com o objetivo de tornar os coeficientes de $\left[\mathrm{V}^{3 *}\right]$ mais expressivos, foi feita a exclusão das importações regionais passando-se a utilizar a matriz [D] ou matriz market-share regional excluídas as importações competitivas efetuadas pela região em relação ao resto país:

$$
[\overline{\mathbf{D}}]_{\mathrm{sxp}}=\left[\mathrm{V}^{3^{*}}[1-\hat{\mathbf{U}}][\hat{\mathbf{Q}}]\right.
$$

onde:

[I] = matriz identidade $\mathrm{p} \times \mathrm{p}$;

$[\hat{Y}]=$ matriz diagonal $\mathrm{p} \times \mathrm{p}$ relativa à proporção da produção nacional importada;

$[\hat{Q}]=$ matriz $\mathrm{p} \times \mathrm{p}$ relativa ao coeficiente de localização em nível de produto

\section{* Matriz de insumos do setor}

A matriz de estrutura de insumos do setor industrial para a região, [B], não necessitou de regionalização. Considerou-se a função de produção da região em estudo, como semelhante à nacional, uma vez que a região em estudo tem considerável peso no cenário nacional.

A matriz de estrutura de insumos do setor industrial, assim como a matriz de produção nacional, foi inicialmente agregada em 25 setores, obtendo-se, após a agregação a matriz $\left[\mathbf{B}^{*}\right]$, cujos elementos correspondem $\mathbf{a}$ : 


$$
\mathbf{B}_{\mathrm{ij}}^{*}=\frac{\sum_{\mathbf{k} \varepsilon \varepsilon_{1}} \mathbf{b}_{\mathbf{i k}} \cdot \mathbf{G}_{\mathbf{k}}}{\sum_{\mathbf{k} \varepsilon \varepsilon_{j}} \mathbf{G}_{\mathbf{k}}} \quad \mathrm{k}=1, \ldots, 58 ; \mathrm{j}=1, \ldots, 25 ; \mathrm{i}=1, \ldots, 98
$$

onde:

$\mathbf{G}_{\mathbf{k}}=\sum_{i=1}^{98} \mathbf{b}_{\mathbf{i k}}$

$\mathbf{A}_{\mathrm{j}}=$ conjunto de índice $\mathrm{k}$, tal que estes índices pertençam à j-ésima agregação;

$b_{\mathrm{ik}}=$ elementos da matriz B de estrutura de insumos do setor industrial na sua forma original de $98 \times 58$ elementos.

Finalmente, o produto entre a matriz de market - share estimada [D] e a matriz de estrutura de insumos do setor industrial após a agregação, $\left[\mathbf{B}^{*}\right]$, fornece a matriz de coeficientes diretos de produção:

$\left[\overline{\mathbf{D}} \mathbf{B}^{*}\right]$

A matriz $\left[\overline{\mathbf{D}} \mathbf{B}^{\star}\right]$ permite obter $\left[\mathbf{I}-\overline{\mathbf{D}} \mathbf{B}^{*}\right]^{-1}$. As duas mostram as interrelações dos fluxos industriais na região.

\subsubsection{Matriz dos coeficientes de poluição}

A incorporação das variáveis ambientais ao estudo foi feita a partir das matrizes $\left[\overline{\mathbf{D}} \mathbf{B}^{*}\right]$ e $\left[\mathbf{I}-\overline{\mathbf{D}} \mathbf{B}^{*}\right]^{-1}$. Estas matrizes, expressam as relações entre os setores produtivos da região. Além de permitirem a análise do impacto das alterações no nível de demanda final sobre seus totais de produção, proporcionam ainda a verificação do impacto da variação na produção total dos setores na qualidade da água da região em termos de abastecimento público. Porém, para que isto seja possível, é necessário que 
sejam estabelecidas algumas considerações descritas em Miranda (1980): obtenção de uma matriz de coeficientes relativos a cada poluente i no setor industrial $\mathrm{k}$, matriz [W].

A matriz [W] relativa aos coeficientes de poluição em nível setorial é composta por elementos que indicam o quanto é despejado na água, do i-ésimo efluente da indústria $\mathrm{j}$, por unidade monetária produzida. Essa quantidade é obtida a partir da seguinte ponderação ${ }^{36}$ :

$$
P_{i k}=\frac{\sum C g_{i j}}{\sum Q t_{j}}
$$

onde:

$\mathrm{P}_{\mathrm{ik}}=$ coeficiente relativo ao poluente $\mathrm{i}$ no setor industrial $\mathrm{k}$, expresso em unidades físicas;

$\mathrm{Cg}_{\mathrm{ij}}=$ cargas do i-ésimo poluente da j-ésima indústria do setor $\mathrm{k}$;

$\mathrm{Qt}_{\mathrm{j}}=$ quantidade produzida por unidade de tempo da j-ésima industria do setor $\mathrm{k}$.

Porém, como os dados relativos à produção de cada setor são expressos em unidades monetárias, não se pode multiplicá-los pelo coeficiente $\mathrm{P}_{\mathrm{ik}}$, expressos em unidades físicas, sendo necessária a criação de um coeficiente que estabeleça um preço equivalente às quantidades de poluentes:

$$
P_{r i}=\frac{\sum P_{r j} \cdot Q t_{j}}{\sum Q t_{j}}
$$

onde:

$\mathrm{P}_{\mathrm{ri}}=$ relação que permite que o coeficiente $\mathrm{P}_{\mathrm{ik}}$ (expresso em unidades físicas) seja multiplicado pelos valores de produção setorial (expressos em unidades monetárias);

\footnotetext{
${ }^{36}$ maiores detalhes sobre esta ponderação e suas limitações podem ser encontrados em Miranda (1980).
} 
$P_{r j}=$ preço da j-ésima mercadoria no período t;

Assim, multiplicando-se $\mathrm{P}_{\mathrm{ik}}$ por $1 / \mathrm{P}_{\mathrm{ri}}$,obtem-se a matriz $\mathrm{W}$.

\subsubsection{Tabelas de impacto}

A partir das matrizes regionalizadas das relações interindustriais, $\left[\overline{\mathbf{D}} \mathbf{B}^{*}\right]$ e $\left[\mathbf{I}-\overline{\mathbf{D}}^{\star}\right]^{-1}$, e da matriz dos coeficientes de poluição das indústrias [W], obteve-se as tabelas de impacto, as quais medem os impactos diretos e indiretos que uma unidade monetária de demanda final exerce sobre o ambiente através da produção de despejos industriais. Essas tabelas são expressas da seguinte forma:

$$
\begin{aligned}
& I C=W\left[\left[I-\bar{D} B^{*}\right]^{-1} D^{-1}\right] \\
& I S=W\left[I-\bar{D} B^{*}\right]^{-1}
\end{aligned}
$$

onde:

IC = tabela de impactos em nível de produto (produção do i-ésimo despejo, associado à oferta de uma unidade monetária da j-ésima mercadoria.

Cada elemento de $\mathbf{W}$ refere-se à quantidade do i-ésimo despejo produzido por uma unidade monetária do produto do setor $\mathrm{j}$.

$\left[\mathbf{I}-\mathbf{D B}^{*}\right]^{-1} \mathbf{D}^{-1}$ = matriz de coeficientes diretos e indiretos, onde cada elemento explicita os impactos diretos e indiretos da produção de uma unidade monetária da j-ésima mercadoria no i-ésimo setor.

IS = tabela de impacto em um nível mais agregado, onde a produção do i-ésimo despejo é associada à oferta de uma unidade monetária do j-ésimo setor. 
A partir dos resultados obtidos o autor concluiu que no curto prazo, a situação do Rio Paraíba não apresenta riscos à saúde da população embora, em alguns locais específicos as águas deste rio apresentem elevadas concentrações tóxicas. No médio prazo, no entanto, caso persistam as tendências de elevação na poluição da água, constatadas no trabalho poderão surgir problemas letais à população. Assim, torna-se premente um planejamento mais efetivo quanto à localização das indústrias na região.

$\mathrm{O}$ trabalho de Miranda teve o mérito de adotar uma metodologia que relaciona a economia de uma região a seu meio ambiente, sendo possível aplicá-la a outras regiões. Porém algumas limitações devem ser ressaltadas:

- A área de aplicação do modelo é muito restrita. Como a análise em questão refere-se a um curso de água, os resultados seriam mais proveitosos se o estudo envolvesse um número maior de municípios ao longo da bacia. Além disso, em uma área maior tem-se ligações intersetoriais mais fortes e diversificadas.

- Devido à precariedade e qualidade dos dados não são mencionados os insumos ambientais demandados pela produção econômica, ou seja, não se faz um "feedback " sobre como os impactos sofridos pelo meio ambiente afetam os setores econômicos da região.

- A regionalização dos dados diminui a eficiência da análise de insumoproduto pois afeta a precisão dos coeficientes.

\subsection{Modelo insumo-produto e estimação do valor da água}

O propósito de atribuir preço a um recurso natural como a água é evitar seu desperdício. Estimar o valor da água é importante e controverso, particularmente nas regiões onde há escassez e em planejamento de projetos de investimento em recursos hídricos. 
Muitos estudos vêm sendo realizados neste sentido. Segundo Lima (1999), estes estudos devem considerar os vários usos da água, possibilidades de poluição $\mathrm{e}$ deterioração dos mananciais.

Young e Gray (1985), apresentaram uma metodologia que utiliza o modelo insumo-produto, através de uma aproximação do valor adicionado para atribuir preço à água. Este trabalho tem a vantagem de fazer uma ligação explícita entre os princípios econômicos de bem-estar e a estrutura usada nas análises de insumo-produto.

\subsubsection{Aproximação valor adicionado}

A aproximação "valor adicionado", baseada nos modelos insumo-produto, tem se mostrado eficiente em atribuir valores aos recursos naturais porém, sob certas restrições.

Uma descrição simples dessa metodologia pode ser feita a partir de um setor de produção em um modelo convencional de insumo-produto, representando uma região. Assume-se que o setor compra bens de outros setores da região e em outras regiões, e adquire recursos primários. As transações de compra do setor j, expressas em termos de valores são representadas por:

$$
\mathbf{X}_{\mathbf{j}}=\sum \mathbf{X}_{\mathbf{i j}}+\mathbf{Z}_{\mathbf{j}}
$$

onde:

$\mathbf{X}_{\mathrm{j}}=$ valor total das compras realizadas pelo setor $\mathbf{j}$;

$\mathbf{X}_{\mathrm{ij}}=$ valor das compras feitas pelo setor $\mathrm{j}$, junto ao setor $\mathrm{i}$;

$\mathbf{Z}_{\mathrm{j}}=$ valor dos recursos primários adquiridos pelo setor $\mathrm{j}$.

Esta expressão pode ser escrita, ainda, da seguinte forma:

$$
\mathbf{X}_{\mathrm{j}}=\sum \mathbf{X}_{\mathrm{ij}}+\mathbf{V}_{\mathrm{j}}+\mathbf{M}_{j}
$$


onde:

$\mathbf{V}_{\mathrm{j}}=$ valor adicionado total, referente ao setor $\mathrm{j}$;

$\mathbf{M}_{\mathrm{j}}=$ importações do setor $\mathrm{j}$.

$\mathrm{O}$ elemento $\mathbf{V}_{\mathrm{j}}$ é uma composição dos gastos com recursos primários. A renda bruta da região é dada por:

$$
\mathbf{G R I}_{\mathrm{j}}=\mathbf{X}_{\mathrm{j}}-\mathbf{X}_{\mathrm{ij}}-\mathbf{M}_{\mathbf{j}}
$$

logo,

$$
\mathbf{G R I}_{j}=\mathbf{V}_{j}
$$

As relações quantitativas do sistema de Leontief requerem que o valor total da produção do setor $\mathrm{j}$ seja igual ao valor das suas vendas. Portanto, assume-se que a renda regional bruta seja igual à produção regional bruta no agregado:

$$
X_{i}=X_{i j}+Y_{i}
$$

onde:

$\mathrm{X}_{\mathrm{i}}=$ valor total das vendas do setor $\mathrm{i}$;

$X_{i j}=$ valor das vendas feitas pelo setor $\mathrm{i}$;

$\mathrm{Y}_{\mathrm{i}}=$ vendas finais do setor $\mathrm{i}$, incluindo as exportações.

Usando esta notação, o valor da água, imposta pelo valor adicionado $\left(\mathrm{V}_{\mathrm{j}}\right)$ será:

$$
\hat{P}_{w j}=\frac{V_{j}}{Q_{w j}}=\frac{G R I_{j}}{Q_{w j}}
$$

onde: 
$\hat{P_{w j}}=$ valor imposto da água usada pelo setor $\mathrm{j}$;

$\mathrm{Q}_{\mathrm{wj}}=$ quantidade física total de água, consumida pelo setor $\mathrm{j}$.

$\mathrm{O}$ valor adicionado é, geralmente, uma agregação de salários $\left(\mathrm{P}_{\mathrm{s}} \mathrm{Q}_{\mathrm{s}}\right)$, aluguéis de recursos primários $\left(\mathrm{P}_{\mathrm{r}} \mathrm{Q}_{\mathrm{r}}\right)$, depreciação $\left(\mathrm{P}_{\mathrm{k}} \mathrm{Q}_{\mathrm{k}}\right)$, pagamentos por serviços do governo, etc.. O resíduo, neste caso, inclui não apenas a contribuição da água para o valor da produção $\left(\mathrm{P}_{\mathrm{w}} \mathrm{Q}_{\mathrm{w}}\right)$, mas a contribuição de todos os recursos primários. Assim, a definição matemática de valor adicionado pode ser reescrita como:

$$
V_{j}=P_{s j} Q_{s j}+P_{r j} Q_{r j}+P_{k j} Q_{k j}+P_{w j} Q_{w j}
$$

Os gastos com serviços do governo não são considerados na estimação pois equivalem a transferências nas análises de benefícios - custos.

Através de um rearranjo na equação acima, tem-se uma aproximação correta para o preço-sombra da água:

$$
P_{w j}^{*}=\left(V_{j}-P_{s j} Q_{s j}-P_{r j} Q_{r j}-P_{k j} Q_{k j}\right)\left(Q_{w}\right)^{-1}
$$

Atribuindo o valor adicionado para a água como em (39), implicitamente assume-se o preço-sombra igual a zero para os outros recursos primários, isto é, $P_{s j}=P_{k j}=P_{r j}=0$ e ignora-se o fato de que os outros recursos possam ser mais escassos que a água.

É importante ressaltar que essa metodologia apresenta uma limitação ao assumir que os custos de oportunidade dos outros fatores primários é zero, o que resulta em valores sobreestimados para a água em comparação com os ganhos potenciais dos usos alternativos do mesmo tipo de investimento.

Essa aproximação só trará resultados corretos se: 
- os custos de oportunidade dos outros fatores primários forem empiricamente identificados.

- a pressuposição de que os custos de oportunidade dos custos dos outros fatores primários é igual a zero for realmente válida.

Os modelos expostos neste capitulo fornecem um instrumental econômico de grande abrangência. Através deles os profissionais responsáveis pelas decisões envolvendo o recurso água podem dispor de fundamentos teóricos que os ajudem a resolver questões como localização industrial sem o comprometimento da qualidade de água, prioridade de uso da água, tarifação. Porém, cabe ressaltar que as dificuldades de obtenção dos dados e a qualidade destes podem comprometer as análises.

A vasta aplicação dessa metodologia revela a importância de sua divulgação junto aos profissionais envolvidos na administração, não apenas dos recursos hídricos, mas também de todos os recursos naturais. 


\section{METODOLOGIA}

Este capítulo tem a intenção de apresentar os procedimentos operacionais necessários à concretização dos objetivos propostos no primeiro capítulo deste trabalho. Estes procedimentos são divididos em quatro partes:

- Construção da matriz de insumo-produto para o Ceará - ano 1999;

- Construção da matriz inter-regional com as regiões: Ceará, resto do Nordeste e resto do Brasil;

- Métodos de análise das relações intersetoriais;

- Incorporação da água à matriz de insumo-produto do Ceará;

Cada uma destas partes envolve metodologias distintas, as quais são descritas a seguir.

\subsection{Matriz de insumo-produto para o Ceará - ano 1992}

A matriz de insumo-produto para o Ceará foi obtida a partir da regionalização da matriz de insumo-produto do Nordeste, 1992. A inexistência de dados primários, conjugada às dificuldades técnicas e financeiras que envolvem a sua obtenção, foram os fatores relevantes nesta escolha.

Segundo Souza (1997), a regionalização de uma matriz de insumo-produto consiste em se estimar, através de técnicas específicas uma matriz de insumo-produto para um determinado Estado ou Região a partir de uma matriz nacional. Neste trabalho optou-se pela técnica do quociente locacional conjugada ao método RAS, por considerá- 
- los bastante abrangentes, dados os objetivos que se deseja atingir e por fornecerem coeficientes relativamente confiáveis.

\subsubsection{Técnica do quociente locacional simples}

Antes de iniciar a explanação do procedimento empregado na construção das matrizes de uso e produção para o Estado do Ceará, convém descrever os princípios da técnica do quociente locacional simples. Esta técnica é um instrumento utilizado em Economia Regional para se obter os valores aproximados das variáveis de uma determinada região a partir dos valores destas variáveis obtidos de dados censitários em nível nacional, sob o pressuposto de que a economia regional mantém a mesma estrutura da economia nacional em relação ao setor $i$.

Conforme Miller e Blair (1985), o quociente locacional simples para um setor $i$ na região $R$, é expresso por:

$$
L Q_{i}^{R}=\left[\frac{X_{i}^{R} / X^{R}}{X_{i}^{N} / X^{N}}\right]
$$

onde:

$X_{i}^{R}$ valor da produção do setor $i$ na região $R$;

$X^{R}$ valor da produção total na região $R$;

$X_{i}^{N} \quad$ valor da produção nacional do setor $i$;

$X^{N}$ valor da produção nacional total.

O quociente locacional simples aponta a capacidade que uma indústria $i$ localizada em uma região $R$, tem para atender à demanda feita a ela pelas indústrias da sua região e à demanda final na região. Se $L Q_{i}^{R}<1$, a indústria $i$ é menos concentrada 
na região $R$ que no resto do país, seu produto é orientado à importação. Se $L Q_{i}^{R}>1$, a indústria $i$ é mais concentrada na região $R$ que no resto do país, seu produto é orientado à exportação. Além disso, este quociente permite estimar, ainda, os coeficientes técnicos regionais de insumos diretos:

$$
a_{i j}^{R R}=\left[\begin{array}{ll}
a_{i j}^{N} & \text { se } L Q_{i}^{R} \geq 1 \\
a_{i j}^{N} \cdot\left(L Q_{i}^{R}\right) & \text { se } L Q_{i}^{R}<1
\end{array}\right.
$$

onde:

$a_{i j}^{R R}$ coeficiente técnico regional;

$a_{i j}^{N}$ coeficiente técnico nacional;

Ao se adotar a técnica do quociente locacional simples para se obter uma tabela regional, poderão surgir problemas quanto às estimativas do produto industrial regional, o qual poderá exceder o produto real. Para evitar uma distorção nos valores do produto regional por setor, fez-se um balanceamento dos coeficientes através do método do balanço iterativo também conhecido como método RÃS, o qual será descrito na seção 5.2.2.

\subsubsection{Construção da matriz de insumo-produto para o Ceará}

A matriz de insumo-produto para o Ceará foi construída a partir da matriz de insumo-produto do Nordeste, referente ao ano de 1992, fornecida pelo Instituto Brasileiro de Geografia e Estatística (IBGE), especificamente das tabelas de produção e de insumo das atividades (tabela de uso). Esta matriz sofreu atualização para o ano de 1999, conforme será descrito na seção 5.2.3 deste capítulo.

A tabela de produção forneceu:

- Matriz V - matriz de produção do Nordeste (setor x produto); 
- Vetor $\mathbf{X}$ - vetor de produção total por setor (setor x 1);

A tabela de insumo das atividades forneceu:

- Matriz $\mathbf{U}$ - matriz de uso do Nordeste (produto x setor).

As linhas de $\mathbf{V}$ indicam em quais setores os produtos são produzidos. As linhas de $\mathbf{U}$ informam os produtos ofertados por setor $\mathrm{e}$ as colunas os produtos demandados. As matrizes $\mathbf{V}$ e $\mathbf{U}$, além do vetor $\mathbf{X}$, foram utilizados no cálculo das matrizes regionais.

A construção das matrizes de produção e uso para o Estado do Ceará, $\mathbf{V}_{\mathbf{c e}} \mathrm{e}$ $\mathbf{U}_{\text {ce, }}$, respectivamente, envolveu inicialmente a compatibilização dos setores pertencentes à matriz de insumo-produto do Nordeste ${ }^{37}$ (Apêndice I), de acordo com os objetivos do trabalho. Em seguida obteve-se o vetor de proporções ${ }^{38}$ da produção estadual por setor na produção do Nordeste que, multiplicado por $\mathbf{X}$, deu origem ao $\mathbf{X}_{\mathrm{ce}}$. Calculou-se então a proporção de cada elemento da matriz de produção do Nordeste na produção total por setor obtendo-se desta forma uma matriz de participação. Através desta matriz de participação fez-se a distribuição do vetor $\mathbf{X}_{\mathbf{c e}}$ entre os produtos dos vários setores da economia resultando na matriz $\mathbf{V}_{\mathbf{c e}}$ permitindo a obtenção do vetor da produção estadual por produto, $\mathbf{Q}_{\mathrm{ce}}$, conforme Moretto (2000).

A partir de $\mathbf{V}_{\mathbf{c e}}$ e $\mathbf{Q}_{\mathbf{c e}}$ foram calculados os coeficientes técnicos de produto para o Ceará através da expressão:

$$
\mathbf{D}_{\mathrm{ce}}=\mathbf{V}_{\mathrm{ce}}\left(\hat{\mathbf{Q}}_{\mathrm{ce}}\right)^{-1}
$$

onde:

\footnotetext{
${ }^{37}$ Utilizou-se nesta compatibilização a Classificação Nacional das Atividades Econômicas, publicada pelo IBGE.

${ }^{38}$ As proporções utilizadas aqui foram obtidas na Fundação Instituto de Planejamento do Ceará (Iplance).
} 
$\mathbf{D}_{\mathrm{ce}} \quad$ matriz de coeficientes técnicos do produto para o Ceará;

$\left(\hat{\mathbf{Q}}_{\mathrm{ce}}\right)^{-1}$ matriz formada pelo vetor $\mathrm{Q}_{\mathrm{ce}}$ diagonalizado e invertido (produto x produto)

As informações contidas em $\mathbf{X}$ e $\mathbf{X}_{\mathbf{c e}}$, permitiram o cálculo dos quocientes locacionais para cada produto, conforme descrito em 5.1.1. Estes quocientes por sua vez, foram usados na obtenção da matriz de coeficientes técnicos de insumos para o Ceará, $\mathrm{B}_{\mathrm{ce}}$, utilizando-se como critério:

$$
b_{i j}^{c e}=\left[\begin{array}{ll}
b_{i j}^{N e} & \text { se } L Q_{i} \geq 1 \\
b_{i j}^{N e} & \left(L Q_{i}\right) \quad \text { se } L Q_{i}<1
\end{array}\right.
$$

onde $\mathrm{b}_{\mathrm{ij}} \mathrm{Ne}$ correspondem aos elementos da matriz coeficientes técnicos de insumos para o Nordeste, $\mathbf{B}^{39}$

A matriz de uso do Ceará foi obtida a partir da equação:

$$
\mathbf{U}_{\mathrm{ce}}=\mathbf{B}_{\mathrm{ce}} * \hat{\mathbf{X}}_{\mathrm{ce}}
$$

A matriz dos coeficientes técnicos de insumos diretos para o Ceará, $\mathbf{A}_{\mathrm{ce}}$ (setor x setor), foi calculada através da expressão ${ }^{40}$ :

$$
\mathbf{A}_{\mathrm{ce}}=\mathbf{D}_{\mathrm{ce}} \cdot \mathbf{B}_{\mathrm{ce}}
$$

A matriz de coeficientes técnicos de insumos diretos e indiretos para o Ceará ou matriz inversa de Leontief, $\mathbf{L}^{\mathrm{R}}$ (setor x setor), foi obtida da seguinte forma:

$$
\mathbf{L}^{\mathbf{R}}=\left(\mathbf{I}-\mathbf{A}^{\mathbf{R}}\right)^{-1}
$$

\footnotetext{
${ }^{39}$ A matriz $\mathbf{B}$ é calculada através da equação: $\mathbf{B}=\mathbf{U} \cdot(\hat{\mathbf{X}})^{-1}$.

${ }^{40}$ Conforme subentendido nesta expressão, este trabalho utilizou o enfoque setor $\mathrm{x}$ setor, tecnologia baseada na indústria, onde cada produto tem a sua produção distribuída por setores, em proporções fixas. A vantagem deste enfoque é que permite diferenciar a tecnologia de produção dos diversos produtos.
} 
A matriz $\mathbf{L}^{\mathbf{R}}$ permitiu a verificação do impacto de uma variação na demanda final de um setor sobre a produção, renda e emprego, conforme será descrito posteriormente.

Estimadas as matrizes de produção e uso para o Ceará, passou-se à etapa seguinte, que consistiu na construção do modelo inter-regional para as regiões Ceará, resto do Nordeste e resto do Brasil.

\subsection{Construção da matriz inter-regional}

O modelo de insumo-produto para o Ceará, descrito acima, é incapaz de captar o efeito de uma variação na demanda do Estado, proveniente de uma variação na demanda de outra região (feedback internacional). Isto ocorre porque o modelo não apresenta relações inter-regionais. Para resolver esta questão e tornar o presente estudo mais abrangente optou-se pela construção de um modelo inter-regional envolvendo as regiões Ceará, resto do Nordeste e resto do Brasil (Quadros 7 e 8), com 26 setores e 29 produtos para cada região. A fundamentação teórica deste modelo encontra-se na seção 3.5 .

O processo de construção da matriz inter-regional de insumo-produto para as regiões Ceará, resto do Nordeste e resto do Brasil, ocorreu basicamente em três etapas: construção da matriz de consumo intermediário (Quadro 8), estimação da demanda final para as três regiões (Quadro 9) e atualização do modelo para o ano de 1999. A seguir faz-se a descrição destas etapas. 


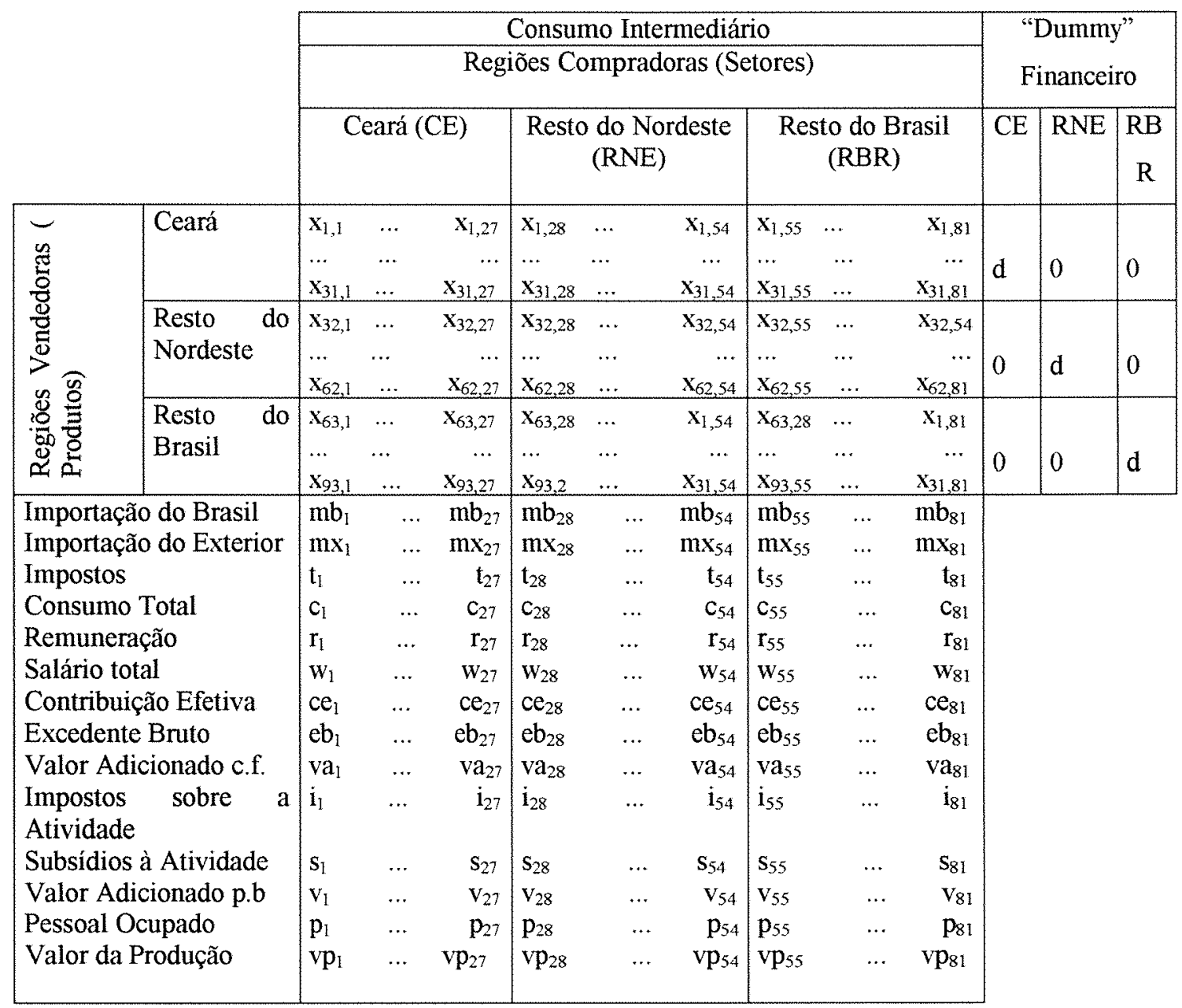

Quadro 7 - Consumo intermediário.

Fonte: Adaptado de Miller e Blair (1985) 


\begin{tabular}{|c|c|c|c|c|c|c|c|c|c|c|c|c|c|c|c|c|}
\hline & \multicolumn{15}{|c|}{ Demanda Final } \\
\hline & & \multicolumn{3}{|c|}{ Consumo Total } & \multicolumn{3}{|c|}{$\begin{array}{c}\text { Formação Bruta de } \\
\text { Capital }\end{array}$} & \multicolumn{3}{|c|}{$\begin{array}{c}\text { Exportações para o } \\
\text { Brasil }\end{array}$} & \multicolumn{3}{|c|}{$\begin{array}{l}\text { Exportações para o } \\
\text { Exterior }\end{array}$} & \multicolumn{3}{|c|}{$\begin{array}{l}\text { Variação de } \\
\text { Estoque }\end{array}$} \\
\hline & & $\overline{C E}$ & RNE & RBR & $\mathrm{CE}$ & RNE & RBR & $\overline{\mathrm{CE}}$ & RNE & RBR & $\mathrm{CE}$ & RNE & RBR & $\overline{C E}$ & RNE & RBR \\
\hline \multirow{3}{*}{ 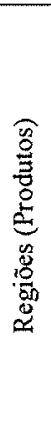 } & Ceará & $\begin{array}{l}\mathrm{C}_{1,1} \\
\ldots \ldots \\
\mathrm{C}_{31, \mathrm{I}}\end{array}$ & $\begin{array}{l}\mathrm{C}_{1,2} \\
\mathrm{C}_{31,2}\end{array}$ & $\begin{array}{l}\mathrm{C}_{1,3} \\
\cdots \cdots \\
\mathrm{C}_{31,3}\end{array}$ & $\begin{array}{l}\mathrm{F}_{1, \mathrm{i}} \\
\\
\mathrm{F}_{31,1}\end{array}$ & $\begin{array}{l}\mathrm{F}_{1,2} \\
\cdots \\
\mathrm{F}_{31,2}\end{array}$ & $\begin{array}{l}\mathrm{F}_{1,3} \\
\mathrm{~F}_{31,3}\end{array}$ & $\begin{array}{l}0 \\
0 \\
0 .\end{array}$ & $\begin{array}{l}\mathrm{B}_{1,2} \\
\cdots \\
\mathrm{B}_{31,2}\end{array}$ & $\begin{array}{l}\mathrm{B}_{1,3} \\
\ldots \ldots \\
\mathrm{B}_{31,3}\end{array}$ & $\begin{array}{l}\mathrm{E}_{\mathrm{I}, \mathrm{I}} \\
\mathrm{E}_{31,1}\end{array}$ & $\begin{array}{l}0 \\
\cdots \cdots \\
0\end{array}$ & $\begin{array}{l}0 \\
0\end{array}$ & $\begin{array}{l}\mathrm{V}_{1,1} \\
\cdots \cdots \\
\mathrm{V}_{31,1}\end{array}$ & $\begin{array}{l}V_{1,2} \\
V_{31,2}\end{array}$ & \begin{tabular}{|l|}
$V_{1,3}$ \\
$\cdots \cdots$ \\
$V_{31,3}$
\end{tabular} \\
\hline & $\begin{array}{l}\text { Resto do } \\
\text { Nordeste }\end{array}$ & $\begin{array}{l}\mathrm{C}_{32,1} \\
\ldots \ldots \\
\mathrm{C}_{62,1}\end{array}$ & $\begin{array}{l}\mathrm{C}_{32,2} \\
\mathrm{C}_{62,2}\end{array}$ & $\begin{array}{l}\mathrm{C}_{32,3} \\
\ldots \ldots \\
\mathrm{C}_{62,3}\end{array}$ & $\begin{array}{l}\mathrm{F}_{32,1} \\
\ldots \ldots \\
\mathrm{F}_{62,1}\end{array}$ & $\begin{array}{l}F_{32,2} \\
\cdots \ldots \\
F_{62,2}\end{array}$ & $\begin{array}{l}\mathrm{F}_{32,3} \\
\ldots \ldots \\
\mathrm{F}_{62,3}\end{array}$ & $\begin{array}{l}\mathrm{B}_{32,1} \\
\ldots \ldots \\
\mathrm{B}_{62,1}\end{array}$ & $\begin{array}{l}0 \\
\cdots \cdots . . \\
0\end{array}$ & $\begin{array}{l}\mathrm{B}_{32,3} \\
\ldots \ldots \\
\mathrm{B}_{62,3}\end{array}$ & $\begin{array}{l}0 \\
\cdots \ldots . . \\
0\end{array}$ & $\begin{array}{l}\mathrm{E}_{32,2} \\
\mathrm{E}_{62,2}\end{array}$ & $\begin{array}{l}0 \\
0 \\
\cdots \cdots\end{array}$ & $\begin{array}{l}V_{32,1} \\
\cdots \cdots \\
V_{62,1}\end{array}$ & $\begin{array}{l}V_{32,2} \\
\cdots \ldots \\
V_{62,2}\end{array}$ & $\begin{array}{l}\mathrm{V}_{32,3} \\
\cdots \\
\mathrm{V}_{62,3}\end{array}$ \\
\hline & $\begin{array}{l}\text { Resto do } \\
\text { Brasil }\end{array}$ & $\begin{array}{l}\mathrm{C}_{63,1} \\
\ldots \ldots \\
\mathrm{C}_{93,1}\end{array}$ & $\begin{array}{l}\mathrm{C}_{63,2} \\
\ldots \ldots \\
\mathrm{C}_{93,2}\end{array}$ & $\begin{array}{l}\mathrm{C}_{63.3} \\
\ldots \ldots \\
\mathrm{C}_{93,3}\end{array}$ & $\begin{array}{l}F_{63,1} \\
\ldots \ldots \\
F_{93,1}\end{array}$ & $\begin{array}{l}F_{63,2} \\
\ldots \ldots \\
F_{93,2}\end{array}$ & $\begin{array}{l}\mathrm{F}_{63,3} \\
\ldots \ldots \\
\mathrm{F}_{93,3}\end{array}$ & $\begin{array}{l}\mathrm{B}_{63,1} \\
\cdots \cdots \\
\mathrm{B}_{93,1}\end{array}$ & $\begin{array}{l}\mathrm{B}_{63,2} \\
\ldots \ldots \\
\mathrm{B}_{93,2}\end{array}$ & $\begin{array}{l}0 \\
\cdots . . . \\
0\end{array}$ & $\begin{array}{l}0 \\
\cdots \cdots \\
0\end{array}$ & $\begin{array}{l}0 \\
\cdots \cdots \\
0\end{array}$ & $\begin{array}{l}E_{63,3} \\
\ldots \ldots \\
E_{93,3}\end{array}$ & $\begin{array}{l}V_{63,1} \\
\ldots \ldots \\
V_{93,1}\end{array}$ & $\begin{array}{l}\mathrm{V}_{63,2} \\
\ldots \ldots \\
\mathrm{V}_{93,2}\end{array}$ & $\begin{array}{l}\mathrm{V}_{63,3} \\
\ldots . \\
\mathrm{V}_{93,3}\end{array}$ \\
\hline \multicolumn{2}{|c|}{ Importação do Brasil } & $\mathrm{Mb}_{\mathrm{I}}$ & $\mathrm{Mb}_{2}$ & $\mathrm{Mb}_{3}$ & $\mathrm{Mb}_{4}$ & $\mathrm{Mb}_{s}$ & $\mathrm{Mb}_{6}$ & $\mathrm{Mb}_{7}$ & $\mathrm{Mb}_{8}$ & $\mathrm{Mb}_{9}$ & $\mathrm{Mb}_{10}$ & $\mathrm{Mb}_{11}$ & $\mathrm{Mb}_{12}$ & $\mathrm{Mb}_{13}$ & $\mathrm{Mb}_{14}$ & $\mathrm{Mb}_{15}$ \\
\hline \multicolumn{2}{|c|}{$\begin{array}{ll}\text { Importação } & \text { do } \\
\text { Exterior } & \end{array}$} & $\mathrm{Me}_{1}$ & $\mathrm{Me}_{2}$ & $\mathrm{Me}_{3}$ & $\mathrm{Me}_{4}$ & $\mathrm{Me}_{5}$ & $\mathrm{Me}_{6}$ & $\mathrm{Me}_{7}$ & $\mathrm{Me}_{8}$ & $\mathrm{Me}_{9}$ & $\mathrm{Me}_{10}$ & $\mathrm{Me}_{11}$ & $\mathrm{Me}_{12}$ & $\mathrm{Me}_{13}$ & $\mathrm{Me}_{14}$ & $\mathrm{Me}_{15}$ \\
\hline \multicolumn{2}{|c|}{ Impostos } & $T_{1}$ & $\mathrm{~T}_{2}$ & $\mathrm{~T}_{3}$ & $\mathrm{~T}_{4}$ & $T_{s}$ & $\mathrm{~T}_{6}$ & $\mathrm{~T}_{7}$ & $\mathrm{~T}_{8}$ & $\mathrm{~T}_{9}$ & $T_{10}$ & $\mathrm{~T}_{11}$ & $\mathrm{~T}_{12}$ & $\mathrm{~T}_{13}$ & $T_{14}$ & $\mathrm{~T}_{15}$ \\
\hline \multicolumn{2}{|c|}{ Consumo Total } & $\mathrm{CT}_{1}$ & $\mathrm{CT}_{2}$ & $\mathrm{CT}_{3}$ & $\mathrm{CT}_{4}$ & $\mathrm{CT}_{5}$ & $\mathrm{CT}_{6}$ & $\mathrm{CT}_{7}$ & $\mathrm{CT}_{8}$ & $\mathrm{CT}_{9}$ & $\mathrm{CT}_{10}$ & $\mathrm{CT}_{11}$ & $\mathrm{CT}_{12}$ & $\mathrm{CT}_{13}$ & $\mathrm{CT}_{14}$ & $\mathrm{CT}_{15}$ \\
\hline
\end{tabular}

Quadro 8-Demanda final.

Fonte: Adaptado de Miller e Blair (1985)

\subsubsection{Construção da matriz de consumo intermediário}

O início da construção do modelo consistiu na consolidação dos produtos e setores das matrizes de produção e uso do Ceará, Nordeste e Brasil, conforme classificação feita em 5.1.2. Em seguida foram obtidas as matrizes de produção do resto do Nordeste e resto do Brasil ${ }^{41}$ através das diferenças:

$$
\begin{aligned}
& V_{\text {rne }}=V_{n e}-V_{\text {ce }} \\
& V_{\text {rbr }}=V_{\text {br }}-V_{\text {ne }} ;
\end{aligned}
$$

\footnotetext{
${ }^{41}$ a matriz de produção da região Ceará foi obtida em 5.1.2.
} 
E as respectivas matrizes de uso $^{42}$ :

$$
\begin{aligned}
& U_{\text {rne }}=U_{\text {ne }}-U_{c e} \\
& U_{\text {rbr }}=U_{b r}-U_{n e}
\end{aligned}
$$

Essas matrizes, no entanto, representam o total de insumos utilizados pelos setores das regiões, sem contudo, informar a sua origem. A distribuição das matrizes $\mathbf{U}_{\mathbf{c e}}$, $\mathbf{U}_{\mathbf{r n e}}$ e $\mathbf{U}_{\mathbf{r b r}}$ conforme a origem dos insumos foi feita através do quociente locacional, cuja metodologia encontra-se em 5.1.1. Porém, como se trata de um modelo com mais de uma região exportadora, os resultados fornecidos pela técnica do quociente locacional não são suficientes para distribuir corretamente o montante correspondente à importação da região analisada entre as regiões exportadoras. A solução para este impasse foi a utilização do método proposto por Leontief onde calcula-se o excesso do produto $j$ da região exportadora $i^{43}$, e em seguida a proporção:

excesso de produto $j$ da região exportadora $i$ / excesso de produção de todas as regiões exportadoras

a qual fornece os percentuais de participação de cada região exportadora na exportação de cada produto para a região importadora.

Além da matriz de consumo intermediário, foi calculada a atividade "dummy" financeira, cuja função, segundo Ramos (1997), é "captar os custos de serviços financeiros de cada atividade a fim de não superestimar o valor adicionado por atividade.Assim, seu valor de produção é nulo". O cálculo desta atividade foi feito segundo Domingues e Haddad (2000).

\footnotetext{
${ }^{42} \mathrm{Na}$ construção das matrizes de uso foi considerada a hipótese de mesma tecnologia de produção para os mesmos setores nas três diferentes regiões. Assim, cada setor apresentou a mesma proporção (produção por setor / produção total) verificada na matriz de uso do Brasil.

${ }^{43}$ Excesso de produto da região exportadora $i=$ valor da produção do produto $j$ que corresponderia a um $\mathrm{QL}=1$ - valor da produção do produto $j$ na região exportadora $i$.
} 


\subsubsection{Estimação da demanda final}

A demanda final do modelo é composta pelos seguintes componentes: consumo final (consumo das famílias + consumo do governo), formação bruta de capital, exportações para o resto do Brasil, exportações para o exterior e variação de estoque.

O consumo final foi obtido a partir da proporção PIB do Ceará / PIB do Nordeste (dados fornecidos pelo IBGE), sendo aplicada em seguida a técnica dos quocientes locacionais. Foi utilizado o mesmo procedimento descrito na seção anterior, para fazer a distribuição do consumo conforme a origem dos bens.

A formação bruta de capital foi calculada de forma similar, sendo que a partir da proporção investimentos no Ceará / investimentos no Nordeste (Iplance, 2000).

As exportações para o resto do Brasil e exportações para o exterior foram obtidas a partir dos valores referentes às exportações do Nordeste na matriz de insumoproduto 1992, multiplicados pela participação da produção do Ceará na produção do Nordeste.

Finalmente, a variação de estoque foi determinada pela diferença entre a soma do consumo intermediário e os demais componentes da demanda e o valor total da produção.

\subsubsection{Atualização das matrizes para o ano de 1999}

O modelo inter-regional construído conforme descrito nas seções $5.2 .1 \mathrm{e}$ 5.2.2 e as matrizes de produção e uso do Ceará referem-se ao ano de 1992. A atualização destes dados para o ano de 1999 ocorreu conforme Miller e Blair (1985), que apontam a técnica RAS como apropriada a este objetivo. Esta técnica tenta identificar as mudanças nos coeficientes técnicos ocorridas no transcorrer do tempo em conseqüência de dois efeitos: efeito substituição e efeito fabricação. 
O efeito substituição é responsável pela alteração na composição dos insumos no processo produtivo e o efeito fabricação refere-se a mudanças na relação entre o valor adicionado e o consumo dos bens intermediários.

Usando a notação $\mathbf{A ( 0 )}$ e $\mathbf{A ( 1 )}$ para matriz de coeficientes técnicos calculados no passado e matriz atualizada para o período desejado, respectivamente, o ponto de partida para a atualização de $\mathbf{A}(\mathbf{0})$ consiste na obtenção dos seguintes vetores:

$$
\mathbf{U}(\mathbf{1})=\left[\begin{array}{l}
\mathbf{U} \mathbf{1} \\
\vdots \\
\mathbf{U n}
\end{array}\right] \quad \text { que representa as vendas interindustriais por setor no }
$$

período 1 .

$\mathbf{V}(\mathbf{1})=[\mathbf{V 1} \cdots \mathbf{V n}]$ que representa a utilização dos produtos intermediários por setor no período 1 .

$$
\mathbf{X}(\mathbf{1})=\left[\begin{array}{l}
\mathbf{X} 1 \\
\vdots \\
\mathbf{X n}
\end{array}\right] \text { que representa a produção total por setor no período } 1
$$

Obtidos estes vetores, a matriz de coeficientes técnicos para o período desejado $\mathbf{A}(\mathbf{1})$ é calculada partindo da hipótese de que $\mathbf{A}(\mathbf{0})=\mathbf{A}(\mathbf{1})$, ou seja, os coeficientes técnicos mantêm-se constantes ao longo do tempo. Para que esta hipótese seja verdadeira a matriz de transações interindustriais deve ser:

$$
\mathbf{Z}(\mathbf{1})=\mathbf{A}(\mathbf{0}) \cdot \hat{\mathbf{X}}(\mathbf{1})
$$

A matriz $\mathbf{Z ( 1 )}$ estima os fluxos interindustriais atualizados. A soma de suas linhas fornece um vetor $\mathbf{U}^{\mathbf{1}}$. Multiplicando-se $\mathbf{Z}(\mathbf{1})$ por um vetor unitário, i, tem-se:

$$
\mathbf{M}(\mathbf{1})=\mathbf{i}^{\prime} \mathbf{A}(\mathbf{0}) \cdot \hat{\mathbf{X}}(\mathbf{1})
$$


A soma das colunas de $\mathbf{M}$ fornece o vetor $\mathbf{V}^{\mathbf{1}}$.

Se $\mathbf{U}^{1}=\mathbf{U}(\mathbf{1})$, deduz-se que não houve efeito substituição. $\mathrm{Se} \mathbf{V}^{1}=\mathbf{V}(\mathbf{1})$, deduz-se que não houve efeito fabricação. As somas das linhas e colunas de $\mathbf{Z}(\mathbf{1})$ e M(1), respectivamente, estão corretas. O processo de atualização está encerrado.

Porém, se $\mathbf{U}^{\mathbf{1}} \neq \mathbf{U}(\mathbf{1})$ e/ou $\mathbf{V}^{\mathbf{1}} \neq \mathbf{V}(\mathbf{1})$ a hipótese de coeficientes fixos falha e é necessário que se faça um ajuste em todos os coeficientes técnicos através de um fator de correção.

O fator de correção para o ajuste dos totais das linhas de $\mathrm{U}^{1}$ é :

$$
r_{i}=\frac{U_{i}(1)}{U_{i}^{1}}
$$

Matematicamente este ajuste é feito através da expressão:

$$
\mathbf{A}^{1}=\mathbf{R}^{\mathrm{i}} \mathbf{A}(\mathbf{0})
$$

onde:

$\mathbf{R}^{\mathrm{i}}$ é um vetor diagonalizado do i-ésimo ajuste das linhas.

Pode-se escrever então:

$$
\left[\mathbf{R}^{\mathrm{i}} \cdot \mathbf{A}(\mathbf{0}) \hat{\mathbf{X}(\mathbf{1})}\right] \mathbf{i}=\left[\mathbf{A}^{1} \hat{\mathbf{X}(1)}\right] \mathbf{i}=\mathbf{Z}_{\mathbf{i}}^{1} \cdot \mathbf{i}=\mathbf{U}(\mathbf{1})
$$

Após o ajuste das linhas adota-se o mesmo procedimento para o ajuste dos totais das colunas, utilizando-se neste caso o fator

$$
s_{i}=\frac{V_{i}(1)}{V_{i}^{1}}
$$

empregado na expressão: 


$$
\mathbf{A}^{2}=\mathbf{A}^{1} \mathbf{S}^{1}
$$

onde:

$\mathbf{S}^{\mathbf{i}}$ é um vetor diagonalizado do i-ésimo ajuste das colunas.

A expressão 5.12 leva a

$$
i^{\prime}\left[A^{2} \cdot \mathbf{X ( 1 )}\right]=i^{\prime} \cdot Z^{2}=V(1)
$$

A alteração do total das colunas modifica o total das linhas sendo necessário um novo ajuste. $O$ processo de ajustamento vai se repetindo sucessivamente até que se encontre um ponto de convergência.

A solução da técnica justifica o nome RÃS, e é dada pela conjugação das equações 50 e 53 :

$$
\mathbf{A}^{\mathrm{i}+1}=\mathbf{R}^{\mathrm{i}} \cdot \mathbf{A}(0) \cdot \mathbf{S}^{\mathrm{i}}
$$

\subsection{Métodos de análise das relações intersetoriais no modelo inter-regional}

Sabe-se que apenas um pequeno grupo de setores tem real importância econômica, isto é, possui muitas ligações com os demais setores da economia. A identificação destes setores, no modelo formulado, será feita a partir de algumas técnicas de determinação de setores-chaves que possibilitam a análise estrutural da economia.

A verificação do impacto de variações na demanda final dos setores sobre as economias estudadas complementará a análise dos setores-chaves. Isto será feito através do cálculo dos multiplicadores de produção, renda e emprego e importação.

A seguir serão descritas as metodologias empregadas no cálculo dos índices de ligação, campo de influência e multiplicadores. 


\subsection{1 Índices de ligação de Hirschman / Rasmussen}

Existe um fluxo contínuo de produtos entre cada setor da economia. Este fluxo é definido por fatores tecnológicos e econômicos e podem ser descritos por um sistema de equações simultâneas representadas por:

$$
\mathbf{X}=\mathbf{A X}+\mathbf{Y}
$$

onde:

X é um vetor ( $\mathrm{n} \times 1$ ) com o valor da produção total por setor;

Y é um vetor ( $\mathrm{n} \times 1$ ) com os valores da demanda final por setor;

A é uma matriz ( $\mathrm{n} \times \mathrm{n}$ ) dos coeficientes técnicos de produção.

Admitindo que o vetor demanda final é exógeno ao sistema, o vetor produção total será função apenas de $\mathbf{Y}$ :

$$
\mathbf{X}=\mathbf{B Y}
$$

onde:

$B=(1-A)^{-1}$

A partir deste modelo Rasmussen (1956) e Hirschman (1958) definiram os setores da economia com maiores índices de ligações com outros setores. Essas ligações podem ocorrer para trás, indicando o quanto um setor demanda dos outros; e para frente, indicando o quanto este setor é demandado pelos outros setores. Os setores são classificados como setores-chaves para o crescimento da economia quando possuem índices maiores que 1, tanto para frente como para trás (McGilvray, 1977).

A matriz inversa de Leontief, aqui representada pela letra B, permite que sejam estabelecidas definições que serão utilizadas no cálculo dos índices de ligações para frente e para trás. $b_{i j}$ corresponde a um elemento da matriz inversa de Leontief; $\mathbf{B}^{*}$ 
à média de todos os elementos da matriz $\mathbf{B} ; \mathbf{B}_{*_{\mathrm{j}}}$ e $\mathbf{B}_{\mathbf{i}^{\star}}$ são, respectivamente, a soma de uma coluna e de uma linha da matriz B. Assim, pode-se escrever:

Índices de ligações para trás :

$$
\mathbf{U}_{j}=\frac{\left\lfloor\mathbf{B}_{*_{j}} / \mathbf{n}\right\rfloor}{\mathbf{B}^{*}}
$$

Índices de ligações para frente:

$$
\mathbf{U} \mathbf{i}=\frac{\left[\mathbf{B}_{\mathbf{i}^{*}} / \mathbf{n}\right]}{\mathbf{B}^{*}}
$$

\subsubsection{Matriz intensidade}

O objetivo de se construir uma matriz intensidade é a visualização do comportamento da economia para que se estabeleça uma comparação entre os setores produtivos. A matriz intensidade apresenta o que é demandado por um setor e o que este setor demanda dos demais setores além de mostrar como os setores se relacionam com o sistema como um todo. Assim, pode-se defini-la através da expressão:

$$
\begin{aligned}
& \mathbf{M}=\frac{\mathbf{1}}{\mathbf{B}^{*}}\left[\begin{array}{l}
\mathbf{B}_{\mathbf{1}^{*}} \\
\vdots \\
\mathbf{B}_{\mathbf{n}^{*}}
\end{array}\right]\left[\mathbf{B}_{* 1} \cdots \mathbf{B}_{* \mathbf{n}}\right] \\
& {\left[\begin{array}{l}
\mathbf{B}_{1 *} \\
\vdots \\
\mathbf{B}_{\mathrm{n} *}
\end{array}\right] \text { soma ao longo de cada linha (o quanto é demandado pelos outros setores) }} \\
& {\left[\mathbf{B}_{* 1} \cdots \mathbf{B}_{* \mathrm{n}}\right] \text { soma ao longo da coluna (o quanto o setor demanda) }}
\end{aligned}
$$

onde: 


\subsubsection{Campo de influência}

Os índices de Hirschman - Rasmussen avaliam a importância de um setor em termos de seu impacto no sistema econômico como um todo, sem contudo identificar os principais elos de ligação dentro da economia, ou seja, os coeficientes que, ao serem alterados, têm um maior impacto econômico. O campo de influência complementa a noção dos índices de ligações propostos por Hirschman - Rasmussen, pois, segundo Sonis e Hewings (1995), permite conhecer como as mudanças nos coeficientes técnicos se distribuem no sistema como um todo, ou seja, quais as relações entre os setores que teriam maior importância na economia.

Desta forma, o campo de influência pode ser compreendido como uma análise adicional à análise dos índices de ligação. O procedimento para a sua obtenção será descrito a seguir.

Sendo:

$\mathbf{A}=\left|a_{i j}\right|=$ matriz dos coeficientes diretos;

$\mathbf{E}=\left|\varepsilon_{i j}\right|=$ matriz de erro, correspondente à matriz de variações incrementais nos coeficientes diretos de insumo;

$\mathbf{B}=\left|b_{i j}\right|=|\mathbf{I}-\mathbf{A}|^{-1}$ e $\mathbf{B}(\varepsilon)=\left|b_{i j}(\varepsilon)\right|=|\mathbf{I}-\mathbf{A}-\boldsymbol{\varepsilon}|^{-1}$ são as correspondentes matrizes inversas de Leontief.

Admitindo uma variação muito pequena que só ocorra em um coeficiente direto:

$$
\varepsilon_{i j}= \begin{cases}\varepsilon & \mathrm{i}=\mathrm{i}_{1}, \mathrm{j}=\mathrm{j}_{1} \\ 0 & \mathrm{i} \neq \mathrm{i}_{1} \text { ou } \mathrm{j} \neq \mathrm{j}\end{cases}
$$


Se B - B(E) corresponde ao impacto resultante da alteração nos coeficientes diretos, para cada coeficiente tem-se uma matriz de alterações ou matriz do campo de influência do coeficiente $a_{\mathrm{ij}}$ :

$$
F\left(\varepsilon_{i j}\right)=\frac{\left\lfloor B\left(\varepsilon_{i j}\right)-B\right\rfloor}{\varepsilon_{i j}}
$$

$\mathrm{O}$ valor atribuído a cada matriz $\mathbf{F}\left(\varepsilon_{\mathrm{ij}}\right)$ permite que se determine quais os coeficientes que possuem o maior campo de influência. Este valor é definido por:

$$
S_{i j}=\sum_{k=1}^{n} \sum_{l=1}^{n}\left[f_{k l}\left(\varepsilon_{i j}\right)\right]^{2}
$$

Os coeficientes diretos com maiores valores de $S_{i j}$ são aqueles com maior campo de influência na economia como um todo, ou seja, aqueles que produzem maior impacto.

\subsection{4 Índices puros de ligações (enfoque GHS)}

Os índices de ligações sugeridos por Hirschman-Rasmussen apresentam a desvantagem de não considerar os diferentes níveis de produção de cada setor da economia. Quando o objetivo é isolar um dado setor do restante da economia deve-se empregar o conceito de índices puros de ligações.

Os índices puros de ligação são aplicados na análise da importância de um setor na economia além de identificarem o impacto da demanda final de uma região sobre outras regiões. A metodologia empregada no cálculo destes índices puros de ligação é um aprofundamento do modelo de Cella (1984), proposto por Guilhoto, Sonis e Hewings (1996).

O cálculo do índice parte da matriz dos coeficientes técnicos com o objetivo de isolar o setor (ou região) $j$ do resto da economia. Para isso, decompõe-se a matriz dos coeficientes técnicos em: 


$$
\mathbf{A}=\left(\begin{array}{l}
\mathbf{A}_{\mathrm{Jj}} \mathbf{A}_{\mathrm{jr}} \\
\mathbf{A}_{\mathrm{rj}} \mathbf{A}_{\mathrm{rr}}
\end{array}\right)=\left(\begin{array}{l}
\mathbf{A}_{\mathrm{jj}} \mathbf{A}_{\mathrm{jr}} \\
\mathbf{A}_{\mathrm{rj}} \mathbf{0}
\end{array}\right)+\left(\begin{array}{cc}
\mathbf{0} & \mathbf{0} \\
\mathbf{0} & \mathbf{A}_{\mathrm{rr}}
\end{array}\right)=\mathbf{A}_{\mathrm{j}}+\mathbf{A}_{r}
$$

onde:

$\mathbf{A}_{\mathbf{j j}}$ é a matriz de insumos diretos dentro do setor $j$;

$\mathbf{A}_{\text {rj }}$ é a matriz de insumos diretos que o setor $j$ adquire do resto da economia;

$\mathbf{A}_{\mathrm{jr}}$ é a matriz de insumos diretos que o resto da economia adquire do setor $j$;

$\mathbf{A}_{\text {rr }}$ é a matriz de insumos diretos dentro do resto da economia;

$\mathbf{A}_{\mathbf{j}}$ refere-se ao setor $j$ isolado do resto da economia; e,

$\mathbf{A}_{\mathbf{r}}$ representa o restante da economia.

Assim, a inversa de Leontief passa a ser:

$$
\mathbf{B}=(\mathbf{I}-\mathbf{A})^{-1}=\left(\begin{array}{ll}
\mathbf{B}_{\mathrm{jj}} & \mathbf{B}_{\mathrm{jr}} \\
\mathbf{B}_{\mathrm{rj}} & \mathbf{B}_{\mathrm{rr}}
\end{array}\right)=\left(\begin{array}{cc}
\Delta_{\mathrm{jj}} & \mathbf{0} \\
\mathbf{0} & \Delta_{\mathrm{rr}}
\end{array}\right)\left(\begin{array}{cc}
\Delta_{\mathrm{j}} & \mathbf{0} \\
\mathbf{0} & \boldsymbol{\Delta}_{\mathrm{r}}
\end{array}\right)\left(\begin{array}{cc}
\mathbf{I} & \mathbf{A}_{\mathrm{jr}} \boldsymbol{\Delta}_{\mathrm{r}} \\
\mathbf{A}_{\mathrm{rj}} \boldsymbol{\Delta}_{\mathrm{j}} & \mathbf{I}
\end{array}\right)
$$

Onde os elementos da equação acima são definidos como:

$\Delta_{\mathrm{j}}=\left(\mathbf{I}-\mathbf{A}_{\mathrm{jj}}{ }^{-1}\right.$, corresponde à interação do setor $j$ com ele mesmo;

$\Delta_{\mathrm{r}}=\left(\mathbf{I}-\mathbf{A}_{\mathrm{rr}}{ }^{-1}\right.$, corresponde à interação do restante da economia com ele mesmo;

$\Delta_{\mathrm{jj}}=\left(\mathbf{I}-\Delta_{\mathrm{j}} \mathbf{A}_{\mathrm{jr}} \Delta_{\mathrm{r}} \mathbf{A}_{\mathrm{rj}}\right)^{-1}$, corresponde a quanto o setor $j$ tem que produzir para o restante da economia para que ela atenda às suas necessidades; $\mathrm{e}$,

$\Delta_{\mathrm{rr}}=\left(\mathbf{I}-\Delta_{\mathrm{r}} \mathbf{A}_{\mathrm{rj}} \Delta_{\mathrm{j}} \mathbf{A}_{\mathrm{jr}}\right)^{-1}$, corresponde a quanto o restante da economia vai ter que produzir para o setor $\mathrm{j}$ para que ele atenda suas necessidade

Admitindo a equação básica do modelo de Leontief: 


$$
\mathbf{X}=(\mathbf{I}-\mathbf{A})^{-1} \mathbf{Y}
$$

e aplicando à decomposição feita acima, tem-se:

$$
\left[\begin{array}{l}
X_{j} \\
X_{r}
\end{array}\right]=\left[\begin{array}{cc}
\Delta_{j j} & 0 \\
0 & \Delta_{r r}
\end{array}\right] *\left[\begin{array}{cc}
\Delta_{j} & 0 \\
0 & \Delta_{r}
\end{array}\right] *\left[\begin{array}{cc}
I & A_{j r} \Delta_{r} \\
A_{r j} \Delta_{j} & I
\end{array}\right] *\left[\begin{array}{l}
F_{j} \\
F_{r}
\end{array}\right]
$$

Multiplicando os últimos termos do lado direito:

$$
\left[\begin{array}{l}
X_{j} \\
X_{r}
\end{array}\right]=\left[\begin{array}{cc}
\Delta_{j j} & 0 \\
0 & \Delta_{r r}
\end{array}\right]\left[\begin{array}{l}
\Delta_{j} F_{j}+\Delta_{j} A_{j r} \Delta_{r} F_{r} \\
\Delta_{r} A_{r j} \Delta_{j} F_{j}+\Delta_{r} F_{r}
\end{array}\right]
$$

onde $\mathrm{A}_{\mathrm{jr}} \Delta_{\mathrm{r}} \mathrm{F}_{\mathrm{r}}$ é o impacto direto da demanda final do resto da economia sobre o setor $j$, isto é, determina o valor da importação vinda do setor $j$ necessário para a produção do resto da economia, dada a demanda $F_{r}$. Analogamente, $A_{r j} \Delta_{j} F_{j}$ é a importação do resto da economia para que $j$ possa atender sua demanda final. (Ghilhoto, Hewings e Sonis, 1998).

A partir desta expressão tem-se os índices puros de ligação.

O índice puro de ligação para trás é dado por:

$$
\mathrm{PBL}=\Delta_{\mathrm{r}} \mathrm{A}_{\mathrm{rj}} \Delta_{\mathrm{j}} \mathrm{F}_{\mathrm{j}}
$$

e refere-se ao impacto puro da produção do setor $j$ na produção do setor $r$, sem considerar a demanda do setor $j$ por insumos do próprio setor e a demanda do resto da economia por insumos de $j$.

O índice puro de ligação para frente é dado por:

$$
\mathrm{PFL}=\Delta_{\mathrm{j}} \mathrm{A}_{\mathrm{jr}} \Delta_{\mathrm{r}} \mathrm{F}_{\mathrm{r}}
$$


e refere-se ao impacto direto da demanda final do resto da economia sobre a produção do setor $j$.

O índice puro total das ligações (PTL) é:

$$
\mathrm{PTL}=\mathrm{PBL}+\mathrm{PFL}
$$

\subsubsection{Multiplicadores}

Nas análises de insumo-produto os multiplicadores permitem verificar o efeito de políticas públicas sobre diferentes variáveis econômicas. Neste trabalho eles foram empregados para analisar o impacto de variações na demanda final dos setores econômicos do Ceará sobre os níveis de produção, emprego, renda e importações. Desta forma, serão usados os multiplicadores de produção, emprego, renda e importações obtidos conforme descrição de Miller e Blair (1985)

\section{Multiplicador de produção}

O multiplicador de produção permite determinar o impacto de variações na demanda final sobre o volume de produção e representa o valor total da produção necessário para atender uma unidade monetária de demanda final total para a produção do setor $j$. Sua expressão é:

$$
O_{j}=\sum_{i=1}^{n} \alpha_{i j}
$$

onde:

$\alpha_{\mathrm{ij}}$ corresponde aos elementos da matriz inversa de Leontief.

\section{Multiplicador de renda}

O multiplicador de renda permite determinar o impacto de variações na demanda final sobre a renda recebida pelas famílias e representa a renda gerada em 
todos os setores da economia resultante de um aumento de uma unidade monetária de demanda final pelo produto do setor $j$. Sua expressão é:

$$
R_{j}=\sum_{i=1}^{n} r_{n+1, i} \cdot \alpha_{i j}
$$

onde:

$r_{n+1}$ corresponde ao coeficiente de renda.

\section{Multiplicador de emprego}

O multiplicador de emprego permite determinar o impacto de variações na demanda final sobre o produto que por sua vez, provoca alterações no emprego, seguidas de variações na renda e conseqüentemente na demanda do consumidor. Representa o número de empregos gerados em todos os setores da economia resultante de um aumento de uma unidade monetária de demanda final pelo produto do setor $j$. Sua expressão é:

$$
E_{j}=\sum_{i=1}^{n} w_{n+1, i} \alpha_{i j}
$$

$\mathrm{W}_{\mathrm{n}+1}$ é o coeficiente de trabalho físico por unidade monetária produzida.

\section{Multiplicador de importações}

O multiplicador de importações permite analisar choques na demanda final e seus impactos sobre as importações de um sistema econômico. Seu valor representa o aumento nas importações de todos os setores da economia resultante de um aumento de uma unidade monetária de demanda final do setor $j$. Sua expressão é:

$$
I_{j}=\sum_{i=1}^{n} \beta_{n+1, i} \cdot \alpha_{i j}
$$


onde:

$\beta_{n+1}$ é um elemento da linha correspondente ao coeficiente de importações

\subsection{Incorporação da água e energia elétrica à matriz de insumo-produto do Ceará}

\subsubsection{Modelo utilizado}

Um dos objetivos deste estudo é a verificação do comportamento dos setores cearenses frente ao consumo de água e energia. Para que esta análise seja possível devese considerar as inter-relações entre setores e fatores água e energia elétrica, ou seja, deve-se associar a utilização da água e da energia elétrica ao modelo tradicional de insumo-produto.

O modelo proposto neste trabalho pretende incorporar a água e a energia à matriz de insumo-produto do Ceará conforme proposto por Miller e Blair (1985).

Esta metodologia enfoca estes dois recursos como participantes de um sistema produtivo e amplia o modelo tradicional descrito no capítulo 3 pela inclusão de duas linhas referentes aos insumos água e energia elétrica. O Quadro 10 apresenta uma economia com três setores produtivos onde incorpora-se os insumos água e energia elétrica. 


\begin{tabular}{|c|c|c|c|c|c|c|}
\hline & Consu & mo inte & mediário & \multirow[b]{3}{*}{$\begin{array}{l}\text { Demanda } \\
\text { final }\end{array}$} & \multirow[b]{3}{*}{$\begin{array}{l}\text { Produção } \\
\text { Total }\end{array}$} \\
\hline & & \multicolumn{3}{|c|}{ Setores consumidores } & & \\
\hline & & $\begin{array}{c}\text { Setor } \\
1\end{array}$ & $\begin{array}{c}\text { Setor } \\
2\end{array}$ & Setor 3 & & \\
\hline \multirow{3}{*}{$\begin{array}{l}\text { Setores } \\
\text { produtores }\end{array}$} & Setor 1 & \multirow[t]{2}{*}{$\mathrm{Z}_{11}$} & $Z_{12}$ & \multirow[t]{2}{*}{$\mathrm{Z}_{13}$} & $\mathrm{Y}_{1}$ & \multirow[t]{2}{*}{$\mathrm{Z}_{1}$} \\
\hline & Setor 2 & & $Z_{22}$ & & \multirow[t]{2}{*}{$Y_{2}$} & \\
\hline & Setor 3 & $\mathrm{Z}_{31}$ & $Z_{32}$ & $\mathrm{Z}_{33}$ & & $\mathrm{Z}_{2}$ \\
\hline \multicolumn{2}{|c|}{ Insumo água } & $\mathrm{D}_{\mathrm{w} 1}$ & $\mathrm{D}_{\mathrm{w} 2}$ & $\mathrm{D}_{\mathrm{w} 3}$ & $\mathrm{Y}_{\mathrm{w}}$ & $\mathrm{D}$ \\
\hline \multicolumn{2}{|c|}{$\begin{array}{l}\text { Insumo energia } \\
\text { elétrica }\end{array}$} & $\mathrm{E}_{\mathrm{g} 1}$ & $\mathrm{E}_{\mathrm{g} 2}$ & $E_{g} 3$ & $\mathrm{Y}_{\mathrm{g}}$ & $\mathrm{E}$ \\
\hline
\end{tabular}

Quadro 9 - Modelo insumo-produto após a incorporação dos insumos água e energia elétrica.

Fonte: Adaptado de Miller \& Blair (1985)

Conforme a teoria básica dos modelos de insumo-produto, a descrição matemática do quadro 9 é feita através das seguintes equações:

$$
\begin{aligned}
& Z_{1}=z_{11}+Z_{12}+z_{13}+Y_{1} \\
& Z_{2}=z_{21}+z_{22}+z_{23}+Y_{2} \\
& Z_{3}=z_{31}+z_{32}+Z_{33}+Y_{3} \\
& D=d_{w 1}+d_{w 2}+d_{w 3}+Y_{w} \\
& E=e_{g 1}+\mathbf{e}_{g 2}+\mathbf{e}_{g 3}+Y_{g}
\end{aligned}
$$

onde: 
$\mathbf{Z}_{\mathrm{i}}$ é o total de produção do setor $i$;

$z_{i j}$ é o fluxo monetário entre os setores $i \mathrm{e} j$;

$\mathbf{Y}_{\mathrm{i}}$ é a demanda final do setor $i$;

D é o consumo total de água;

$d_{w j}$ é o consumo de água do setor $j$ no seu processo produtivo;

$\mathbf{Y}_{\mathbf{w}}$ é a demanda de água por parte das famílias;

E é o consumo total de energia elétrica;

$e_{g j}$ é o consumo de energia elétrica do setor $j$ no seu processo produtivo;

$\mathbf{Y}_{\mathrm{g}}$ é a demanda de energia elétrica por parte das famílias;

Fazendo-se:

$$
\begin{aligned}
& a_{i j}=\frac{z_{i j}}{Z_{j}} \Rightarrow z_{i j}=a_{i j} \cdot Z_{j} \\
& w_{j}=\frac{d_{w j}}{Z_{j}} \Rightarrow d_{w j}=w_{j} \cdot Z_{j} \\
& g_{j}=\frac{e_{g j}}{Z_{j}} \Rightarrow e_{g j}=g_{j} \cdot Z_{j}
\end{aligned}
$$

onde:

$a_{i j}$ é o coeficiente técnico de insumo direto;

$\mathrm{w}_{j}$ é o coeficiente técnico direto da água ou o quanto o setor $j$ utiliza de água por unidade produzida; 
$\mathrm{g}_{j}$ é o coeficiente técnico direto de energia elétrica ou o quanto o setor $j$ utiliza de energia elétrica por unidade produzida;

Substituindo-se $z_{i j}$, $d_{w j}$ e $e_{g j}$ nas equações (67) tem-se:

$$
\begin{aligned}
& Z_{1}=a_{11} Z_{1}+a_{12} Z_{2}+a_{13} Z_{3}+Y_{1} \\
& Z_{2}=a_{21} Z_{1}+a_{22} Z_{2}+a_{23} Z_{3}+Y_{2} \\
& Z_{3}=a_{31} Z_{1}+a_{32} Z_{2}+a_{33} Z_{3}+Y_{3} \\
& D=w_{1} Z_{1}+w_{2} Z_{2}+w_{3} Z_{3}+Y_{w} \\
& E=g_{1} Z_{1}+g_{2} Z_{2}+g_{3} Z_{3}+Y_{g}
\end{aligned}
$$

ou, de forma abreviada:

$$
\begin{aligned}
& \mathbf{Z} \mathbf{i}=\sum_{j=1}^{3} \mathbf{a}_{i j} Z_{j}+Y_{j} \\
& \mathbf{D}=\sum_{j=1}^{3} \mathbf{w}_{j} Z_{j}+Y_{w} \\
& \mathbf{E}=\sum_{j=1}^{3} \mathbf{g}_{j} \mathbf{Z}_{j}+Y_{g}
\end{aligned}
$$

O conjunto de equações acima pode ser escrito na forma matricial:

$$
\begin{aligned}
& Z=A Z+Y=(I-A)^{-1} Y \\
& D=W Z+Y_{w} \\
& E=G Z+Y_{g}
\end{aligned}
$$

Substituindo-se o valor de Z em 72 e 73 :

$$
\mathbf{D}=\mathbf{W}(\mathbf{I}-\mathbf{A})^{-1} \mathbf{Y}+\mathbf{y}_{\mathbf{w}}
$$




$$
\mathbf{E}=\mathbf{G}(\mathrm{I}-\mathrm{A})^{-\mathbf{1}} \mathbf{Y}+\mathbf{y}_{\mathbf{g}}
$$

Onde:

$\mathbf{Z}$ é a matriz de consumo intermediário tradicional;

A é a matriz de coeficientes técnicos diretos dos insumos;

Y é o vetor de demanda final;

D é a matriz de consumo intermediário da água, na qual cada elemento $d_{w j}$ especifica a quantidade de água usada na produção total do setor $j$;

W é a matriz de coeficientes técnicos diretos da água, na qual cada elemento $w_{k j}$ corresponde à quantidade de água necessária à produção de uma unidade monetária pelo setor $j$.

$\mathbf{W}(\mathbf{I}-\mathbf{A})^{-1}$ é a matriz de coeficientes técnicos diretos e indiretos da água ou matriz de requerimentos diretos e indiretos. Cada elemento desta matriz reflete o quanto o setor $j$ necessita, direta e indiretamente, do insumo água, para satisfazer a uma demanda de uma unidade monetária

A soma das suas linhas fornece o total de consumo da água por setor para atender às mudanças na sua demanda final, ou seja, o quanto cada setor irá requerer de água, de si próprio e dos demais setores da economia.

E é a matriz de consumo intermediário da energia elétrica, na qual cada elemento $e_{w j}$ especifica a quantidade de energia elétrica usada na produção total do setor $j$.

G é a matriz de coeficientes técnicos diretos da energia elétrica, na qual cada elemento $g_{k j}$ corresponde à quantidade de energia elétrica necessária à produção de uma unidade monetária pelo setor $j$.

$\mathbf{G}(\mathbf{I}-\mathbf{A})^{-1}$ é a matriz de coeficientes técnicos diretos e indiretos da energia elétrica ou matriz de requerimentos diretos e indiretos. Cada elemento desta matriz reflete o quanto 
o setor $j$ necessita, direta e indiretamente, do insumo energia elétrica, para satisfazer a uma demanda de uma unidade monetária

As relações apresentadas acima permitem entender a importância destes recursos (insumos) no processo produtivo de cada setor. Uma outra característica das matrizes apresentadas é o fornecimento de informações referentes à compreensão das proporções em que os insumos água e energia elétrica deverão ser ofertados no caso de uma expansão na atividade econômica da região em estudo.

\subsubsection{Construção dos vetores de água e energia elétrica}

\section{Consumo de água}

A distribuição de água no Estado do Ceará é feita basicamente pela Companhia de Água e Esgoto do Estado do Ceará (CAGECE), responsável pela água tratada, e pela Companhia de Gestão dos Recursos Hídricos do Estado do Ceará (COGERH), distribuidora da água bruta (não tratada). Assim, estas duas companhias foram a fonte primária dos dados utilizados neste trabalho. É oportuno ressaltar, no entanto, que a precariedade de dados e informações sistemáticas referentes ao uso da água pelos diferentes setores da economia cearense foram um entrave na construção do vetor de consumo da água e um fator limitante para o aprofundamento da análise proposta.

A seguir será descrita a operacionalização das informações obtidas sobre o consumo de água dos setores econômicos analisados neste estudo, para o ano de 1999. Estas informações são expressas $\mathrm{em}^{3}$.

O setor agropecuária divide-se em atividades ligadas à pecuária e à agricultura, e consome essencialmente água bruta. O consumo de água pela pecuária foi calculado conforme proposto por Vieira (2000), através da transformação dos efetivos pecuários em uma unidade hipotética proposta pelo Plano Integrado de Recursos Hídricos do Nordeste (PLIRHINE) denominada BEDA -bovinos equivalentes por 
demanda de água. Essa unidade agrega bovinos, eqüinos, asininos, ovinos, caprinos e suínos e pondera o que cada espécie consome de água em relação ao rebanho bovino:

$B E D A=\sum$ bovino $+\sum$ equino $+\sum$ asinino $+\frac{\sum \text { ovino }+\sum \text { caprino }}{5}+\frac{\sum \text { suino }}{4}$

Para o cálculo do consumo de água aplicou-se o coeficiente de demanda de água dos bovinos adotado pelo PLIRHINE: 50 1/cab/dia. Os efetivos pecuários foram obtidos do Censo Agropecuário de 1999, publicado pelo IBGE.

A demanda de água na irrigação depende de fatores como distribuição anual das chuvas, temperatura, umidade relativa do ar, insolação, tipo de solo, cultura, calendário agrícola e método de irrigação. Este grande número de fatores envolvidos no cálculo da demanda gera uma série de dificuldades no seu cálculo. Além disso, a falta de informações disponíveis quanto ao uso da água nas bacias hidrográficas cearenses fez com que neste trabalho fosse adotado como ponto de partida para o cálculo da demanda de água na agricultura, os coeficientes de consumo de água de diferentes culturas, estimados pelo Plano Diretor para o Desenvolvimento do Vale do São Francisco - PLANVASF apresentados no Quadro 11, e o número de hectares irrigados por cultura, fornecido pela Secretaria de Agricultura Irrigada do Ceará- Seagri. 


\begin{tabular}{|c|c|c|}
\hline CULTURAS & CONSUMO DE ÁGUA $\left(\mathrm{m}^{3} / \mathrm{ha}\right)^{44}$ & DEMANDA DE ÁGUA (m³/ha) \\
\hline Algodão & 5.208 & 7.440 \\
\hline Alho & 4.870 & 6.957 \\
\hline Arroz & 19.862 & 28.374 \\
\hline Batata & 6.176 & 8.823 \\
\hline Cebola & 5.348 & 7.640 \\
\hline Feijão & 4.573 & 6.533 \\
\hline Fruticultura & 9.679 & 13.827 \\
\hline Hortaliças & 10.288 & 14.697 \\
\hline Melancia & 11.729 & 16.756 \\
\hline Melão & 11.896 & 16.994 \\
\hline Milho & 6.057 & 8.653 \\
\hline Soja & 2.824 & 4.034 \\
\hline Tomate & 5.900 & 8.429 \\
\hline Trigo & 3.640 & 5.200 \\
\hline Uva & 10.624 & 15.177 \\
\hline
\end{tabular}

Quadro 11 - Coeficientes de consumo de água para diferentes culturas em um ano.

Fonte: PLANVASF (1989)

Os dados referentes ao consumo de água das indústrias foram obtidos diretamente da CAGECE e da COGERH, uma vez que uma parcela muito pequena de indústrias apresenta sistemas independentes de captação e tratamento de água.

Segundo dados do IPLANCE, o Ceará apresentou um total de 11000 indústrias no ano de 1999. Devido à inexistência de informações sobre o consumo de

\footnotetext{
${ }^{44}$ O PLANVASF afirma que $30 \%$ deste volume retorna à calha do rio. Assim, o consumo efetivo de água corresponde a $70 \%$ da demanda para a irrigação.
} 
água de todas as indústrias, adotou-se estimativas a partir da agregação dos dados obtidos por setor ${ }^{45}$.

O setor serviços teve o consumo de água calculado a partir de dados coletados junto à CAGECE, sendo adotada a mesma lógica empregada na indústria.

\section{Consumo de energia elétrica}

Diferente do que ocorre com o consumo de água, existe um grande número de informações referentes à utilização da energia elétrica no Ceará. Diante disto, o vetor de consumo de energia elétrica apresenta informações bem mais confiáveis e consistentes, informações estas, obtidas junto à Companhia Energética do Ceará, Coelce e expressas em MWh.

A aplicação das técnicas descritas até aqui permitiu a obtenção dos resultados que serão apresentados e discutidos no próximo capítulo.

\footnotetext{
45 - Apesar de não existirem informaçôes quanto ao consumo de água de todas as indústrias cearenses, os dados fornecidos pela CAGECE e pela COGERH incluem o consumo das indústrias mais importantes do Estado, sendo desta forma, representativos.
} 


\section{RESULTADOS E DISCUSSÃO}

O presente capítulo tem como objetivo identificar as relações intersetoriais e a influência das demandas finais sobre a produção no modelo inter-regional para as regiões Ceará, resto do Nordeste e resto do Brasil ano 1999, apresentado no Anexo B. Os resultados discutidos aqui foram obtidos a partir da aplicação da teoria de insumo-produto conforme descrita no capítulo 5 .

Os instrumentos escolhidos para à análise da estrutura produtiva do modelo foram: índices de ligação Hirschman-Rasmussen, campo de influência, matriz de intensidade e índices puros de ligação. A influência das demandas finais sobre a produção foi observada através do modelo GHS.

Os modelos inter-regionais permitem que sejam calculados índices de ligação de Hirschman-Rasmussen ou índices puros através de dois procedimentos. No primeiro, cada economia regional é analisada de forma isolada, sem considerar os efeitos inter-regionais sofridos pela mesma, ou seja, como se não houvesse qualquer tipo de relação com as demais regiões. Neste caso o cálculo é feito a partir da matriz inversa de Leontief de cada região e os índices obtidos são classificados como índices independentes. $O$ segundo procedimento considera os elos entre todas as regiões de tal modo que os índices trazem embutidos os efeitos inter-regionais e são obtidos a partir da matriz inversa de Leontief para o modelo total. Os índices obtidos desta forma são classificados como índices dependentes. 
Os resultados obtidos através dos dois procedimentos são muito parecidos e a escolha de um ou de outro não interfere na importância dos setores. Porém na determinação dos impactos deve-se considerar o sistema global. Diante disto, neste estudo, para análise estrutural de cada região isoladamente, optou-se pelo emprego dos índices independentes. Porém, os índices dependentes podem ser encontrados no Anexo C. Na identificação dos impactos da demanda final os resultados referem-se ao sistema como um todo.

\section{1 Índices de ligação de Hirschman- Rasmussen}

Conforme exposto no capítulo 4, os índices de ligação de HirschmanRasmussen permitem traçar o perfil da economia de uma ou mais regiões, identificando as relações de compra e venda entre seus setores. Quanto maior o índice de ligação para trás, maior a interação do setor com os setores vendedores de insumos, da mesma forma, quanto maior o índice de ligação para frente, maior a interação do setor com os setores compradores de insumos.

Existem dois critérios básicos para determinação dos setores-chave de uma economia a partir dos índices de ligação de Hirschman-Rasmussen. O primeiro, proposto por Hirschman-Rasmussen, classifica como setores-chave aqueles que apresentam pelo menos um dos índices de ligação, para frente ou para trás, acima de 1 . O segundo critério, proposto por McGilvray (1977), é mais restritivoque o anterior e admite um setor como setor-chave, se este apresentar ambos os índices de ligação, para frente e para trás, simultaneamente maiores que 1 .

Os índices de ligação de Hirschman-Rasmussen calculados neste estudo serão apresentados da seguinte forma: inicialmente será feita a análise dos índices independentes para cada região separadamente e a identificação dos setores-chave. Em seguida será feita a mesma análise, sendo que, aplicada ao sistema inter-regional como um todo. 
A Tabela 21 mostra os índices de ligação Hirschman-Rasmussen, para frente e para trás, para cada regiãodo sistema inter-regional: Ceará, Resto do Nordeste e Resto do Brasil.

$\mathrm{Na}$ ordenação dos índices para trás pode-se observar que os cinco setores com ligações mais fortes no Ceará são: Siderurgia (4), Têxtil (15), Vestuário (16), S.I.U.P (20) e Comunicação (24). Neste mesmo contexto, os menos expressivos são: Fabricação de eletrônicos (7), Extrativa mineral (2), Comércio (22), Agropecuária (1) e Indústrias diversas (19).

O destaque do setor Têxtil (15) como o de maior interação com os setores vendedores de insumos, comprova a importância que este setor vem adquirindo na economia estadual nos últimos anos. Quanto ao setor S.I.U.P. (20), a baixa industrialização do Estado pode ser uma explicação para o seu destaque. No resto do Brasil, onde há uma maior concentração de indústrias, este setor ocupa a vigésima primeira posição no "ranking" dos índices de ligação para trás, prevalecendo os setores pertencentes à indústria de transformação.

Na Região Resto do Nordeste destacam-se como setores mais interligados: Siderurgia (4), Fab. de material elétrico (6), Química (12), Têxtil (15) e Indústrias alimentares (18).

Quando a análise recai sobre o Resto do Brasil constata-se que os setores com maior capacidade de interação são: Indústrias alimentares (18), Siderurgia (4), Têxtil (15), Fab. de material elétrico (6) e Vestuário (16).

Comparando-se o comportamento dos setores nas três regiões podem ser observadas algumas características: os setores Siderurgia (4) e Têxtil (15) apresentaram boa capacidade de interação com os setores fornecedores de insumos nas três regiões podendo assim ser classificados como estimuladores da atividade econômica. Por outro lado, os setores menos interativos: Fabricação 
de Eletrônicos (7) e Extrativa mineral (2) no Ceará e Resto do Nordeste, regiões onde a atuação destes setores é quase inexistente, e Comunicação (24) e Outros Serviços (26) no Resto do Brasil.

Ainda na Tabela 21 a análise dos índices de ligação para frente mostra que o Ceará é ainda menos dinâmico quando a análise recai sobre a sua capacidade de interagir sob a ótica da oferta de produtos. Apenas seis setores caracterizam-se como bons vendedores de produtos para os demais setores: Outros serviços (26), Têxtil (15), Comércio (22), S.I.U.P. (20), Siderurgia (4) e Agropecuária (1) ${ }^{47}$.

O Resto do Nordeste apresenta nove setores importantes na oferta de produtos: Comércio (22), Química (12), Siderurgia (4), Agropecuária (1), S.I.U.P. (20), Outros serviços (26) Minerais não metálicos (2), e Papel e gráfica (10) e Têxtil (15).

Quanto ao Resto do Brasil também foram identificados nove setores importantes: Química (12), Siderurgia (4), Comércio (22), Outros serviços (26), Agropecuária (1), Têxtil (15), S.I.U.P. (20), Transportes (23) e Papel e gráfica $(10)$.

${ }^{47}$ O setor agropecuário tem um comportamento instável como fornecedor de produtos no Ceará. O seu bom desempenho em 1999 deve-se às condições climáticas favoráveis verificadas neste ano. 


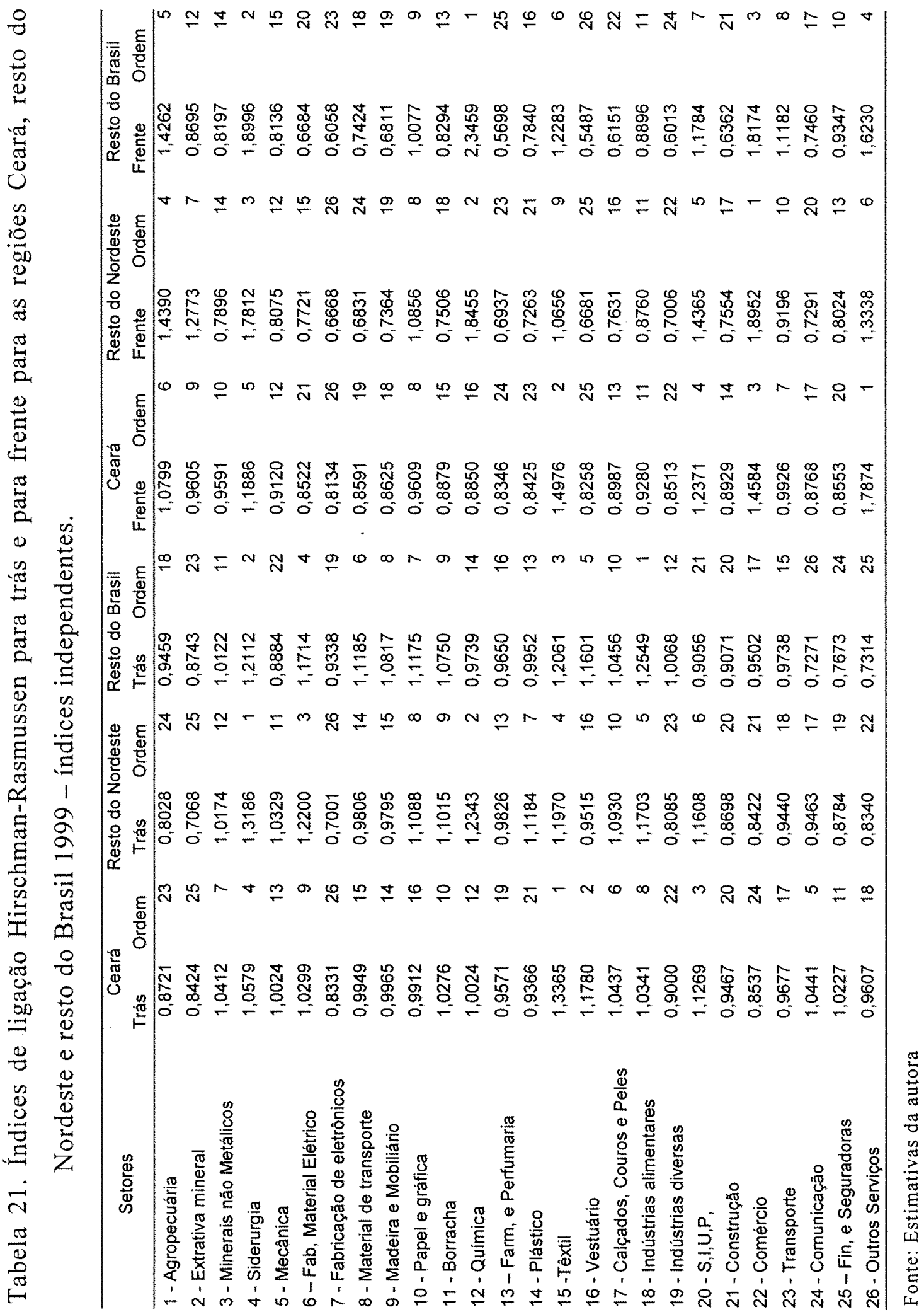


Uma comparação entre as três regiões através das Figuras 14 a 16 permite conjeturar que as economias do Resto do Nordeste e Resto do Brasil são as mais parecidas do ponto de vista estrutural. ${ }^{48} \mathrm{O}$ Ceará apresenta-se como uma economia pouco aquecida sem a presença de setores influentes na demanda e oferta de produtos, com os menores índices de ligação para frente e para trás em relação às demais regiões. As três regiões possuem ligações para trás mais fortes que as ligações para frente na maioria dos setores, o que demonstra uma maior dinamização dos setores na demanda por insumos. Porém é importante ressaltar a existência de picos para frente em alguns setores isolados como Têxtil (15), Comércio (22) e Outros serviços (26) no Ceará, Agropecuária (1), Siderurgia (4), Química (12), S.I.U.P (20) e Comércio (22) no Resto do Nordeste e no Resto do Brasil.

${ }^{48}$ Os índices utilizados neste estudo são normalizados, isto é, independem das unidades de medidas. Diante disto pode-se fazer uma comparação entre as estruturas internas de cada região do sistema interregional analisando seus encadeamentos. 


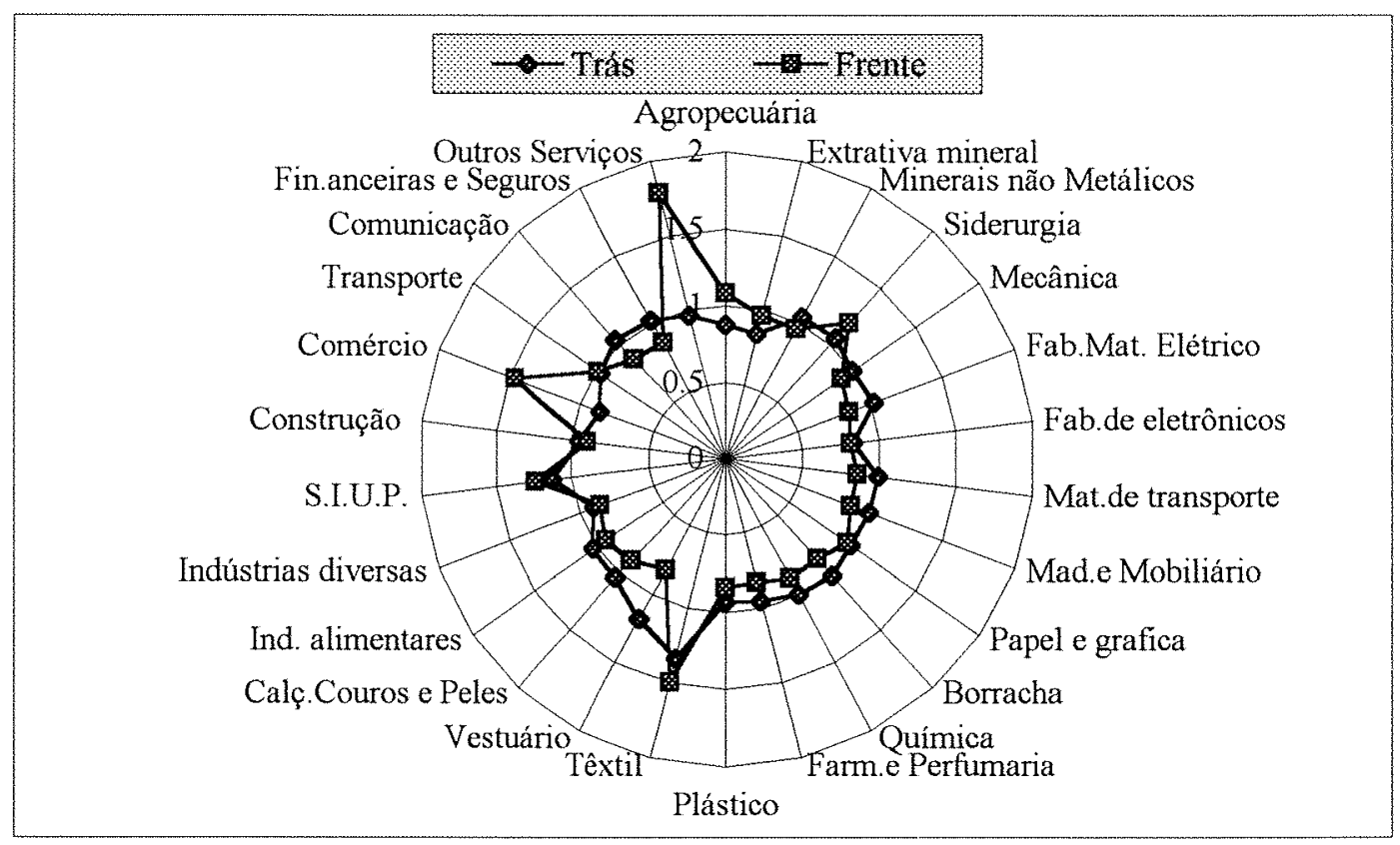

Figura 14 - Ligações para trás e para frente de Hirschman-Rasmussen para o Ceará no sistema inter-regional.

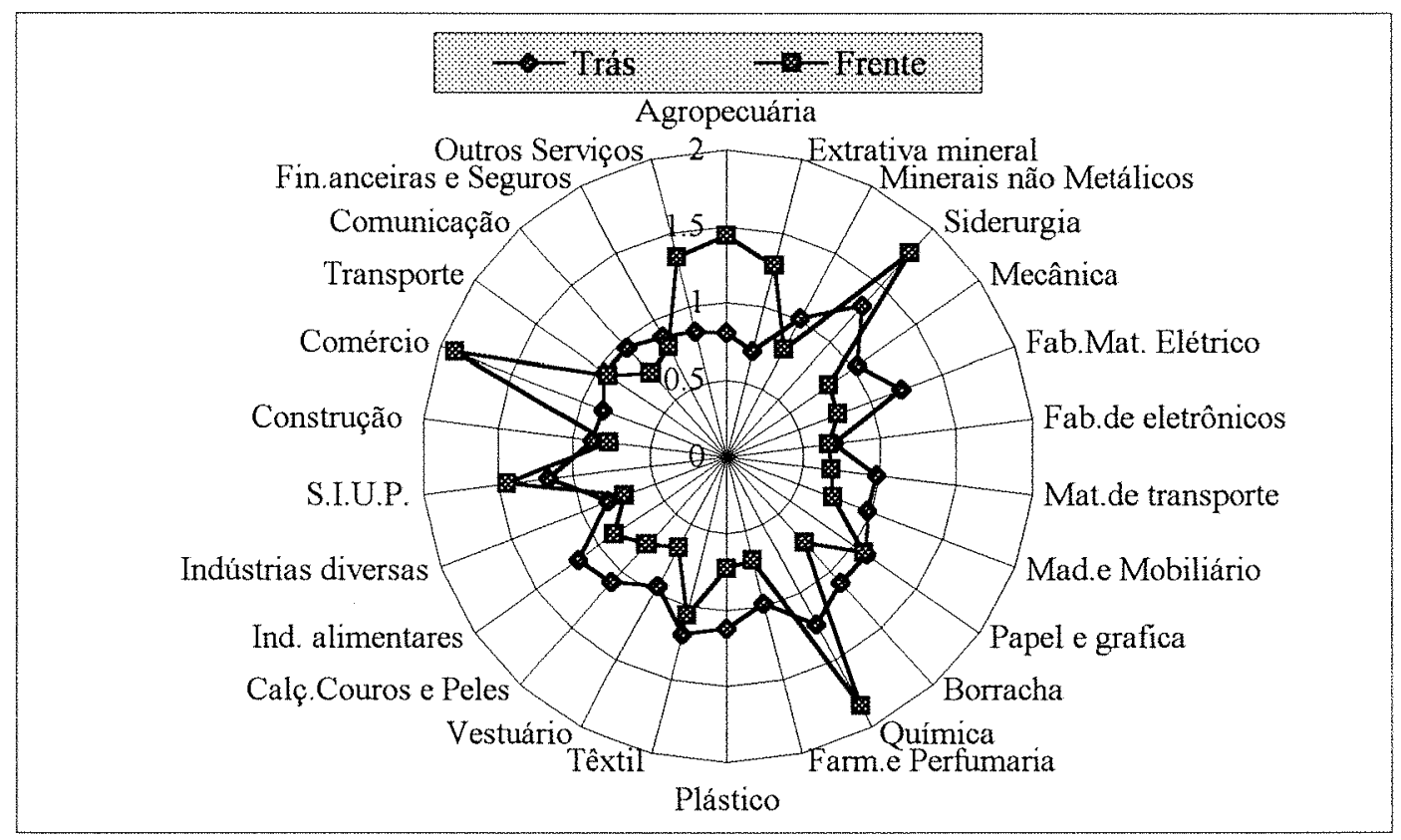

Figura 15 - Ligações para trás e para frente de Hirschman-Rasmussen para o resto do Nordeste no sistema inter-regional. 


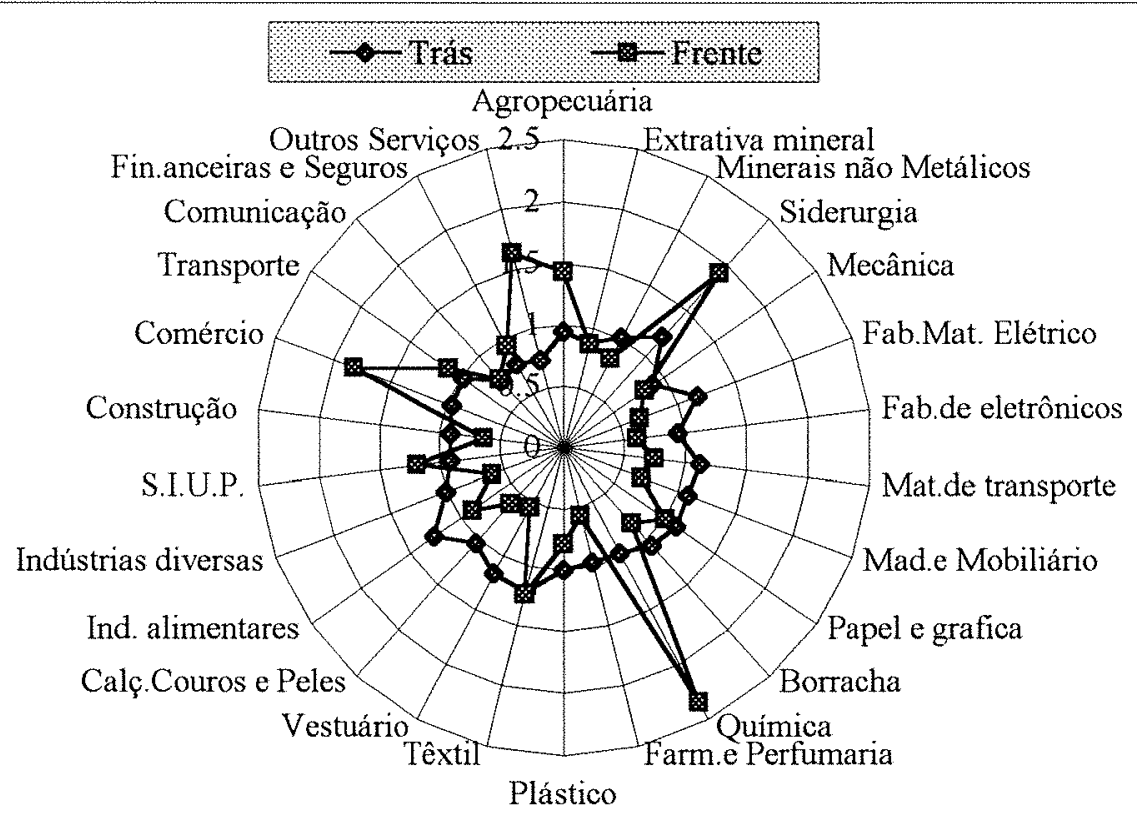

Figura 16 - Ligações para trás e para frente de Hirschman-Rasmussen para o resto do Brasil no sistema inter-regional.

Através da análise de cada região separadamente, sob o critério de McGilvray, observa-se a existência de três setores-chave na economia cearense no ano de 1999: Siderurgia (4), Têxtil (15) e S.I.U.P. (20). No resto do Nordeste destacam-se: Siderurgia (4), Papel e gráfica (10), Química (12), Têxtil (15) e S.I.U.P. (20) e no resto do Brasil: Siderurgia (4), Papel e gráfica (10) e Têxtil (15).

Aplicando um critério mais abrangente onde o setor-chave é aquele que apresenta pelo menos um dos índices com valor maior que 1 , tem-se como resultado: Ceará com vinte setores-chave (treze com ligações para trás e sete com ligações para frente), resto do Nordeste com vinte e um (doze com ligações para trás e nove com ligações para frente) e o resto do Brasil com vinte e um setores-chave (doze com ligações para trás e nove com ligações para frente). 
O segmento serviços no Ceará e resto do Nordeste apresenta-se como um setor-chave na análise dos índices de ligação para trás. Os setores Siderurgia (4) e Têxtil (15) comportam-se como setores-chave nas três economias com índices de ligação para frente e para trás maiores que 1. Este dois setores foram favorecidos pela desvalorização do real no início do ano de 1999.

A Tabela 22 apresenta os índices de ligação para trás e para frente, considerando o sistema inter-regional como uma única região.

Considerando os dez maiores índices de ligação para trás, quatro deles pertencem ao Resto do Nordeste: Siderurgia (4), Farm. e perfumaria (13), Têxtil (15) e Calçados, couros e peles (17), quatro encontram-se no Ceará: Siderurgia (4), Farm. e perfumaria (13), Têxtil (15) e Calçados, couros e peles (17), e dois no Resto do Brasil: Têxtil (15) e Indústrias alimentares (19).

Considerando as ligações para frente, os setores mais dinâmicos do ponto de vista da oferta são Química (12) e Siderurgia (4), Comércio (22), Outros serviços (26), Agropecuária (1) e Têxtil(15) no Resto do Brasil, Química (12), Comércio (22), e Siderurgia (4) e Agropecuária (1) no resto do Nordeste.

Os setores da economia cearense apresentaram pouca expressividade no sistema econômico analisado, com um padrão médio de ligações para frente correspondendo a 0,6841 . Isto aponta para a pequena expressividade dos setores desta região como indutores de crescimento no país, porém, esta pequena expressividade é reflexo também, do tamanho da economia cearense em relação às demais regiões.

A Figura 17 sintetiza o comportamento médio dos índices de ligação Hirschman-Rasmussen para trás e para frente no sistema inter-regional. 


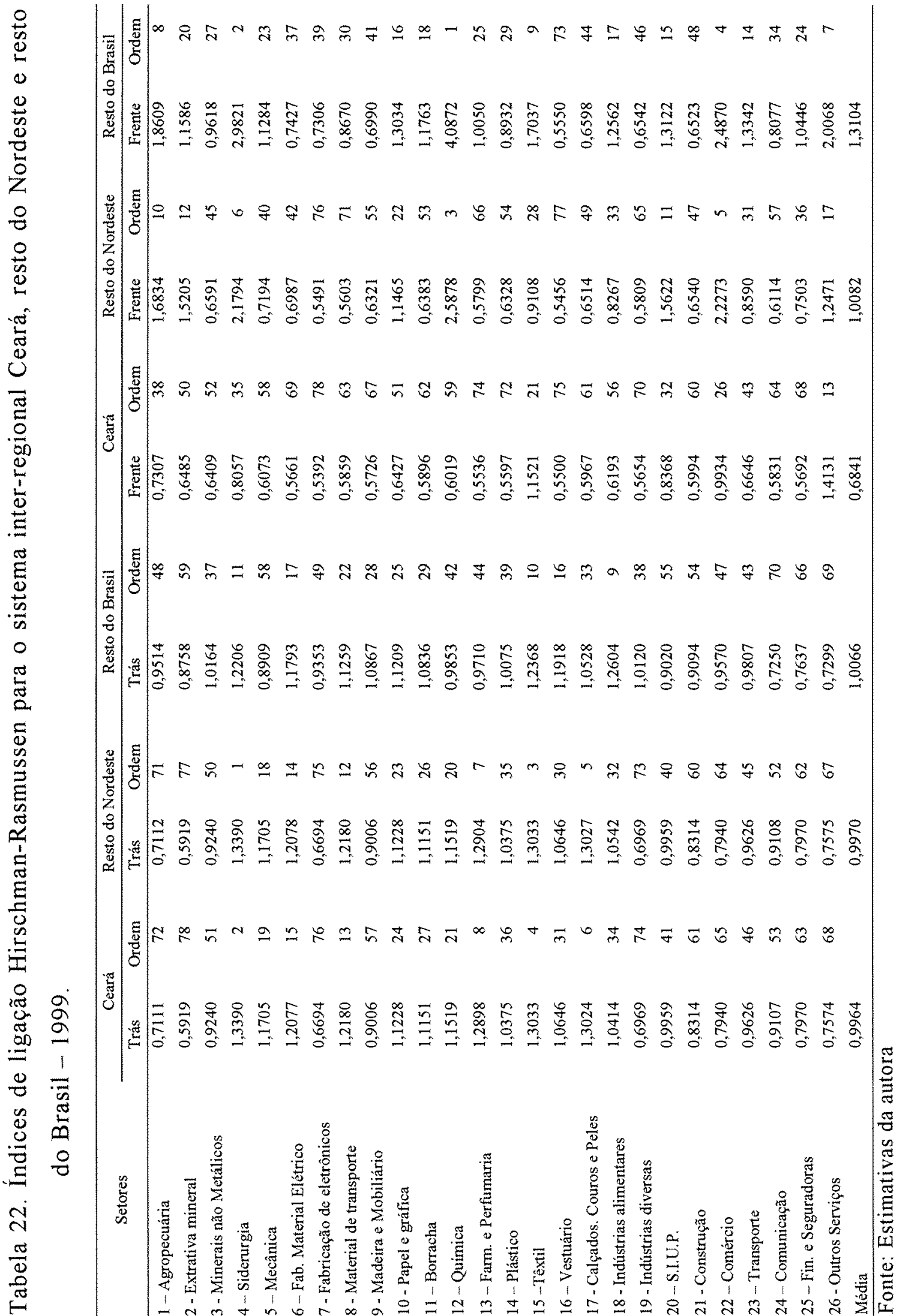




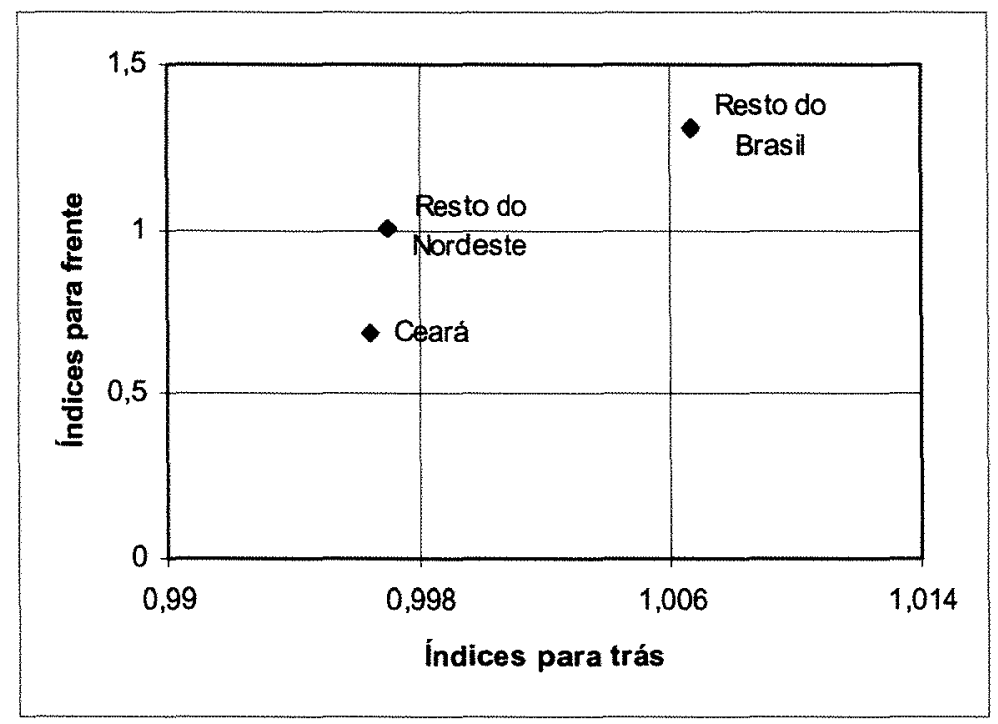

Figura 17 - Padrões médios de comportamento dos índices de ligação de Hirschman-Rasmussen para o sistema inter-regional.

Algumas observações podem ser feitas a partir da comparação entre as economias das três regiões:

a) o Resto do Brasil apresenta uma economia mais articulada, com maiores índices de ligação para frente e para trás em relação à média das Regiões Resto do Nordeste e Ceará.

b) o Ceará apresenta os menores índices de ligação para trás e para frente, 0,9964 e 0,6841 respectivamente. Este baixo padrão de ligações é justificado pela fase de consolidação da economia, principalmente do setor industrial, que ainda está ocorrendo no Estado e sugere que políticas estaduais de desenvolvimento devam estimular a demanda por insumos intermediários e favorecer os setores com maiores poderes de ligação para trás, como: Siderurgia (4), Têxtil (15) e Vestuário (16), uma vez que estes são 
mais propensos a induzir o crescimento da região. Porém, a heterogeneidade inter-setorial não é desprezível.

c) O padrão médio das ligações para trás das Regiões Resto do Nordeste e Ceará é muito próximo demonstrando a semelhança da estrutura das duas Regiões no que se refere à interação de seus setores com os fornecedores de insumos.

A identificação dos setores-chave do sistema inter-regional ocorreu a partir da definição de McGilvray (1977). Sob este critério o sistema interregional apresentou dez setores-chave: Siderurgia (4), Papel e gráfica (10), Borracha (11), Têxtil (15), Indústrias alimentares (19) e Outros serviços (26) no Resto do Brasil, Siderurgia (4), Papel e gráfica (10) e Química (12) no Resto do Nordeste e Têxtil (15) no Ceará. Uma seleção menos rígida dos setores-chave, onde pelo menos um dos índices de ligação ( para frente ou para trás) é maior que 1, identificou sessenta e quatro setores-chaves distribuídos da seguinte forma: quinze setores chaves no Ceará (treze com ligações para trás e dois com ligações para frente), vinte e um no Resto do Nordeste (treze com ligações para trás e oito com ligações para frente), e 28 no Resto do Brasil (treze com ligações para trás e quinze com ligações para frente).

Os resultados obtidos através dos índices de ligação de HirschmanRasmussen permitem duas considerações a respeito do sistema inter-regional Ceará, Resto do Nordeste e Resto do Brasil:

a) Sob o aspecto dos índices de ligações paras trás, o sistema mostrou-se uma economia articulada e diversificada, onde a demanda por insumos está bem distribuída entre as três regiões

b) interação entre os setores ofertantes de produtos ocorre principalmente nas Regiões Resto do Nordeste e Resto do Brasil, as quais concentram 
respectivamente, oito e quinze setores com índices de ligação para frente maiores que a média.

\subsection{Matriz de Intensidade}

A matriz de intensidade é um instrumento utilizado nas análises de insumoproduto com o objetivo de comparar as estruturas econômicas de diferentes regiões ou de uma mesma região em períodos distintos, tendo como base uma matriz padrão.

Neste estudo optou-se pela matriz do Resto do Brasil para servir de base para a comparação, por se tratar por se tratar da região mais desenvolvida do sistema interregional. A sua estrutura está retratada na Figura 18 onde as linhas representam a hierarquia das ligações para frente e as colunas a hierarquia das ligações para trás. Como podem ser observados, os cruzamentos das ligações para frente e para trás dos setores Química (12) e Indústrias alimentares (18), Química (12) e Têxtil (15) representam os picos da hierarquia da estrutura econômica do Resto do Brasil. O setor Química é responsável pelas maiores elevações da matriz apresentando ligações para frente com quase todos os setores, excetuando-se Comunicações (24), Financeiras e seguros (25) e Outros serviços (26). Seguindo a hierarquia da matriz de intensidade surgem os setores Siderurgia (4) e Comércio (22) com fortes cruzamentos no sistema.

Além do setor Química (12), merecem destaque as ligações para frente dos setores Siderurgia (4), Comércio (22), Outros serviços (26) e Agropecuária (1) com as ligações para trás dos demais setores. A partir destas ligações os cruzamentos vão diminuindo sua importância. 


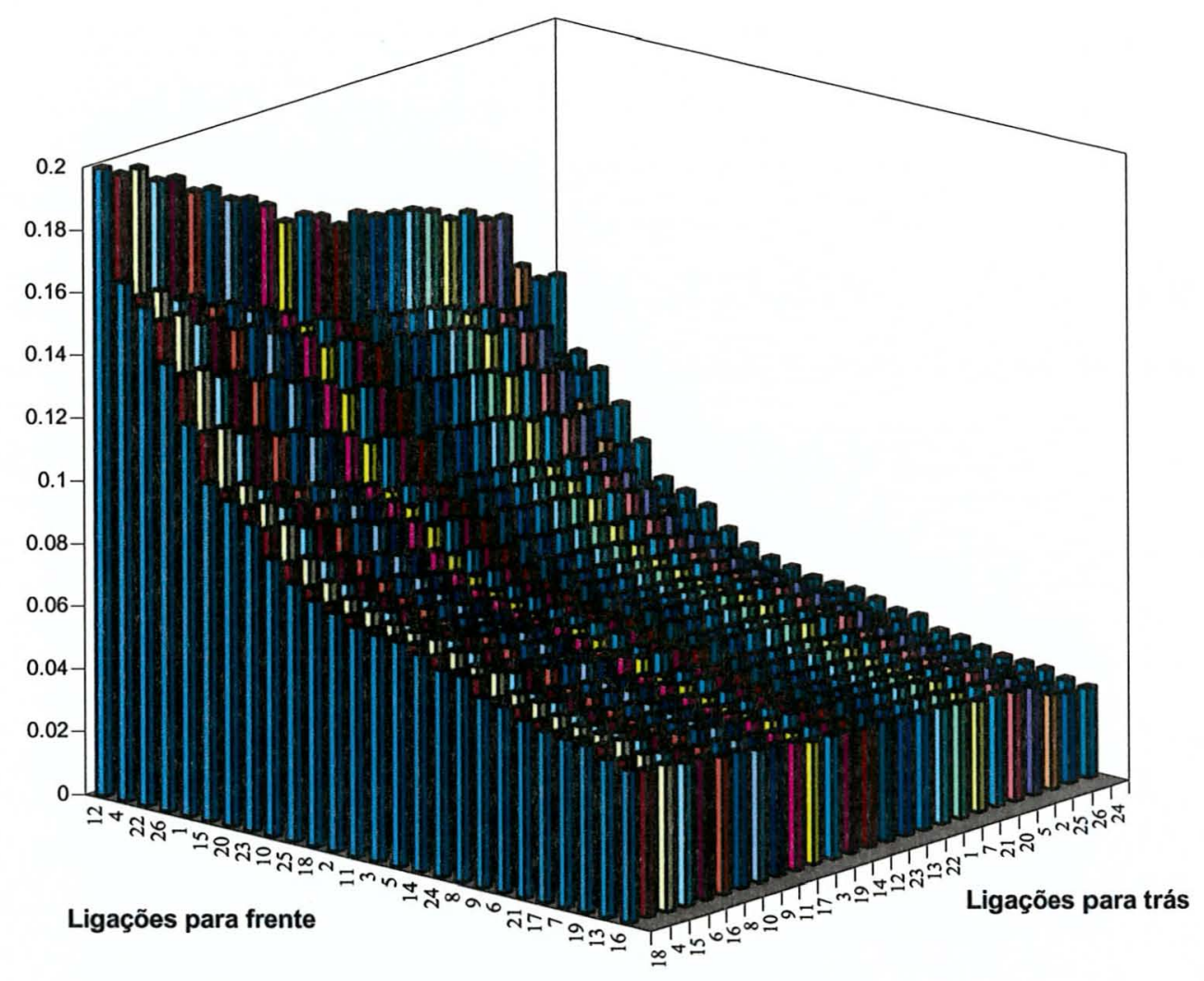

Figura 18 - Matriz de intensidade do resto do Brasil.

A matriz de intensidade do Resto do Nordeste, ordenada conforme a hierarquização do Resto do Brasil está representada na Figura 19. Vê-se claramente as diferenças entre as duas regiões. Os principais cruzamentos desta região envolvem as ligações para frente do setor Siderurgia (4) com ele mesmo, com Comércio (22) e Química (12) Os setores Extrativa mineral (2), Mecânica (5), Farm. e perfumaria (13), Calçados, couros e peles (17), S.I.U.P (20), Construção (21) e Comunicações (24) apresentam ligações mais fortes nesta região que no Resto do Brasil. 


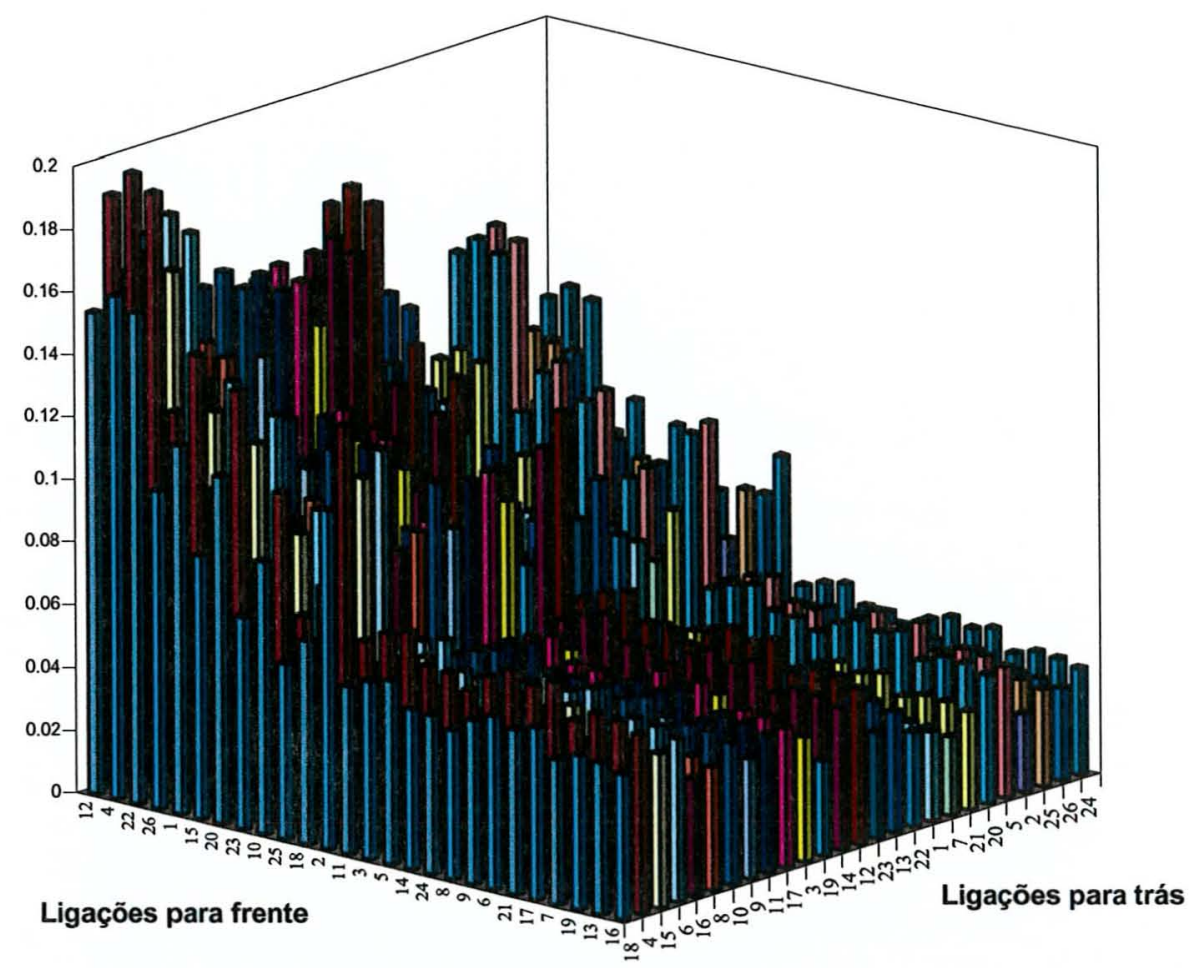

Figura 19 - Matriz de intensidade do resto do Nordeste usando a hierarquia do resto do Brasil.

A estrutura econômica do Ceará está representada na Figura 20. Nesta região, os cruzamentos mais elevados ocorrem entre as ligações para trás do setor Outros serviços (26) com os setores Têxtil (15), S.I.U.P. (20), Vestuário (16), Comunicações (24) e Fin. e seguros (25). A topografia da economia cearense apresenta as ligações mais fracas do sistema inter-regional. 


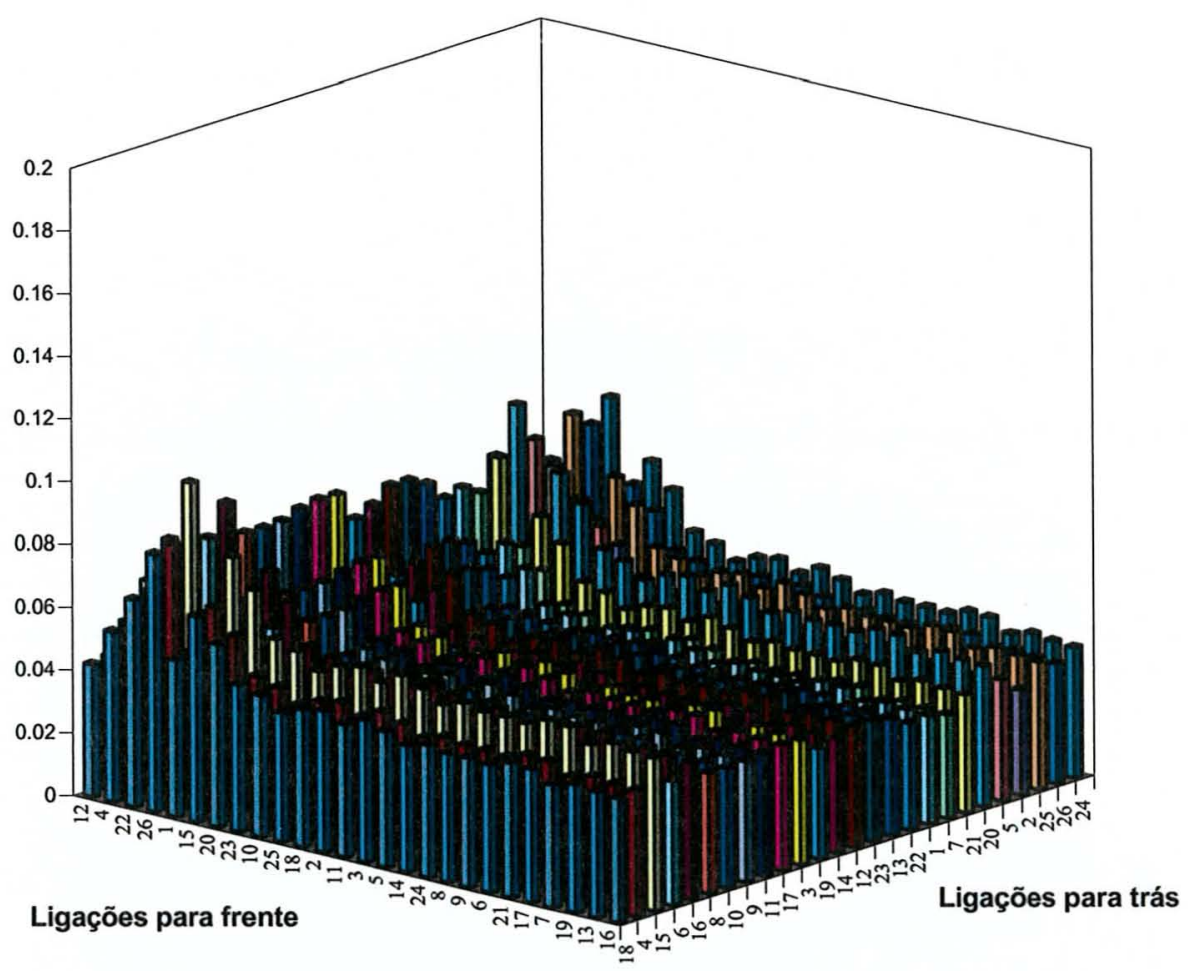

Figura 20 - Matriz de intensidade do Ceará usando a hierarquia do resto do Brasil .

Pelo comportamento das estruturas apresentadas pode-se constatar diferenças significativas entre as três regiões. No Resto do Brasil os setores mais interligados pertencem à indústria [Siderurgia (4) e Química (12)]. No Resto do Nordeste observa-se um padrão mais forte nas ligações dos setores relacionados aos serviços. O Ceará apresenta uma estrutura menos interligada, com exceção do setor Têxtil (15). Assim como no Resto do Nordeste os cruzamentos mais fortes ocorrem nos setores relacionados ao segmento serviços. 


\subsection{Campo de Influência}

O campo de influência, conforme já discutido, é uma análise complementar aos índices de ligação de Hirschman-Rasmussen, pois permite a visualização dos principais elos existentes na economia e a identificação de quais setores apresentam as relações mais importantes no processo produtivo.

O cálculo do campo de influência permite encontrar os coeficientes setoriais de uma região que provocam maiores impactos na economia ao sofrerem pequenas variações. Neste trabalho foi considerada uma variação $\varepsilon=0,001$ na matriz de coeficientes técnicos do sistema inter-regional. A Figura 21 apresenta os duzentos coeficientes técnicos com maior campo de influência.

Os coeficientes selecionados indicam que os principais elos de ligação do sistema inter-regional ocorrem nos setores de Siderurgia (4) do Resto do Nordeste e Resto do Brasil, sendo estes setores os que podem causar maior impacto na economia como um todo, caso haja mudanças na sua produção. Como exemplo da sua importância, no Resto do Brasil a Siderurgia movimenta treze setores no Ceará, dezenove no Resto do Nordeste e vinte na sua região através de suas compras, e dois setores no Ceará, seis no Resto do Nordeste e dez no Resto do Brasil através de suas vendas. Tradicionalmente este setor é responsável pela geração e difusão de tecnologia para o resto da economia.

É válido ressaltar ainda a importância dos setores Papel e gráfica (10), Química (12), Têxtil (15) e S.I.U.P. (20) no Resto do Nordeste e Resto do Brasil que, assim como na análise dos índices de ligação de HirschmanRasmussen, apresentam-se bastante integrados na economia. 
Ceará Resto do Nordeste Resto do Brasil

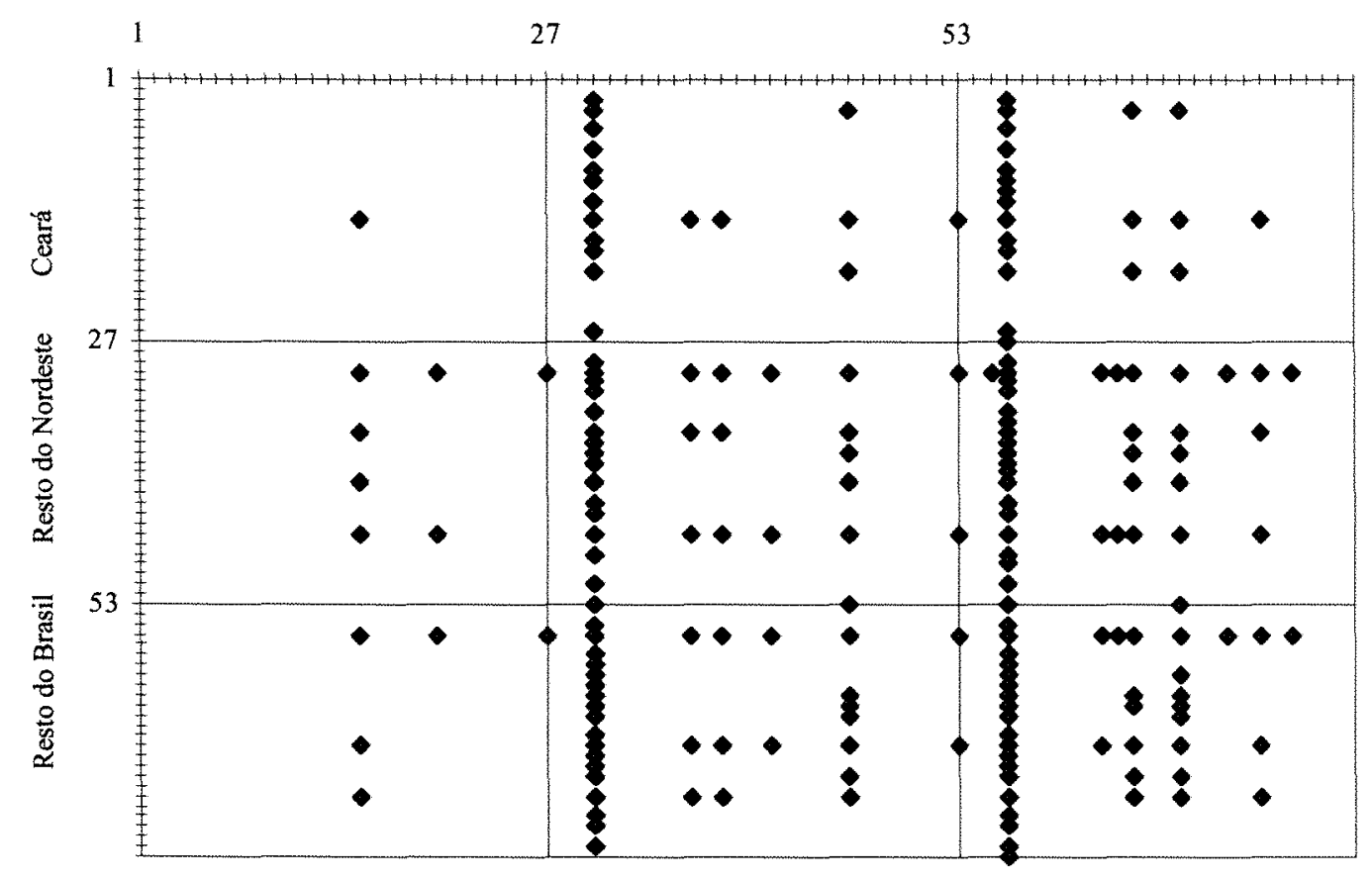

Figura 21 - Coeficientes setoriais com maior campo de influência no sistema inter-regional: Ceará, resto do Nordeste e resto do Brasil.

O Ceará apresenta-se como uma região sem elos de ligação fortes sob os aspectos intra e inter-regionais. $O$ único destaque da região cabe ao setor Têxtil, que aciona os setores Siderurgia (4), Papel e Gráfica (10), Têxtil (15) e S.I.U.P (20) do Resto do Nordeste e Siderurgia (4), Têxtil (15) e S.I.U.P (20) do Resto do Brasil, como comprador de insumos e é acionado pelo por ele mesmo no Ceará, por Siderurgia (4), Papel e Gráfica (10), Química (12) e S.I.U.P (20) no Resto do Nordeste e Agropecuária (1), Siderurgia (4), Química (12), Têxtil (15) e S.I.U.P (20) do Resto do Brasil como vendedor de insumos.

Concluindo a análise do campo de influência tem-se que as Regiões Resto do Nordeste e Resto do Brasil apresentam-se como as regiões mais 
dinâmicas, com fortes elos de ligações intra e inter-regionais. Os setores do Ceará comprovaram a sua irrelevância no conjunto de ligações interindustrias do sistema estudado.

Uma das críticas sofridas pelas análises dos índices de ligação de Hirschman-Rasmussen e do campo de influência é que estas consideram apenas a estrutura interna da economia na identificação dos setores-chave sem considerar, no entanto, o volume de transações.Visando superar esta limitação, na próxima seção será feita a análise dos índices puros de ligação conforme proposto por Guilhoto at al. (1996).

\section{4 Índices Puros de Ligação}

Os índices puros de ligação, conforme Guilhoto et al.(1996), medem a importância econômica de um setor, em termos de valor da produção gerado por esse setor. Os índices puros de ligação para frente apontam o impacto puro da produção total de todos os outros setores da economia sobre um determinado setor e os índices puros de ligação para trás apontam o impacto da produção total de um setor sobre o restante da economia. O índice puro de ligação total mostra os setores mais dinâmicos da economia.

Os índices puros de ligação apresentam a vantagem, em relação aos índices de Hirschman-Rasmussen, de classificar os setores-chave considerando, não apenas as suas ligações com outros setores, como também a sua produção total.

Os resultados dos cálculos dos índices puros totais para cada economia individualmente foram normalizados e estão apresentados na Tabela 23. Foram considerados setores-chave aqueles cujos valores foram superiores a 1. 
Assim, a Região Ceará destacou-se com nove setores-chave: Agropecuária (1), Minerais não metálicos (3), Têxtil (15), Indústrias alimentares (18), Construção (21), Comércio (22), Transporte (23) e Outros serviços (26).

No Resto do Nordeste os setores com maior volume de transações foram: Agropecuária (1), Extrativa mineral (2), Química (12), Indústrias alimentares (18), Construção (21), Comércio (22), Transporte (23) e Outros serviços (26).

O Resto do Brasil apresentou oito setores-chave: Agropecuária (1), Siderurgia (4), Química (12), Indústrias alimentares (18), Construção (21), Comércio (22), Transporte (23) e Outros serviços (26).

Pode-se observar ainda, que os setores Agropecuária (1), Indústrias alimentares (18), Construção (21), Comércio (22), Transporte (23) e Outros serviços (26) desempenham papel importante dentro de cada uma das regiões estudadas e que o setor Química (12) se destaca nas Regiões Resto do nordeste e Resto do Brasil. 
Tabela 23. Índices puros totais nas regiões do sistema inter-regional - Índices independentes e normalizados.

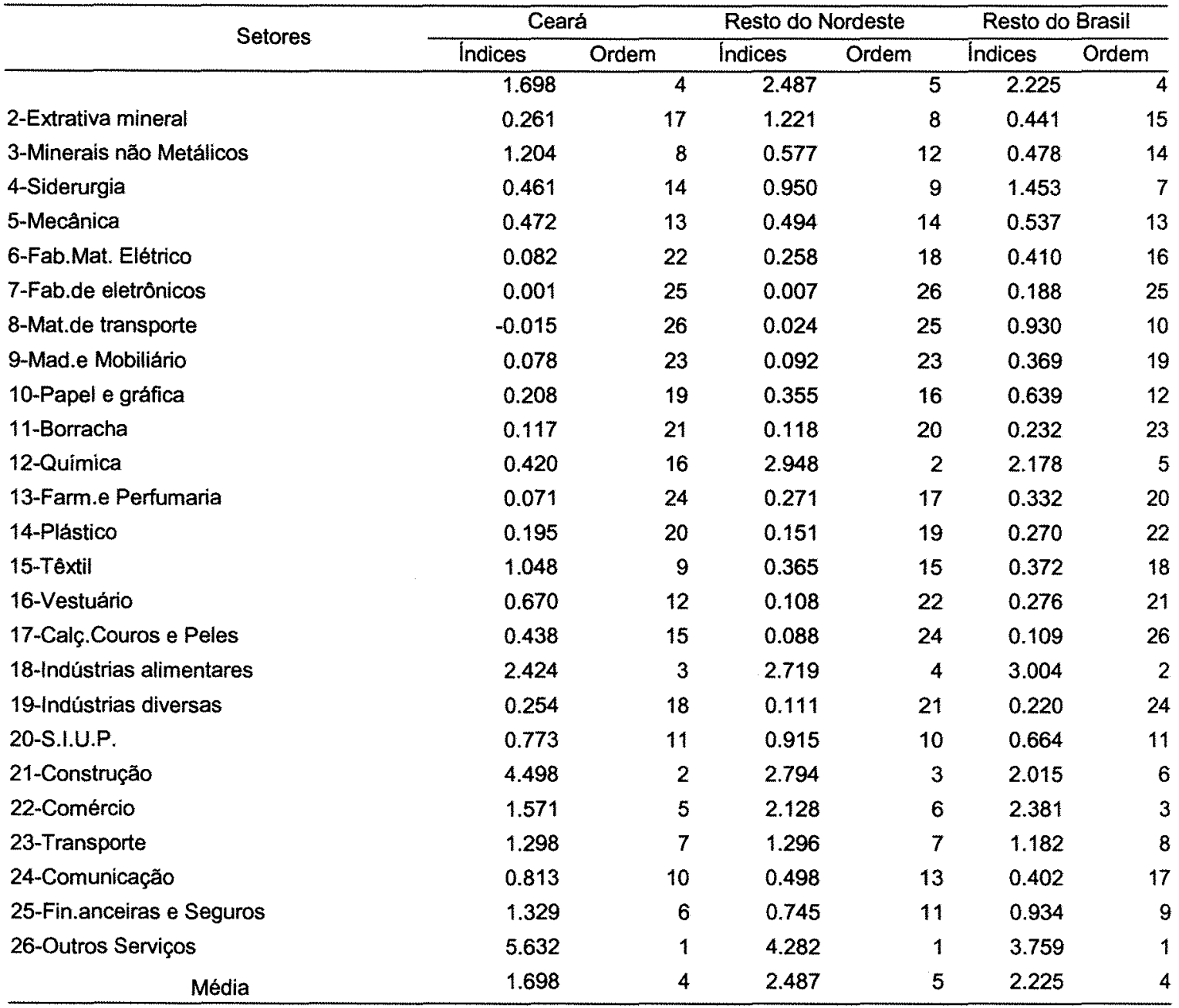

Fonte: Estimativas da autora

A seguir será feita a análise dos índices puros de ligação nacionais considerando o sistema inter-regional como uma única região. Tabela 24.

Considerando-se os índices puros para trás observa-se que os setores do Ceará não apresentam uma interação significativa no que se refere a compra de produtos de outros setores. Os seus índices são os menores do sistema. Isto demonstra que mudanças na produção dos setores cearenses são quase imperceptíveis para os setores das demais regiões. 
O setor Outros serviços (26) da região Resto do Nordeste encontra-se na nona posição no "ranking" do sistema e é o único setor que merece destaque na região como bom comprador de produtos.

Os valores negativos em alguns setores das Regiões Ceará e Resto do Nordeste podem ser explicados pelos elevados valores da componente variação de estoque, na demanda final destas Regiões. Estes valores elevados correspondem a uma espécie de penalização pelo consumo de insumos, devido a uma baixa produção setorial no ano em estudo, de estoques produtivos acumulados em anos anteriores. 


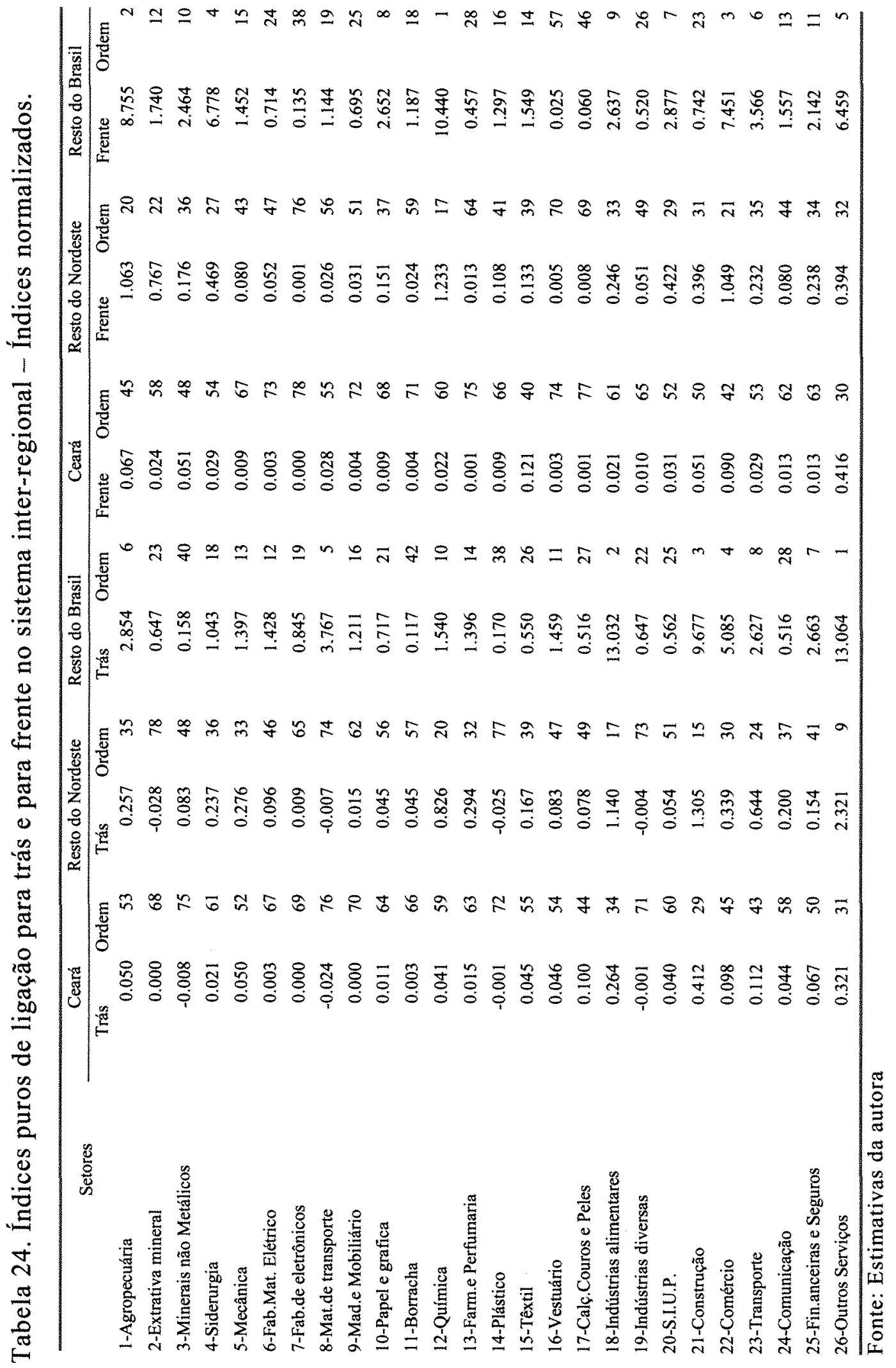


O Resto do Brasil apresenta-se como a região com maior número de setores cujos valores da produção provocam impacto sobre a produção de outros setores, isto é, setores com altos índices puros para trás. Destacam-se nesta região os oito setores com maiores índices puros para trás no sistema: Outros serviços (26), Produtos alimentares (18), Construção (21), Comércio (22), Material de transporte (8), Agropecuária (1), Financeiras e seguros (25) e Transportes (23).

Os setores mencionados acima devem receber um tratamento especial ao serem adotadas políticas de incentivos, uma vez que possuem a habilidade de interagir e estimular outros setores.

Analisando-se agora os índices puros para frente torna-se mais evidente, até mesmo pelo próprio tamanho da região, a importância do Resto do Brasil na economia do sistema inter-regional no que se refere às ligações comerciais com outros setores do sistema. Dos 78 setores listados, os dezesseis mais importantes na venda de produtos para outros setores, ou seja, os dezesseis maiores índices de ligação para frente encontram-se nesta região. Entre eles se sobressaem: Química (12), Agropecuária (1), Comércio (22), Siderurgia (4) e Outros serviços (26).

A escolha dos setores-chave utilizando-se os índices puros de ligação usa como critério único a existência de um valor do índice puro total maior que a média da região. A Tabela 25 e a Figuras 22 permitem a comparação dos índices setoriais de cada região com seu respectivo índice médio (barra vermelha) no sistema inter-regional. 
Tabela 25 - Índices puros totais no sistema inter-regional - Normalizados.

\begin{tabular}{|c|c|c|c|c|c|c|}
\hline \multirow{2}{*}{ Setores } & \multirow{2}{*}{$\frac{\text { Ceará }}{\text { Ind, Puro total }}$} & & \multicolumn{2}{|c|}{ Resto do Nordeste } & \multicolumn{2}{|c|}{ Resto do Brasil } \\
\hline & & Ordem I & nd, Puro total & Ordem & Ind, Puro total & Ordem \\
\hline 1-Agropecuária & 0.058 & 51 & 0.659 & 28 & 5.798 & $\overline{5}$ \\
\hline 2-Extrativa mineral & 0.012 & 67 & 0.369 & 33 & 1.192 & 16 \\
\hline 3-Minerais não Metálicos & 0.022 & 66 & 0.130 & 45 & 1.308 & 15 \\
\hline 4-Siderurgia & 0.025 & 62 & 0.353 & 35 & 3.904 & 7 \\
\hline 5-Mecânica & 0.030 & 60 & 0.178 & 40 & 1.424 & 13 \\
\hline 6-Fab.Mat. Elétrico & 0.003 & 75 & 0.074 & 49 & 1.072 & 17 \\
\hline 7-Fab.de eletrônicos & 0.000 & 78 & 0.005 & 71 & 0.491 & 31 \\
\hline 8-Mat.de transporte & 0.002 & 76 & 0.009 & 69 & 2.459 & 9 \\
\hline 9-Mad.e Mobiliário & 0.002 & 77 & 0.023 & 65 & 0.954 & 21 \\
\hline 10-Papel e gráfica & 0.010 & 68 & 0.098 & 46 & 1.682 & 12 \\
\hline 11-Borracha & 0.004 & 74 & 0.034 & 58 & 0.651 & 29 \\
\hline 12-Química & 0.032 & 59 & 1.029 & 20 & 5.980 & 4 \\
\hline 13-Farm.e Perfumaria & 0.008 & 70 & 0.154 & 41 & 0.928 & 22 \\
\hline 14-Plástico & 0.004 & 73 & 0.041 & 55 & 0.732 & 25 \\
\hline 15-Têxtil & 0.083 & 48 & 0.150 & 42 & 1.049 & 18 \\
\hline 16-Vestuário & 0.025 & 63 & 0.044 & 53 & 0.743 & 24 \\
\hline 17-Calç.Couros e Peles & 0.051 & 52 & 0.043 & 54 & 0.289 & 36 \\
\hline 18-Indústrias alimentares & 0.143 & 43 & 0.694 & 26 & 7.847 & 2 \\
\hline 19-Indústrias diversas & 0.005 & 72 & 0.024 & 64 & 0.584 & 30 \\
\hline 20-S.I.U.P. & 0.035 & 57 & 0.238 & 37 & 1.717 & 11 \\
\hline 21-Construção & 0.232 & 38 & 0.851 & 23 & 5.220 & 6 \\
\hline 22-Comércio & 0.094 & 47 & 0.693 & 27 & 6.265 & 3 \\
\hline 23-Transporte & 0.071 & 50 & 0.438 & 32 & 3.095 & 8 \\
\hline 24-Comunicação & 0.028 & 61 & 0.140 & 44 & 1.035 & 19 \\
\hline 25-Fin.anceiras e Seguros & 0.040 & 56 & 0.196 & 39 & 2.403 & 10 \\
\hline 26-Outros Serviços & 0.368 & 34 & 1.360 & 14 & 9.769 & 1 \\
\hline Média & 0.053 & & 0.309 & & 2.638 & \\
\hline
\end{tabular}

Fonte: Estimativas da autora

O Ceará apresenta sete setores-chave (barras verdes): Agropecuária (1), Têxtil (15), Indústrias alimentares (18) Construção (setor 21), Comércio (22), Transporte (23) e Outros serviços (setor 27). 

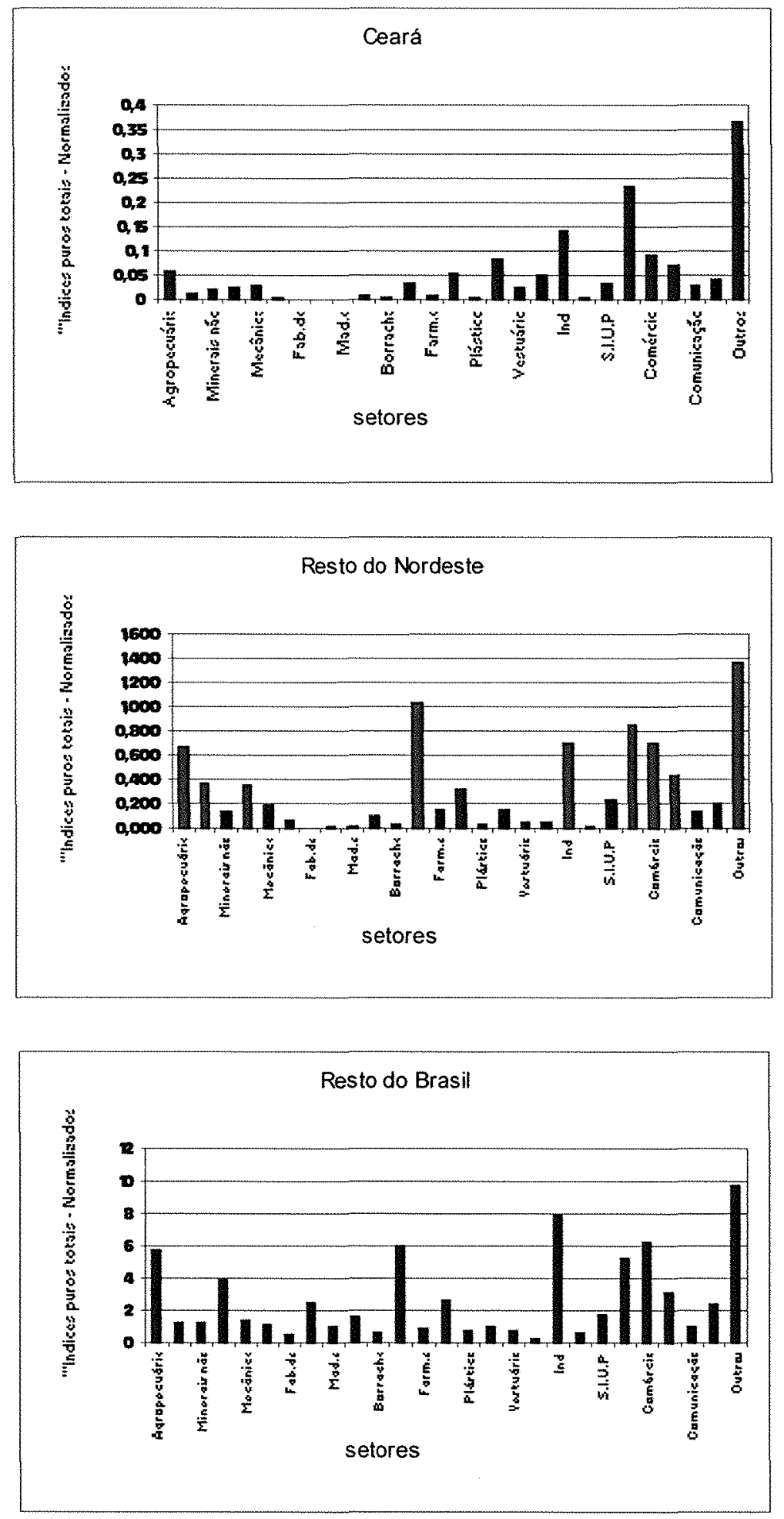

Figura 22 - Índice puro total das regiões Ceará, resto do Nordeste e resto do Brasil no sistema inter-regional - Normalizado. 
O resto do Nordeste apresenta nove setores-chave: Agropecuária (1), Extrativa mineral (2), Siderurgia (4), Química (12), Indústrias alimentares (18), Construção (21), Comércio (22), Transporte (23) e Outros serviços (26).

O resto do Brasil apresenta oito setores-chave: Agropecuária (1), Siderurgia (4), Química (12), Indústrias alimentares (18), Construção (21), Comércio (22), Transportes (23) e Outros serviços (26).

Agropecuária (1), Indústrias alimentares (18), Construção (21), Comércio (22), Transportes (23) e Outros serviços (26) aparecem como setoreschave nas três regiões estudadas, conforme aconteceu na análise dos índices de ligação de Hirschman-Rasmussen.

Os índices puros de ligação nos permitem, ainda, verificar qual a importância de uma região na economia como um todo. Através da Tabela 26 pode-se analisar os índices puros de ligação regionais. A interpretação desta tabela pode ser feita da seguinte forma: a coluna dos índices puros para trás mostra o quanto a economia da região na respectiva linha gera de produção nas demais economias do sistema para atender a sua demanda final; a coluna dos índices puros para frente mostra o quanto a economia da região na respectiva linha produz, para atender à demanda final das demais regiões; finalmente, a coluna dos índices puros totais mostra o volume total de produção envolvido nas transações realizadas na economia da região na respectiva linha para atender à demanda final total do sistema.

Deste modo, o Ceará gera 8,81 bilhões de reais de produção no Resto do Nordeste e Resto do Brasil para atender a sua demanda final. Por outro lado, produz 4,28 bilhões de reais para atender à demanda destas duas regiões. Assim, o volume total de produção resultante das transações cearenses corresponde a 13,09 bilhões de reais. 
Tabela 26. Índices puros de ligação regionais ( $\mathrm{R} \$ 1000,00$ correntes de 1999).

\begin{tabular}{lccccc}
\hline Regiões & $\begin{array}{c}\text { Indice puro } \\
\text { para trás }\end{array}$ & $\begin{array}{c}\% \text { do índice } \\
\text { puro total }\end{array}$ & $\begin{array}{c}\text { Indice puro } \\
\text { para frente }\end{array}$ & $\begin{array}{c}\% \text { do índice puro } \\
\text { total }\end{array}$ & $\begin{array}{c}\text { Índice puro } \\
\text { total }\end{array}$ \\
\hline $\begin{array}{l}\text { Ceará } \\
\text { Resto do }\end{array}$ & 8.806 .422 & 67,29 & 4.281 .789 & 32,71 & 13.088 .211 \\
$\begin{array}{l}\text { Nordeste } \\
\begin{array}{l}\text { Resto do } \\
\text { Brasil }\end{array}\end{array}$ & 24.067 .059 & 60,12 & 15.898 .366 & 39,88 & 39.965 .425 \\
\hline
\end{tabular}

Fonte: Estimativas da autora.

Apesar de o Resto do Brasil ter apresentado as melhores posições no "ranking" dos índices puros totais de ligação, a região Resto do Nordeste apresentou o maior volume de transações com as demais regiões do sistema, no período analisado (39,99 bilhões de reais). Isto ocorreu principalmente devido ao grande volume de produção gerado pela demanda final desta região nas regiões Ceará e Resto do Brasil, correspondente a 24,01 bilhões de reais. O Resto do Brasil, por sua vez, como era de se esperar, mostrou-se menos dependente das produções do Ceará e Resto do Nordeste, demandando destas Regiões um volume de produção de 12,33 bilhões de reais.

Enquanto o Ceará e o Resto do Nordeste comportaram-se como demandantes de insumos com respectivamente $67,29 \%$ e $60,12 \%$ do total das suas transações envolvendo a geração de produção em outras regiões, o Resto do Brasil apresentou características de vendedor de insumos com $66,98 \%$ de suas transações relacionadas ao atendimento da demanda final do Ceará e do Resto do Nordeste.

Como mencionado anteriormente, a abordagem dos índices puros de ligação aponta a importância dos setores econômicos considerando, além das ligações inter-setoriais, o seu volume de produção. Porém, estes índices não conseguem captar a importância econômica dos setores com baixos volumes de produção, o que é possível através dos índices de ligação de Hirschman- 
Rasmussen. Assim, é válida a comparação dos dois índices, para que seja feita uma identificação correta dos setores-chave.

Comparando-se os dois índices, observa-se um número maior de setores-chaves quaṇdo são considerados os índices de ligação de HirschmanRasmussen (critério de escolha menos restrito).

A Tabela 27 auxilia na visualização do comportamento dos setores no sistema inter-regional. Como se pode verificar o Ceará apresentou três setoreschave sob os dois enfoques: Têxtil (15), Indústrias alimentares (18) e Outros serviços (26). O resto do Nordeste, seis setores: Agropecuária (1), Extrativa mineral (2), Siderurgia (4), Química (12), Indústrias alimentares (18 ), Comércio (22) e Outros serviços (26). O resto do Brasil, sete: Agropecuária (1), Siderurgia (4), Química (12), Indústrias alimentares (18 ), Comércio (22), Transportes (23) e Outros serviços (26).

Considerando o volume de produção, merecem destaque quanto ao dinamismo nas três regiões estudadas os setores: Agropecuária (1), Indústrias alimentares (18 ), Construção (21), Comércio (22), Transportes (23) e Outros serviços (26). Segundo a classificação de Hirschman-Rasmussen como setoreschave comuns a todas as regiões do sistema inter-regional tem-se: Siderurgia (4), Mecânica (5), Fab. de material elétrico (6), Marerial de transporte (8), Papel e gráfica (10), Borracha (11), Química (12), Farm. e perfumaria (13), Plástico (14), Têxtil (15), Calçados, couros e peles (17), Indústrias alimentares (18) e Outros serviços (26). 
Tabela 27. Setores-chaves consolidados no sistema inter-regional - Critério menos restrito dos índices de Hirschman-Rasmussen e critério do índice puro total de ligação.

\begin{tabular}{|c|c|c|c|c|c|c|}
\hline \multirow{2}{*}{ Setores } & \multicolumn{2}{|c|}{ Ceará } & \multicolumn{2}{|c|}{ Resto do Nordeste } & \multicolumn{2}{|c|}{ Resto do Brasil } \\
\hline & $\mathrm{R} / \mathrm{H}$ & Puro & $\mathrm{R} / \mathrm{H}$ & Puro & $\mathrm{R} / \mathrm{H}$ & Puro \\
\hline 1 - Agropecuária & & $x$ & $\mathrm{x}$ & $x$ & $x$ & $x$ \\
\hline 2- Extrativa mineral & & & $x$ & $x$ & $x$ & \\
\hline 3 - Minerais não Metálicos & & & & & $x$ & \\
\hline 4 - Siderurgia & $x$ & & $x$ & $x$ & $x$ & $x$ \\
\hline 5-Mecânica & $x$ & & $x$ & & $\mathrm{x}$ & \\
\hline 6 - Fab, Material Elétrico & $x$ & & $x$ & & $\mathrm{x}$ & \\
\hline \multicolumn{7}{|l|}{7 - Fabricação de eletrônicos } \\
\hline 8-Material de transporte & $x$ & & $x$ & & $x$ & \\
\hline 9 - Madeira e Mobiliário & & & & & $x$ & \\
\hline 10 - Papel e gráfica & $x$ & & $x$ & & $x$ & \\
\hline 11-Borracha & $x$ & & $x$ & & $x$ & \\
\hline 12 - Química & $x$ & & $x$ & $x$ & $x$ & $x$ \\
\hline 13 - Farm, e Perumaria & $x$ & & $x$ & & $x$ & \\
\hline 14 - Plástico & $x$ & & $x$ & & $x$ & \\
\hline $15-$ Têxtil & $x$ & $x$ & $x$ & & $x$ & \\
\hline 16 - Vestuário & $x$ & & $x$ & & $\mathrm{x}$ & \\
\hline 17 - Calçados, Couros e Peles & $x$ & & $x$ & & $x$ & \\
\hline 18 - Indústrias alimentares & $x$ & $x$ & $x$ & $x$ & $x$ & $x$ \\
\hline 19 - Indústrias diversas & & & & & $x$ & \\
\hline 20 - S.I.U.P. & & & $x$ & & $x$ & \\
\hline 21 - Construção & & $x$ & & $x$ & & $x$ \\
\hline 22 - Comércio & & $x$ & $x$ & $x$ & $\mathrm{x}$ & $x$ \\
\hline 23 - Transporte & & $x$ & & $x$ & $x$ & $\mathrm{x}$ \\
\hline \multicolumn{7}{|l|}{24 - Comunicação } \\
\hline 25 - Fin, e Seguradoras & & & & & $x$ & \\
\hline 26 - Outros Serviços & $x$ & $x$ & $x$ & $x$ & $x$ & $x$ \\
\hline
\end{tabular}

Fonte: Estimativas da autora

Analisando-se a região Ceará pode-se observar que a mesma apresentou um baixo dinamismo econômico em relação às demais regiões no período analisado. O desempenho dos setores-chave identificados na região, Têxtil (15) e Outros serviços (26), pode ser atribuído ao aumento na produção de algodão e à atividade turística no Estado no ano de 1999. 


\subsection{Influência das demandas finais sobre a produção no sistema inter- regional}

Uma das aplicações do modelo GHS é a decomposição da produção total de uma região ou setor em produção induzida pela demanda da própria região e produção induzida pela demanda de outras regiões, identificando, dessa forma, o nível de integração dos mercados entre as regiões, a estrutura de suas relações comerciais.

Um aumento na demanda final de uma região provoca aumentos diretos e indiretos na produção dos setores desta região e de outras regiões com as quais mantém ligações comerciais. Os setores cuja produção sofreu aumento direto induzem os setores que lhe fornecem insumos, localizados na própria região ou em outras regiões, a também aumentarem a sua produção. Assim, setores localizados em regiões diferentes daquela onde houve o aumento na produção também passam a produzir mais e têm a sua demanda por insumos, da própria região de outras regiões também aumentada, reiniciando o ciclo.

Deste modo, tem-se uma produção total induzida pelo aumento na demanda final mencionada no início deste ciclo, que pode ser dividida em produção induzida pelo aumento na demanda final na própria região, que corresponde ao aumento na produção dos setores localizados na região que sofreu o choque na demanda e produção induzida pela demanda final de outras regiões, que corresponde ao aumento na produção dos setores localizados em regiões diferentes daquela que sofreu o choque.

Esta sub-seção tem como objetivo analisar a importância de cada região no sistema inter-regional: Ceará, Resto do Nordeste e Resto do Brasil em relação a sua capacidade de induzir a produção das outras regiões e de ter a sua produção influenciada pelas demandas finais das mesmas. Pretende-se ainda identificar a participação de cada setor na produção induzida total da região, isto 
é, quais os setores mais vulneráveis a variações nas demandas finais da própria região em que está localizado e das demais regiões do sistema.

A partir da metodologia descrita no capítulo 5, pôde-se chegar aos resultados apresentados nas Tabela 28 e 29. Conforme consta na Tabela 28, o nível de integração entre as regiões do sistema é muito baixo principalmente, quando se observa o Resto do Brasil, onde apenas $1,70 \%$ da sua produção é influenciada pelas demandas finais do Ceará e do Resto do Nordeste. A região Ceará, menor e menos desenvolvida entre as três regiões, é a que mais interage com os mercados das demais regiões e, portanto, é a mais dependente.

Tabela 28. Produção total induzida pela demanda final no sistema inter-regional (R\$ 1000,00 correntes de 1999).

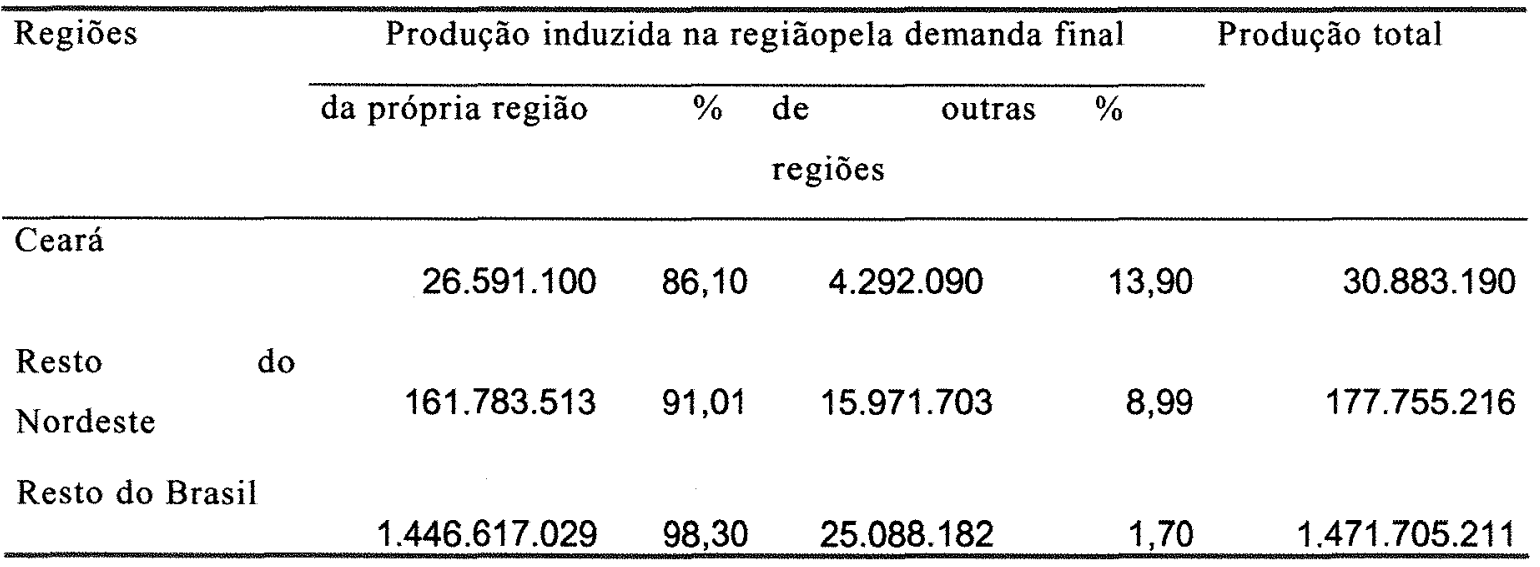

Fonte: Estimativas da autora

Os dados da Tabela 29 mostram que o Resto do Brasil respondeu por $87,58 \%$ do valor da produção total induzida pela demanda final em 1999, enquanto que o Resto do Nordeste e o Ceará participaram com e 10,58\% e $1,84 \%$, respectivamente. 
Tabela 29. Participação da produção induzida das regiões Ceará, Resto do Nordeste e Resto do Brasil na produção induzida total do sistema,1999 (R $\$ 1000,00$ correntes de 1999).

\begin{tabular}{|c|c|c|c|c|c|c|}
\hline \multirow[t]{2}{*}{ Regiões } & \multicolumn{4}{|c|}{ Produção induzida na regiãopela demanda final } & \multirow{2}{*}{$\begin{array}{c}\text { Produção } \\
\text { total }\end{array}$} & \multirow[t]{2}{*}{$\%$} \\
\hline & $\begin{array}{l}\text { da própria } \\
\text { região }\end{array}$ & $\%$ & $\begin{array}{l}\text { de outras } \\
\text { regiões }\end{array}$ & $\%$ & & \\
\hline Ceará & 26.591 .100 & 1.58 & 4.292 .090 & 0.26 & 30.883 .190 & 1.84 \\
\hline $\begin{array}{l}\text { Resto do } \\
\text { Nordeste }\end{array}$ & 161.783 .513 & 9.63 & 15.971 .703 & 0.95 & 177.755 .216 & 10.58 \\
\hline $\begin{array}{l}\text { Resto do } \\
\text { Brasil }\end{array}$ & 1.446.617.029 & 86.09 & 25.088 .182 & 1.49 & 1.471.705.211 & 87.58 \\
\hline Total & 1.635 .991 .642 & 97,30 & 45.351 .975 & 2,70 & 1.680 .343 .617 & 100,00 \\
\hline
\end{tabular}

Fonte: Estimativas da autora

O modelo empregado permite ainda identificar a importância de cada região como indutora da produção das demais regiões do sistema, ou seja, qual a participação da demanda final de cada região sobre a produção das demais.

Conforme a Tabela 30 , onde nas linhas tem-se a produção induzida de cada região e nas colunas a região que deu origem à produção, vê-se que as produções do resto do Nordeste e do Resto do Brasil praticamente independem da demanda final do Ceará, com apenas $0,58 \%$ de suas produções sendo induzidas pela demanda final do Ceará. Do total produzido pelas duas regiões, 1,649 bilhões, apenas 0,008 bilhão foi induzido pela demanda final cearense.

Como era de se esperar, o Resto do Brasil comportou-se como a região com maior capacidade de influenciar a produção das demais regiões, o que significa que uma crise econômica nesta região, tendo como reflexo uma 
diminuição na sua demanda, poderá trazer conseqüências negativas para a produção do Nordeste.

Tabela 30. Importância de cada região na indução da produção no sistema interregional.

\begin{tabular}{|c|c|c|c|c|c|c|}
\hline \multirow[t]{2}{*}{ Regiões* $^{*}$} & \multicolumn{4}{|c|}{$\begin{array}{c}\text { Produção induzida nas regiões pela demanda } \\
\text { final }\end{array}$} & \multirow{2}{*}{\multicolumn{2}{|c|}{ Produção total }} \\
\hline & Da região $j^{* *}$ & $\%$ & $\begin{array}{l}\text { Das próprias } \\
\text { regiões }\end{array}$ & $\%$ & & \\
\hline $\begin{array}{lr}\text { Resto } & \text { do } \\
\text { nordeste } & \text { e } \\
\text { Resto } & \text { do } \\
\text { Brasil } & \end{array}$ & 8.826 .547 & 0,58 & 1.640 .633 .881 & 99,46 & 1.649 .460 .428 & 49,08 \\
\hline $\begin{array}{l}\text { Ceará e Resto } \\
\text { do Brasil }\end{array}$ & 24.171 .664 & 1,61 & 1.478 .416 .738 & 98,39 & 1.502 .588 .402 & 44,71 \\
\hline $\begin{array}{l}\text { Ceará e Resto } \\
\text { do Nordeste }\end{array}$ & 12.353 .764 & 5,92 & 196.284 .642 & 94,08 & 208.638 .406 & 6,21 \\
\hline Total & & & & & 3.360 .687 .236 & 100,00 \\
\hline
\end{tabular}

* Regiões do sistema inter-regional excluindo a região $j$.

** Região do sistema inter-regional excluindo as regiões correspondentes na primeira coluna.

Fonte: Estimativas da autora.

As tabelas 29 e 30 mostraram que os volumes de produção de cada região induzidos pela demanda final da própria região são ainda muito elevados em relação ao volume de produção induzidos pelas demandas finais das outras regiões. O que aponta a baixa ligação inter-regional.

Os volumes de produção de cada região se distribuem através dos setores da economia. Desagregando-se os volumes de produção expressos nas Tabelas 28 e 30 pode-se analisar as relações entre as demandas finais de cada região e a produção dos setores nelas inseridos. 
A Tabela 31 apresenta a produção induzida em cada setor pela demanda final da região em que está localizado e das demais regiões. O valor da produção induzida do Ceará pela demanda do próprio Estado corresponde a R\$ 26,59 bilhões. A distribuição deste valor entre os setores da economia mostra que Agropecuária (1), Indústrias alimentares (18), Construção (21), Comércio (22) e Outros serviços (26) apresentam produções induzidas que em conjunto correspondem a $74,99 \%$ da produção total do Estado induzida pela própria demanda. Isto mostra a dependência doméstica da produção destes setores.

Considerando o impacto das demandas finais do Resto do Nordeste e do Resto do Brasil sobre a produção setorial induzida do Ceará pode-se constatar que o setor Têxtil (15), que mostrou-se pouco influenciado pela demanda interna, apresenta interação significativa com as demais regiões do sistema o que permite concluir que parte da importância atribuída ao setor devese as suas transações fora do Estado. 


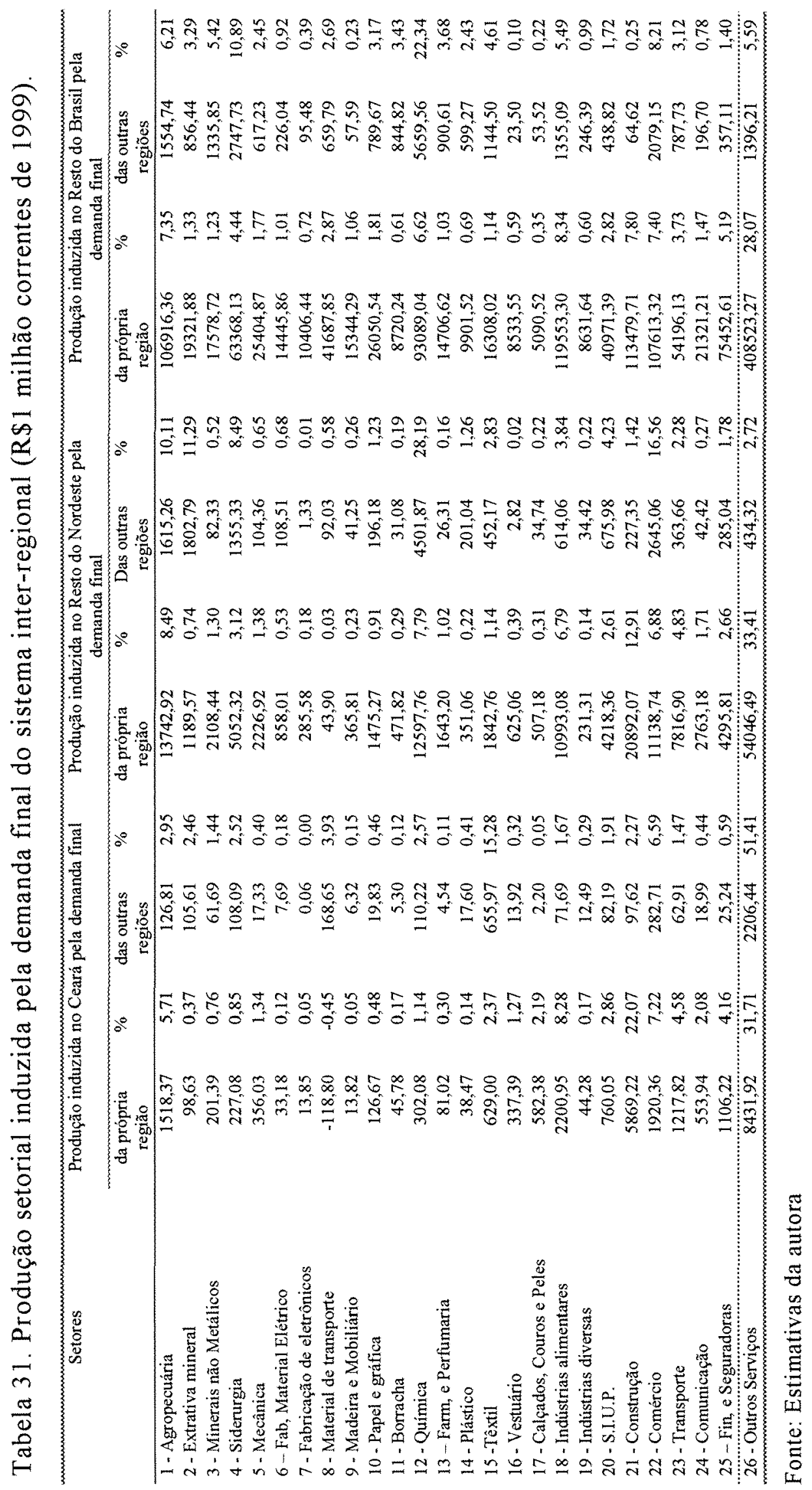


A produção industrial não recebe grande influência das demandas finais do sistema, observa-se que existem 11 setores cuja participação da produção na produção total induzida pela demanda doméstica não ultrapassa $1 \%$ e que não desempenham um papel decisivo na economia da região. Todos estes setores pertencem à Indústria de transformação. Isto que demonstra a necessidade de intensificação das transações do setor.

A Figura 23 permite comparar as participações das produções setoriais induzidas pelas demandas interna e do resto do sistema inter-regional, na produção total induzida do Ceará. Foram selecionados apenas os setores cuja participação foi superior a $5 \%$ em pelo menos um tipo de demanda.

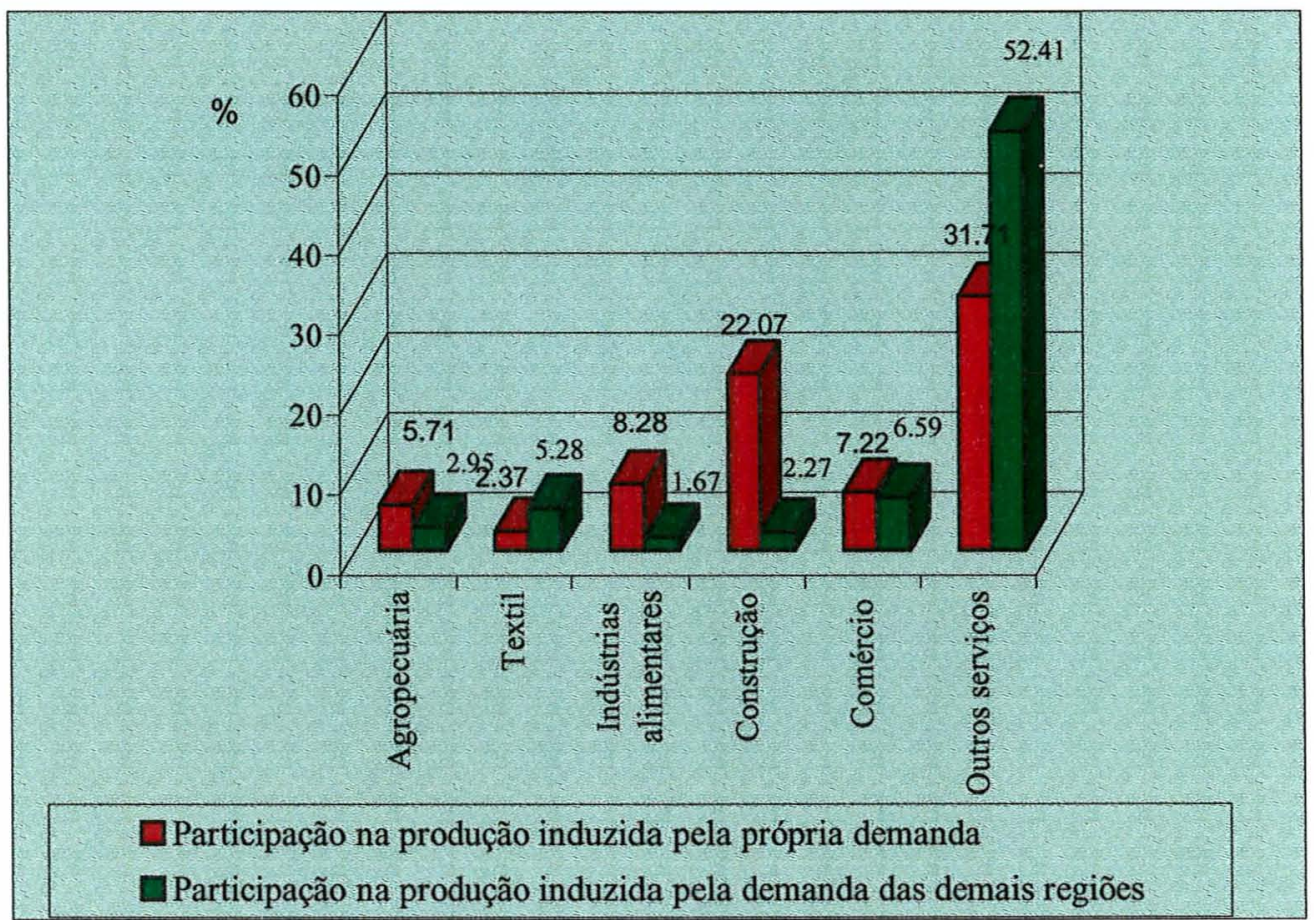

Figura 23 - Participações das produções setoriais na produção total induzida pela própria demanda e das demandas finais das outras regiões Região Ceará. 
Apenas os setores Comércio (22) e Outros serviços (26) mostraram-se integrados com as economias local e das outras regiões. A grande concentração da produção total induzida pelas demandas finais em poucos setores aponta para o pouco dinamismo do Estado do Ceará, cuja maioria dos setores são ainda inexpressivos.

No Resto do Nordeste os setores que receberam o maior impacto da demanda final da própria região foram: Agropecuária (1), Química (12), Indústrias alimentares (18), Construção (21), Comércio (22) e Outros serviços (26), cujas produções correspondem a $76,27 \%$ da produção total induzida pela demanda da região.

A maioria dos setores do Resto do Nordeste mostrou-se pouco sensível ao impacto das demandas finais das outras regiões. Apenas os setores Agropecuária (1), Extrativa mineral (2), siderurgia (4), Química (12) e Comércio (22) apresentaram participações maiores que $5 \%$.

Como pode ser observado na Figura 24 a demanda final da região Resto do Nordeste tem um impacto mais significativo sobre um maior número de setores que a demanda final das demais regiões. As produções dos setores Agropecuária (1), Química (12) e Comércio (22) apresentaram-se como as mais dependentes das demandas da própria região e das demais regiões. No entanto, setores importantes da região conforme análise dos índices de ligação, Siderurgia (4) e Química (12), mostraram-se mais influenciados pelas demandas finais das outras regiões. 


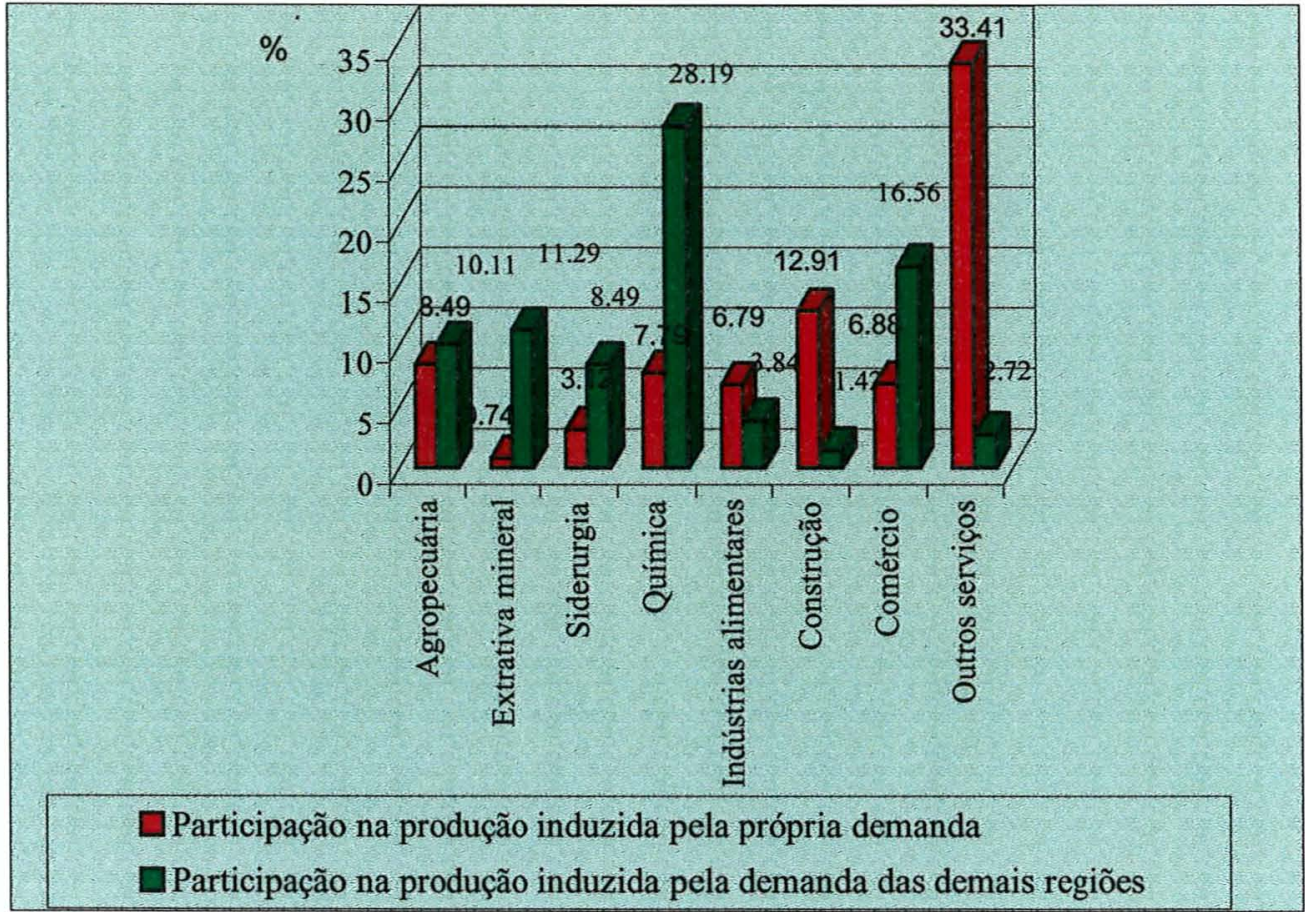

Figura 24 - Participações das produções setoriais na produção total induzida pela própria demanda e das demandas finais das outras regiões Região Resto do Nordeste.

De acordo com a Figura 25, no Resto do Brasil a produção de sete setores selecionados correspondem a $70,77 \%$ da produção total induzida pela demanda final da própria região. O destaque cabe aos setores: Agropecuária (1), Química (12), Indústrias alimentares (18), Construção (21), Comércio (22), Financeiras e seguros (25) e Outros serviços (26). Os demais setores mostraram pouco interativos com participações inferiores a $5 \%$.

Analisando-se o impacto das demandas finais do Ceará e do Resto do Nordeste sobre a produção setorial do Resto do Brasil, verifica-se a importância destas duas economias para os setores Agropecuária (1), Minerais não metálicos 
(3), Siderurgia (4), Química (12), Indústrias alimentares (18), Comércio (22) e Outros serviços (26).

A análise acima mostrou que os setores Agropecuária (1), Química (12), Indústrias alimentares (18), Comércio (22) e Outros serviços (26) interagem no sistema inter-regional como um todo, sendo influenciados pelas demandas finais de todo o sistema.

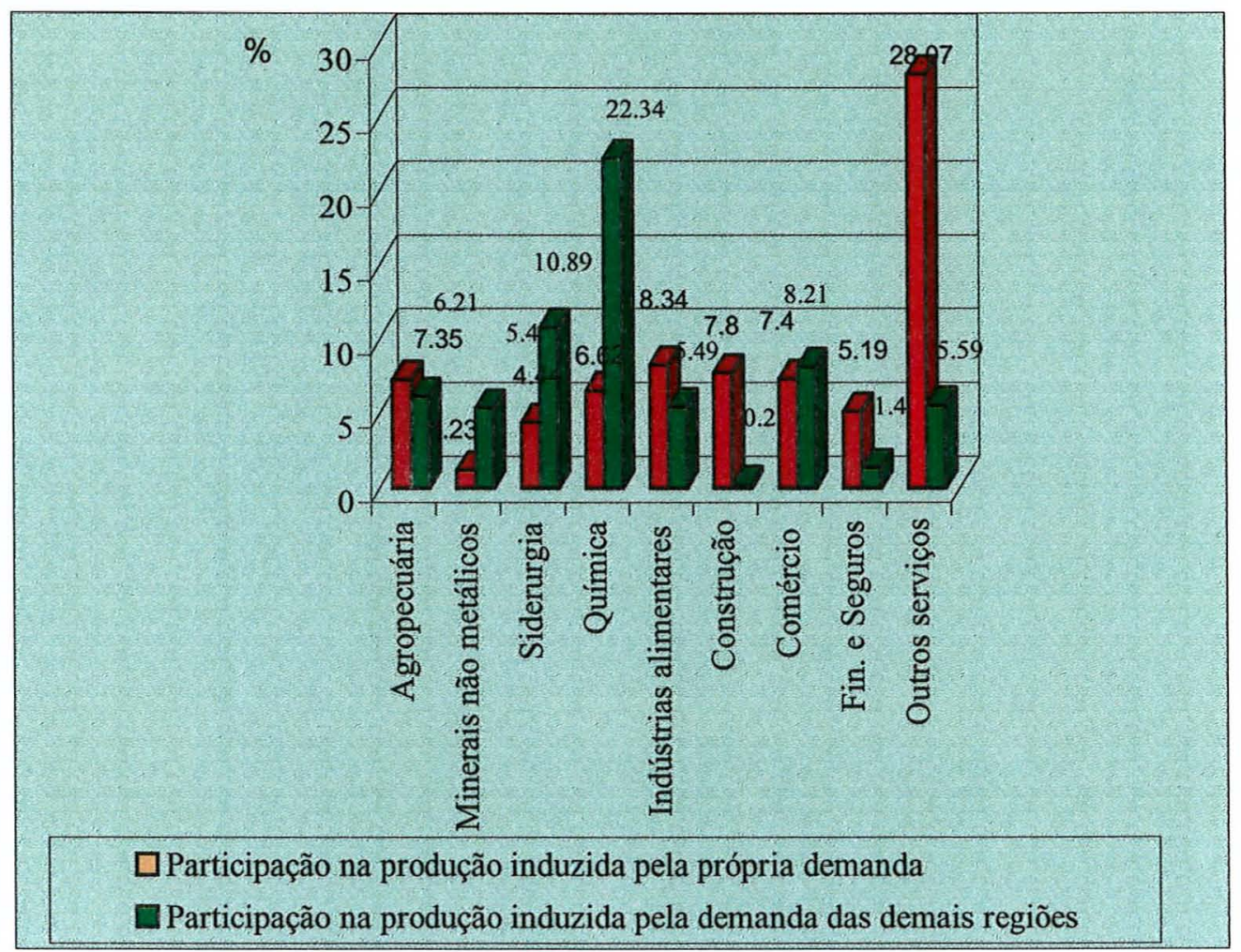

Figura 25 - Participações das produções setoriais na produção total induzida pela própria demanda e das demandas finais das outras regiões Região Resto do Brasil.

Comparando-se as três regiões vê-se que os setores apresentam comportamentos parecidos em todas elas. Agropecuária (1) e Outros serviços 
(26) são interativos nas três economias; Siderurgia (4), Química (12) e Comércio (22) nas regiões Resto do Nordeste e Resto do Brasil. O Ceará é a região que demonstra o menor nível de interação no modelo.

\subsection{Impactos provocados na produção, renda, emprego e importações decorrentes de variações na demanda final}

A matriz de insumo-produto permite que sejam analisados os impactos provocados em diferentes variáveis do sistema econômico em conseqüência de alterações em qualquer um dos componentes da demanda final.

Neste estudo serão apresentados os impactos sobre a produção, renda, emprego e importações decorrentes de um aumento de $\mathrm{R} \$ 1$ milhão na demanda final em cada um dos setores do sistema inter-regional isoladamente, no ano de 1999. A análise será feita sob duas circunstâncias: inicialmente admitindo o sistema inter-regional com o consumo das famílias exógeno ao sistema (multiplicadores tipo I) e em seguida incorporando-o ao sistema (multiplicadores tipo II).

\section{Impactos sobre a produção}

O multiplicador de produção mede o impacto provocado na produção dos diversos setores em decorrência de variações na demanda final do sistema econômico. $\mathrm{O}$ conhecimento dos multiplicadores de produção revela o quanto cada setor gera de produção no próprio setor e nos demais setores, para atender a uma unidade monetária de sua demanda final. Nas Tabelas 32, 33 e 34 são apresentados os multiplicadores de produção, tipos I e II para o sistema inter-regional. Nestas tabelas constam respectivamente o que os setores do Ceará, resto do Nordeste e resto do Brasil induzem de produção na própria região e nas demais regiões, diante de um aumento de uma unidade monetária na demanda final. 
Os multiplicadores de produção do tipo I das três regiões mostram o quanto cada setor é capaz de gerar de produção na região onde está localizado e nas demais, diante de um aumento de uma unidade monetária na sua demanda final, admitindo o consumo das famílias como uma variável exógena do sistema.

Como pode ser observado, os efeitos da variação na demanda final do Ceará sobre a produção das economias do resto do Nordeste e resto Brasil são muito pequenos e podem ser observados com maior facilidade no segmento industrial, principalmente nos setores Siderurgia (4), Material de transportes (8), Farmacêutico e perfumaria (13) e Calçados, couros e peles (17). Dentro do próprio Estado, os setores com maior capacidade de aumentar a produção no próprio setor e nos demais setores internos são: Têxtil (15), Vestuário (16) e Construção (21).

A análise dos multiplicadores do tipo II, isto é, considerando a variável consumo das famílias como endógena ao sistema, mostra duas alterações no quadro descrito acima. Inicialmente se observa um aumento no valor dos multiplicadores, em seguida vê-se que os efeitos do aumento na demanda final do Ceará na produção das regiões Ceará, resto do Nordeste e resto do Brasil são potencializados. Os setores do Ceará passam a provocar aumentos maiores na produção do resto do Brasil que na própria região. Isto sugere que os produtos finais consumidos pelas famílias cearenses utilizam no seu processo produtivo uma grande quantidade de insumos produzidos no resto do Brasil. 
Tabela 32. Multiplicadores de produção para o Ceará ( $\$ \$ 1000,00 /$ unidade monetária de demanda final).

\begin{tabular}{|c|c|c|c|c|c|c|c|c|}
\hline \multirow[t]{2}{*}{ Setores } & \multicolumn{4}{|c|}{ Multiplicadores Tipo I } & \multicolumn{4}{|c|}{ Multiplicadores Tipo II } \\
\hline & Ceará & $\begin{array}{l}\text { Resto do } \\
\text { Nordeste }\end{array}$ & $\begin{array}{c}\text { Resto } \\
\text { do } \\
\text { Brasil }\end{array}$ & Total & Ceará & $\begin{array}{l}\text { Resto do } \\
\text { Nordeste }\end{array}$ & $\begin{array}{c}\text { Resto } \\
\text { do } \\
\text { Brasil }\end{array}$ & Total \\
\hline 1 - Agropecuária & 1,074 & 0,152 & 0,093 & 1,319 & 1,146 & 0,601 & 3,688 & 5,435 \\
\hline 2 - Extrativa mineral & 1,036 & 0,039 & 0,023 & 1,098 & 1,108 & 0,486 & 3,604 & 5,198 \\
\hline 3- Minerais não Metálicos & 1,283 & 0,288 & 0,143 & 1,714 & 1,342 & 0,655 & 3,076 & 5,073 \\
\hline 4 - Siderurgia & 1,308 & 0,720 & 0,456 & 2,484 & 1,368 & 1,094 & 3,451 & 5,913 \\
\hline 5 - Mecânica & 1,237 & 0,363 & 0,572 & 2,171 & 1,290 & 0,693 & 3,214 & 5,197 \\
\hline 6-Fab, Material Elétrico & 1,273 & 0,608 & 0,359 & 2,240 & 1,329 & 0,954 & 3,124 & 5,406 \\
\hline 7 - Fabricação de eletrônicos & 1,025 & 0,040 & 0,177 & 1,242 & 1,086 & 0,417 & 3,192 & 4,695 \\
\hline 8 - Material de transporte & 1,227 & 0,309 & 0,724 & 2,259 & 1,274 & 0,602 & 3,069 & 4,946 \\
\hline 9 - Madeira e Mobiliário & 1,228 & 0,287 & 0,155 & 1,671 & 1,303 & 0,749 & 3,847 & 5,898 \\
\hline 10 - Papel e gráfica & 1,225 & 0,486 & 0,372 & 2,083 & 1,292 & 0,903 & 3,712 & 5,907 \\
\hline 11 - Borracha & 1,268 & 0,441 & 0,360 & 2,069 & 1,322 & 0,774 & 3,023 & 5,118 \\
\hline 12 - Química & 1,238 & 0,657 & 0,242 & 2,137 & 1,304 & 1,065 & 3,514 & 5,883 \\
\hline 13 - Farm, e Perfumaria & 1,181 & 0,337 & 0,875 & 2,393 & 1,243 & 0,723 & 3,967 & 5,934 \\
\hline 14 - Plástico & 1,157 & 0,566 & 0,202 & 1,925 & 1,223 & 0,977 & 3,488 & 5,688 \\
\hline $15-$ Têxtil & 1,649 & 0,373 & 0,395 & 2,418 & 1,715 & 0,784 & 3,682 & 6,181 \\
\hline 16 - Vestuário & 1,452 & 0,146 & 0,377 & 1,975 & 1,522 & 0,579 & 3,843 & 5,944 \\
\hline 17 - Calçados, Couros e Peles & 1,288 & 0,403 & 0,725 & 2,416 & 1,354 & 0,810 & 3,982 & 6,146 \\
\hline 18 - Indústrias alimentares & 1,276 & 0,506 & 0,150 & 1,932 & 1,339 & 0,899 & 3,293 & 5,531 \\
\hline 19 - Indústrias diversas & 1,108 & 0,134 & 0,051 & 1,293 & 1,183 & 0,598 & 3,762 & 5,542 \\
\hline 20 - S.I.U.P. & 1,392 & 0,399 & 0,057 & 1,848 & 1,462 & 0,833 & 3,531 & 5,826 \\
\hline 21 - Construção & 1,166 & 0,170 & 0,206 & 1,542 & 1,236 & 0,603 & 3,673 & 5,511 \\
\hline 22 - Comércio & 1,052 & 0,232 & 0,189 & 1,473 & 1,123 & 0,674 & 3,732 & 5,530 \\
\hline 23 - Transporte & 1,194 & 0,278 & 0,314 & 1,786 & 1,262 & 0,699 & 3,684 & 5,645 \\
\hline 24 - Comunicação & 1,287 & 0,200 & 0,203 & 1,689 & 1,358 & 0,639 & 3,716 & 5,712 \\
\hline 25 - Fin, e Seguradoras & 1,262 & 0,131 & 0,086 & 1,478 & 1,335 & 0,583 & 3,708 & 5,626 \\
\hline 26 - Outros Serviços & 1,183 & 0,116 & 0,106 & 1,405 & 1,260 & 0,593 & 3,929 & 5,782 \\
\hline
\end{tabular}

Fonte: Estimativas da autora

No resto do Nordeste, a resposta dos setores às variações de uma unidade monetária nas suas demandas finais, considerando os multiplicadores do tipo I, ocorre de forma muito parecida no Ceará e no Resto do Nordeste, uma vez que este estudo adotou a hipótese de mesma estrutura de produção para as duas regiões. Porém, pode-se observar algumas diferenças. Os setores com maior poder de propagação de produção na região são: Siderurgia (4), Fabricação de material elétrico (6), Química (12), Têxtil (15) e Indústrias alimentares (18). 
Nenhum dos setores mostrou-se capaz de propagar seus efeitos nas outras regiões. Em relação aos multiplicadores tipo II, as observações feitas para o Ceará, são válidas também para o resto do Nordeste.

Tabela 33. Multiplicadores de produção para o Resto do Nordeste (R\$1000,00/ unidade monetária de demanda final).

\begin{tabular}{|c|c|c|c|c|c|c|c|c|}
\hline \multirow[t]{2}{*}{ Setores } & \multicolumn{4}{|c|}{ Multiplicadores Tipo I } & \multicolumn{4}{|c|}{ Multiplicadores Tipo II } \\
\hline & Ceará & $\begin{array}{l}\text { Resto do } \\
\text { Nordeste }\end{array}$ & $\begin{array}{c}\text { Resto } \\
\text { do } \\
\text { Brasil }\end{array}$ & Total & Ceará & $\begin{array}{l}\text { Resto do } \\
\text { Nordeste }\end{array}$ & $\begin{array}{c}\text { Resto } \\
\text { do } \\
\text { Brasil }\end{array}$ & Total \\
\hline 1 - Agropecuária & 0,008 & 1,218 & 0,093 & 1,319 & 0,081 & 1,667 & 3,688 & 5,436 \\
\hline 2 - Extrativa mineral & 0,004 & 1,071 & 0,023 & 1,098 & 0,076 & 1,518 & 3,604 & 5,198 \\
\hline 3 - Minerais não Metálicos & 0,026 & 1,546 & 0,143 & 1,714 & 0,085 & 1,912 & 3,076 & 5,073 \\
\hline 4 - Siderurgia & 0,020 & 2,008 & 0,456 & 2,484 & 0,080 & 2,382 & 3,451 & 5,913 \\
\hline 5 - Mecânica & 0,025 & 1,574 & 0,572 & 2,171 & 0,079 & 1,904 & 3,214 & 5,197 \\
\hline 6-Fab, Material Elétrico & 0,024 & 1,857 & 0,359 & 2,240 & 0,080 & 2,202 & 3,124 & 5,406 \\
\hline 7 - Fabricação de eletrônicos & 0,004 & 1,062 & 0,177 & 1,242 & 0,064 & 1,438 & 3,192 & 4,695 \\
\hline 8 - Material de transporte & 0,036 & 1,500 & 0,724 & 2,259 & 0,083 & 1,793 & 3,069 & 4,946 \\
\hline 9 - Madeira e Mobiliário & 0,026 & 1,489 & 0,155 & 1,671 & 0,101 & 1,951 & 3,847 & 5,898 \\
\hline 10 - Papel e gráfica & 0,024 & 1,687 & 0,372 & 2,083 & 0,091 & 2,104 & 3,712 & 5,907 \\
\hline 11 - Borracha & 0,030 & 1,678 & 0,360 & 2,069 & 0,084 & 2,011 & 3,023 & 5,118 \\
\hline 12 - Química & 0,019 & 1,876 & 0,242 & 2,137 & 0,085 & 2,284 & 3,514 & 5,884 \\
\hline 13 - Farm, e Perfumaria & 0,018 & 1,500 & 0,875 & 2,394 & 0,081 & 1,887 & 3,971 & 5,939 \\
\hline 14 - Plástico & 0,023 & 1,700 & 0,202 & 1,925 & 0,089 & 2,111 & 3,488 & 5,688 \\
\hline 15 -Têxtil & 0,168 & 1,854 & 0,395 & 2,418 & 0,234 & 2,265 & 3,682 & 6,182 \\
\hline 16 - Vestuário & 0,126 & 1,472 & 0,377 & 1,975 & 0,196 & 1,905 & 3,843 & 5,944 \\
\hline 17 - Calçados, Couros e Peles & 0,024 & 1,667 & 0,725 & 2,417 & 0,090 & 2,075 & 3,984 & 6,148 \\
\hline 18 - Indústrias alimentares & 0,024 & 1,777 & 0,154 & 1,956 & 0,089 & 2,180 & 3,377 & 5,646 \\
\hline 19 - Indústrias diversas & 0,015 & 1,227 & 0,051 & 1,293 & 0,090 & 1,691 & 3,762 & 5,542 \\
\hline 20 - S.I.U.P. & 0,029 & 1,762 & 0,057 & 1,848 & 0,099 & 2,196 & 3,531 & 5,826 \\
\hline 21 - Construção & 0,015 & 1,321 & 0,206 & 1,542 & 0,084 & 1,754 & 3,673 & 5,511 \\
\hline 22 - Comércio & 0,005 & 1,279 & 0,189 & 1,473 & 0,076 & 1,722 & 3,732 & 5,530 \\
\hline 23 - Transporte & 0,033 & 1,438 & 0,314 & 1,786 & 0,101 & 1,859 & 3,684 & 5,645 \\
\hline 24 - Comunicação & 0,047 & 1,440 & 0,203 & 1,689 & 0,118 & 1,879 & 3,716 & 5,713 \\
\hline 25 - Fin, e Seguradoras & 0,057 & 1,336 & 0,086 & 1,478 & 0,130 & 1,789 & 3,708 & 5,626 \\
\hline 26 - Outros Serviços & 0,031 & 1,267 & 0,106 & 1,405 & 0,109 & 1,745 & 3,929 & 5,783 \\
\hline
\end{tabular}

Fonte: Estimativas da autora 
A Tabela 34 mostra a pequena influência dos aumentos na demanda final dos setores localizados no resto do Brasil sobre a produção dos setores localizados no Ceará e resto do Nordeste, o que sugere a produção dos setores desta região é quase independente dos insumos produzidos do Nordeste. O mesmo comportamento pode ser observado na análise dos multiplicadores de produção.

Tabela 34. Multiplicadores de produção para o Resto do Brasil (R $\$ 1000,00 /$ unidade monetária de demanda final).

\begin{tabular}{|c|c|c|c|c|c|c|c|c|}
\hline \multirow[t]{2}{*}{ Setores } & \multicolumn{4}{|c|}{ Multiplicadores Tipo I } & \multicolumn{4}{|c|}{ Multiplicadores Tipo II } \\
\hline & Ceará & $\begin{array}{l}\text { Resto do } \\
\text { Nordeste }\end{array}$ & $\begin{array}{l}\text { Resto } \\
\text { do } \\
\text { Brasil }\end{array}$ & Total & Ceará & $\begin{array}{l}\text { Resto do } \\
\text { Nordeste }\end{array}$ & $\begin{array}{c}\text { Resto } \\
\text { do } \\
\text { Brasil }\end{array}$ & Total \\
\hline 1 - Agropecuária & 0,001 & 0,019 & 1,745 & 1,765 & 0,072 & 0,461 & 5,279 & 5,813 \\
\hline 2 - Extrativa mineral & 0,001 & 0,012 & 1,612 & 1,625 & 0,067 & 0,419 & 4,868 & 5,353 \\
\hline 3 - Minerais não Metálicos & 0,001 & 0,018 & 1,866 & 1,886 & 0,062 & 0,394 & 4,876 & 5,332 \\
\hline 4 - Siderurgia & 0,002 & 0,027 & 2,236 & 2,264 & 0,057 & 0,371 & 4,993 & 5,422 \\
\hline 5 - Mecânica & 0,001 & 0,013 & 1,639 & 1,653 & 0,066 & 0,414 & 4,847 & 5,326 \\
\hline 6-Fab, Material Elétrico & 0,002 & 0,024 & 2,162 & 2,188 & 0,052 & 0,337 & 4,662 & 5,051 \\
\hline 7 - Fabricação de eletrônicos & 0,001 & 0,012 & 1,722 & 1,735 & 0,052 & 0,328 & 4,249 & 4,629 \\
\hline 8 - Material de transporte & 0,003 & 0,020 & 2,065 & 2,089 & 0,053 & 0,328 & 4,524 & 4,904 \\
\hline 9 - Madeira e Mobiliário & 0,002 & 0,019 & 1,995 & 2,016 & 0,066 & 0,416 & 5,168 & 5,649 \\
\hline 10 - Papel e gráfica & 0,001 & 0,018 & 2,061 & 2,079 & 0,059 & 0,375 & 4,925 & 5,359 \\
\hline 11 - Borracha & 0,003 & 0,024 & 1,984 & 2,010 & 0,058 & 0,367 & 4,726 & 5,151 \\
\hline 12 - Química & 0,002 & 0,029 & 1,797 & 1,828 & 0,059 & 0,384 & 4,634 & 5,077 \\
\hline 13 - Farm, e Perfumaria & 0,001 & 0,020 & 1,780 & 1,801 & 0,062 & 0,394 & 4,772 & 5,227 \\
\hline 14 - Plástico & 0,002 & 0,030 & 1,837 & 1,869 & 0,060 & 0,389 & 4,709 & 5,157 \\
\hline 15 -Têxtil & 0,016 & 0,047 & 2,232 & 2,294 & 0,066 & 0,357 & 4,714 & 5,137 \\
\hline 16 - Vestuário & 0,018 & 0,045 & 2,148 & 2,211 & 0,072 & 0,382 & 4,842 & 5,296 \\
\hline $\begin{array}{l}17 \text { - Calçados, Couros e } \\
\text { Peles }\end{array}$ & 0,002 & 0,021 & 1,929 & 1,953 & 0,059 & 0,373 & 4,748 & 5,180 \\
\hline 18 - Indústrias alimentares & 0,002 & 0,022 & 2,314 & 2,338 & 0,064 & 0,411 & 5,421 & 5,896 \\
\hline 19 - Indústrias diversas & 0,002 & 0,018 & 1,857 & 1,877 & 0,062 & 0,393 & 4,856 & 5,311 \\
\hline 20 - S.I.U.P. & 0,000 & 0,004 & 1,669 & 1,673 & 0,066 & 0,413 & 4,941 & 5,420 \\
\hline 21 - Construção & 0,001 & 0,013 & 1,673 & 1,687 & 0,065 & 0,409 & 4,841 & 5,315 \\
\hline 22 - Comércio & 0,001 & 0,021 & 1,753 & 1,775 & 0,069 & 0,443 & 5,125 & 5,636 \\
\hline 23 - Transporte & 0,002 & 0,021 & 1,797 & 1,819 & 0,065 & 0,412 & 4,931 & 5,408 \\
\hline 24 - Comunicação & 0,001 & 0,004 & 1,340 & 1,345 & 0,069 & 0,428 & 4,727 & 5,224 \\
\hline 25 - Fin, e Segurad & 0,001 & 0,003 & 1,414 & 1,417 & 0,074 & 0,455 & 5,037 & 5,566 \\
\hline 26 - Outros Serviços & 0,001 & 0,005 & 1,348 & 1,354 & 0,075 & 0,468 & 5,053 & 5,597 \\
\hline
\end{tabular}

Fonte: Estimativas da autora 
Como pode-se observar, as respostas na produção dos setores às variações de uma unidade monetária nas suas demandas finais apresentam semelhanças entre as regiões Ceará e resto do Nordeste porém, são bastante diferentes em relação ao resto Brasil, o que mostra a necessidade de políticas de produção específicas para o Nordeste e o resto do Brasil.

\section{Impactos na renda}

O nível de renda da população é um dos fatores capazes de afetar o padrão de consumo da população e consequentemente o nível de produção de todos os setores da economia. Além disso, segundo Hirschmann (1958), quanto maior a renda "per capita", mais numerosas serão as transações inter-setoriais, maior será o grau de encadeamento da economia.

Sendo assim, programas voltados para a criação de renda além de beneficiarem a população, fornecem também condições para a dinamização da economia. Nesta sub-seção são apresentados os setores com maior capacidade de geração de renda. Com estes resultados pretende-se fornecer informações sobre quais os setores estratégicos para as políticas de geração de renda na economia do sistema inter-regional, isto é, Ceará, resto do Nordeste e resto do Brasil.

A análise descrita a seguir, bem como as análises feitas nas subseções sub-sequentes: 6.7.3 e 6.7.4, foi possível a partir do cálculo dos multiplicadores descrito no capítulo 5, sub-seção 5.3.5. Os multiplicadores de renda representam a renda gerada em todos os setores da economia resultante de uma variação de uma unidade monetária na demanda final de um determinado setor.

A Tabela 35 mostra as conseqüências de um choque de $R \$ 1$ milhão na demanda final de cada setor sobre a renda gerada na produção dos insumos 
utilizados no processo produtivo, quer de forma direta ou indireta. Cada uma destas formas de geração de renda pode ser entendida da seguinte maneira:

- Renda direta: o choque na demanda final de um setor faz com que este setor aumente a sua produção e consequentemente a utilização de insumos. $\mathrm{O}$ aumento na produção de insumos usados no setor que recebeu o choque na demanda gera uma renda classificada como renda direta.

- Renda indireta: é definida a partir do quanto um setor é capaz de gerar de renda nos outros setores devido a um aumento na sua produção; mais especificamente, é a renda gerada na produção dos insumos empregados no processo produtivo do setor que recebeu o choque na demanda final (quando este se comporta como fornecedor), e dos setores fornecedores de insumo.

Como pode ser observado, a capacidade de geração de renda pelas formas direta e indireta é pequena em todas as regiões do sistema.

Os setores do segmento serviços, apesar de apresentarem multiplicadores de produção mais baixos que os da indústria, apresentam uma capacidade de gerar mais renda. A análise setorial aponta que os cinco principais setores geradores de renda encontram-se neste segmento: Comércio (22), Transporte (23), Financeiras e Seguros (25) e Outros serviços (26), o que mostra a importância dos mesmos na economia regional.

A semelhança verificada entre as regiões Ceará e resto do Norte é decorrente da hipótese admitida neste estudo, de que ambas apresentam a mesma estrutura de produção. Sendo assim, a análise de seus resultados deve estar concentrada na comparação entre os setores. 
Tabela 35. Geração de renda direta e indireta decorrente de um choque de $\mathrm{R} \$ 1$ milhão na demanda final no sistema inter-regional - 1999.

\begin{tabular}{|c|c|c|c|c|c|c|}
\hline \multirow[b]{2}{*}{ Setores } & \multicolumn{2}{|c|}{ Ceará } & \multicolumn{2}{|c|}{ Resto do Nordeste } & \multicolumn{2}{|c|}{ Resto do Brasil } \\
\hline & Direta & Indireta & Direta & Indireta & Direta & Indireta \\
\hline 1 - Agropecuária & 98,2 & 45,6 & 98,2 & 45,6 & 76,8 & 94,2 \\
\hline 2 - Extrativa mineral & 77,2 & 16,6 & 77,2 & 16,6 & 82,7 & 126,5 \\
\hline 3 - Minerais não Metálicos & 122,5 & 121,1 & 122,5 & 121,1 & 128,6 & 142,4 \\
\hline 4 - Siderurgia & 29,2 & 143,2 & 29,2 & 143,2 & 89,5 & 172,5 \\
\hline 5 - Mecânica & 179,9 & 168,2 & 179,9 & 168,2 & 173,9 & 97,0 \\
\hline 6 - Fab, Material Elétrico & 76,3 & 134,6 & 76,3 & 134,6 & 92,9 & 178,3 \\
\hline 7 - Fabricação de eletrônicos & 80,1 & 33,7 & 80,1 & 33,7 & 91,7 & 124,2 \\
\hline 8 - Material de transporte & 86,7 & 169,7 & 86,7 & 169,7 & 97,3 & 158,9 \\
\hline 9 - Madeira e Mobiliário & 162,2 & 115,9 & 162,2 & 115,9 & 159,7 & 149,4 \\
\hline 10 - Papel e gráfica & 84,9 & 151,6 & 84,9 & 151,6 & 141,6 & 192,9 \\
\hline 11 - Borracha & 39,1 & 147,7 & 39,1 & 147,7 & 66,7 & 125,4 \\
\hline 12 - Química & 35,4 & 140,4 & 35,4 & 140,4 & 50,6 & 115,3 \\
\hline 13 - Farm, e Perfumaria & 55,1 & 187,4 & 55,1 & 187,7 & 122,5 & 128,2 \\
\hline 14 - Plástico & 75,7 & 129,9 & 75,7 & 129,9 & 155,4 & 128,1 \\
\hline 15 -Têxtil & 89,2 & 185,8 & 89,2 & 185,8 & 67,9 & 164,9 \\
\hline 16 - Vestuário & 153,0 & 136,5 & 153,0 & 136,5 & 138,3 & 152,8 \\
\hline 17 - Calçados, Couros e Peles & 132,5 & 191,3 & 132,5 & 191,4 & 186,4 & 151,8 \\
\hline 18 - Indústrias alimentares & 56,5 & 120,8 & 57,9 & 123,9 & 63,8 & 166,6 \\
\hline 19 - Indústrias diversas & 46,5 & 42,2 & 46,5 & 42,2 & 149,4 & 167,4 \\
\hline 20 - S.I.U.P. & 212,6 & 188,5 & 212,6 & 188,5 & 266,7 & 168,7 \\
\hline 21 - Construção & 138,2 & 81,3 & 138,2 & 81,3 & 48,0 & 98,1 \\
\hline 22 - Comércio & 331,1 & 62,8 & 331,1 & 62,8 & 234,1 & 150,2 \\
\hline 23 - Transporte & 261,6 & 133,8 & 261,6 & 133,8 & 209,2 & 136,9 \\
\hline 24 - Comunicação & 138,0 & 152,1 & 138,0 & 152,1 & 179,7 & 83,3 \\
\hline 25 - Fin, e Seguradoras & 402,6 & 146,2 & 402,6 & 146,2 & 409,0 & 137,4 \\
\hline 26 - Outros Serviços & 379,0 & 83,6 & 379,0 & 83,6 & 411,7 & 71,6 \\
\hline
\end{tabular}

Fonte: Estimativas da autora

\section{Impactos sobre o emprego}

O conhecimento dos setores econômicos com maior capacidade de geração de empregos é imprescindivel para os planejadores de políticas cujo objetivo seja a diminuição do desemprego. Deste modo, pretende-se neste tópico apresentar o número de empregos gerados pelos setores econômicos em decorrência de um aumento equivalente a R\$ 1 milhão na demanda final. 
Segundo Miller e Blair (1985), o choque na demanda provoca aumento na produção dos setores e como conseqüência aumento no número de empregos. Os empregos decorrentes deste processo podem ser classificados em três classes:

- Empregos diretos: correspondem ao aumento no número de empregos no setor onde se observa o aumento na produção.

- Empregos indiretos: correspondem ao aumento de empregos nos setores que fornecem insumos para outros setores (inclui-se aqui o próprio setor que recebeu o choque na demanda). Estes empregos são considerados indiretos em relação ao setor que teve sua produção elevada originalmente.

- Empregos induzidos: correspondem aos empregos gerados na economia com a incorporação do consumo das famílias ao sistema e o esperado estímulo à produção.

A Tabela 36 apresenta os empregos diretos, indiretos e induzidos resultantes de um aumento de $\mathrm{R} \$ 1$ milhão de reais na demanda final. Os setores com maior capacidade de geração de empregos no próprio setor onde houve aumento na produção, ou seja os principais geradores de empregos diretos são: Agropecuária (1), Madeira e mobiliário (9) e Vestuário (16) no Ceará e no Resto do Nordeste e Agropecuária (1), Vestuário (16) e Comércio (22) no Resto do Brasil. Comparando-se as três regiões, o Ceará mostrou ser a região com maior capacidade de gerar empregos diretos diante do aumento na demanda final. A estrutura econômica verificada no Resto do Brasil permitiu que apenas 586 empregos diretos fossem criados, contra 3.202 do Ceará e 1.806 do Resto do Nordeste. $\mathrm{O}$ fato de o Ceará pagar os menores salários no sistema estudado pode explicar este resultado, uma vez que o custo de mão-de-obra é tido, na maioria dos países, como o obstáculo mais importante à geração de empregos. 
Dando continuidade à análise, o setor Indústrias alimentares (18) do Ceará e Resto do Nordeste mostrou a maior capacidade de criar empregos indiretos, seguido dos setores Madeira e mobiliário (9) e Têxtil (15) do Ceará.

$\mathrm{O}$ aumento na demanda final de todos os setores provoca inicialmente o aumento na produção destes setores e de seus fornecedores. Isto faz com que as empresas aumentem a utilização de todos os seus fatores de produção, inclusive mão-de-obra. Um maior número de empregos representa um aumento na renda das famílias que passam então a demandar mais produtos levando as empresas a aumentar ainda mais a sua produção e a empregar mais pessoas.Os empregos gerados nesta etapa do ciclo são os chamados empregos induzidos.

Conforme pode ser observado, os empregos gerados de forma induzida representam a maior parcela dos empregos gerados na região resto do Brasil, o que não ocorre no Ceará e no resto do Nordeste. Mais uma vez os salários médios de cada região podem explicar tal tendência. No resto do Brasil, onde os salários e a propensão a consumir são mais altos em relação ao Nordeste, verifica-se que o aumento na renda é significativo o bastante para que as famílias aumentem o consumo de modo a provocar aumentos maiores na produção do que os aumentos provocados pela famílias do Nordeste sob as mesmas condições. No Nordeste, mesmo havendo aumentos na renda em decorrência de aumento no número de empregos diretos e indiretos, como os salários médios são inferiores, esses aumentos não são tão expressivos.

O Ceará mostrou a maior capacidade de gerar novos empregos diante de um aumento na demanda final em todos os setores. Portanto, o Estado é o menos desenvolvido e de menor população entre as três regiões, mas apresenta o maior potencial para responder a políticas de geração de empregos. Isto pode ser atribuído não só aos baixos salários pagos pelas empresas como também a uma menor exigência de qualificação de mão-de-obra 
胥

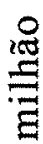

$\ddot{\mathscr{6}}$

o

응

$\Xi$

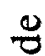

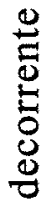

莫

0

용

: $\stackrel{0}{0}$

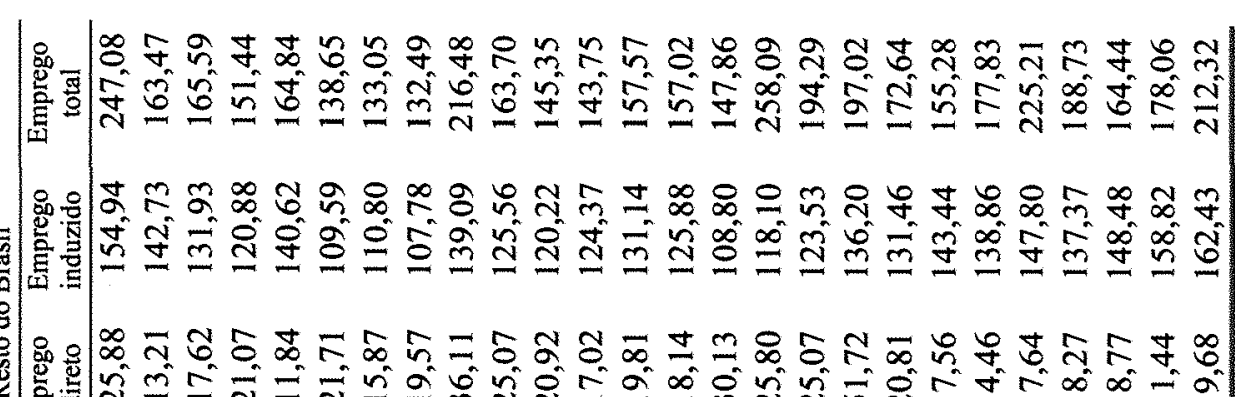

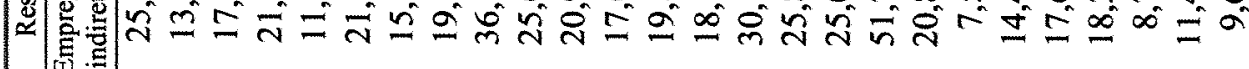

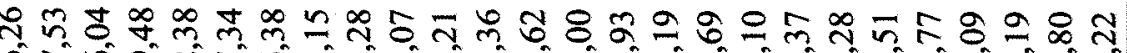

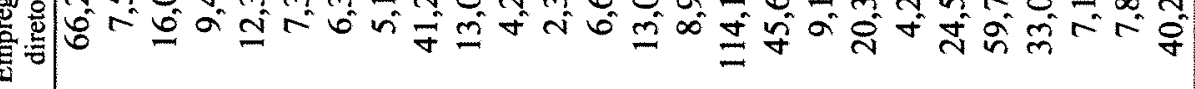

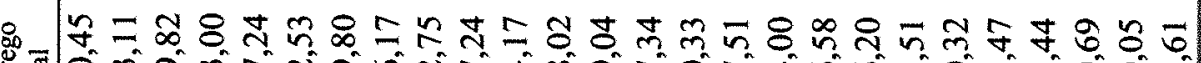

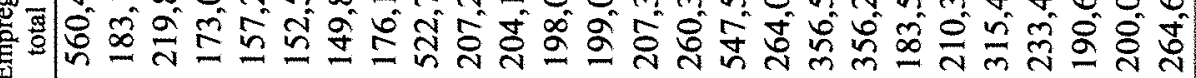

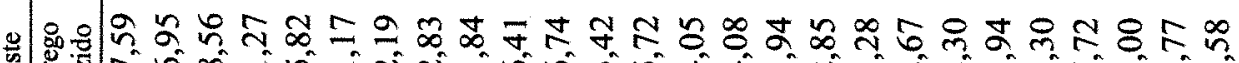

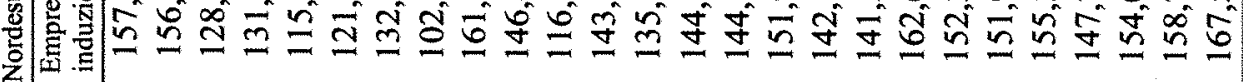
용

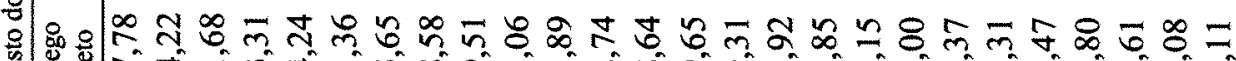

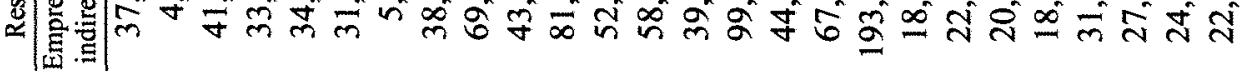

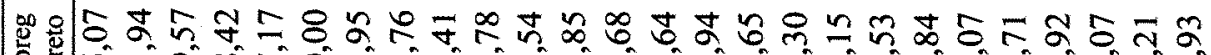

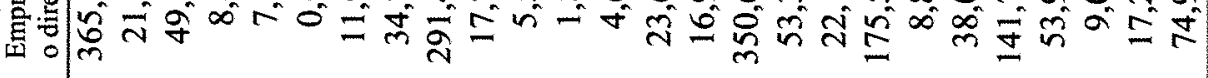
요요

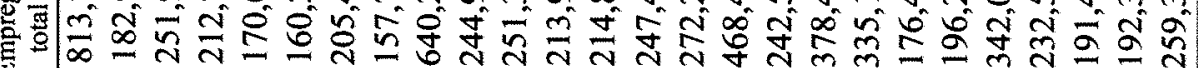

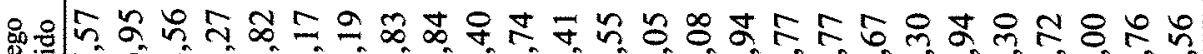

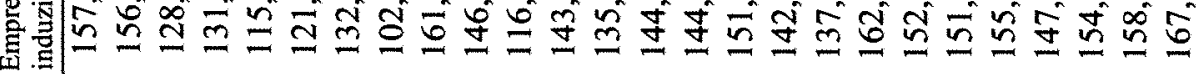

욱

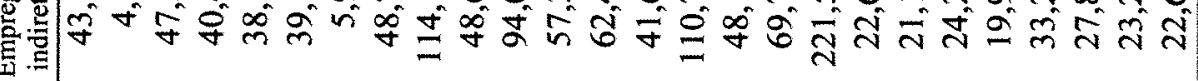

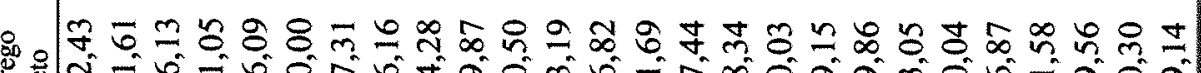

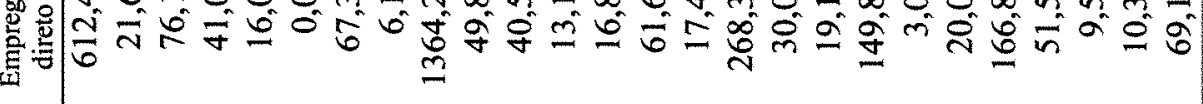
电 $\circ \frac{\pi}{0}$ ख్ 
A Tabela 37 permite fazer uma comparação entre a participação de cada setor no número de empregos gerados com um choque de $\mathrm{R} \$ 1$ milhão na demanda final e o valor total da produção.

Conforme pode ser observado, no Ceará os setores que mais contribuem para a produção total são: Agropecuária (1), Madeira e mobiliário (9), Vestuário (16), Indústrias alimentares (18), Indústrias diversas (19) e Outros serviços (26). A indústria, apesar de não ter grande participação no volume de produção apresenta quatro setores com capacidade de geração de empregos acima da média: Madeira e mobiliário (9), Vestuário (16), Indústrias alimentares (18) e Indústrias diversas (19). Apesar de não se tratar de um Estado de tradição industrial, este comportamento é explicado pelo grande número de pequenas empresas que trabalham sem condições de adotar tecnologias sofisticadas que substituem a mão-de-obra e aumentam a produção. Assim, as indústrias cearenses necessitam de um maior número de empregados para suprir a sua carência de equipamentos e não são tão exigentes quanto à qualificação dos meus, propiciando assim a geração de mais emprego..

O Resto do Nordeste apresenta um comportamento bastante parecido com o do Ceará na capacidade de geração de emprego. A indústria nesta região, apesar de participar em apenas $29,56 \%$ do volume total de produção, apresenta seis setores com capacidade de geração de emprego acima da média: Madeira e mobiliário (9), Têxtil (15), Vestuário (16), Calçados, couros e peles (17), Indústrias alimentares (18) e Indústrias diversas (19)

No Resto do Brasil, a maior e mais desenvolvida das três regiões, observa-se uma maior participação da indústria no valor total da produção porém, uma menor capacidade de geração de empregos em relação a todos os setores do Ceará e Resto do Nordeste. Isto pode ser atribuído à maior produtividade desta região em relação às demais e a sua maior exigência quanto à qualificação de mão-de-obra. Nesta região os setores mais propensos a criar 
empregos são: Agropecuária (1), Vestuário (16) e Comércio (22). Por outro lado, aqueles com menor capacidade de criar empregos são os setores de capital intensivo como: Fabricação de material elétrico (6), Fabricação de eletrônicos (7),

O setor Agropecuária (1), apresentou-se entre os cinco setores com maiores participações no valor da produção e na geração de empregos nas três regiões, demonstrando a sua importância na economia do sistema inter-regional. Porém, é importante ressaltar, algumas características específicas do Ceará em relação às demais regiões, principalmente o resto do Brasil.

A maior capacidade de geração de empregos da Agropecuária cearense em relação ao resto do Nordeste e resto do Brasil pode ser atribuída ao baixo grau de mecanização do setor. Além disso, a sua baixa participação no valor total da produção no Brasil é resultado não apenas das condições climáticas desfavoráveis que enfrenta, como ainda da má condução de políticas agrícolas, carência de tecnologias modernas, técnicas ineficientes de irrigação e consequentemente, baixa produtividade. 


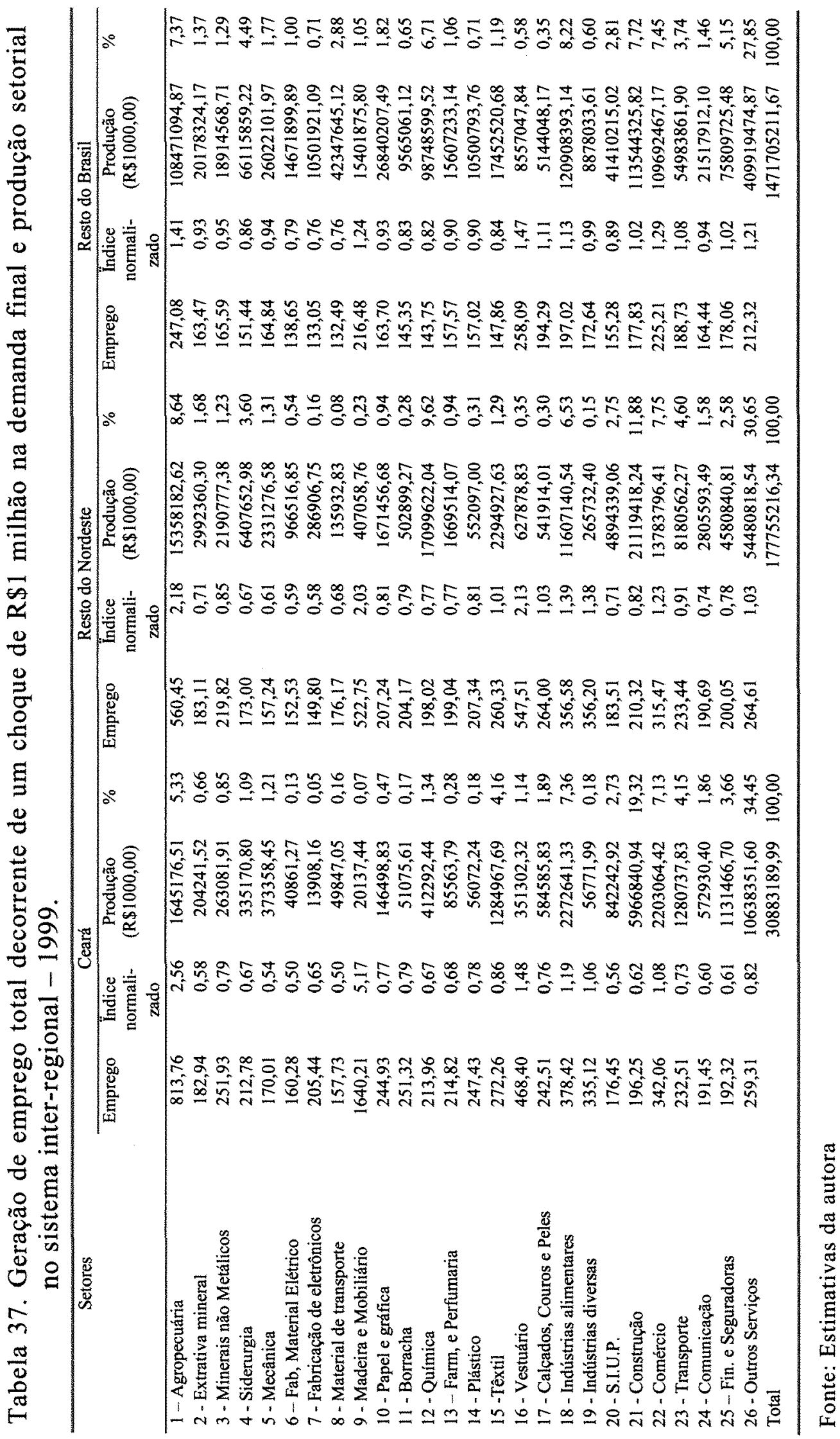


- Impactos sobre as importações

$\mathrm{O}$ aumento na demanda final de um sistema econômico provoca um aumento na produção dos setores e conseqüentemente no consumo de insumos domésticos e importados. Este tópico pretende analisar o impacto de um aumento de $\mathrm{R} \$ 1$ milhão de reais na demanda final, sobre o nível de importações do Ceará, Resto do Nordeste e Resto do Brasil.

Será apresentada inicialmente, através da Tabela 38, a participação do volume de importados no valor da produção. Como pode-se notar, apenas 5 setores apresentaram participação acima de 10\%: Fab. de material elétrico (6), Fab. de eletrônicos (7), Material de transporte (8), Química (12) e Têxtil (15), todos localizados no Resto do Brasil o que classifica a região como dependente da economia do exterior.

As regiões Ceará e Resto do Nordeste apresentaram as mesmas participações. Isto ocorre porque este estudo trabalhou com a hipótese de que as duas regiões apresentam a mesma estrutura de importações. Nestas regiões os setores com maior presença de insumos importados em seu consumo intermediário são: Mecânica (5), Fab. material elétrico (6), Material de transporte (8), Plástico (14) e Indústrias alimentares (18). 
Tabela 38. Participação das importações no volume total de produção no sistema inter-regional em 1999 - \%.

\begin{tabular}{|c|c|c|c|}
\hline Setores & Ceará & Resto do Nordeste & Resto do Brasil \\
\hline 1-Agropecuária & 6,63 & 6,63 & 2,45 \\
\hline 2 - Extrativa mineral & 6,55 & 6,55 & 3,27 \\
\hline 3-Minerais não Metálicos & 4,96 & 4,96 & 4,24 \\
\hline 4 - Siderurgia & 5,61 & 5,61 & 6,56 \\
\hline 5-Mecânica & 9,90 & 9,90 & 3,85 \\
\hline 6-Fab, Material Elétrico & 8,39 & 8,39 & 10,54 \\
\hline 7 - Fabricação de eletrônicos & 6,18 & 6,18 & 15,67 \\
\hline 8-Material de transporte & 8,14 & 8,14 & 11,80 \\
\hline 9-Madeira e Mobiliário & 0,62 & 0,62 & 2,74 \\
\hline 10 - Papel e gráfica & 3,48 & 3,48 & 5,74 \\
\hline 11 - Borracha & 5,01 & 5,01 & 7,17 \\
\hline 12-Química & 4,62 & 4,62 & 10,89 \\
\hline 13 - Farm, e Perfumaria & 5,03 & 5,03 & 6,66 \\
\hline 14 - Plástico & 7,66 & 7,66 & 8,99 \\
\hline 15 -Têxtil & 3,44 & 3,44 & 10,67 \\
\hline 16-Vestuário & 3,32 & 3,32 & 4,41 \\
\hline 17 - Calçados, Couros e Peles & 0,65 & 0,65 & 6,31 \\
\hline 18 - Indústrias alimentares & 7,69 & 7,69 & 2,36 \\
\hline 19 - Indústrias diversas & 2,70 & 2,70 & 6,59 \\
\hline $20-$ S.I.U.P. & 0,97 & 0,97 & 3,02 \\
\hline 21 - Construção & 2,75 & 2,75 & 2,86 \\
\hline 22 - Comércio & 1,15 & 1,15 & 1,69 \\
\hline 23 - Transporte & 2,38 & 2,38 & 6,08 \\
\hline 24 - Comunicação & 0,66 & 0,66 & 4,73 \\
\hline 25 - Fin. E Seguradoras & 0,41 & 0,41 & 1,97 \\
\hline 26 - Outros Serviços & 1,60 & 1,60 & 2,03 \\
\hline
\end{tabular}

Fonte: Estimativas da autora

A Tabela 39 fornece o valores das importações de insumos decorrentes de um aumento de $R \$ 1$ milhão de reais na demanda final. Os valores da tabela incluem as importações feitas diretamente pelo setor impactado na sua produção e também as importações feitas por seus fornecedores e os fornecedores deste.

Como pode ser observado, os setores com maior caacidade de estimular as importações no sistema inter-regional são aqueles intensivos em tecnologia: Mecânica (5), Fabricação de material elétrico(6), Material de Transporte (8) e Indústrias alimentares (18). 
As características analisadas neste capítulo permitiram conhecer a estrutura produtiva e o grau de dependência de cada região em relação às demais e a sua importância como indutora de crescimento. Outras contribuições importantes foram o conhecimento do comportamento da produção setorial em relação às demandas finais dos setores e os impactos dos aumentos na demanda final sobre a renda, emprego e importações do sistema inter-regional. Com estas informações pretende-se fornecer subsídios para a adoção de políticas de desenvolvimento específicas para cada região.

No próximo capítulo serão apresentados os resultados referentes à incorporação da água e energia elétrica ao modelo construído para o Ceará. 


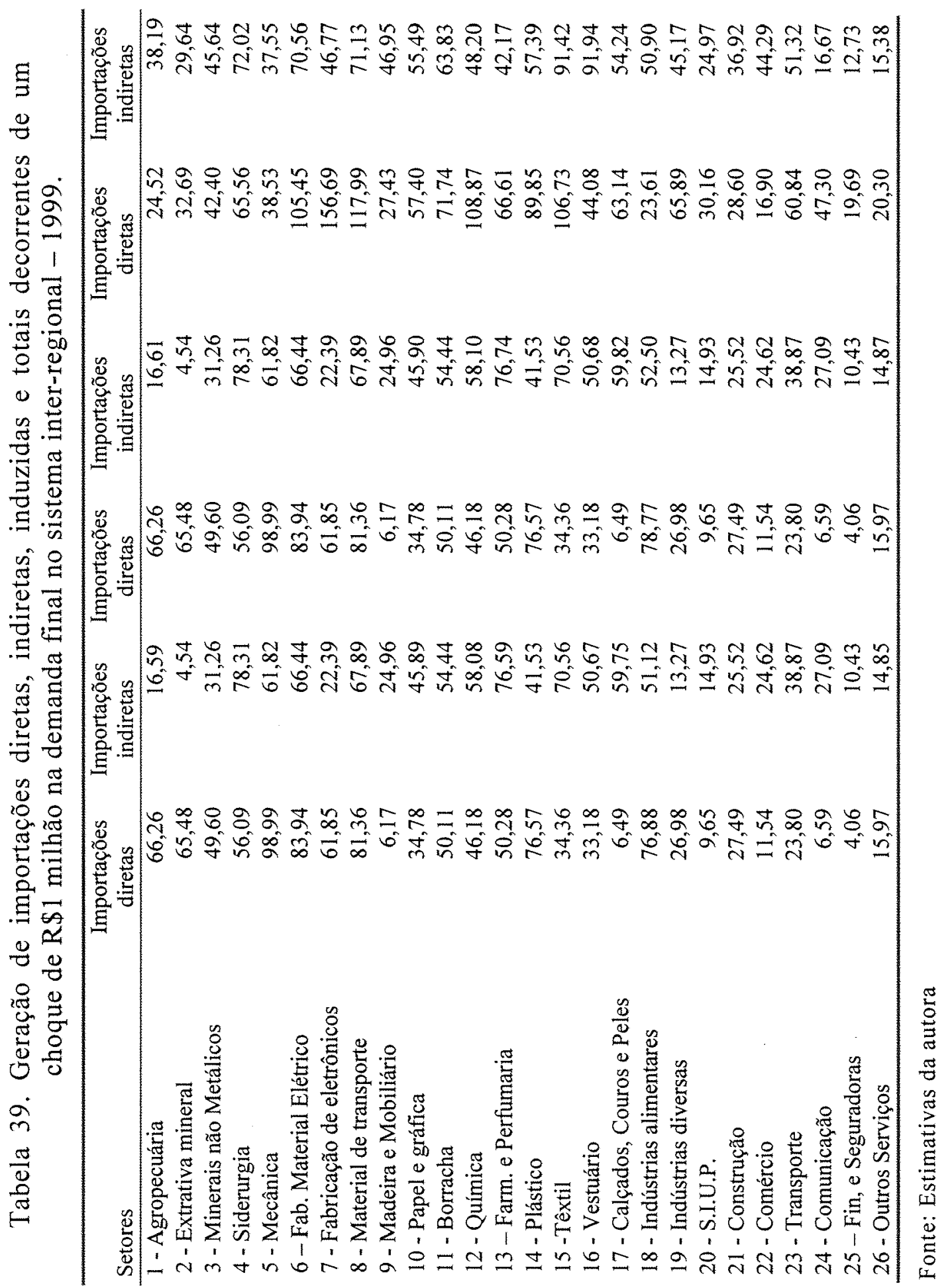




\section{ALOCAÇÃO DA ÁGUA E dA ENERGIA ELÉTRICA ENTRE OS SETORES ECONÔMICOS DO ESTADO DO CEARÁ}

A disponibilidade de água para suprir as necessidades da população diminui a cada ano, não apenas pelo aumento no consumo ou ausência de chuvas, mas principalmente pelo mau gerenciamento dos recursos hídricos. A energia elétrica, como função da quantidade de água disponível ${ }^{49}$, torna-se, desta forma, um recurso cuja distribuição e uso também necessita de gerenciamento.

No Ceará, onde as ofertas de água e energia elétrica são limitadas devido à escassez de recursos hídricos da própria da região, existe uma grande preocupação quanto a necessidade de gerenciamento destes recursos.

O modelo de insumo-produto empregado neste estudo permitiu a estimação dos coeficientes de uso e dos multiplicadores de água e energia elétrica para o Estado do Ceará em 1999, os quais serão apresentados neste capítulo. Deve-se enfatizar que os resultados referentes à água devem ser considerados preliminares, dadas a qualidade e a precariedade das informações referentes a seu consumo pelos diferentes setores econômicos.

\footnotetext{
49 A principal fonte de energia elétrica no Brasil é a energia hidráulica. Isto torna a disponibilidade de energia elétrica atrelada à disponibilidade de água.
} 


\subsection{Coeficientes de consumo de água e energia elétrica nos diferentes setores da economia do Ceará}

Os coeficientes de consumo apresentados nesta seção permitem identificar o perfil de consumo de água e energia elétrica dos setores da economia cearense no ano de 1999. O seu cálculo foi feito conforme descrito no capítulo 5 .

De acordo com a Tabela 40, onde estão listados os coeficientes de consumo de água e energia elétrica por unidade de valor da produção, vê-se que para cada RS 1000,00 de produto gerado na Agropecuária (1) são consumidos $542,16 \mathrm{~m}^{3}$ de água, enquanto que para produzir o mesmo valor, setores como o Têxtil (15) e Outros Serviços (26) que se destacam no Estado como os de maior integração com outros setores, gastam apenas $15,94 \mathrm{~m}^{3}$ e $0,62 \mathrm{~m}^{3}$ por unidade de valor da produção, respectivamente.

Considerando a média de consumo da economia, observa-se que o consumo de água das indústrias é muito pequeno. Apenas o setor Agropecuária (1) apresentou valor superior à média. $\mathrm{O}$ elevado coeficiente da Agropecuária pode ser explicado, entre outros fatores, pelo baixo regime pluvial do Estado aliado a técnicas ineficientes de irrigação e produção.

Os coeficientes de consumo de energia elétrica apresentam-se mais homogêneos em relação aos coeficientes da água. Como pode ser observado, o setor S.I.U.P (20), que abrange abastecimento de água, gás e energia elétrica mostrou-se como o maior consumidor de energia elétrica por unidade de valor da produção, com um coeficiente equivalente a $0,90 \mathrm{MWh}$. Oito setores mostraram coeficientes de consumo acima da média: Minerais não metálicos (3), Siderurgia (4), Fabricação de material elétrico (6), Material de transportes (8), Madeira e mobiliário (9), Plástico (14), Têxtil (15) e S.I.U.P.(20). Porém, vale ressaltar que estes altos coeficientes não têm um impacto maior no consumo total de energia elétrica uma vez que envolvem que apresentam baixos valores de produção, participando com apenas $9,37 \%$ do valor total da produção do Estado. Consumidores não incluídos na análise, como as famílias e o 
governo, por exemplo, apresentam uma participação bem mais expressiva no consumo de energia elétrica.

Tabela 40. Coefícientes de consumo de água e energia elétrica dos setores econômicos do Estado do Ceará - 1999.

\begin{tabular}{lcc}
\hline \multicolumn{1}{c}{ Setores } & $\begin{array}{c}\text { Coeficiente de consumo da água } \\
\left(\mathrm{m}^{3} / \mathrm{R} \$ 1000,00\right)\end{array}$ & $\begin{array}{c}\text { Coeficiente de consumo de energia } \\
\text { elétrica }(\mathrm{MWh} / \mathrm{R} \$ 1000,00)\end{array}$ \\
\hline 1 - Agropecuária & 542,16 & 0,21 \\
2 - Extrativa mineral & 0,01 & 0,13 \\
3 - Minerais não Metálicos & 5,47 & 0,75 \\
4 - Siderurgia & 15,23 & 0,45 \\
5 - Mecânica & 1,04 & 0,02 \\
6 - Fab, Material Elétrico & 31,40 & 0,27 \\
7 - Fabricação de eletrônicos & 3,69 & 0,00 \\
8 - Material de transporte & 2,59 & 0,46 \\
9 - Madeira e Mobiliário & 41,67 & 0,86 \\
10 - Papel e gráfica & 37,84 & 0,20 \\
11 - Borracha & 0,73 & 0,14 \\
12 - Química & 0,86 & 0,09 \\
13 - Farm, e Perfumaria & 1,78 & 0,05 \\
14 - Plástico & 6,84 & 0,81 \\
15 -Têxtil & 15,94 & 0,54 \\
16 - Vestuário & 36,94 & 0,07 \\
17 - Calçados, Couros e Peles & 20,37 & 0,18 \\
18 - Indústrias alimentares & 38,06 & 0,10 \\
19 - Indústrias diversas & 12,20 & 0,05 \\
20 - S.I.U.P. & 0,01 & 0,90 \\
21 - Construção & 0,02 & 0,00 \\
22 - Comércio & 0,62 & 0,06 \\
23 - Transporte & 0,62 & 0,06 \\
24 - Comunicação & 0,62 & 0,06 \\
25 - Fin, e Seguradoras & 0,62 & 0,06 \\
26 - Outros Serviços & 0,62 & 0,06 \\
& 31,46 & 0,25 \\
\hline
\end{tabular}

Fonte: Estimativas da autora

Os coeficientes de consumo apresentados nesta seção permitiram o cálculo dos multiplicadores de consumo de água e energia elétrica, os quais tornaram possível a análise dos impactos de um aumento de $\mathrm{R} \$ 1$ milhão na demanda final de todos os setores sobre os consumos setoriais de água e energia elétrica no Ceará, apresentados a seguir. 


\subsection{Impactos sobre o consumo de água, decorrentes de uma variação da demanda final}

Segundo Parente (2001), desde 1990 até os dias atuais o Estado do Ceará vem empreendendo uma política de atração de investimentos que já alcança U\$ 5 bilhões em recursos privados e atinge principalmente, os setores: Siderurgia (4), Química (12), Plásticos (14), Têxtil (15), Vestuário (16), Calçados, couros e peles (17) e Indústrias alimentares (18).

A cada ano surgem novos projetos. Atualmente estão sendo construídos o Açude Castanhão, o Complexo Industrial Portuário do Pecém, o Parque eólico e o gasoduto, além da adoção de uma política de atração de investimentos para as indústrias. Juntos, estes projetos ultrapassam U\$ 500 milhões em investimentos.

Toda esta infra-estrutura tem proporcionado ao Ceará bons resultados econômicos em relação aos demais estados brasileiros. Porém, o cenário encontrado no Estado não se compõe apenas de elementos positivos. Existem entraves que podem ameaçar a continuidade do seu desenvolvimento econômico. Um destes entraves se refere ao gerenciamento dos recursos hídricos que, por sua vez, envolve a alocação racional da água.

Um dos objetivos deste trabalho é analisar o perfil de consumo da água entre os setores da economia do Ceará. Pretende-se com isso fornecer informações preliminares aos planejadores de políticas públicas para que estes possam relacionar estas políticas à disponibilidade de água no Estado, percebendo seus impactos sobre o consumo de água entre os diferentes setores usuários. Para tanto, será feita a seguir a análise do impacto de um aumento de R\$ 1 milhão na demanda final, sobre o consumo de água dos setores da economia cearense.

Diante do atual crescimento econômico cearense torna-se premente conhecer os possíveis impactos dos investimentos que estão sendo realizados, sobre o consumo de água dos setores econômicos. A Tabela 41 traz a quantidade total de água consumida 
pelos setores em decorrência de um aumento de $\mathrm{R} \$ 1$ milhão na demanda final de todos os setores isoladamente. Como podem ser observados, tal aumento provoca reações diferenciadas nos setores da economia cearense quanto ao seu consumo de água.

Analisando-se os consumos diretos e indiretos, ou seja, respectivamente, o aumento no consumo de água de um setor provocado pelo aumento na sua produção, aumento este decorrente de um choque na demanda final; e o aumento no consumo de água nos outros setores decorrentes do mesmo aumento na produção, a Agropecuária (1) mostrou-se como o setor que mais consome água, seguida dos segmentos indústria e serviços.

Aumentos no consumo de água, ocorridos de forma induzida, ou seja, decorrentes do aumento na renda das familias devido ao aumento no nível de emprego para atender às necessidades das empresas de produzir mais, foram verificados com maior intensidade no segmento serviços. 
Tabela 41. Impactos de um aumento de R \$ 1 milhão na demanda final sobre o consumo de água dos setores econômicos do Estado do Ceará - 1999. $\left(\mathrm{hm}^{3}\right)$

\begin{tabular}{|c|c|c|c|c|}
\hline Setores & Consumo direto & $\begin{array}{l}\text { Consumo } \\
\text { indireto }\end{array}$ & $\begin{array}{l}\text { Consumo } \\
\text { induzidos }\end{array}$ & Consumo total \\
\hline 1 - Agropecuária & 542,16 & 12,72 & 58,70 & 613,58 \\
\hline 2 - Extrativa mineral & 0,00 & 0,25 & 65,04 & 65,30 \\
\hline 3 - Minerais não Metálicos & 5,47 & 5,78 & 40,30 & 51,55 \\
\hline 4 - Siderurgia & 15,23 & 3,82 & 23,98 & 43,03 \\
\hline 5-Mecânica & 1,04 & 1,78 & 24,71 & 27,53 \\
\hline 6-Fab, Material Elétrico & 31,40 & 3,29 & 27,50 & 62,20 \\
\hline 7 - Fabricação de eletrônicos & 3,69 & 0,14 & 50,59 & 54,42 \\
\hline 8 - Material de transporte & 2,59 & 1,71 & 16,94 & 21,24 \\
\hline 9-Madeira e Mobiliário & 41,67 & 10,12 & 54,19 & 105,98 \\
\hline 10 - Papel e gráfica & 37,84 & 8,07 & 36,82 & 82,73 \\
\hline 11 - Borracha & 0,73 & 20,20 & 23,68 & 44,62 \\
\hline 12 - Química & 0,86 & 7,14 & 28,38 & 36,39 \\
\hline 13 - Farm. e Perfumaria & 1,78 & 9,01 & 20,34 & 31,14 \\
\hline 14 - Plástico & 6,84 & 0,69 & 37,99 & 45,52 \\
\hline 15-Têxtil & 15,94 & 34,01 & 38,00 & 87,95 \\
\hline 16 - Vestuário & 36,94 & 11,07 & 52,14 & 100,16 \\
\hline 17 - Calçados, Couros e Peles & 20,37 & 7,00 & 29,19 & 56,56 \\
\hline 18 - Indústrias alimentares & 38,06 & 74,88 & 30,95 & 143,89 \\
\hline 19 - Indústrias diversas & 12,20 & 2,62 & 62,66 & 77,48 \\
\hline 20 - S,I,U,P, & 0,00 & 0,46 & 50,42 & 50,88 \\
\hline 21 - Construção & 0,02 & 1,10 & 54,19 & 55,31 \\
\hline 22 - Comércio & 0,62 & 0,15 & 55,08 & 55,85 \\
\hline 23 - Transporte & 0,62 & 0,63 & 46,73 & 47,98 \\
\hline 24 - Comunicação & 0,62 & 1,01 & 53,39 & 55,02 \\
\hline 25 - Fin. e Seguradoras & 0,62 & 0,70 & 61,68 & 63,00 \\
\hline 26 - Outros Serviços & 0,62 & 2,32 & 66,57 & 69,52 \\
\hline Média & 31,46 & 8,49 & 42,70 & 82,65 \\
\hline
\end{tabular}

Fonte: Estimativas da autora

Como uma ilustração da aplicação dos resultados acima pode-se inferir que diante de aumentos na demanda final, os setores que provocam impactos no consumo de água no Ceará, acima da média dos outros setores são: Agropecuária (1), Madeira e mobiliário (9), Papel e gráfica (10), Têxtil (15), Vestuário (16) e Indústrias alimentares (18). Enquanto isso, setores do segmento serviços sofrem um impacto bem menor no seu consumo de água nas mesmas condições. Portanto, diante de uma necessidade de contenção de água, investimentos em serviços, cuja participação no PIB é bastante 
expressiva (42,7\% em 2000), bem como a capacidade de gerar renda e emprego devem ser priorizadas em relação aos outros setores.

Admitindo-se que o aumento de R\$ 1 milhão na demanda final de todos os setores provocou um aumento médio de $82,65 \mathrm{hm}^{3}$ no consumo de água, e que o consumo total de água no Ceará em 1999, dos setores em estudo, foi de 1050153,82 $\mathrm{hm}^{3}$, tem-se um aumento de apenas $0,01 \%$ no consumo de água.

Embora o aumento na demanda final do Ceará verificado nos últimos anos, seja bem maior que o proposto aqui, os resultados obtidos permitem concluir que a disponibilidade de água não se constitui um impedimento ao crescimento econômico do Estado. Porém, como se trata de um recurso escasso, são necessárias políticas de gerenciamento hídrico para garantir que as gerações futuras possam usufruir de seus benefícios.

A Tabela 42 tem como objetivo tornar mais visíveis os possíveis impactos de políticas setoriais destinadas à geração de renda e emprego sobre o consumo de água no Ceará, uma vez que permite uma comparação dos resultados obtidos na Tabela $41 \mathrm{com}$ os resultados referentes aos impactos sobre a geração de renda (Tabela 34) e emprego (Tabela 36) diante de um mesmo choque na demanda. Os setores estão ordenados decrescentemente segundo a magnitude do impacto sofrido. A análise da tabela permitir constatar que:

- A geração de renda através de investimentos nos setores: Financeiras e Seguros (25), Outros serviços (26), S.I.U.P. (20) e Transportes (23) deve considerar o seu impacto sobre o consumo de água

- Setores identificados como importantes geradores de empregos: Madeira e mobiliário (9), Agropecuária (1), Vestuário (16) e Indústria alimentares (18) são também importantes consumidores água. 
- Setores como Madeira e mobiliário (9), Têxtil (15),Vestuário (16), e Outros serviços (26), que estão situados entre os dez principais setores geradores de renda e emprego são também fortemente impactados no seu consumo de água quando sujeitos a aumentos na demanda final.

Tabela 42. Ordenação decrescentes dos setores conforme sua capacidade de geração de renda, emprego e consumo de água diante de um aumento de R\$ 1 milhão na demanda final de todos os setores da economia.

\begin{tabular}{llll} 
Principais setores geradores de renda & \multicolumn{1}{c}{$\begin{array}{c}\text { Principais setores geradores } \\
\text { de emprego }\end{array}$} & $\begin{array}{c}\text { Principais setores geradores de } \\
\text { donsumo de água }\end{array}$ \\
\hdashline Fin. e Seguros & Mad.e Mobiliário & Agropecuária \\
Outros Serviços & Agropecuária & Indústrias alimentares \\
Comércio & Vestuário & Madeira e Mobiliário \\
S.I.U.P. & Ind. alimentares & Vestuário \\
Transporte & Comércio & Têxtil \\
Mad.e Mobiliário & Indústrias diversas & Papel e gráfica \\
Comunicação & Têxtil & Indústrias diversas \\
Vestuário & Outros Serviços & Outros Serviços \\
Calç.Couros e Peles & Minerais não Metálicos & Extrativa mineral \\
Têxtil & Borracha & Fin. e Seguradoras \\
Construção & Plástico & Fab, Material Elétrico \\
Papel e gráfica & Papel e gráfica & Calçados, Couros e Peles \\
Agropecuária & Calç.Couros e Peles & Comércio \\
Indústrias diversas & Transporte & Construção \\
Plástico & Farm.e Perfumaria & Comunicação \\
Farm.e Perfumaria & Química & Fabricação de eletrônicos \\
Extrativa mineral & Siderurgia & Minerais não Metálicos \\
Química & Fab.de eletrônicos & S,I,U,P, \\
Mecânica & Construção & Transporte \\
Minerais não Metálicos & Fin.anceiras e Seguros & Plástico \\
Ind. alimentares & Comunicação & Borracha \\
Siderurgia & Extrativa mineral & Siderurgia \\
Fab.Mat. Elétrico & S.I.U.P. & Química \\
Fab.de eletrônicos & Mecânica & Farm. e Perfumaria \\
Borracha & Fab.Mat. Elétrico & Mecânica \\
Mat.de transporte & Mat.de transporte & Material de transporte \\
. & &
\end{tabular}

Fonte: Estimativas da autora

Uma constatação que pode ser feita a partir dos comentários acima é que para que haja um desenvolvimento sustentável no Ceará, as políticas econômicas devem estar associadas a políticas de gerenciamento dos recursos hídricos. 


\subsection{Impactos sobre o consumo de energia elétrica, decorrentes de uma variação da demanda final}

Um dos fatores limitantes do crescimento econômico de uma região é a dificuldade de aumentar a oferta de energia elétrica. Atualmente se observa no Brasil e como conseqüência no Ceará, um descompasso entre a expansão da demanda e da oferta de energia elétrica.

Esta situação ocorre apesar do novo modelo do setor elétrico instituído pela lei 9074/95, - cujo objetivo é expandir o parque gerador do país e modernizar as malhas de transporte de energia elétrica - e obriga o governo a adotar medidas emergenciais para assegurar o fornecimento de energia no período 2000-2003. Entre estas medidas destaca-se a diminuição no consumo de energia através do racionamento de energia elétrica.

No Ceará existe uma alternativa à energia elétrica gerada nas hidrelétricas que é a energia eólica ou energia dos ventos. Este tipo de energia começou a ser usada na geração de eletricidade a pouco mais de trinta anos. No Brasil, o Ceará foi o primeiro Estado a utilizar a força dos ventos como energia alternativa, o que aconteceu em 1996 com a inauguração do parque eólico experimental de Fortaleza. O pioneirismo do Ceará neste campo pode ser atribuído a duas características do Estado: a presença de ventos constantes e a escassez de recursos hídricos que acentua os riscos de uma dependência total de energia hidráulica na geração de energia elétrica.

No ano 2001 existiam no Ceará três usinas eólicas em funcionamento com capacidade de 17,400 MW e dezesseis em fase de outorga, isto é, que ainda não iniciaram a construção. As perspectivas são que as usinas em outorga gerem 1.402,7 MW quando entrarem em operação. Esta quantidade de energia, no entanto, é ainda muito pequena, dado que o consumo de energia elétrica no Ceará em 2000 foi de $(5,9$ milhões de MWh. 
Apesar de possuir a energia dos ventos como alternativa à geração de energia, o Ceará não está imune à crise energética vivenciada no Brasil. Não basta apenas a substituição das fontes hidráulicas de energia elétrica. É necessário uma política séria, que priorize a racionalização dos usos da energia elétrica assim como acontece com a política de gerenciamento dos recursos hídricos, para eliminar o risco de racionamentos futuros.

Está comprovado que a redução no consumo de energia elétrica traz conseqüências diretas em todos os setores da economia uma vez que provoca mudanças não apenas nos hábitos domésticos como também no potencial de produção das indústrias e na rotina de trabalho do comércio. Um trabalho realizado pelo IPLANCE (2001) aponta as principais repercussões do racionamento de energia elétrica na economia do Ceará, apresentadas resumidamente na Tabela 43. 
Tabela 43. Repercussões econômicas decorrentes de uma restrição no consumo de energia elétrica no Ceará - Tendências.

\begin{tabular}{lc}
\hline \multicolumn{1}{c}{ VARIÁVEIS } & TENDÊNCIA ESPERADA \\
\hline 1. Taxa de Crescimento Oferta Agregada $(\mathrm{PIB}+\mathrm{M})$ & - \\
2. Taxa de Crescimento do PIB & - \\
3. Nível de emprego & + \\
4. Inflação & - \\
5. Salário Real (W/P) & - \\
6. Taxa de Crescimento das importações & - \\
7. Taxa de Crescimento das exportações & - \\
8. Taxa de Crescimento Demanda Agregada $(\mathrm{C}+\mathrm{I}+\mathrm{X})$ & - \\
9. Saldo Balança Comercial & + \\
10. Taxa de Crescimento ICMS & + \\
11. Eficiência no uso de energia elétrica & + \\
12. Substituição de energia elétrica hidráulica por outras fontes \\
13. Preço tarifa energia elétrica \\
14. Investimentos setor elétrico \\
15. Nível de bem-estar da população
\end{tabular}

Fonte: IPLANCE (2001)

Como podem ser observados, os efeitos sobre a economia são na sua maioria negativos, apontando para a diminuição do crescimento econômico no Estado. Para evitar os transtornos provocados por uma crise no abastecimento de energia elétrica torna-se necessária a adoção de um conjunto de políticas que busquem soluções permanentes pelo lado da oferta e da demanda.

A Tabela 44 traz os resultados referentes às respostas no consumo de energia elétrica dos setores econômicos cearenses frente a um aumento de $\mathrm{R} \$ 1$ milhão na demanda final. Com estes resultados pretende-se mostrar o comportamento dos demandantes de energia elétrica no Ceará e fornecer informações aos gerenciadores deste setor. 
Tabela 44. Impactos de um aumento de R\$ 1 milhão na demanda final sobre o consumo de energia elétrica dos setores econômicos do Estado do Ceará - 1999. (MWh).

\begin{tabular}{lrrrr}
\hline \multicolumn{1}{c}{ Setores } & Diretos & Indiretos & Induzidos & Total \\
\hline 1 - Agropecuária & 205,50 & 11,20 & 212,20 & 428,90 \\
2 - Extrativa mineral & 132,07 & 7,37 & 235,14 & 374,59 \\
3 - Minerais não Metálicos & 746,24 & 99,81 & 145,70 & 991,74 \\
4 - Siderurgia & 452,29 & 121,13 & 86,69 & 660,11 \\
5 - Mecânica & 19,62 & 54,09 & 89,32 & 163,03 \\
6 - Fab. Material Elétrico & 271,68 & 91,01 & 99,43 & 462,12 \\
& 0,07 & 4,03 & 182,89 & 186,99 \\
7 - Fabricação de eletrônicos & & & & \\
8 - Material de transporte & 464,38 & 64,26 & 61,23 & 589,87 \\
9 - Madeira e Mobiliário & 859,79 & 73,89 & 195,91 & 1129,59 \\
10 - Papel e gráfica & 197,19 & 37,61 & 133,12 & 367,92 \\
11 - Borracha & 139,44 & 51,50 & 85,62 & 276,57 \\
12 - Química & 87,72 & 53,12 & 102,61 & 243,45 \\
13 - Farm. e Perfumaria & 47,25 & 22,04 & 73,55 & 142,83 \\
14 - Plástico & 810,56 & 20,19 & 137,34 & 968,09 \\
15 -Têxtil & 535,80 & 275,43 & 137,38 & 948,61 \\
16 - Vestuário & 66,21 & 177,45 & 188,50 & 432,16 \\
17 - Calçados, Couros e Peles & 175,71 & 45,35 & 105,52 & 326,58 \\
18 - Indústrias alimentares & 103,94 & 49,96 & 111,89 & 265,79 \\
19 - Indústrias diversas & 49,48 & 25,26 & 226,51 & 301,24 \\
20 - S,l,U,P, & 899,01 & 263,42 & 182,29 & 1344,71 \\
21 - Construção & 3,45 & 55,77 & 195,91 & 255,13 \\
22 - Comércio & 63,39 & 8,36 & 199,12 & 270,87 \\
23 - Transporte & 63,39 & 23,96 & 168,93 & 256,28 \\
24 - Comunicação & 63,39 & 36,16 & 193,02 & 292,57 \\
25 - Fin. e Seguradoras & 63,39 & 22,28 & 222,98 & 308,64 \\
26 - Outros Serviços & 63,39 & 22,79 & 240,68 & 326,86 \\
Média & 253,24 & 66,06 & 154,36 & 473,66 \\
\hline
\end{tabular}

Fonte: Estimativas da autora

A indústria é o segmento que recebe o maior impacto no consumo de energia elétrica quer de forma direta, indireta ou induzida, diante de um aumento na demanda final. Analisando-se diretamente o o aumento no consumo total de energia elétrica, pode-se observar que os maiores impactos no consumo de energia elétrica ocorrem nos setores: Minerais não metálicos (3), Madeira e mobiliário (9), Plásticos (14), Têxtil (15) e S.I.U.P. (20). 
Considerando que o consumo total de energia elétrica em 1999 foi de 5.690.802 MWh em 1999, o aumento médio no total de consumo de energia elétrica destes setores, 473,66 MWh é pequeno. Porém, dado que os aumentos verificados na demanda final no Ceará são superiores ao choque de R\$ 1 milhão aplicado neste estudo, e que a crise na oferta de energia elétrica atual, exige da sociedade cortes no consumo de até $20 \%$, este resultado adquire proporções maiores.

Diante disto, os resultados discutidos permitem afirmar que o crescimento econômico do Ceará está atrelado ao aumento no consumo de energia de energia elétrica e que o racionamento de energia, exigindo uma diminuição deste consumo por parte dos setores econômicos provavelmente levaria a uma queda no nível de produção e consequentemente, nos níveis de emprego e renda. Sendo assim, é essencial que os empresários passem a utilizar a energia elétrica de forma racional, evitando desperdícios, utilizando fontes alternativas e adotando tecnologias poupadoras. Além disso, espera-se que as políticas de desenvolvimento priorizem os setores menos eletrointensivos, ou seja, que consomem menos energia no seu processo produtivo, ao decidirem onde aplicar seus investimentos.

A Tabela 45 apresenta a ordenação dos setores cearenses em ordem decrescente, conforme os impactos das variações na demanda final sobre a renda, emprego e consumo de energia elétrica nos diferentes setores econômicos do Ceará. Os setores estão ordenados segundo a magnitude do impacto sofrido. 
Tabela 45. Ordenação decrescente dos setores conforme sua capacidade de geração de renda, emprego e consumo de energia elétrica, diante de um impacto de $\mathrm{R} \$$ 1 milhão na demanda final de todos os setores da economia.

\begin{tabular}{ccc}
\hline Geração de Renda & Geração de Emprego & Geração de Consumo de energia \\
\hline Fin. e Seguros & Mad.e Mobiliário & S,I,U,P, \\
Outros Serviços & Agropecuária & Madeira e Mobiliário \\
Comércio & Vestuário & Minerais não Metálicos \\
S.I.U.P. & Ind. alimentares & Plástico \\
Transporte & Comércio & Têxtil \\
Mad.e Mobiliário & Indústrias diversas & Siderurgia \\
Comunicação & Têxtil & Material de transporte \\
Vestuário & Outros Serviços & Fab, Material Elétrico \\
Calç.Couros e Peles & Minerais não Metálicos & Vestuário \\
Têxtil & Borracha & Agropecuária \\
Construção & Plástico & Extrativa mineral \\
Papel e gráfica & Papel e gráfica & Papel e gráfica \\
Agropecuária & Calç.Couros e Peles & Outros Serviços \\
Indústrias diversas & Transporte & Calçados, Couros e Peles \\
Plástico & Farm.e Perfumaria & Fin. e Seguradoras \\
Farm.e Perfumaria & Química & Indústrias diversas \\
Extrativa mineral & Siderurgia & Comunicação \\
Química & Fab.de eletrônicos & Borracha \\
Mecânica & Construção & Comércio \\
Minerais não Metálicos & Fin.anceiras e Seguros & Indústrias alimentares \\
Ind. alimentares & Comunicação & Transporte \\
Siderurgia & Extrativa mineral & Construção \\
Fab.Mat. Elétrico & S.I.U.P. & Química \\
Fab.de eletrônicos & Mecânica & Fabricação de eletrônicos \\
Borracha & Fab.Mat. Elétrico & Mecânica \\
Mat.de transporte & Mat.de transporte & Farm. e Perfumaria \\
\hline
\end{tabular}

Fonte: Estimativas da autora

Diante das restrições atuais no abastecimento de energia elétrica observa-se que políticas voltadas para a geração de renda através de aumentos no nível de investimentos devem optar por setores como: Comércio (22), Transporte (23), Financeiras e seguros (25) e Outros serviços (26), pois estes comportam-se como bons geradores de renda sem aumentos consideráveis no consumo de energia. Por outro lado, se o objetivo for aumentar o nível de emprego, os setores mais apropriados para receberem o choque são Agropecuária (1), Indústrias alimentares (18), Indústrias diversas (19) e Comércio (22). 
Os comentários feitos nesta seção permitem uma visualização mais clara do padrão de consumo de energia elétrica no Ceará. Porém, é importante ressaltar que os resultados apresentados neste capítulo não têm a pretensão de serem definitivos quanto à identificação do perfil de consumo da água e energia elétrica do Ceará, uma vez que a qualidade e consistência dos dados utilizados não permitem maiores aprofundamentos.

Ë válido ressaltar, no entanto, que este estudo torna-se importante à medida que é uma primeira tentativa de fundamentar os conhecimentos relativos ao padrão de consumo de água e energia elétrica do Ceará, em nível setorial, criando desta forma, a possibilidade de aprimoramento do bando de dados já existente e o surgimento de novos trabalhos na área. 


\section{CONCLUSÕES}

Neste capítulo estão expostas as principais conclusões obtidas durante o desenvolvimento do trabalho aqui apresentado. Inicialmente serão abordadas as questões referentes à análise das relações econômicas do Ceará com o resto do Nordeste e resto do Brasil e em seguida será discutida a importância da água e da energia elétrica no crescimento do Estado.

As técnicas de insumo-produto, ao considerarem as estruturas internas do modelo inter-regional formado por Ceará, resto do Nordeste e resto do Brasil, levaram à identificação dos setores-chave e das interdependências existentes em cada região. Ficou clara a supremacia da região resto do Brasil em relação às demais quanto ao seu papel como fornecedora e demandadora de insumos. No entanto, isto é conseqüência das relações comerciais propriamente ditas mas, principalmente devido ao seu tamanho em relação ao Ceará e resto do Nordeste.

A desvalorização cambial que marcou a economia brasileira no ano de 1999, ano de referência para este estudo, fez com que alguns setores apresentassem um bom desempenho, estimulando assim, a atividade econômica no país. A análise do sistema inter-regional como um todo, mostra que, dentre estes setores, os que mais estabelecem relações comerciais com os outros setores, localizados ou não na própria região, são: Agropecuária, Siderurgia, Química, Têxtil e Indústrias alimentares. O desempenho dos setores citados, devido a condições econômicas favoráveis, tem reflexos positivos sobre os demais setores e estimula as transações na economia, o que foi constatado através da análise do campo de influência. Com relação ao Ceará isoladamente, pode-se concluir que o Estado se encontra em uma fase de consolidação da economia. De um modo geral, 
a Agropecuária, a Indústria e os Serviços cearenses apresentam relações fracas no sistema inter-regional. A Agropecuária apesar de se mostrar integrada como fornecedora de insumos, apresenta um papel instável na economia estadual. No ano de 1999, especificamente, foi favorecida pela desvalorização cambial e pelas condições climáticas verificadas.

A Indústria apresenta baixo dinamismo, com os menores padrões de ligação com os outros setores, o que sugere que os benefícios alcançados através dos incentivos políticos que vem recebendo do governo estadual por meio de programas como o Programa de Incentivos ao Financiamento de Empresas e o Fundo de Investimento do Nordeste, ainda não estão sendo propagados aos demais setores econômicos. Porém é importante ressaltar o comportamento do setor Têxtil, que se destaca como um setorchave na economia do Ceará, interagindo tanto com os setores fornecedores de insumos quanto com os setores demandantes.

Os Serviços apresentam os mais altos índices de ligação para trás e para frente, desempenhando assim um papel fundamental como indutor do crescimento no Ceará.

A decomposição da produção total induzida de cada região pela demanda final em produção induzida pela demanda da própria região e das demais regiões mostra a pequena influência das outras regiões, ou seja, a baixa capacidade de interação entre as regiões uma vez que nenhuma região desempenha um papel importante como indutora de produção nas outras regiões no ano de 1999.

A análise das relações entre as demandas finais de cada região e a produção dos setores nela inseridos mostra que os setores são mais vulneráveis a variações na demanda da própria região que a variações na demanda das outras regiões.

Com relação a estas constatações, são sugeridos aqui, alguns trabalhos que ajudem a responder às seguintes indagações: até que ponto, a integração regional que geralmente é apontada como algo positivo pelo fato de promover o comércio e a ligação 
entre as regiões, é importante para o crescimento econômico regional? Sabe-se que o comércio entre regiões envolve perdas e ganhos para os setores. No caso do Ceará, até que ponto os setores que ganham com o comércio com o resto do país podem compensar as perdas dos demais setores e ainda contribuir com o crescimento econômico do Estado?

Ao se analisar os impactos de um choque na demanda final sobre a renda, emprego e importação do sistema inter-regional constata-se diferentes reações entre as três regiões o que demonstra a necessidade de políticas específicas para cada uma delas. O Ceará mostra-se como o mais importante gerador de renda e emprego em relação ao Resto do Nordeste e Resto do Brasil.

No modelo inter-regional os setores mais importantes na geração de renda pertencem ao segmento serviços, enquanto que os maiores geradores de emprego estão inseridos na indústria. $\mathrm{O}$ maior aumento nas importações decorrente de choques na demanda ocorrem nas indústrias mostrando que as mesmas formam o segmento mais aberto do país.

É importante observar que estes resultados refletem, no caso da geração de empregos no Ceará, a menor exigência quanto à qualificação de mão-de-obra e os baixos salários médios pagos no Estado. Um outro ponto importante a ser abordado é que além de se conhecer os principais setores geradores de emprego, é preciso a adoção de políticas voltadas para as questões salariais (geralmente os maiores entraves para a geração de novos empregos), ou ainda, políticas destinadas a aperfeiçoar o mercado de trabalho através da qualificação de mão-de-obra e criação de empregos diretos.

A separação da região Ceará do modelo inter-regional seguida da incorporação da água e da energia elétrica ao modelo cearense originou um modelo ecológico de insumo-produto para o Ceará. Através deste modelo foi possível estimar os coeficientes de consumo de água e energia elétrica que permitiram identificar os principais setores consumidores destes recursos. No caso da água, o consumo está 
bastante concentrado na agricultura irrigada, já o consumo de energia é distribuído fé forma homogênea entre todos os setores da economia.

Os coeficientes de água e energia levaram aos multiplicadores. Segundo estes, o maior propagador de consumo de água e energia no Ceará é a indústria.

Os impactos de aumentos na demanda final sobre os consumos de água energia e uma comparação destes com a geração de renda e emprego no Ceará mostram a necessidade de políticas econômicas associadas a políticas de gerenciamento destes recursos.

Outra constatação importante é que, a disponibilidade de água não se constitui um impedimento ao crescimento econômico do Estado. Porém, como se trata de um recurso escasso, são necessárias políticas de gerenciamento hídrico para garantir que as gerações futuras possam usufruir de seus beneficios.

Quanto ao consumo de energia elétrica pode-se afirmar que o crescimento econômico do Ceará está atrelado ao aumento no consumo de energia de energia elétrica e que o racionamento de energia, exigindo uma diminuição deste consumo por parte dos setores econômicos provavelmente levaria a uma queda no nível de produção e consequentemente, nos níveis de emprego e renda. Sendo assim, é essencial que os empresários passem a utilizar a energia elétrica de forma racional, evitando desperdícios, utilizando fontes alternativas e adotando tecnologias poupadoras. Além disso, espera-se que as políticas de desenvolvimento priorizem os setores menos eletrointensivos, ou seja, que consomem menos energia no seu processo produtivo, ao decidirem onde aplicar seus investimentos.

Os comentários feitos neste capítulo referentes à água e à energia elétrica, permite uma visualização mais clara do padrão de consumo de energia elétrica no Ceará. Porém, é importante ressaltar que as conclusões apresentadas não têm a pretensão de serem definitivas quanto à identificação do perfil de consumo da água e energia elétrica 
do Ceará, uma vez que a qualidade e consistência dos dados utilizados não permitem maiores aprofundamentos.

Ë válido ressaltar no entanto, que este estudo torna-se importante à medida que é uma primeira tentativa de fundamentar os conhecimentos relativos ao padrão de consumo de água e energia elétrica do Ceará, em nível setorial, criando desta forma, a possibilidade de aprimoramento do banco de dados já existente e o surgimento de novos trabalhos na área.

Assim, como forma de dar continuidade a este trabalho, sugere-se a criação de um banco de dados consistente com informações sobre consumo de água e energia elétrica em nível setorial, que permita a identificação das trocas de água e energia elétrica entre os setores de modo a fornecer informações sobre o quanto destes recursos, em casos de racionamento, pode ser transferido de um setor para outro sem danos à produção. É interessante ainda, a ampliação do modelo ecológico através da adição das regiões Resto do Nordeste e Resto do Brasil para que sejam analisadas as possibilidades de transferência de água e energia de regiões onde estes recursos são mais abundantes para as regiões mais carentes. 


\section{REFERÊNCIAS BIBLIOGRÁFICAS}

ABDALlAH, P.R.; MONTOYA, M.A. Perspectivas da utilização de modelos de insumo-produto na administração do meio ambiente. In: MONTOYA, M. A. (Org.). Relações intersetoriais do mercosul e da economia brasileira: uma abordagem de equilíbrio geral do tipo insumo-produto. Passo Fundo: EDIUPF, 1998. 289p.

AGÊNCIA NACIONAL DE ENERGIA ELËTRICA - ANEEL. Banco de informações de geração. http://ww.aneel.gov.br/aplicacoes/ capacidadegeracaodobrasil/ resumobrasil.asp (6 fev 2002)

AGÊNCIA NACIONAL DE ENERGIA ELËTRICA - ANEEL. Informações do setor elétricohttp://www.aneel.gov.br/aplicacoes/leituraarquivo/default.cfm?idaplicacao= (15 fev. 2002)

BOTHA, S.J.; VILJOEN, M.F. Use of the input-output technique to determine the total economic consequences of water restrictions for uses of Vaal River water. Agrekon: [s. ed.], 1991. 352p.

BRASIL. Ministério da Fazenda. Secretaria de Planejamento. Panorama macroeconômico brasileiro: efeitos do racionamento de energia elétrica sobre a oferta agregada. Brasília, 2001. 141p.

BRASIL. Ministério da Integração Nacional. Projeto São Francisco: uso racional da água. http://ww.integracao.gov.br/uso-racional-da-agua.html. (16 nov. 2001) 
BRASIL. Ministério do Planejamento Orçamento e Gestão. A oferta de energia elétrica no mercado brasileiro. http://ww.infraestruturabrasil. gov.br/perfis/ene2asp (15 fev. 2002)

CAVALCANTE, I.N. As águas subterrâneas do Estado do Ceará. http://www.iica.org.br/aguatrab/itacaraci\%20cavalcante/p1tbaas 2 .htm $\quad(12 \mathrm{dez}$. 2000)

CHENERY, H. Regional analysis. In: CHENER, Y.H. ; CAO PINA, V. The structure and growth of italian economy. Rome: U.S. Mutual Security Agency, 1953.

CNI Indústria e Produtividade. Rio de Janeiro, n.10, jan./fev. 2001. 52p.

COMPANHIA ENERGÉTICA DO CEARÁ. Demostrações financeiras da COELCE: relatório anual. Fortaleza: COELCE, 2000. 23p.

COMPANHIA DE GESTÃO DOS RECURSOS HIDRICOS DO CEARÁ - COGERH. Gestão das águas. http://ww. cogerh.com.br/gestao2.asp?page=planejam $(29 \mathrm{fev}$. 2001)

CONSIDERA, C.M.; RAMOS, R.L.O.; MAGALHÃES, K.M.M. et. al. Matrizes de insumo-produto regionais 1985 e 1992: metodologia e resultados. Rio de Janeiro: IPEA, NEMESIS, 1997. 55p.

CUMBERLAND, J.H. A regional interindustry model for analysis of development objectives. Regional Science Association, v.7, n.4, p.64, Oct.1966.

DABI, D. D.; ANDERSON, W. P. Application of a commodity-by-industry economic-ecologic model to water demand in a rural economy. [s.1.]: [s. ed.], 1998.

DALY, H. On economics as a life science. Journal of Political Economy, v.3, n.76, May/June 1968. 
DAVIS, H.C. Multirregional input-output techniques and western water resources development. In: Economic evaluation of water. Berkeley: University of California, Water Resources Center, 1968. 142p. (Contribution, 125)

DECALUWÉ, B.; PATRY, A.; SAVARD, L. Quand l'eau n'est plus un don du ciel: un MEGC appliqué au Maroc. Colloque international sur la modelisation en equilibre general calculable en economie du developpment. Québec: Université Laval, 1997. 26p.

DERVIS, K.J.M.; ROBINSON, S. General equilibrium models for development policy. Cambridge: University Press, 1984. 526p.

DOMINGUES, E.P.; HADDAD, E.A. EFES: um modelo aplicado de equilíbrio geral para economia brasileira: projeções setoriais para 1999 a 2004. São Paulo: IPEA, 2000. 67p. (Texto para Discussão, 25)

DRACUP, J.A.; TURNAGE, J.J.; HUSSEINY, A.A. Desalted fresh water demand and suply projections, an case study of Saudi Arabia. In: INTERNATIONAL SYMPOSIUM ON FRESH WATER, 7., 1980. v.11, p.19-29.

FIGUEROA, M. O problema agrário no Nordeste do Brasil: análise e proposições. São Paulo: HUCITEC, 1977. 272p.

FUNDAÇÃO INSTITUTO DE PESQUISA E INFORMAÇÃO DO CEARÁ - Atlas do Ceará. Forlaleza: IPLANCE, 1997. v.1.

FUNDAÇÃO INSTITUTO DE PESQUISA E INFORMAÇÃO DO CEARÁ . Indicadores Econômicos. Forlaleza: IPLANCE, 2000.

FUNDAÇÃO INSTITUTO DE PESQUISA E INFORMAÇÃO DO CEARÁ. Anuário Estatístico do Ceará. Forlaleza: IPLANCE, 2001.

FUNDO DAS NAÇÕES UNIDAS PARA A INFÂNCIA - UNICEF. O progresso das nações. http://ww.unicef.pt/pdf/nations.pdf (10 out. 2001) 
GARJULLI, R. A participação dos usuários na implementação dos instrumentos de gestão dos recursos hídricos: o caso do Ceará. http://www.ivdialogo. com $/ \% 5$ ctrabalhos $\% 5$ cdial004.pdf (13 maio 2001)

GOVERNO do CEARA. Ceará: localização e características geográficas. http://ww.ceara.gov.br/cara.htm (15 jul. 2000)

GUILHOTO, J.J.M. Um modelo computável de equilíbrio geral para planejamento e análise de políticas agrícolas (Papa), na economia brasileira. Piracicaba, 1995. 258p. Tese (Livre Docência) - Escola Superior de Agricultura "Luiz de Queiroz", Universidade de São Paulo.

GUILHOTO, J.; SONIS, M.; HEWINGS, G. Linkages and multipliers in a multiregional framework: integration of alternative approaches. Urbana: University of Illinois, Regional Economics Applications Laboratory, 1996. (Discussion paper)

HADDAD, P. Contabilidade social e economia regional: análise de insumo-produto. Rio de Janeiro: Zahar Editores, 1976. 242p.

HADDAD, P. Análise de insumo-produto regional e interregional: multiplicadores de produção, de renda e de emprego. In: HADDAD, P.R. (Org.). Economia regional: teoria e métodos de análise. Fortaleza: BNB, ETENE, 1989.

HAMILTON, J.R.; ROBINSON, M.H.; WHITTLESEY, N.K.; DELLIS, J. Interregional spillovers in regional impact assessment: New Mexico, Texas, and the Supreme Court. Growth and Change, v.25, p.75, 1994.

HANSEN, W.; TIEBOUT, C. An intersectorial flow analysis of the California economy. The Review of Economics and Statistics, v.3, n. 45, 1963.

HIRSCHMAN, A.O. The strategy of economic development. New Haven: Yale University Press, 1958. 181p. 
ISARD, W. Interregional and regional input-output analysis: a model of a spaceeconomy. Review of Economics and Statistics, v.33, p.319, 1951.

ISARD, W. Ecological-economic analysis for regional development. New York: Free Press, 1972. 352p.

ISARD, W. Location analysis for industry and service trades: comparative cost and other approaches. In: ISARD, W.; AZIS, I.J.; DRENNAN, M.P. et al. Methods of interregional and regional analysis. London: Ashgate, 1998. 127p.

JANARY JUNIOR. Pressionada pela seca a agricultura perde espaço na economia. Gazeta Mercantil, São Paulo, 27 jul. 1999. p.7.

KEMPER, H.E. O custo da água gratuita : alocação e usos dos recursos hídricos no Vale do Curu, Ceará, Nordeste brasileiro. Linkoping: Binkopeing Studies in Arts and Science, 1997. 152p.

LEE, K.C.; WANG, D.C. A regional input-output analysis for forestry and wood-based industries in the Pingtung area. Quaterly Journal of the Experimental Forest of National Taiwan University, v.3, n. 1, p.35, July 1989.

LEONTIEF, W. The structure of american economy: 1919-1939. New York: Oxford University Press, 1951. $152 \mathrm{p}$.

LEONTIEF, W. Enviromental repercussion and the economic structure: an input-output approach. The Review of Economics and Statistics, v.52, n.3, p.262, Aug.1970.

LEONTIEF, W. A economia do insumo-produto. São Paulo: Abril Cultural, 1983. 226 p.

LEONTIEF, W. Input-output economics. 2.ed. New York: Oxford University Press, 1986. 
LEONTIEF, W.; HOFFENBERG, M. The economic effect of disarmament. Scientic American, April 1961.

LEONTIEF, W.; STROUT, A. Multirregional input-output analysis. In: BARNA, T. (Org.). Structural interdependence and economic development. New York: Macmillan, 1963.

LIMA, J. F. Os recursos hídricos no Brasil: algumas considerações preliminares. Revista Econômica do Nordeste, v.30, n.1, p.64, jan./mar. 1999.

MCGILVRA, Y.J. Linkages key sectors and development strategy. In: LEONTIEF, W. (Ed.). Structure, system and economic policy. Cambridge: University Press, 1977. p.49-56.

MEI, X.; GUISHENG, N.; XIANGLAN, J. Application of an input-output model to the Beijing urban water: use system. In: POLENSK, K.; XIKANG, C. (Eds.). Chinese economic planning and input-output analysis. Hong Kong: Oxford University Press, 1991. p.239-253.

METZLER, L. A multiple region theory of income and trade. Econometrica, v.8, n.5, Oct. 1950.

MIERNYK, W.H. Elementos de análise do insumo-produto. São Paulo: Atlas, 1974. $164 p$.

MILLER, R.E.; BLAIR, P.D. Input-output analysis: foundations and extensions. New Jersey: Prentice Hall, 1985. 463p.

MIRANDA, C.R. Economia e meio ambiente: uma abordagem de insumo-produto. Pesquisa e Planejamento Econômico, v.10, n.2, p.601, ago. 1980. 
MONTOYA, M.A. Matriz de insumo-produto interregional do Mercosul para 1990, as desigualdades regionais e os impactos intersetoriais do comércio interregional. Piracicaba, 1998. 175p. Tese (Doutorado) - Escola Superior de Agricultura "Luiz de Queiroz", Universidade de São Paulo.

MORETTO, A.C. Relações intersetoriais e interregionais na economia paranaense em 1995. Piracicaba.2000. 161p. Tese (Doutorado) - Escola Superior de Agricultura "Luiz de Queiroz", Universidade de São Paulo.

MORGAN, W.D.; MERCER, L.J.; DINAR, A.; ZILBERMAN, D. Analyses of irrigation and drainage problems: input-output and econometric models. The economics and management of water and drainage in agriculture. [s.1.]: [s.ed.], 1991. p.511-529.

MOSES, L. The stability of interregional trading patterns and input-output analysis. The American Economic Review, v.45, n.5, p.803, 1955.

MOTTA, R.S. Utilização dos critérios econômicos para a valorização de água no Brasil. Rio de Janeiro: IPEA, 1998. (Texto para Discussão, 556)

PIQUEIRA, J.R.C.; BRUNORO, C.M. Energia, uso, geração e impactos ambientais. São Paulo: Ave Maria, 2000.30p.

POLERNSK, K. An empirical test of interregional input-output models: estimation of 1963 japonese production. American Economic Review, v.60, n.1, p.76, 1970.

POSTEL, S. Last oasis: facing water scarcity. New York: Norton \& Company, 1992. $145 \mathrm{p}$.

RASMUSSEN, P. Studies in intersectorial relations. Amsterdam: North Holland, 1956. $187 \mathrm{p}$.

RICHARDSON, H.W. Input-output and regional economics. Wiltshire: Redwood Press, 1972. 294p. 
RODRIGUES, R.L. A evolução do cooperativismo agropecuário na economia paranaense (1980-1995): uma análise de insumo-produto. Piracicaba, 2000. 171p. Tese (Doutorado) - Escola Superior de Agricultura "Luiz de Queiroz", Universidade de São Paulo.

ROUND, J.I. An interregional input-output approach to the evaluation of nonsurvey methods. Journal of Regional Science, v. 18, n.2, 1978.

ROUND, J.I. Nonsurvey techniques: a critical review of the theory and the evidence Internacional Regional Science Review, v.8, n.3, 1983.

SANTOS, A.R.S. dos A biodiversidade da Terra e o desenvolvimento sustentável. http://www. aultimaarcadenoe.com/artigo41.htm (12 nov. 2001)

SILVEIRA, S.F.R. Inter-relações econômicas dos estados na bacia do Rio São Francisco: uma análise de insumo-produto. Piracicaba, 2000. 245p. Tese (Doutorado) - Escola Superior de Agricultura "Luiz de Queiroz", Universidade de São Paulo.

SOARES, R.L.de A.; GARJULLI, R. Cartilha sobre gestão dos recursos hídricos. http://www.cogerh.com.br/nivel2.asp?page $=$ cart\# (12 out. 2001)

SONIS, M.; HEWINGS, G.J.D. Error and sensitivity input-output analysis: a new approach. In: MILLER, R.E.; POLENSK, K.R.; ROSE, A .Z. (Ed.). Frontier of input-output analysis. New York: Oxford University Press, 1989.

SONIS, M.; GUILHOTO, J.J.M.; HEWINGS, G.J.D. "The asian economy: trade structure interpreted by feedback loop analysis". Journal of Applied Input-output Analysis, v.2, n.2, p.24, 1995.

SOUZA, N. de J. Metodologia de obtenção das matrizes de insumo-produto dos estados da região Sul, 1985 e 1995. Porto Alegre: UFRGS, 1997. 15p. (Texto para Discussão, 14) 
SUPERINTENDÊNCIA DO DESENVOLVIMENTO DO NORDESTE - SUDENE. Polígono das secas. http://www.pageserver-nt.sudene.gov.br/isapi/sig.html (02 jan. 2000)

SUPERINTENDÊNCIA DO DESENVOLVIMENTO DO NORDESTE - SUDENE. Carta de conjuntura do Nordeste do Brasil - 2000. http://www sudene gov br/economicos/carta2000/atividadeglobal.html $\quad$ (05 fev. 2001)

TUCCI, C.E.M.; HESPANHOL, I.; CORDEIRO NETTO, O. de M. Gestão da água no Brasil: uma primeira avaliação da situação atual e das perpectivas para 2025. Porto Alegre: UFRS, 2001. 139p.

VASCONCELOS, J.R. Ceará, Pernambuco, Paraná e Rio Grande do Sul: economia, finanças públicas e investimentos nos anos de 1986-1996. Rio de Janeiro: IPEA, 1999. (Texto para Discussão, 626)

VIEIRA, V.P.P.B. A água e o desenvolvimento sustentável no Nordeste. Brasília: IPEA, 2000. 264p.

VITOR,P.A. Pollution: economy and environment. London: George Allen \& Unwin, 1972. 210p.

WINPENNY, J.T. Managing water as an economic resource. London: Rotledge, 1994. $87 \mathrm{p}$.

WORLDWATCH INSTITUTE. Qualidade de vida. http://www wwiuma.org.br /alerta01.html (10 out. 2001)

YOUNG, R.A.; GRAY, L. Input-output models, economics surplus, and the evaluation of state or regional water plans. Water Resources Research, v.21, n.12, p.18191823, Dec. 1985. 
ANEXOS 
ANEXO A - Agregações dos setores e produtos das matrizes do Nordeste e do Brasil referentes a 1992.

\begin{tabular}{|c|c|c|c|}
\hline Ordem & Setores da Matriz Brasil 1992 & Ordem & Setores Agregados \\
\hline 1 & Agropecuária & 1 & Agropecuária \\
\hline 2 & Extrativa Mineral & \multirow{2}{*}{2} & \multirow{2}{*}{ Extrativa Mineral } \\
\hline 3 & Extração de Petróleo e Gás & & \\
\hline 4 & Mineral não Metálico & 3 & Mineral não Metálico \\
\hline 5 & Siderurgia & \multirow[t]{3}{*}{4} & \multirow[t]{3}{*}{ Siderurgia } \\
\hline 6 & Metalurgia não Ferrosos & & \\
\hline 7 & Outros Metalúrgicos & & \\
\hline 8 & Máquinas e Tratores & 5 & Mecanica \\
\hline 9 & Material Elétrico & 6 & Fabricação de material eletrico \\
\hline 10 & Equipamentos Eletrônicos & 7 & Fabricação de eletrônicos \\
\hline 11 & Autom., Caminhões e Ônibus & \multirow[t]{2}{*}{8} & \multirow[t]{2}{*}{ Material de transporte } \\
\hline 12 & Peças e Outros Veículos & & \\
\hline 13 & Madeira e Mobiliário & 9 & Madeira e Mobiliário \\
\hline 14 & Papel e Gráfica & 10 & Papel e Gráfica \\
\hline 15 & Indústria da Borracha & 11 & Indústria da Borracha \\
\hline 16 & Elementos Químicos & \multirow{3}{*}{12} & \multirow{3}{*}{ Química } \\
\hline 17 & Refino do Petróleo & & \\
\hline 18 & Químicos Diversos & & \\
\hline 19 & Farmacêutica e perfumaria & 13 & Farmácia e Perfumaria \\
\hline 20 & Artigos Plásticos & 14 & Artigos Plásticos \\
\hline 21 & Indústria Têxtil & 15 & Indústria Têxtil \\
\hline 22 & Artigos do Vestuário & 16 & Artigos do vestuário \\
\hline 23 & Fabricação de Calçados & 17 & Fab. de calçados e produtos de couros e peles \\
\hline 24 & Indústria do Café & \multirow[t]{6}{*}{18} & \\
\hline 25 & Benef. Produtos Vegetais & & \\
\hline 26 & Abate de Animais & & \\
\hline 27 & Indústria de Laticínios & & \\
\hline 28 & Fabricação de Açúcar & & \\
\hline 29 & Fabricação de Óleos Vegetais & & \\
\hline 30 & Outros Produtos Alimentares & 19 & Bebidas \\
\hline
\end{tabular}

Quadro 1 - Agregação dos setores usados na construção do modelo insumo-produto inter-regional 1992 - Brasil/Ceará. 


\begin{tabular}{|c|l|c|l|}
\hline 31 & Indústrias Diversas & 20 & Indústrias Diversas \\
\hline 32 & S.I.U.P. & 21 & S.I.U.P. \\
\hline 33 & Construção Civil & 22 & Construção Civil \\
\hline 34 & Comércio & 23 & Comércio \\
\hline 35 & Transporte & 24 & Transporte \\
\hline 36 & Comunicações & 25 & Comunicações \\
\hline 37 & Instituições Financeiras & 26 & Financeiras e seguradoras \\
\hline 38 & Serviços prestados às famílias & 27 & Outros serviços \\
\cline { 1 - 2 } & & & \\
\hline 49 & Serv. Prestados às Empresas & & \\
\hline 41 & Aluguel de Imóveis & & \\
\hline 42 & Administração Pública & & \\
\hline
\end{tabular}

Quadro 1 - Agregação dos setores usados na construção do modelo insumo-produto interregional 1992 - Brasil/Ceará.

Fonte: Dados da autora 


\begin{tabular}{|c|c|c|c|}
\hline Ordem & Setores da Matriz Nordeste 1992 & Ordem & Setores Agregados \\
\hline 1 & Agricultura & \multirow[t]{2}{*}{1} & \multirow[t]{2}{*}{ Agropecuária } \\
\hline 2 & Pecuária & & \\
\hline 3 & Extrativa mineral & 2 & Extrativa Mineral \\
\hline 4 & Minerais não metálicos & 3 & Mineral não Metálico \\
\hline 5 & Siderurgia & 4 & Siderurgia \\
\hline 6 & Mecânica & 5 & Mecanica \\
\hline 7 & Fab. Material elétrico & 6 & Fabricação de material eletrico \\
\hline 8 & Fab. Eletrônicos & 7 & Fabricação de eletrônicos \\
\hline 9 & Automóveis, cam. E ônibus & \multirow[t]{2}{*}{8} & \multirow[b]{2}{*}{ Material de transporte } \\
\hline 10 & Mat de transporte & & \\
\hline 11 & Madeira e mobiliário & 9 & Madeira e Mobiliário \\
\hline 12 & Papel e celulose & \multirow[t]{2}{*}{10} & \multirow[t]{2}{*}{ Papel e Gráfica } \\
\hline 13 & Editorial e gráfica & & \\
\hline 14 & Borracha & 11 & Indústria da Borracha \\
\hline 15 & Química & 12 & Química \\
\hline 16 & Farm. E perfumaria & 13 & Farmácia e Perfumaria \\
\hline 17 & Plástico & 14 & Artigos Plásticos \\
\hline 18 & Têxtil & 15 & Indústria Têxtil \\
\hline 19 & Vestuário & 16 & Artigos do vestuário \\
\hline 20 & Calç. Couros e peles & 17 & Fab. de calçados e produtos de couros e peles \\
\hline 21 & Ind. Alimentares & 18 & Ind. Alimentares \\
\hline 22 & Bebidas & 19 & Bebidas \\
\hline 23 & Ind. Diversas & 20 & Indústrias Diversas \\
\hline 24 & S.I.U.P. & 21 & S.I.U.P. \\
\hline 25 & Construção & 22 & Construção Civil \\
\hline 26 & Comércio & 23 & Comércio \\
\hline 27 & Transporte & 24 & Transporte \\
\hline 28 & Comunicação & 25 & Comunicações \\
\hline 29 & Financeiras e seguros & 26 & Financeiras e seguradoras \\
\hline 30 & Outros serviços & 27 & Outros serviços \\
\hline
\end{tabular}

Quadro 2 - Agregação dos setores usados na construção do modelo insumo-produto inter-regional 1992 - Nordeste/Ceará.

Fonte: Dados da autora 


\begin{tabular}{|c|c|c|c|}
\hline Ordem & Produtos da Matriz Brasil 92 & Ordem & Produtos Agregados \\
\hline 1 & Café em coco & \multirow{4}{*}{1} & \multirow{11}{*}{ Produtos da Agricultura } \\
\hline 2 & Cana-de-açúcar & & \\
\hline 3 & Arroz em casca & & \\
\hline 4 & Trigo em grão & & \\
\hline 5 & Soja em grão & \multirow{7}{*}{2} & \\
\hline 6 & Algodão em caroço & & \\
\hline 7 & Milho em grão & & \\
\hline 8 & Bovinos e suínos & & \\
\hline 9 & Leite natural & & \\
\hline 10 & Aves vivas & & \\
\hline 11 & Outros produtos agropecuários & & \\
\hline 12 & Minério de ferro & \multirow{4}{*}{3} & \multirow{4}{*}{ Extrativa mineral } \\
\hline 13 & Outros minerais & & \\
\hline 14 & Petróleo e gás & & \\
\hline 15 & Carvão e outros & & \\
\hline 16 & Produtos minerais não-metálicos & 4 & Minerais não Metálicos \\
\hline 17 & Produtos siderúrgicos básicos & \multirow[t]{4}{*}{5} & \multirow[t]{4}{*}{ Siderurgia } \\
\hline 18 & Laminados de aço & & \\
\hline 19 & Produtos metalúrgicos não-ferrosos & & \\
\hline 20 & Outros produtos metalúrgicos & & \\
\hline 21 & Fabricação e manutenção de máquinas & \multirow{2}{*}{6} & \multirow{2}{*}{ Maquinas e tratores } \\
\hline 22 & Tratores e máquinas de terraplanagem & & \\
\hline 23 & Material elétrico & \multirow[t]{2}{*}{7} & \multirow[t]{2}{*}{ Material Elétrico } \\
\hline 24 & Equipamentos eletrônicos & & \\
\hline 25 & Automóveis, caminhões e ônibus & \multirow[t]{2}{*}{8} & \multirow[t]{2}{*}{ Automóveis, caminhões ônibus e peças } \\
\hline 26 & Outros veículos e peças & & \\
\hline 27 & Madeira e mobiliário & 9 & Madeira e Mobiliário \\
\hline 28 & Papel, celulose, papelão e artefatos & 10 & Celulose, papel, papelão e artefatos \\
\hline 29 & Produtos derivados da borracha & 11 & Produtos derivados da borracha \\
\hline
\end{tabular}

Quadro 3-Agregação dos Produtos usados na construção do modelo insumo-produto inter-regional 1992 - Brasil/Ceará. 


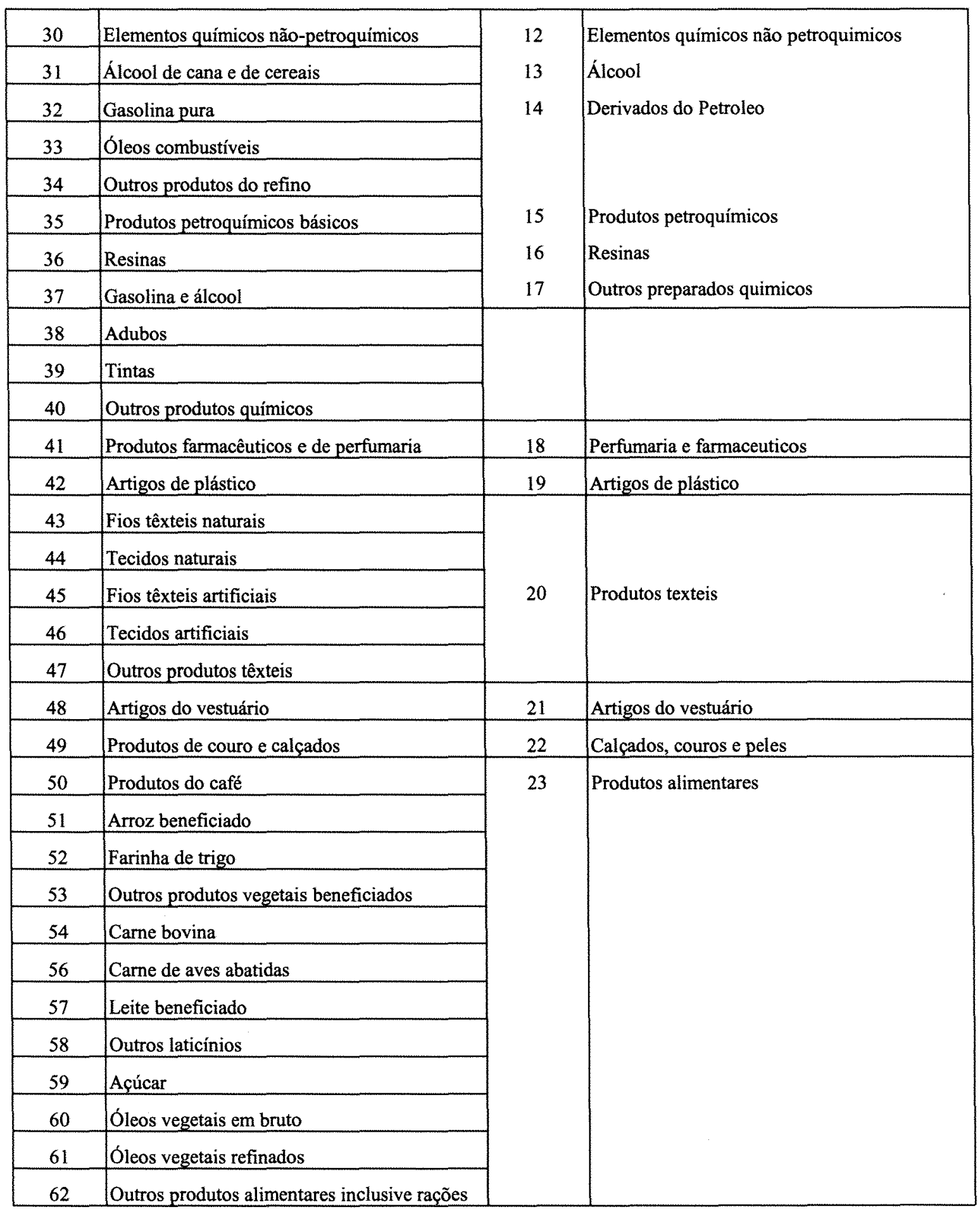

Quadro 3- Agregação dos Produtos usados na construção do modelo insumo-produto inter-regional 1992 - Brasil/Ceará. 


\begin{tabular}{|c|c|c|c|}
\hline 63 & Bebidas & 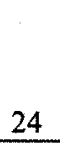 & Bebidas \\
\hline 64 & Produtos diversos & 25 & Produtos diversos \\
\hline 65 & Serviços industriais de utilidade pública & 26 & Serviços industriais de utilidade pública \\
\hline 66 & Produtos da construção civil & 27 & Construção Civil \\
\hline 67 & Margem de comércio & \multirow[t]{2}{*}{28} & \multirow[t]{2}{*}{ Margens de distribuição } \\
\hline 68 & Margem de transporte & & \\
\hline 69 & Comunicações & 29 & Comunicações \\
\hline 70 & Seguros & \multirow{2}{*}{30} & \multirow[t]{2}{*}{ Financeiro e seguros } \\
\hline 71 & Serviços financeiros & & \\
\hline 72 & Alojamento e alimentação & 31 & Outros serviços \\
\hline 73 & Outros serviços & & \\
\hline 74 & Aluguel imputado & & \\
\hline 75 & Saúde e educação mercantis & & \\
\hline 76 & Administração pública & & \\
\hline 77 & Saúde pública & & \\
\hline 78 & Educação pública & & \\
\hline 79 & Serviços prestados às empresas & & \\
\hline 80 & Aluguel de imóveis & & \\
\hline 81 & Serviços privados não-mercantis & & \\
\hline
\end{tabular}

Quadro 3 - Agregação dos Produtos usados na construção do modelo insumo-produto inter-regional 1992 - Brasil/Ceará.

Fonte: Dados da autora 


\begin{tabular}{|c|c|c|c|}
\hline Ordem & Produtos da Matriz Nordeste 92 & & Produtos da Matriz Ceará 92 \\
\hline 1 & Produtos da agricultura & 1 & Produtos da Agricultura \\
\hline 2 & Produtos da agropecuária & 2 & Produtos da Pecuária \\
\hline 3 & Produtos da extrativa mineral & 3 & Produtos da Extrativa Mineral \\
\hline 4 & Minerais não metálicos & 4 & Minerais não metálicos \\
\hline 5 & Produtos siderúrgicos & 5 & Produtos Siderúrgicos \\
\hline 6 & Maquinas e tratores & 6 & Maquinas e tratores \\
\hline 7 & Equipamentos de energia elétrica & \multirow[t]{3}{*}{7} & \multirow[t]{3}{*}{ Equip. em. elet., elet., mat. Eletronico } \\
\hline 8 & Eletrodomésticos & & \\
\hline 9 & Material eletrônico & & \\
\hline 10 & Aut., caminhões e ônibus & \multirow[t]{2}{*}{8} & \multirow[t]{2}{*}{ Aut. Cam. Ônibus, out veíc. e peças } \\
\hline 11 & Outros veículos & & \\
\hline 12 & Madeira & \multirow[t]{2}{*}{9} & \multirow[t]{2}{*}{ Madeira e mobiliário } \\
\hline 13 & Móveis & & \\
\hline 14 & Celulose & \multirow[t]{3}{*}{10} & \multirow[t]{3}{*}{ Celul., papel, papelão artefatos } \\
\hline 15 & Papel, papelão e artefatos & & \\
\hline 16 & Serviços gráficos & & \\
\hline 17 & Produtos derivados da borracha & 11 & Produtos derivados da borracha \\
\hline 18 & El. Químicos não petroquímicos & 12 & El. Químicos não petroquímicos \\
\hline 19 & Álcool & 13 & Álcool \\
\hline 20 & Derivados do petróleo & 14 & Derivados do petróleo \\
\hline 21 & Produtos petroquimicos & 15 & Produtos petroquímicos \\
\hline 22 & Resinas & 16 & Resinas \\
\hline 23 & Outros preparados químicos & 17 & Outros preparados químicos \\
\hline 24 & Farmacêuticos & \multirow[t]{2}{*}{18} & \multirow[t]{2}{*}{ Perfumaria e farmaceuticos } \\
\hline 25 & Perfumaria & & \\
\hline
\end{tabular}

Quadro 4 - Agregação dos Produtos usados na construção do modelo insumo-produto inter-regional 1992 - Nordeste/Ceará. 


\begin{tabular}{|c|l|l|l|}
\hline 26 & Artidos de plástico & 19 & Artidos de plástico \\
\hline 27 & Produtos têxtteis & 20 & Produtos têxtteis \\
\hline 28 & Artigos de vestuárioVestuário & 21 & Artigos de vestuárioVestuário \\
\hline 29 & Couros e peles & 22 & Calçados, couros e peles \\
\hline 30 & Calçados & & \\
\hline 1 & Prod. Alimentares & 23 & Prod. Alimentares \\
\hline 32 & Bebidas & 24 & Bebidas \\
\hline 33 & Prod. Diversas & 25 & Produtos diversos \\
\hline 34 & S.I.U.P. & 26 & S.I.U.P. \\
\hline 35 & Construção & 27 & Construção Civil \\
\hline 36 & Margens de distribuição & 28 & Margens de distribuição \\
\hline 37 & Comunicação & 29 & Comunicação \\
\hline 38 & Financeiras e seguros & 30 & Financeiras e seguros \\
\hline 39 & Outros serviços & 31 & Outros serviços \\
\hline
\end{tabular}

Quadro 4 - Agregação dos Produtos usados na construção do modelo insumo-produto inter-regional 1992 - Nordeste/Ceará.

\section{Fonte: Dados da autora}




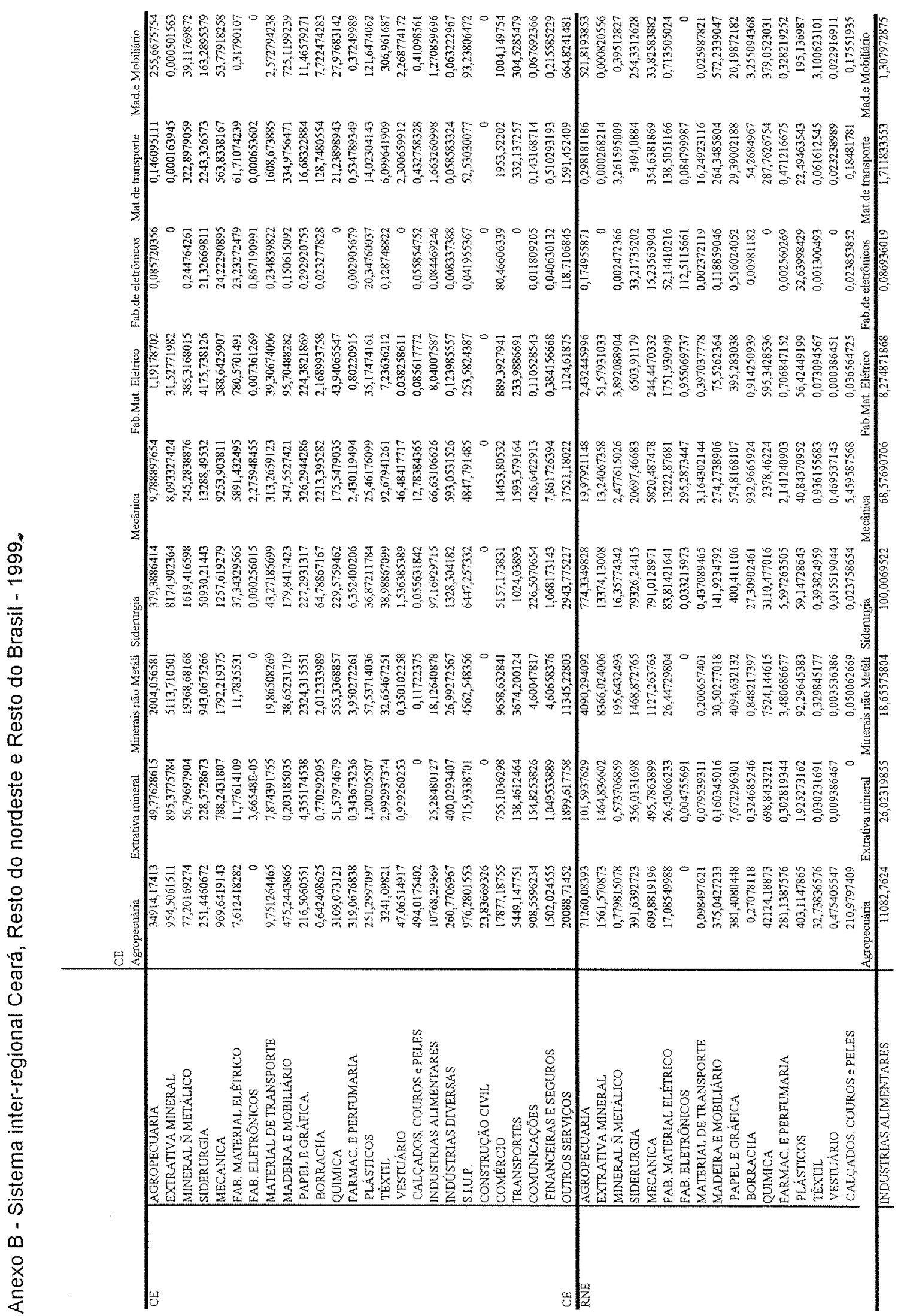




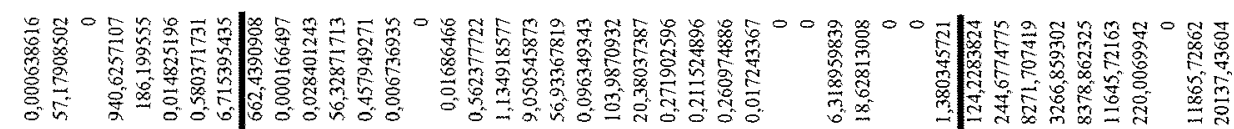
Wun 篔 Wrow

(2)

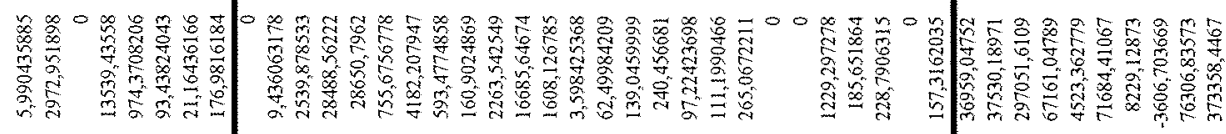

$\frac{\text { क }}{\frac{8}{5}}$

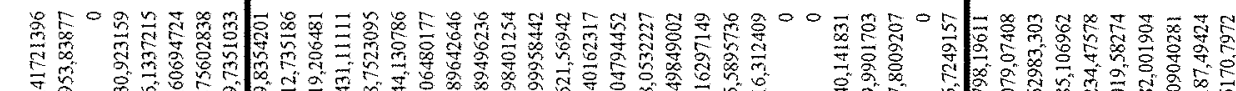

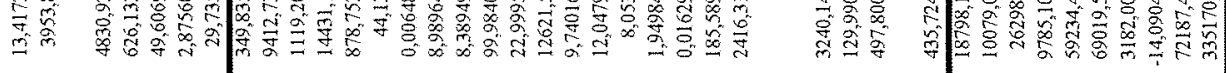

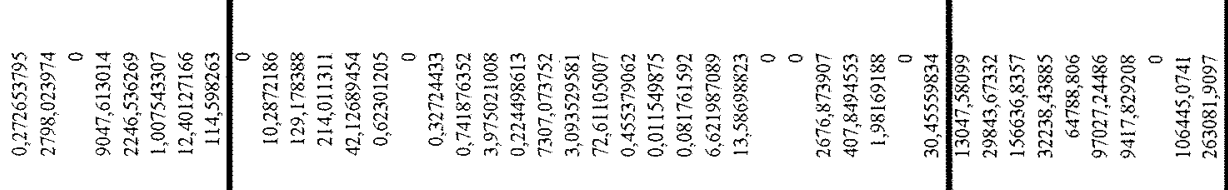
a

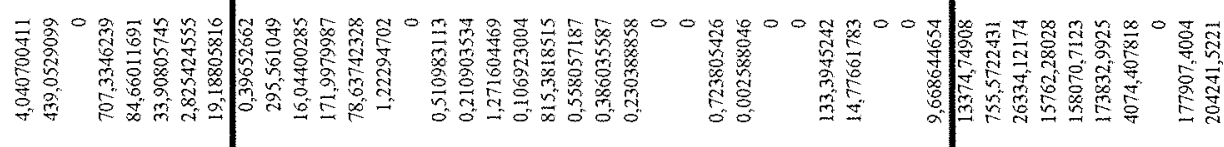

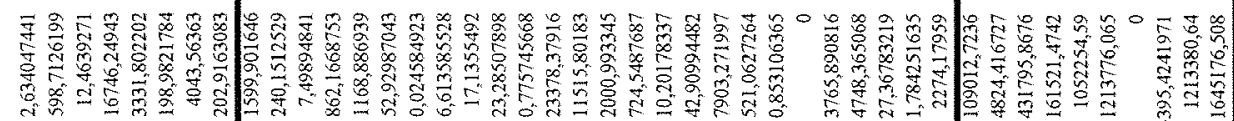
$\alpha$

$\stackrel{\square}{8}$

$\bar{\pi}$

$\frac{\pi}{\frac{\pi}{5}}$

$\frac{1}{1}$

$\stackrel{\frac{1}{9}}{\Xi}$

$\frac{\frac{\pi}{\infty}}{\frac{\pi}{\infty}}$

向

일

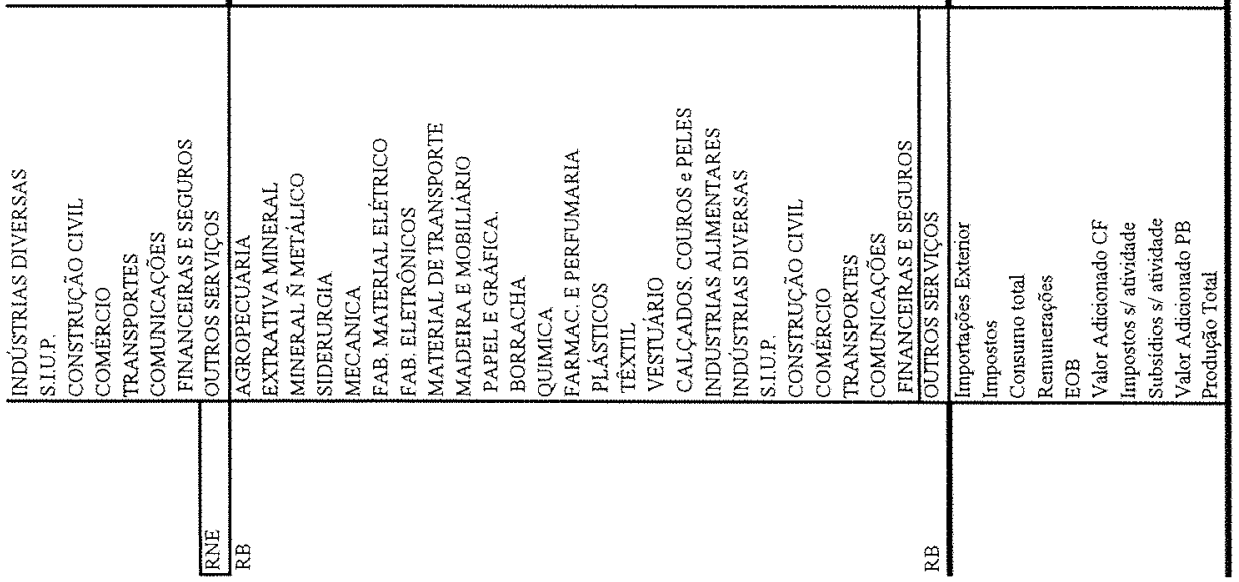




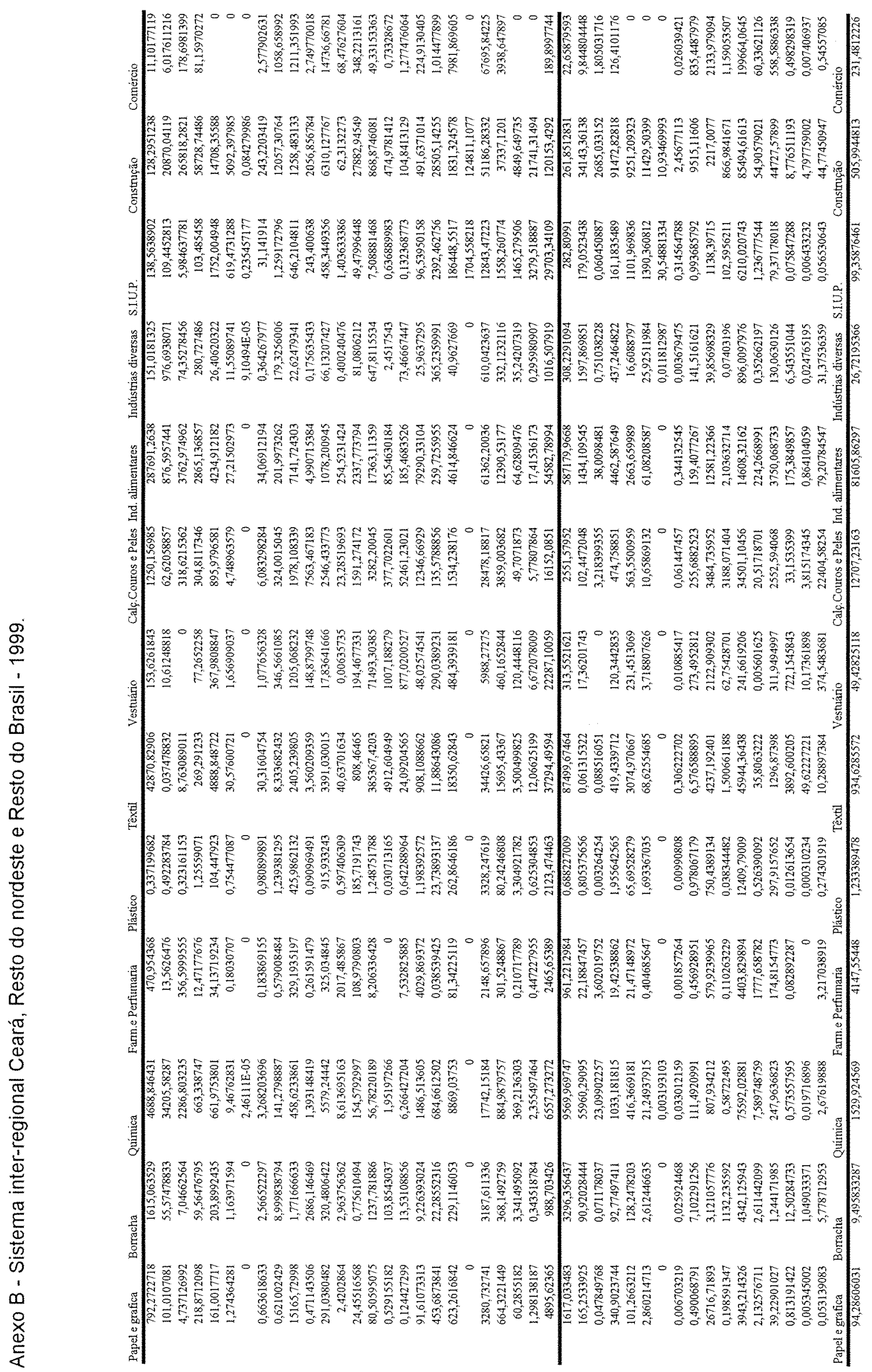




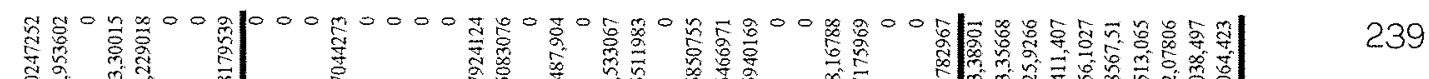

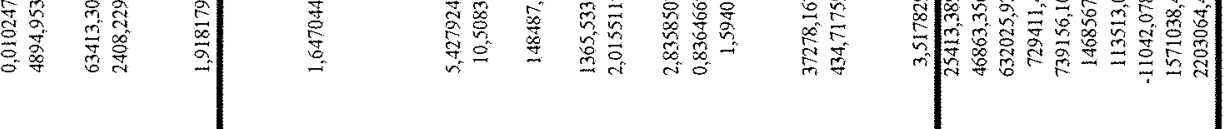

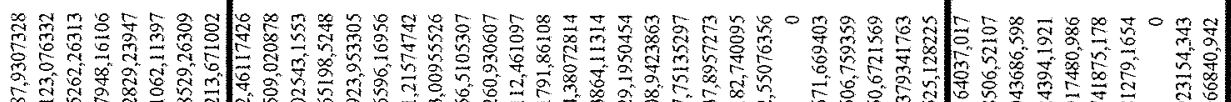

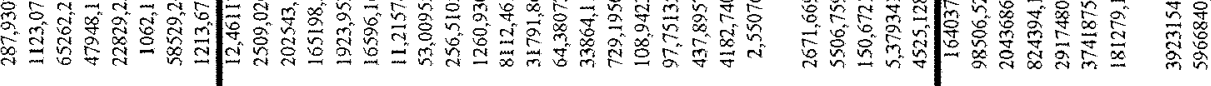

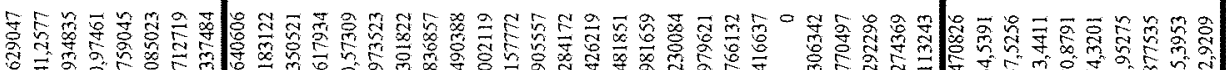

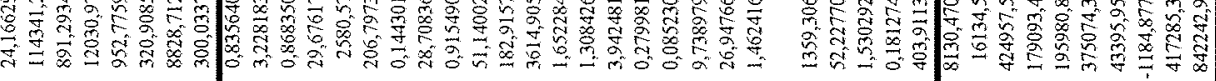

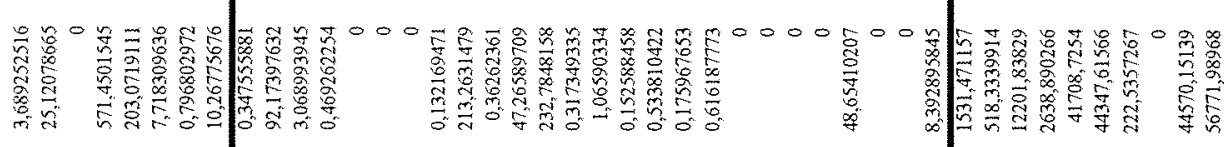

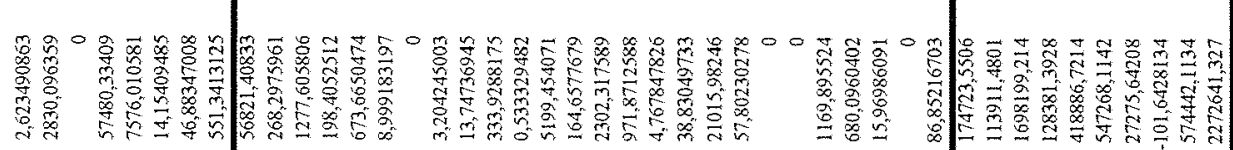

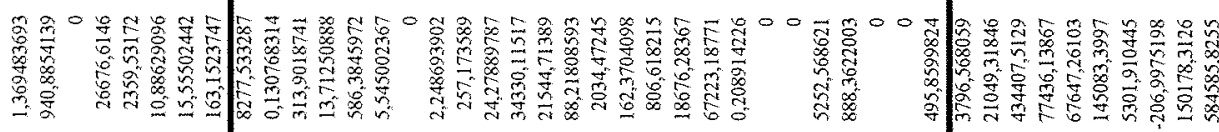

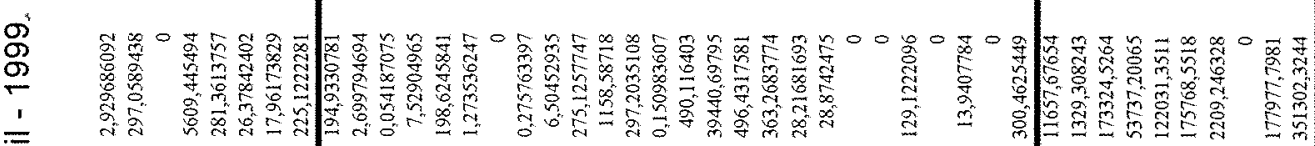

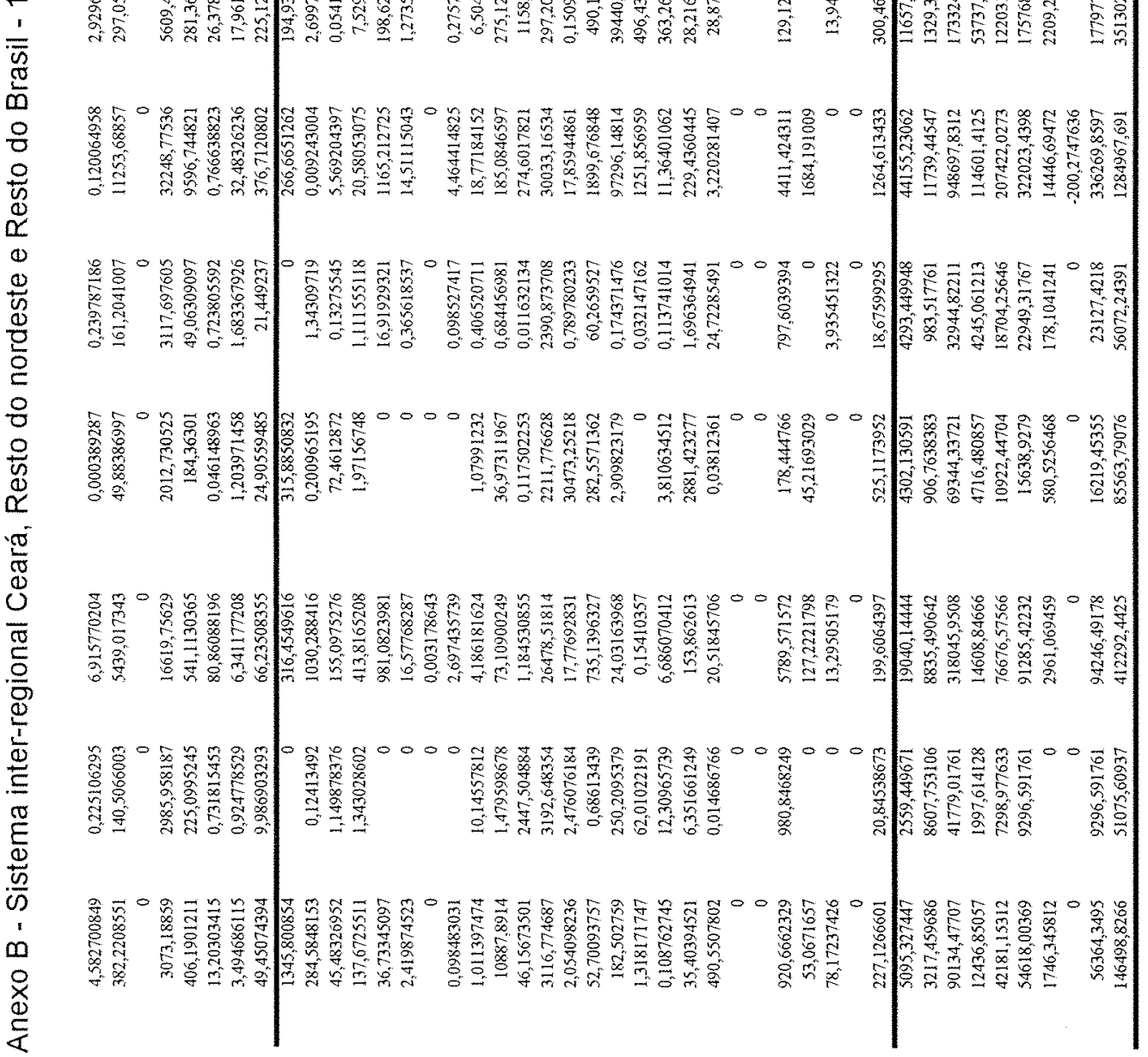




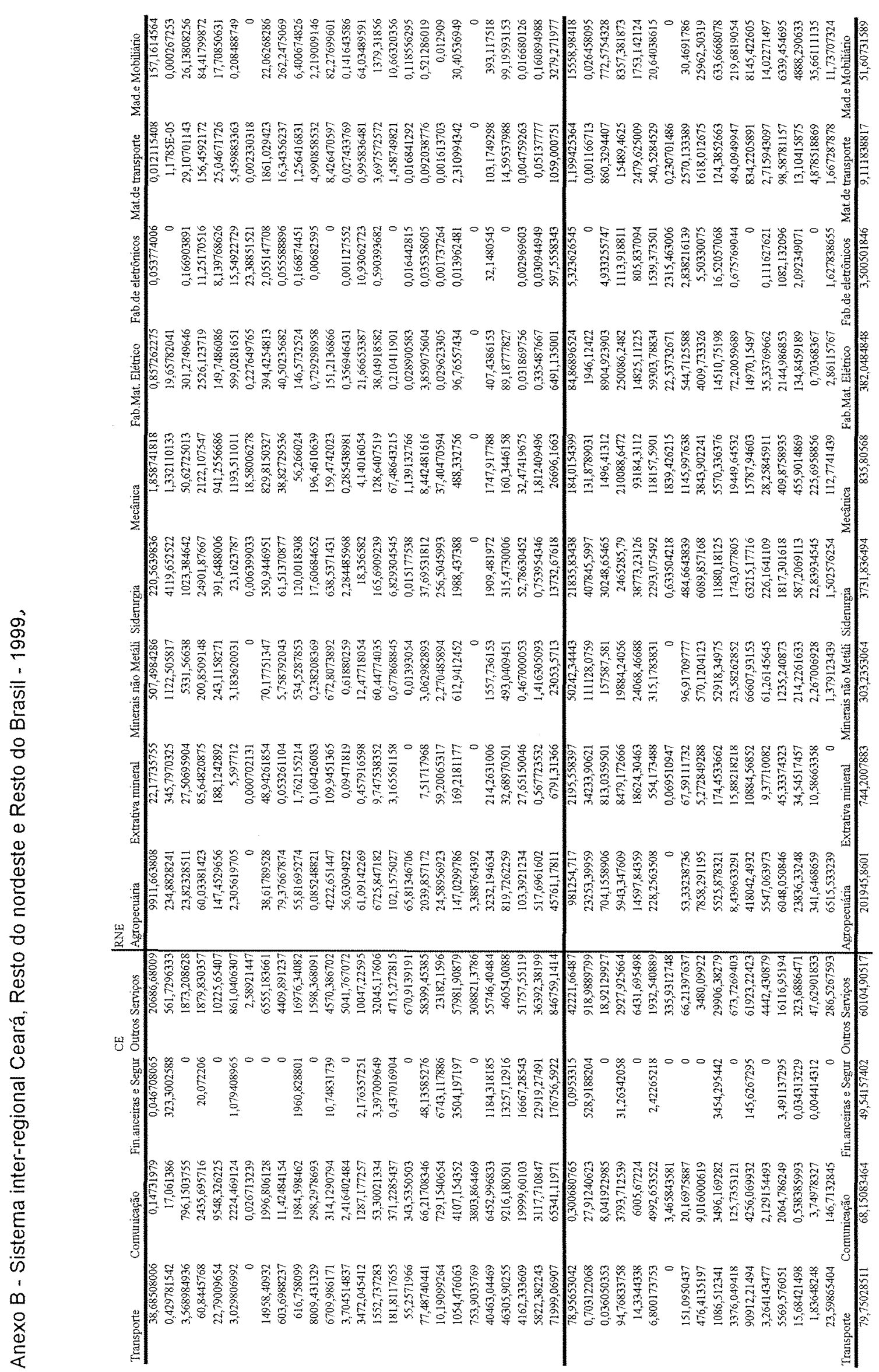




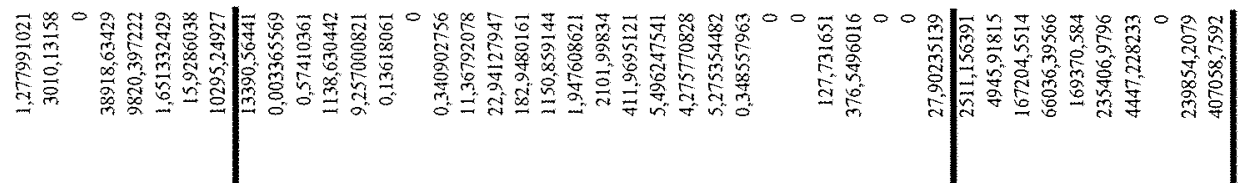

Irin

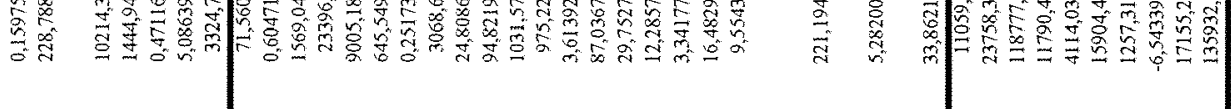

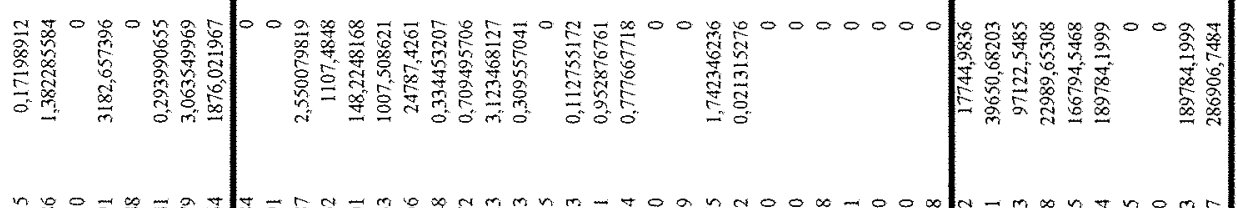

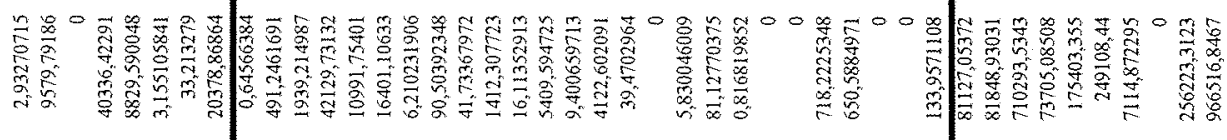

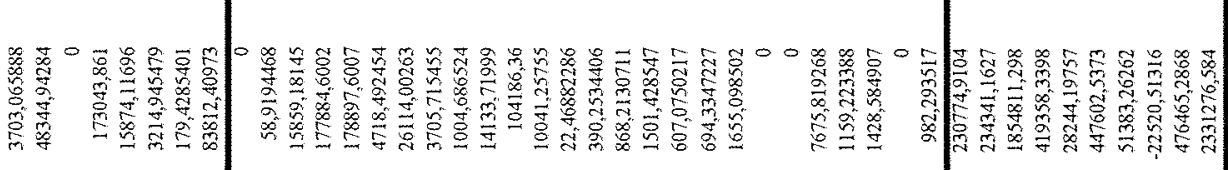

$\stackrel{\text { I }}{\mathscr{O}}$

W

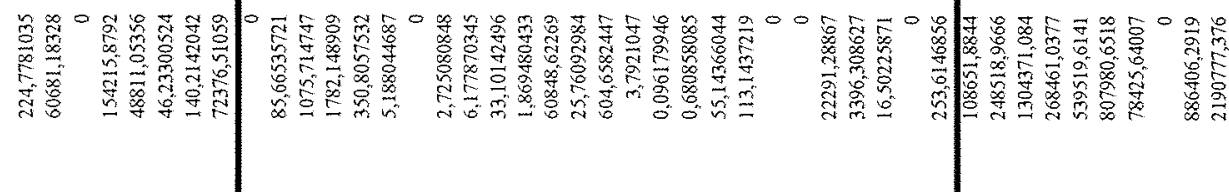

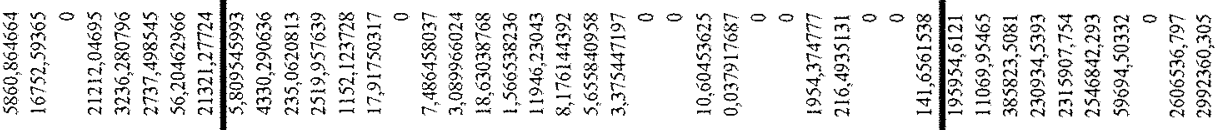

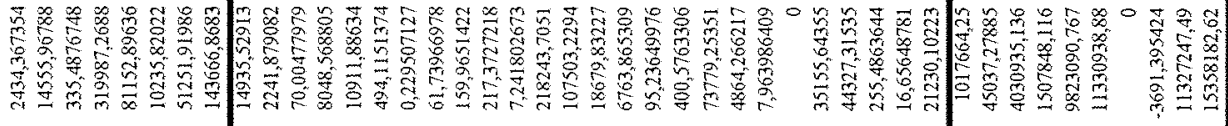

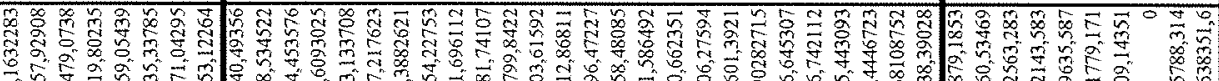

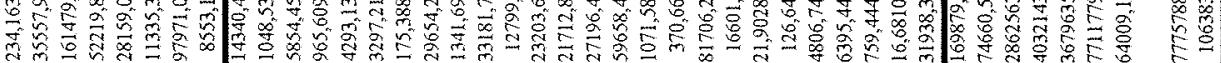

(19)

$\mathcal{U}$

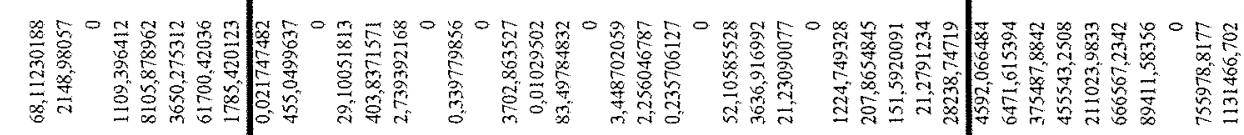

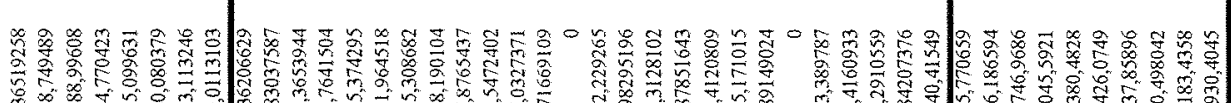

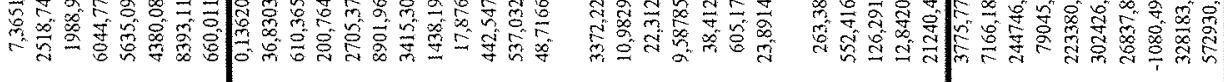

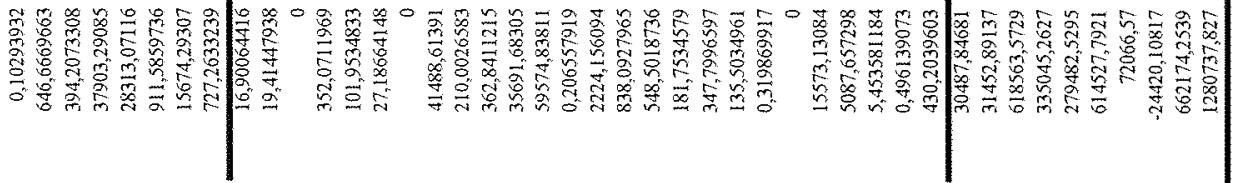




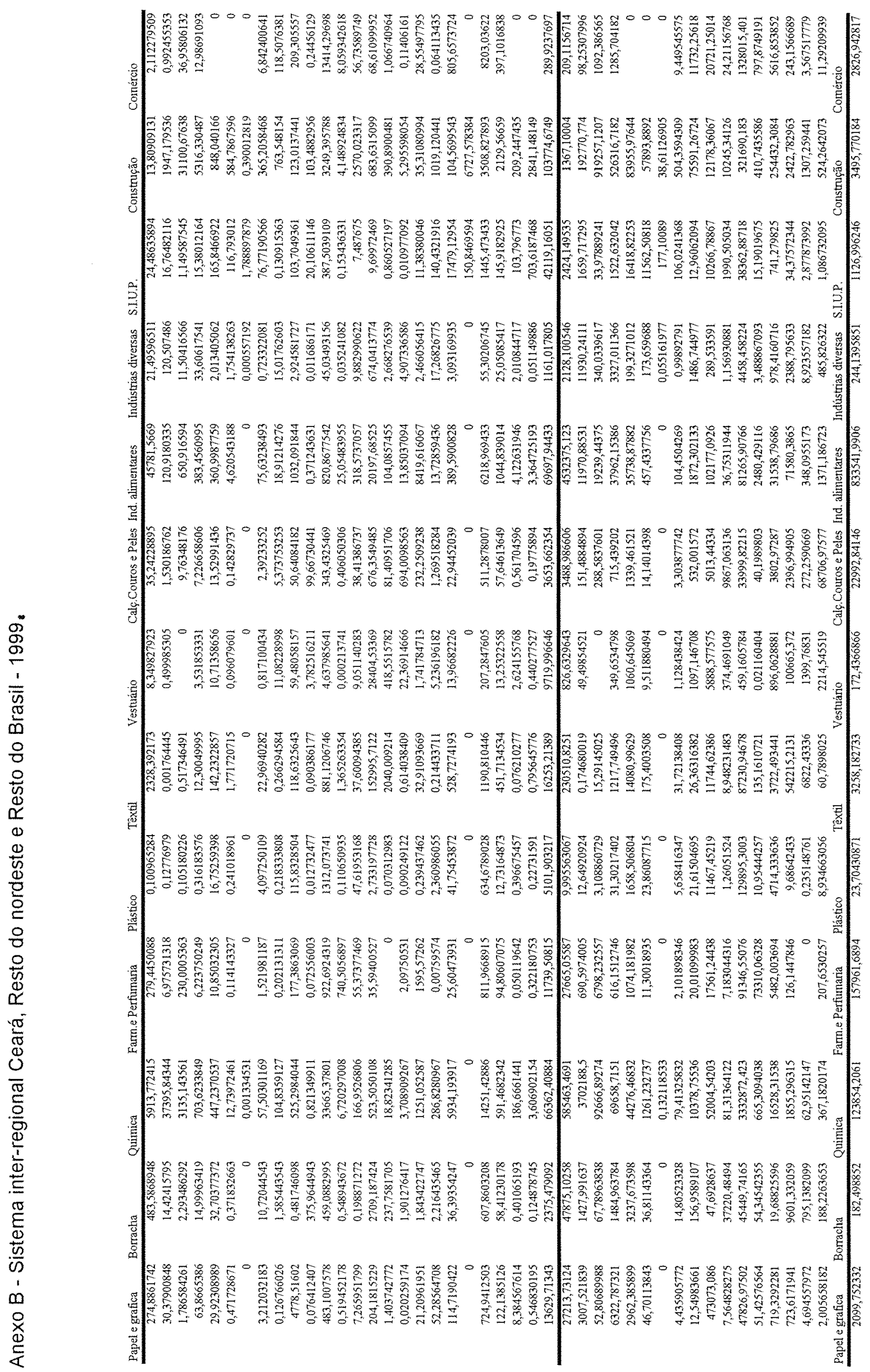


Un'

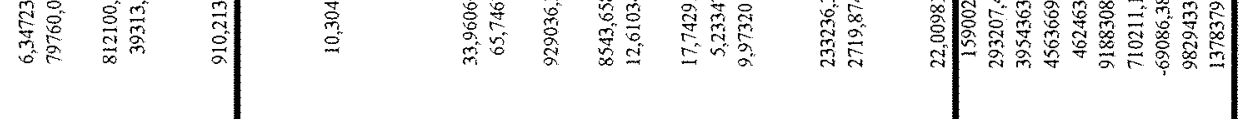

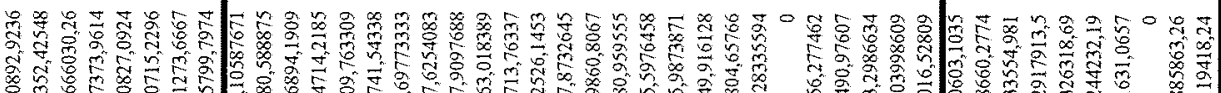

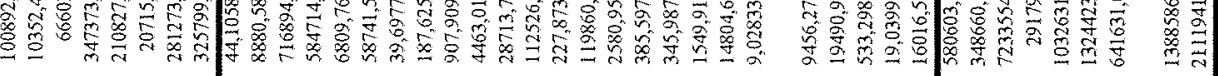

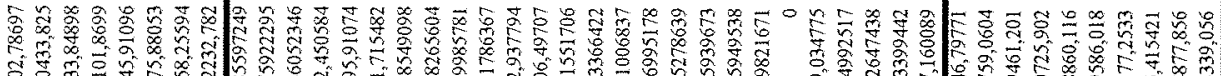

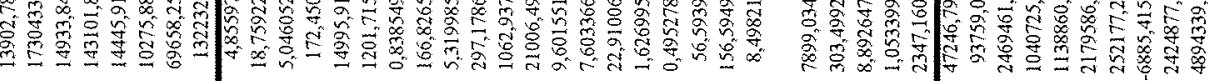

Wh

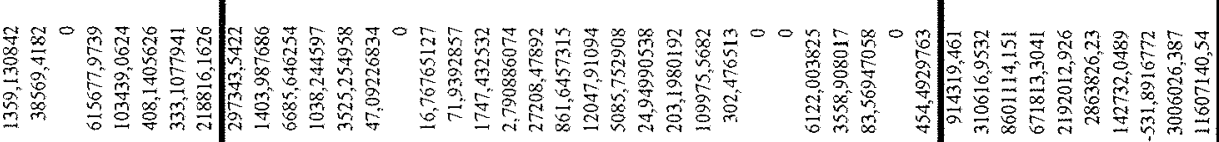

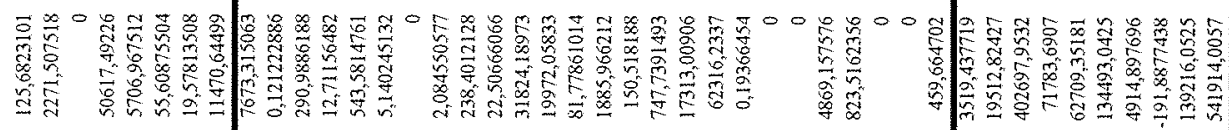

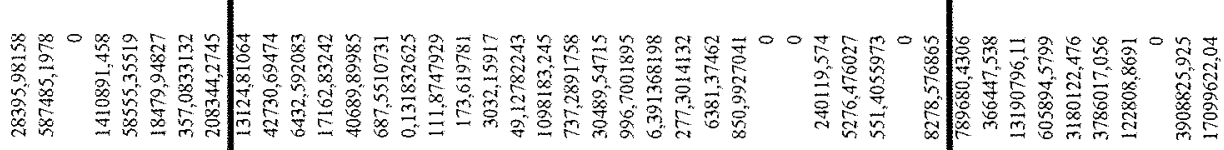

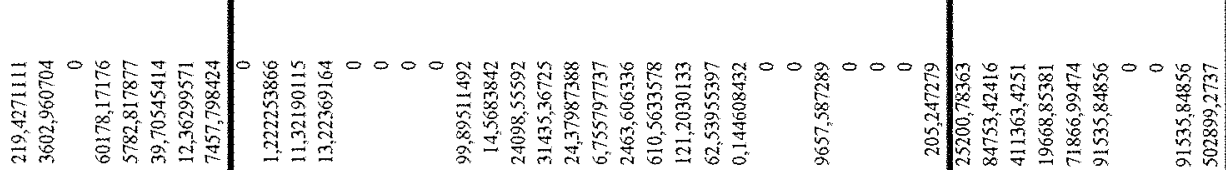

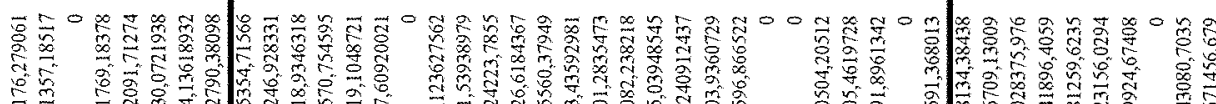

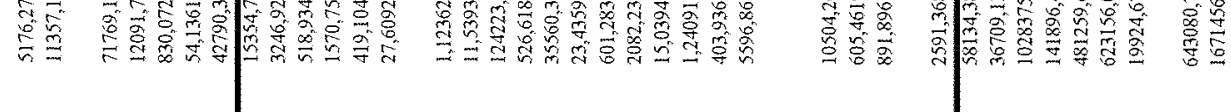




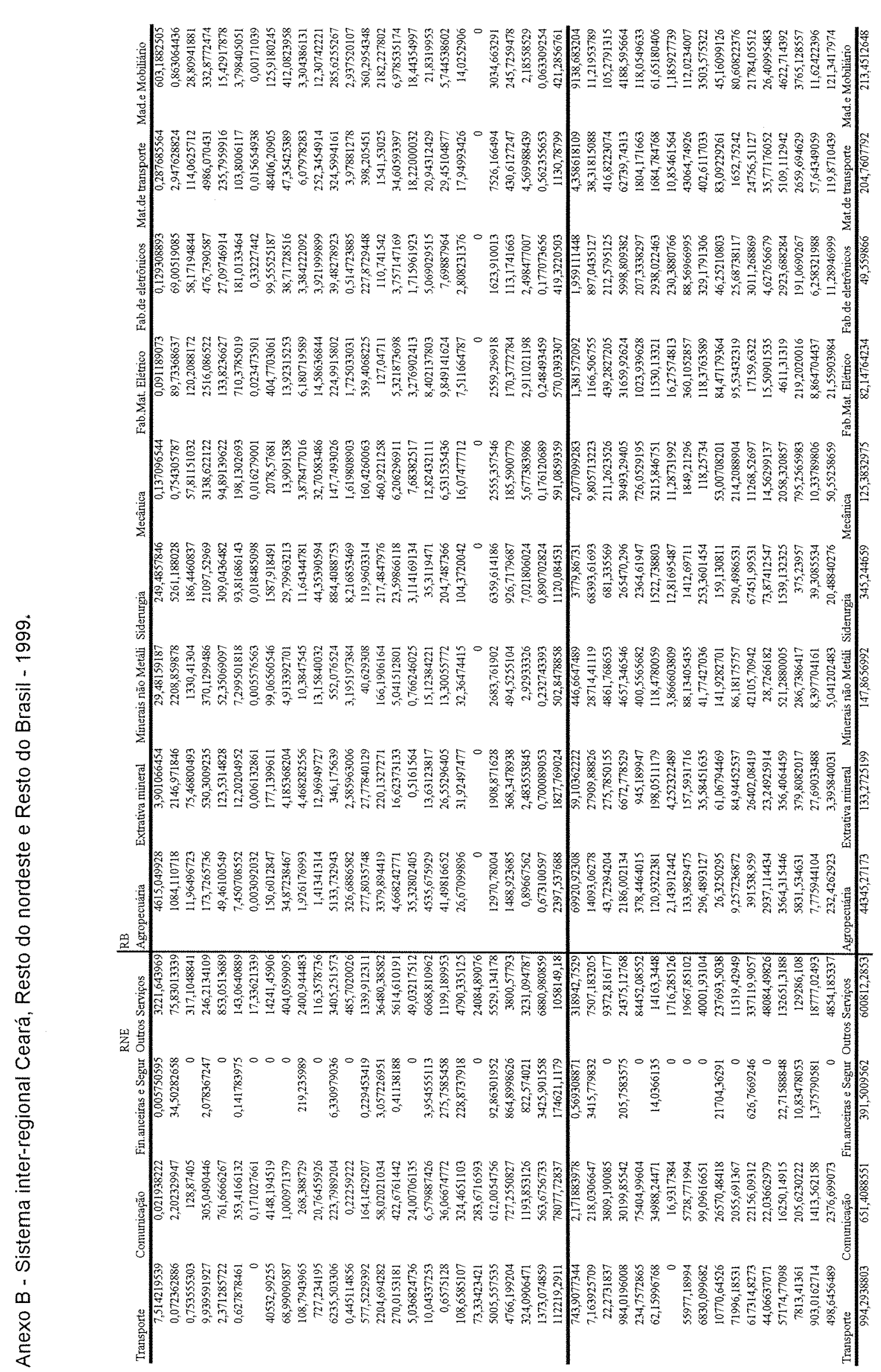




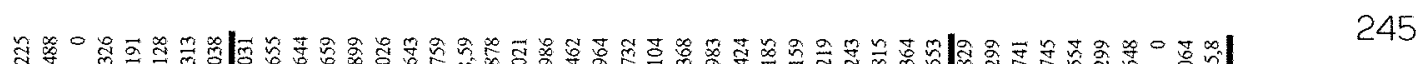

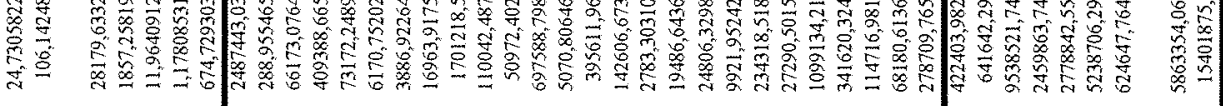

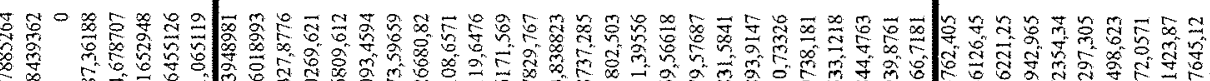

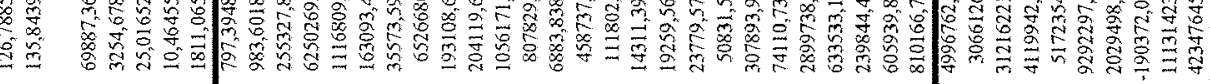

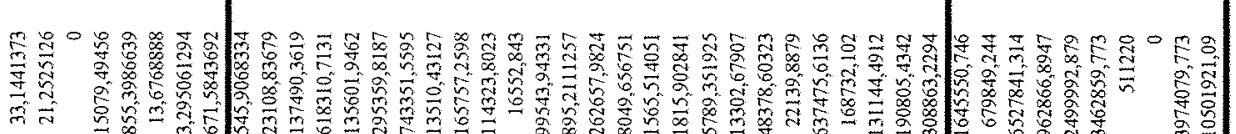

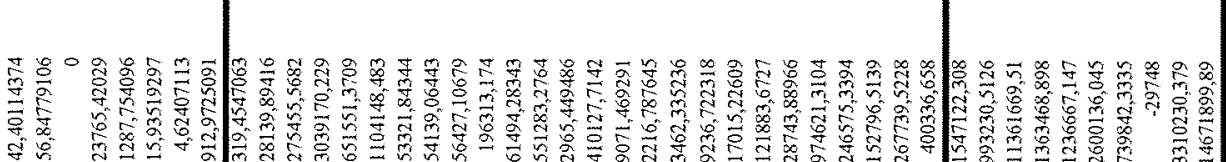

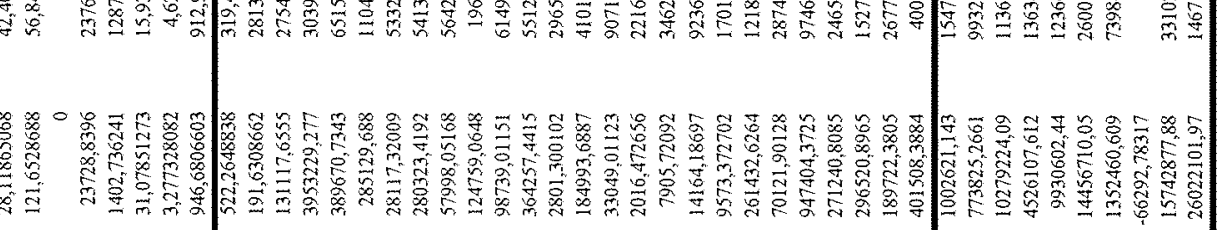

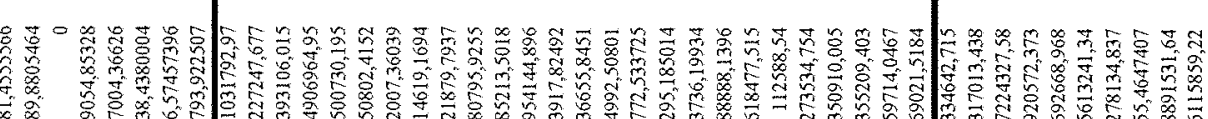

I্

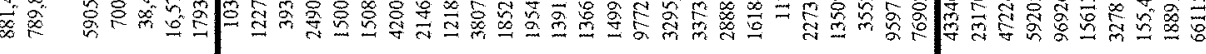

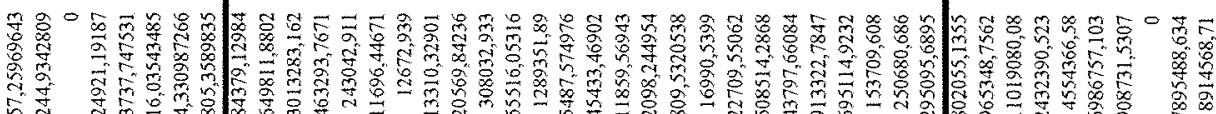

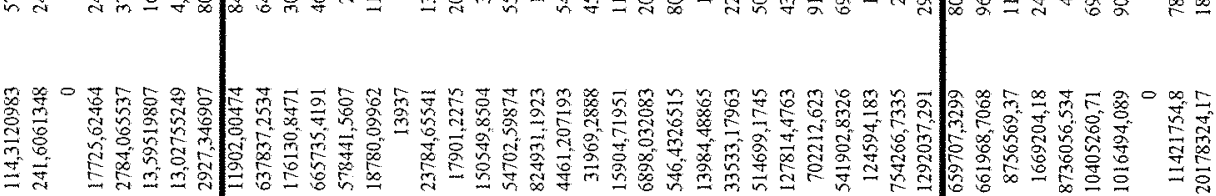

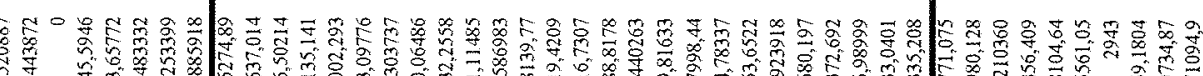

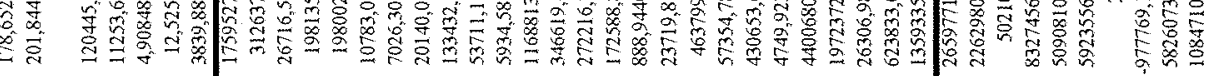

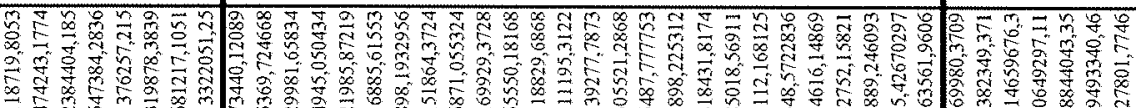

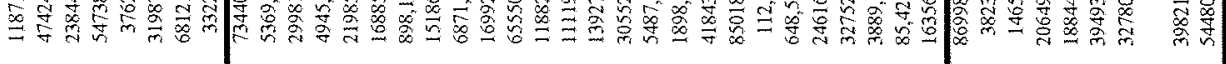

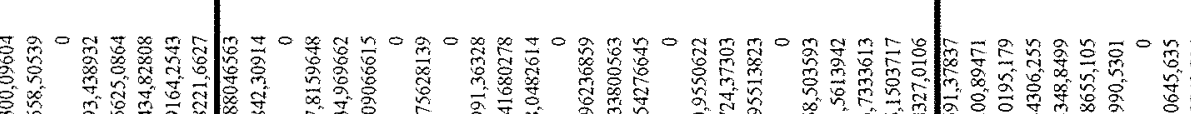

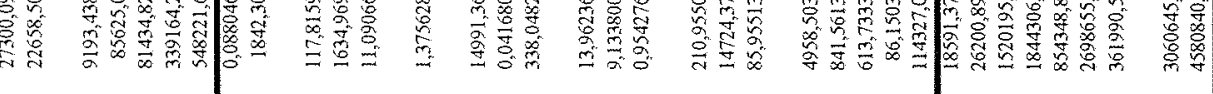

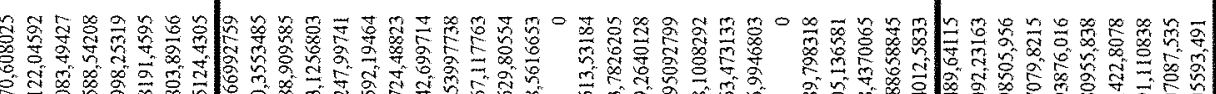

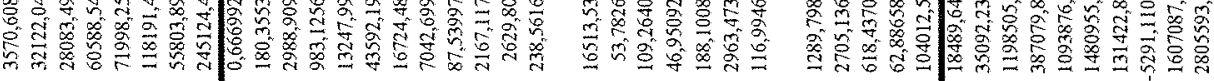

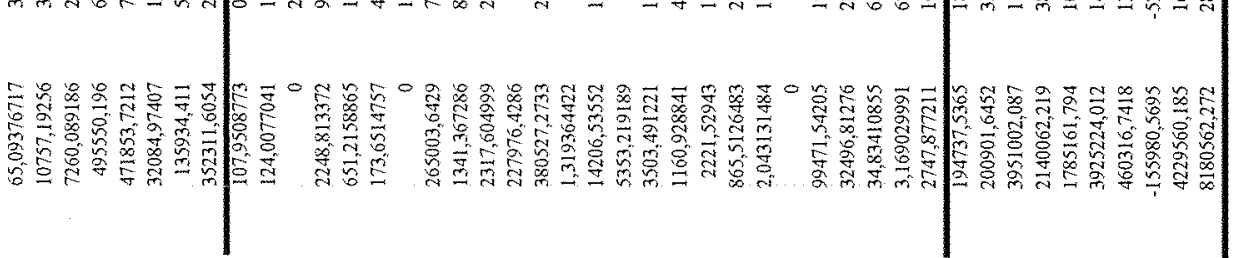




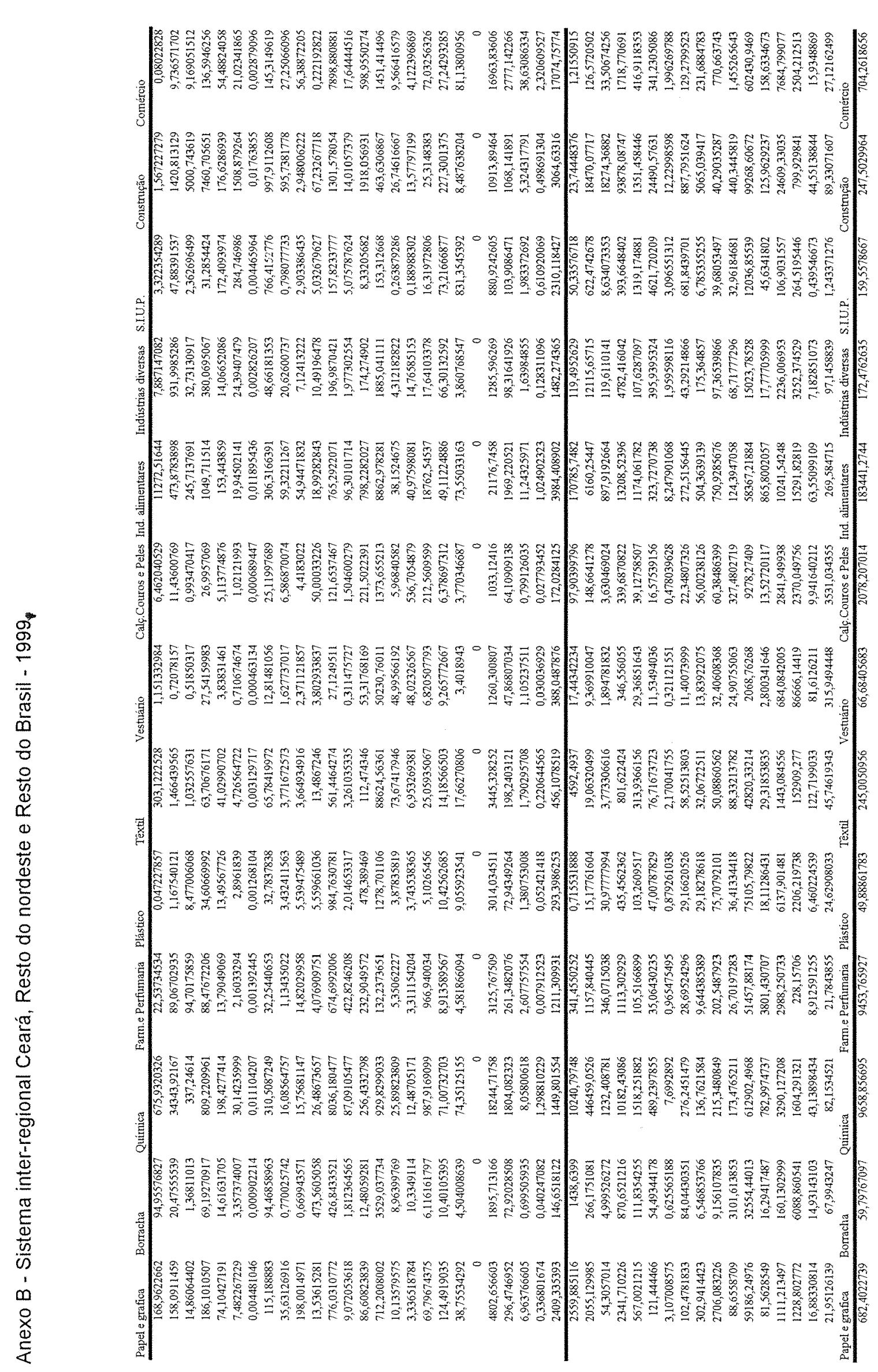




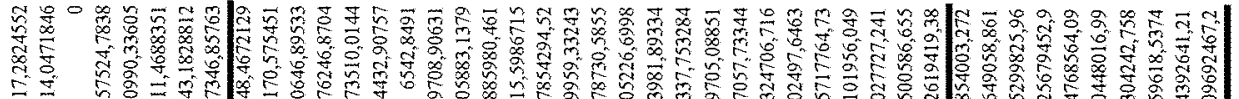

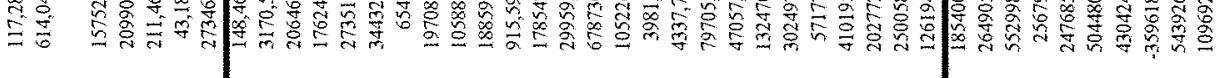

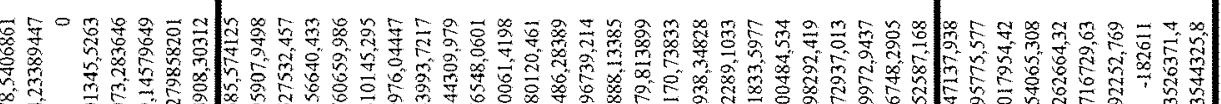

等

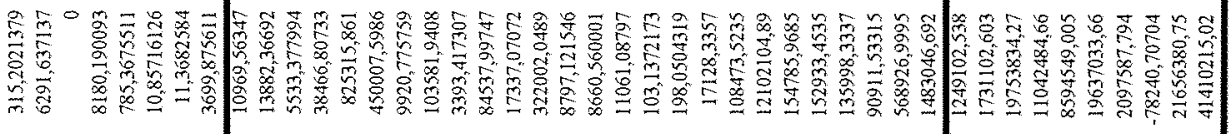

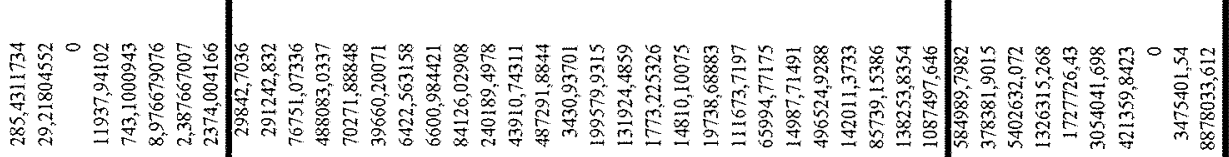

I্

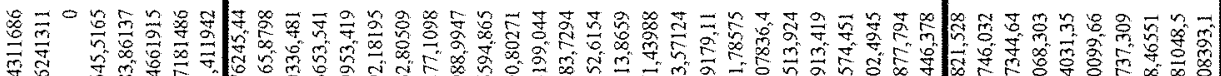

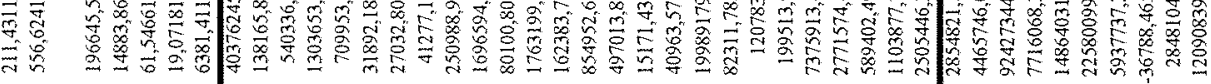

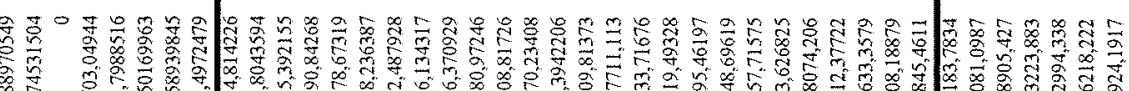

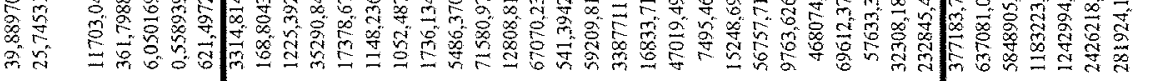

욤

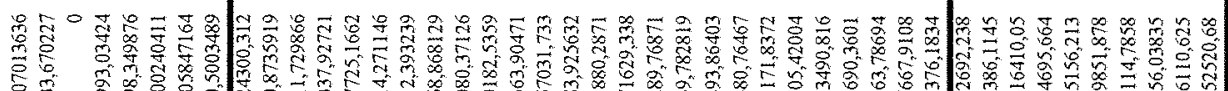

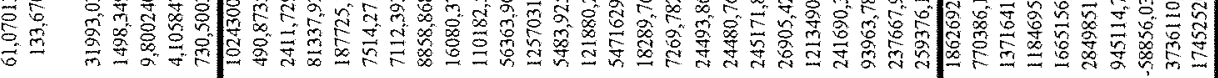

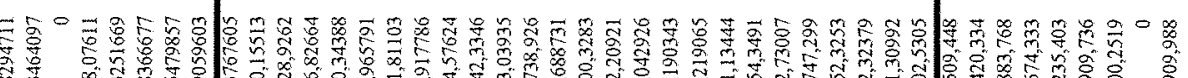

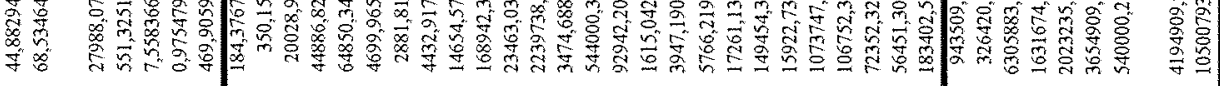

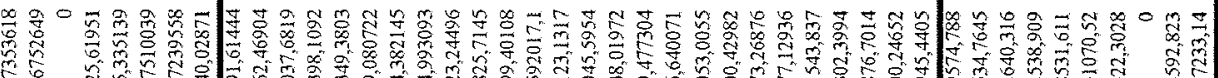

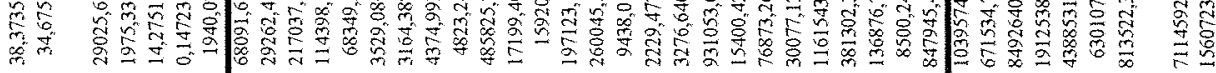

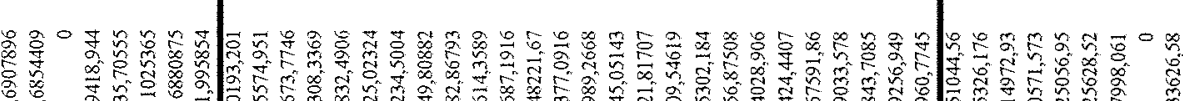

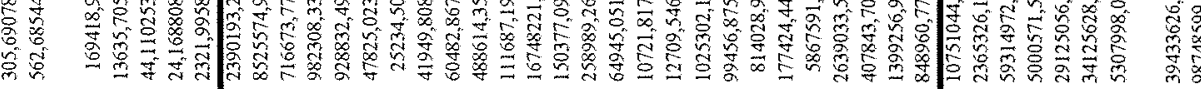

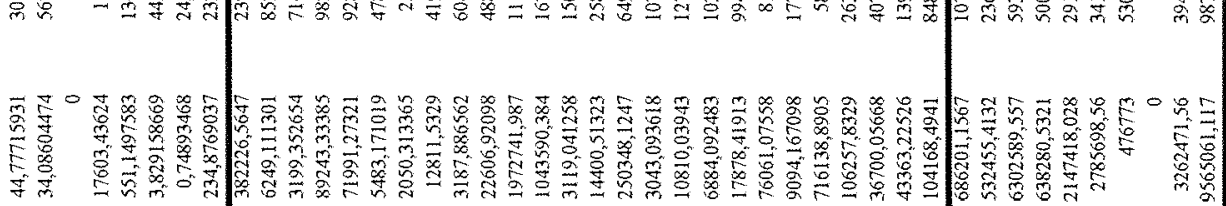

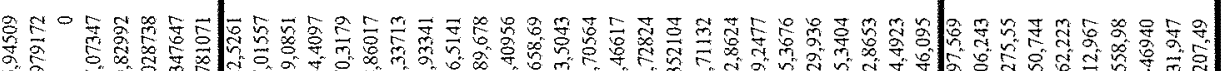

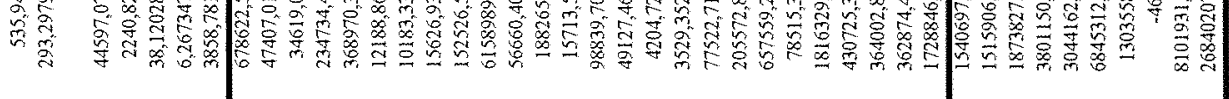




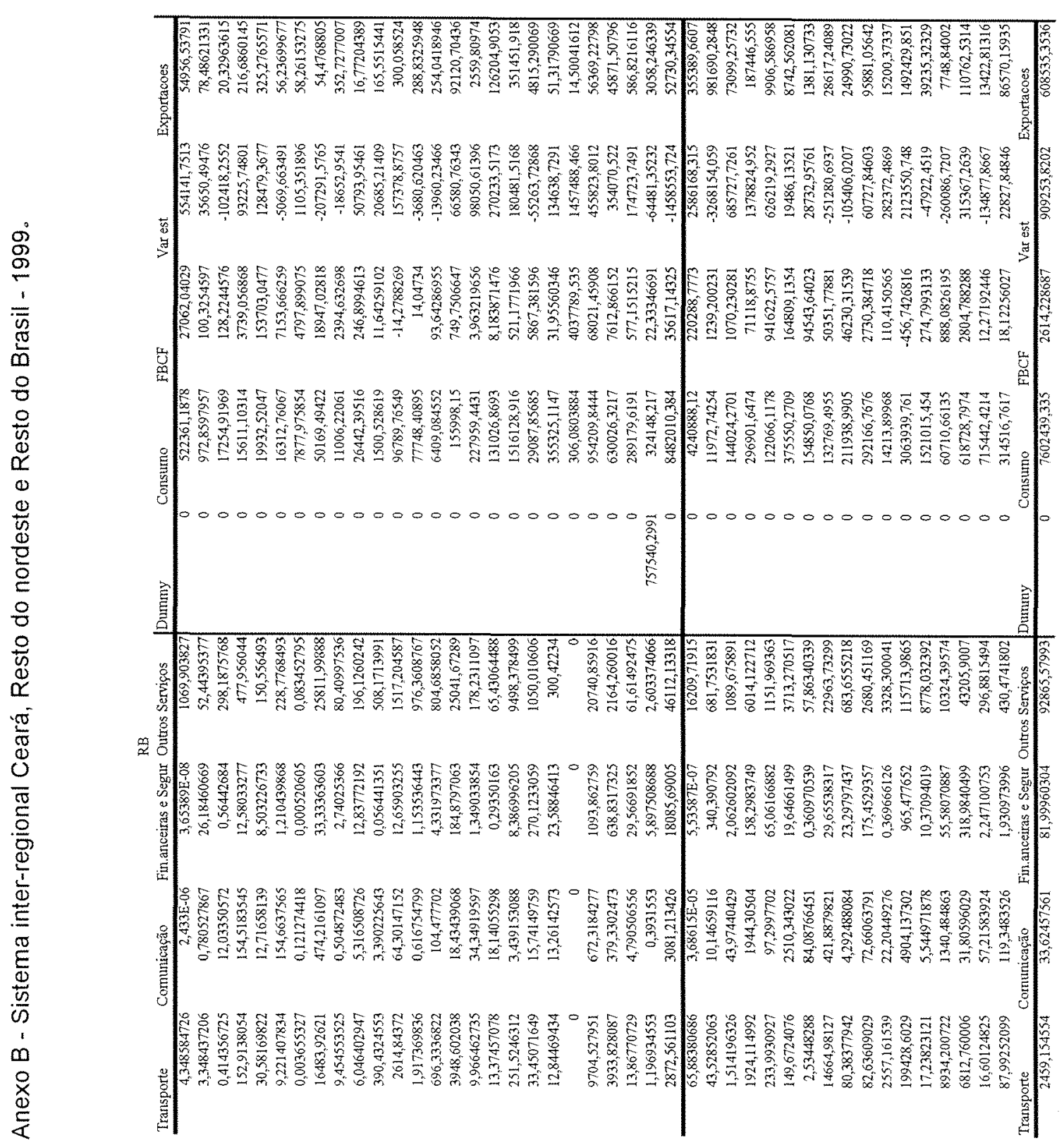




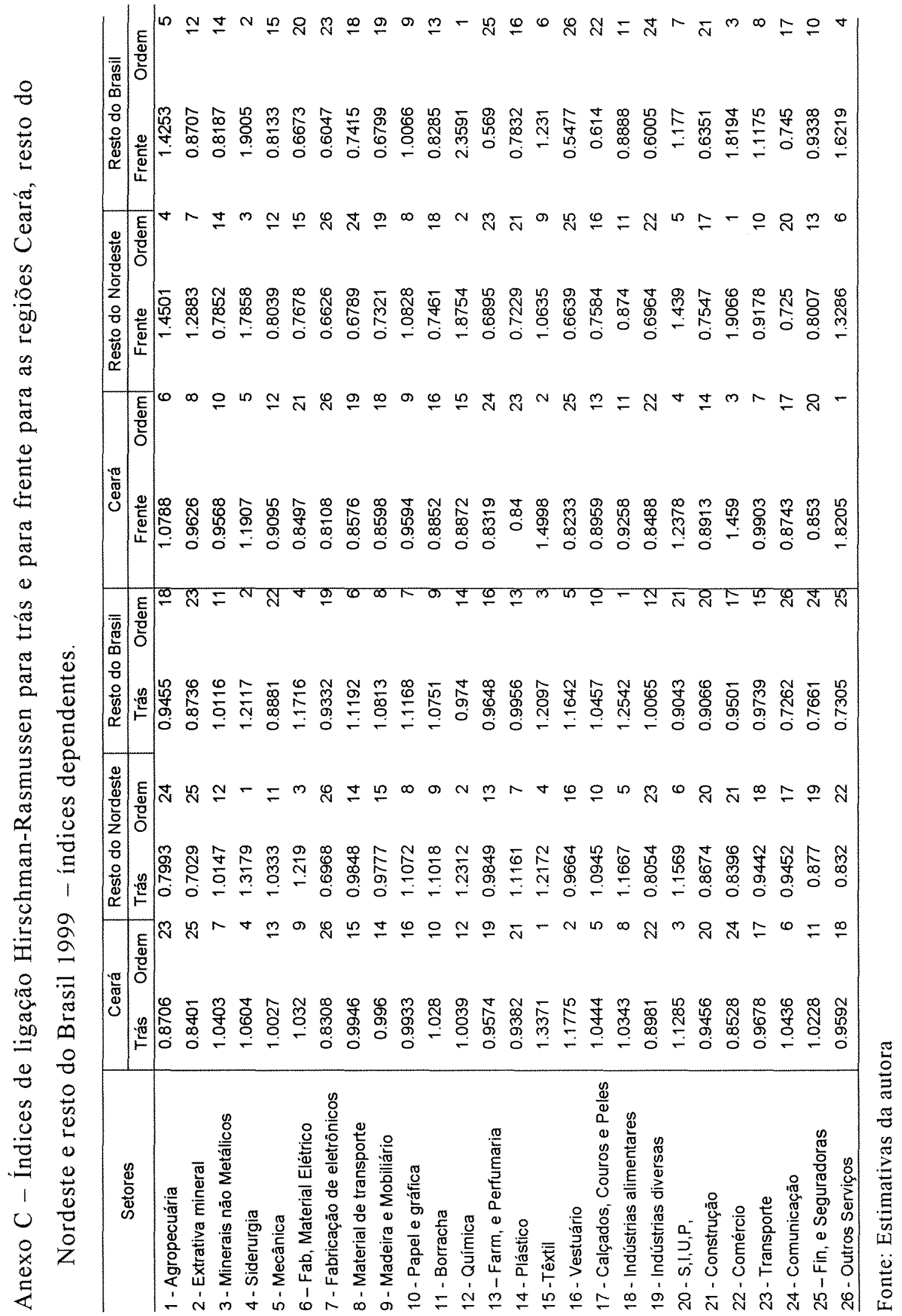

